\title{
The Native Trouts of the Genus Salmo Of Western North America
}

\section{Robert J. Behnke August 1979}

This report was funded by USDA, Forest Service

Fish and Wildlife Service 
Bureau of Land Management

Library,

Blog. 50, Denver Federal Center

Dewer, CO 80225

ERRATA SHEET

Please correct these errata in figures $2 \mathrm{~B}, 4 \mathrm{~B}, 6,9,11,13 \mathrm{~B}$, and 15

in spelling: Malmeur should be Malheur, Warmer should be Warner,

Alvoro should be Alvord, and Lamontan should be Lahontan. These

basin names appear in the upper left hand corner of each map. 


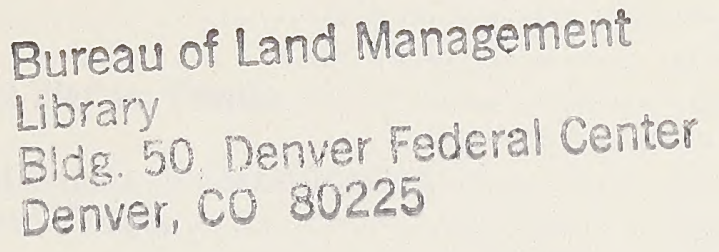

Aquatic resources are a vital part of public land habitat administered by the Bureau of Land Management. The BLM is responsible for over 668,000 miles of perennial streams and four million surface acres of lakes and reservoirs. The public lands also contain some 95,000 miles of fishable streams, supporting many species of warmwater and coldwater fish, including several species of trout. This monograph is dedicated to these valuable fishery resources. It is specifically intended to assist biologists and managers in better understanding the biological needs of trout as an aid in achieving improved aquatic habitat management.

This monograph was originally prepared by Dr. Robert J. Behnke under a contract jointly funded by the Bureau of Land Management, the U.S. Forest Service, and the U.S. Fish and Wildlife Service. The version presented herein has received additional editorial change and comment by BLM personnel and others. Appreciation is extended to the following individuals and offices who assisted with this effort: Mr. Paul Cuplin and Mr. Donald Duff, Fishery Biologists, BLM; Dr. Richard Wallace, University of Idaho; and the Idaho, Wyoming, Utah, Nevada and Colorado BLM State Offices. Special recognition is also given to the respective State Wildlife Agencies that have worked with BLM, BLM's Rock Springs District in Wyoming, and other BLM offices for their fine work in developing management plans and habitat improvement projects for native trouts and other fisheries resources on the public lands. 



\section{TABLE OF CONTENTS}

Preface

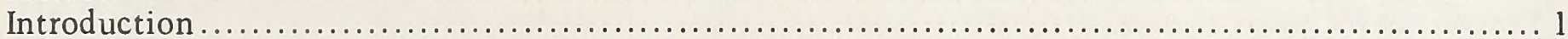

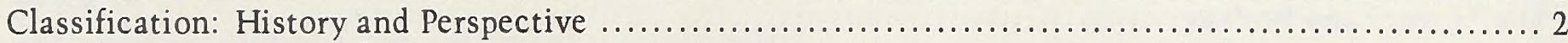

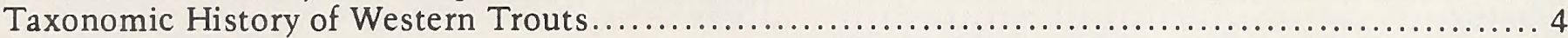

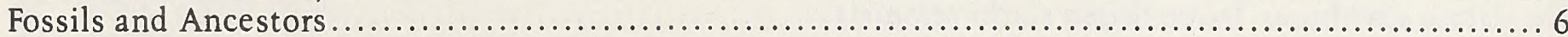

Distribution of Parasalmo ....................................................................... 8

General Life History Notes .................................................................... 12

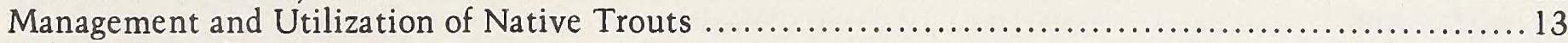

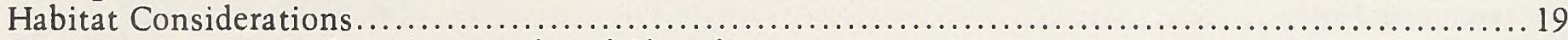

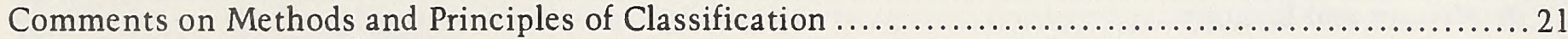

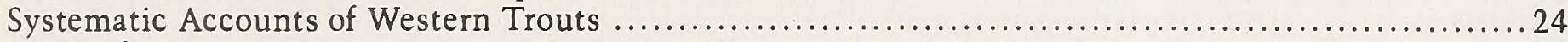

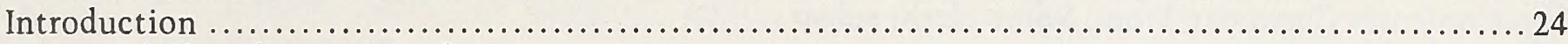

Causes of Classification Confusion ....................................................... 24

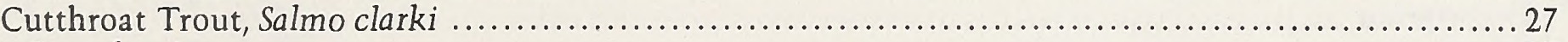

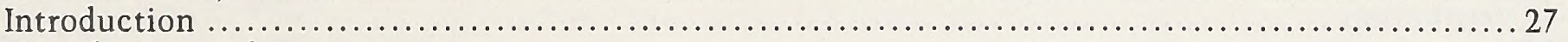

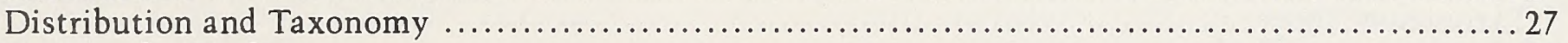

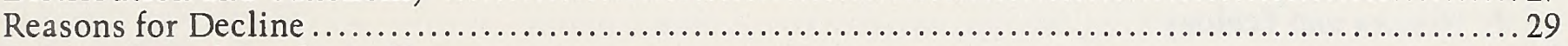

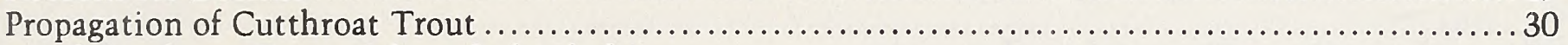

Coastal Cutthroat Trout, Salmo clarki clarki ................................................ 33

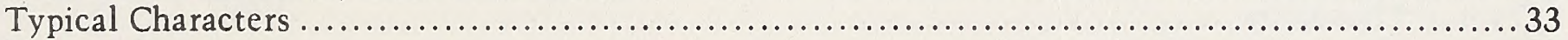

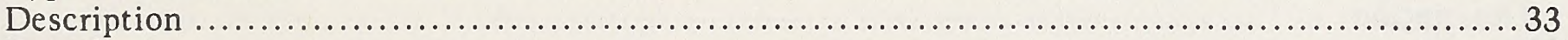

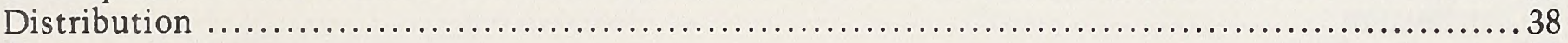

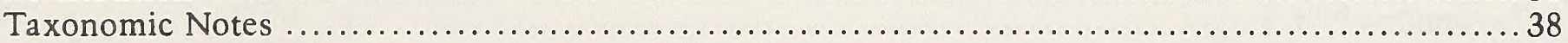

Life History and Ecology ................................................................. 40

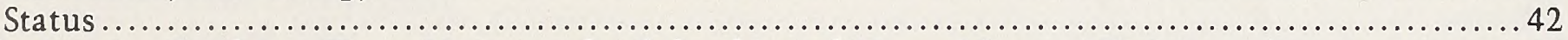

The Interior Cutthroat Trout Native to the Columbia and Upper Missouri Basins .................. 43

"Westslope" Cutthroat Trout, Salmo clarki lewisi................................................ 47

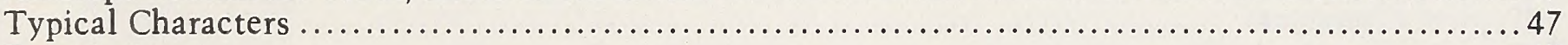

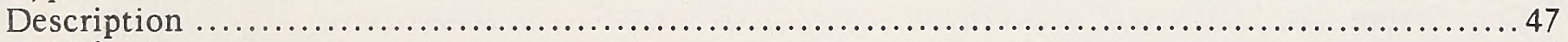

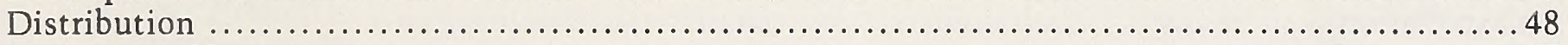

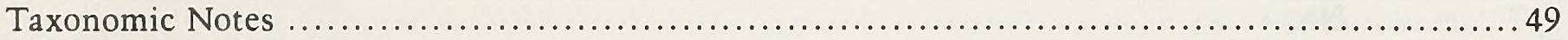

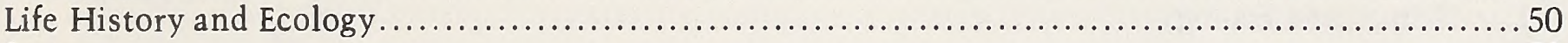

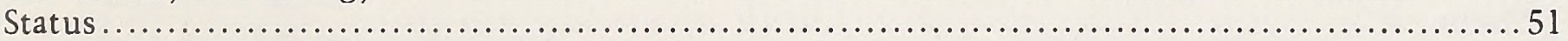

Yellowstone Cutthroat Trout, Salmo clarki bouvieri .......................................... 53

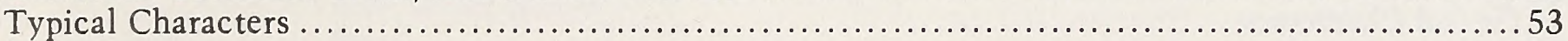

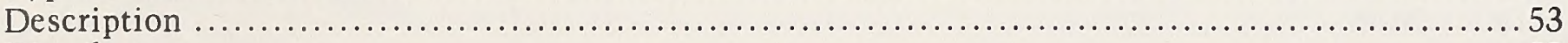

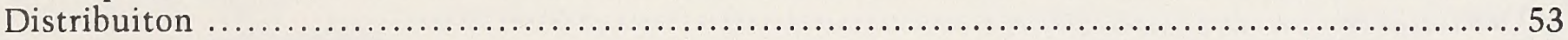

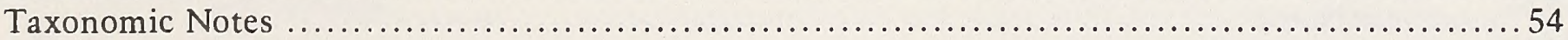

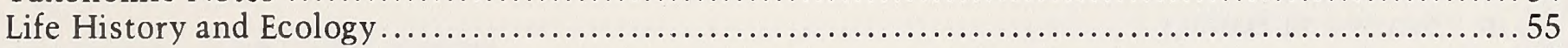

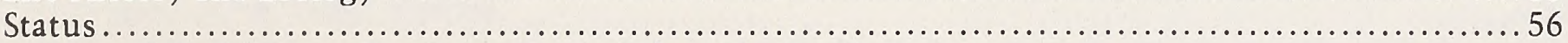

Fine-Spotted Snake River Cutthroat Trout, Salmo clarki subsp ................................. 58

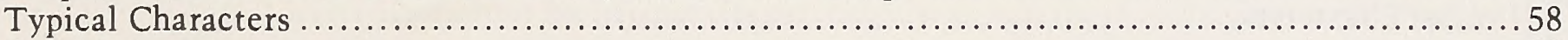

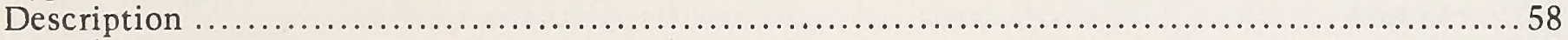

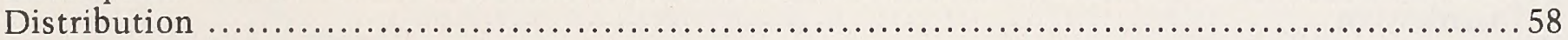

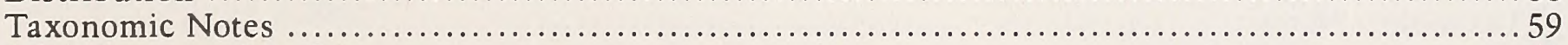

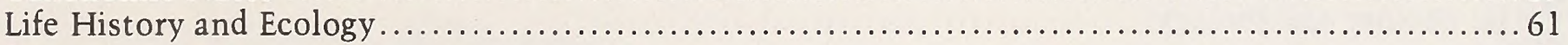

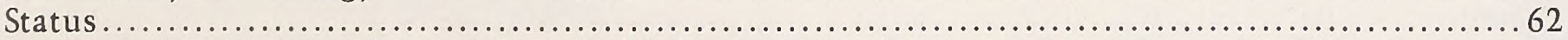

The Mountain Cutthroat Trout, Salmo clarki alpestris .......................................63 63

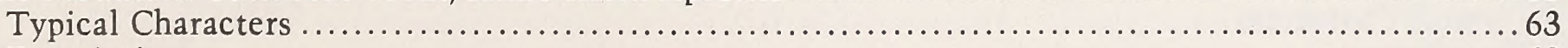

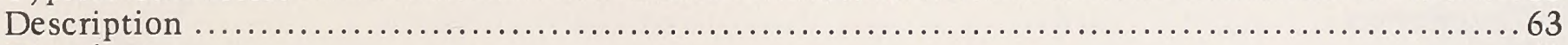

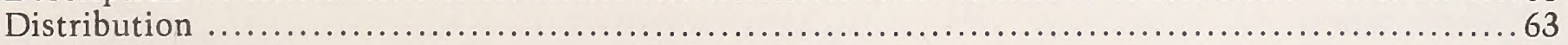

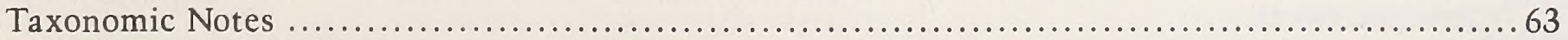

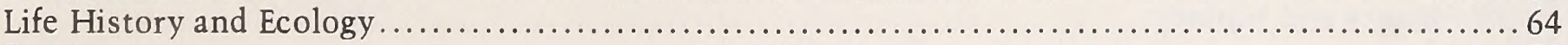

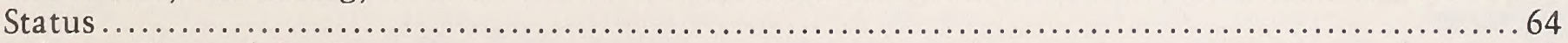

Cutthroat Trout of the Great Basin ......................................................... 65

Lahontan Cutthroat Trout, Salmo clarki henshawi ................................................ 71

Typical Characters .........................................................................

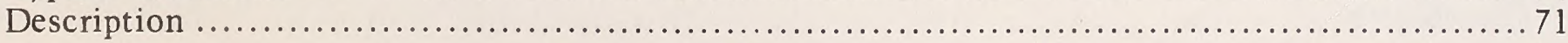




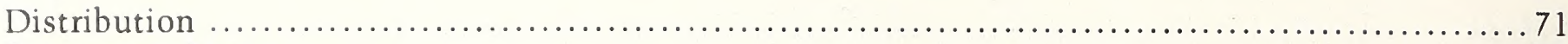

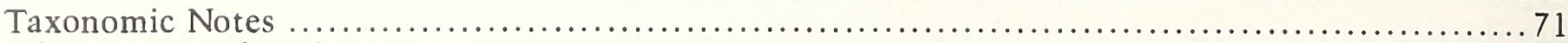

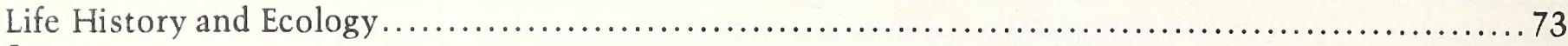

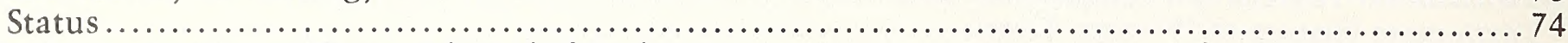

The Paiute Cutthroat Trout, Salmo clarki seleniris ............................................... 75

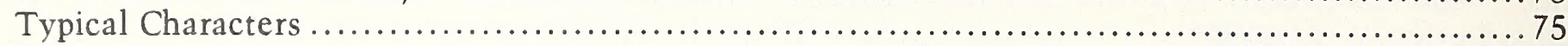

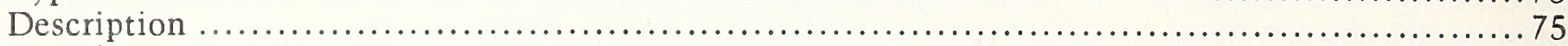

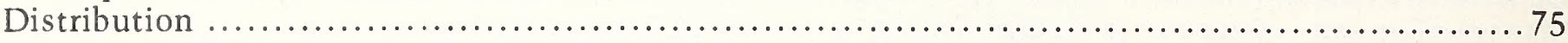

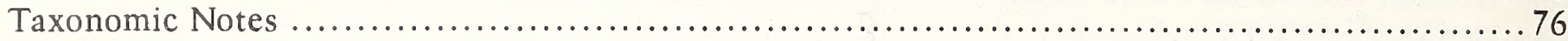

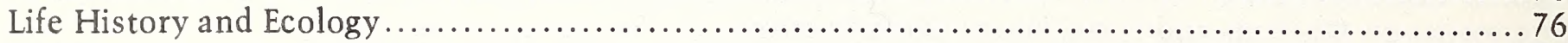

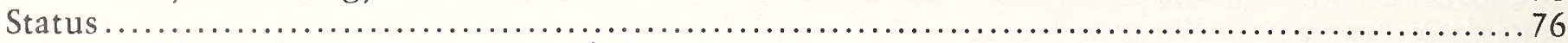

The Humboldt Cutthroat Trout, Salmo clarki subsp ........................................... 77

Typical Characters ..................................................................... 77

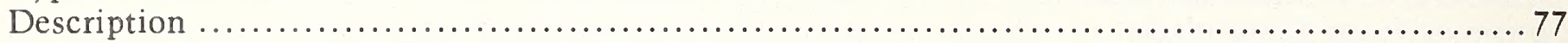

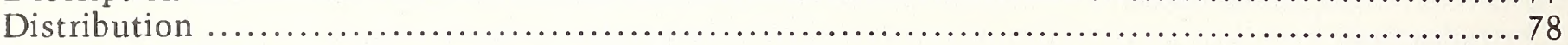

Taxonomic Notes ..................................................................... 78

Life History and Ecology ............................................................ 78

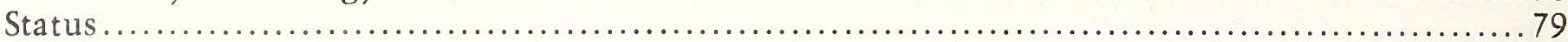

Bonneville Cutthroat Trout, Salmo clarki utah .............................................. 80

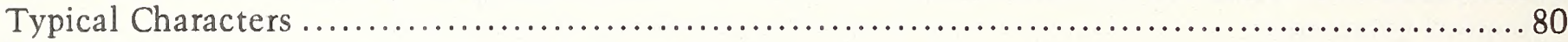

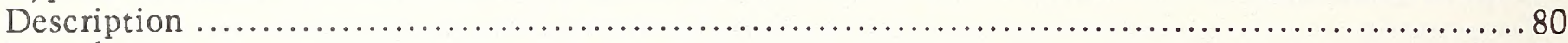

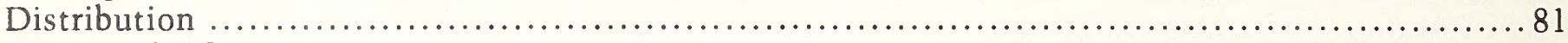

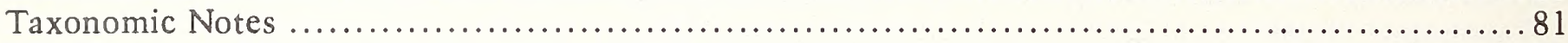

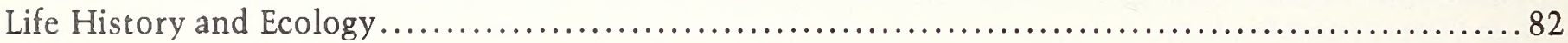

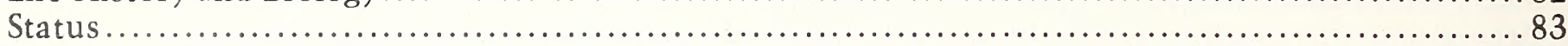

Alvord Basin Cutthroat Trouts ........................................................... 85

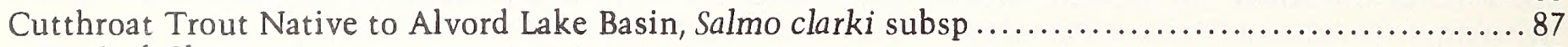

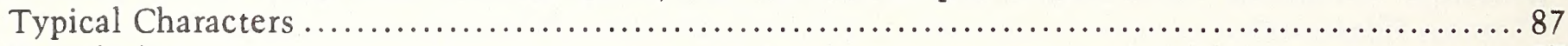

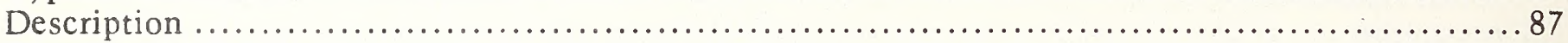

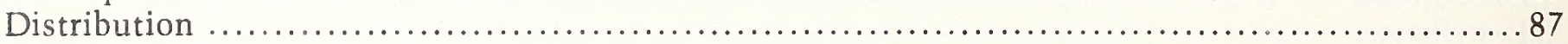

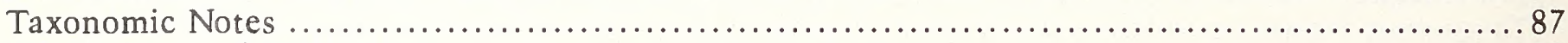

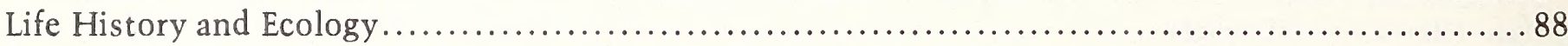

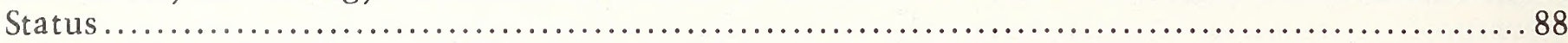

Cutthroat Trout of Willow and Whitehorse Creeks .......................................... 89

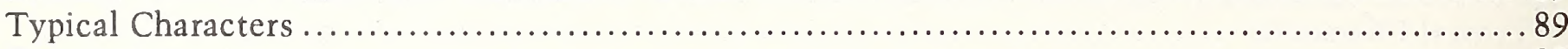

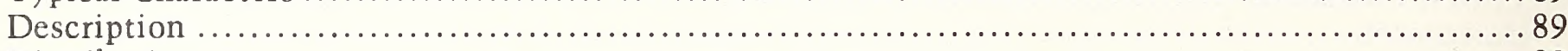

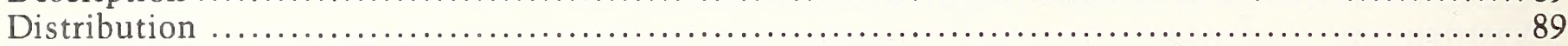

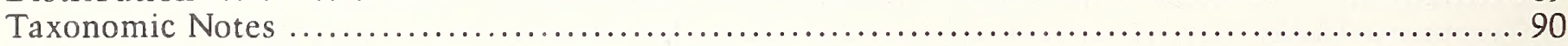

Life History and Ecology............................................................... 90

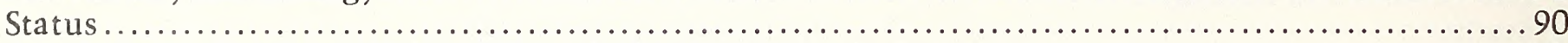

Colorado River Cutthroat Trout, Salmo clarki pleuriticus ...................................... 91

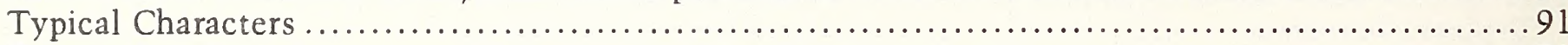

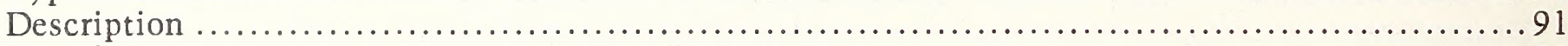

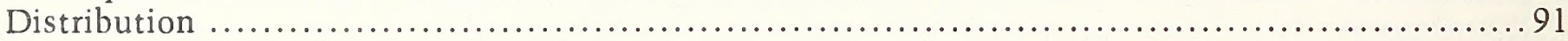

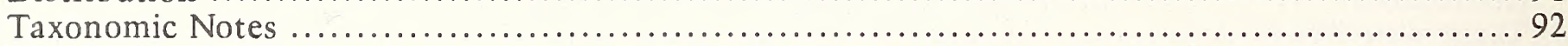

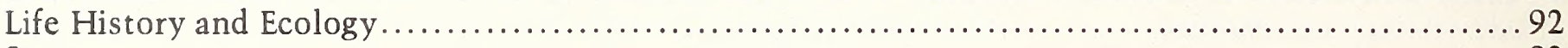

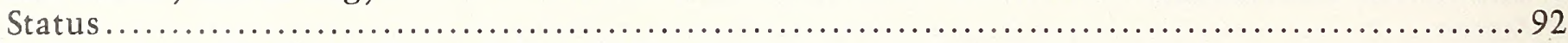

The Greenback Cutthroat Trout, Salmo clarki stomias ....................................... 94

Typical Characters ..................................................................... 94

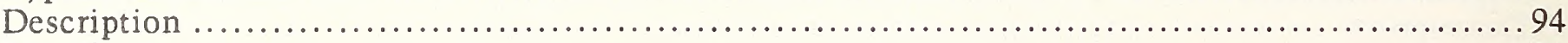

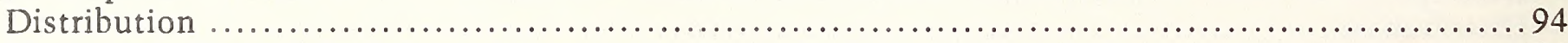

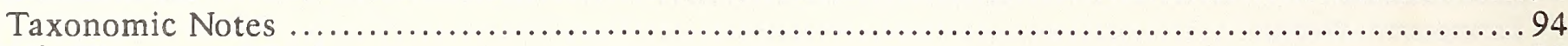

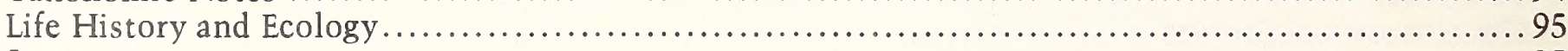

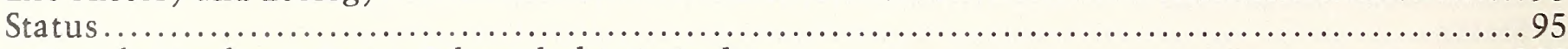

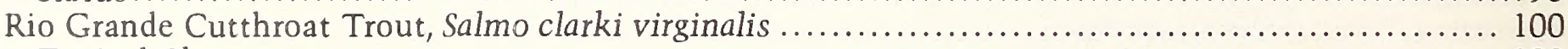

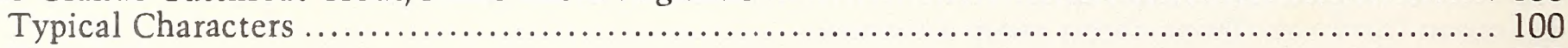

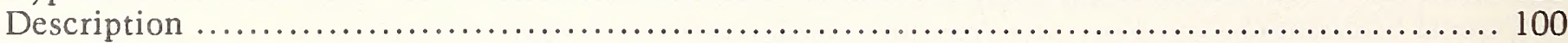

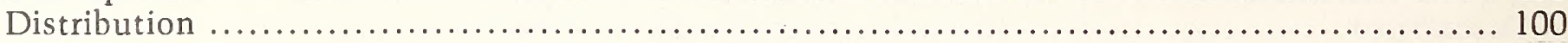


Taxonomic Notes

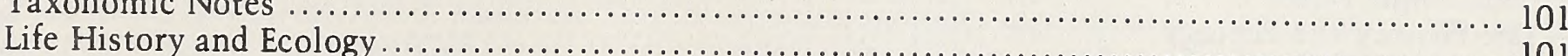

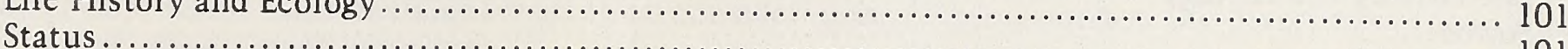

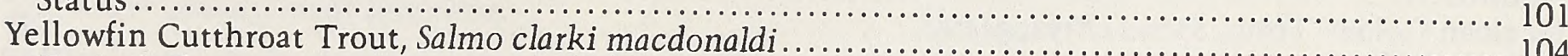

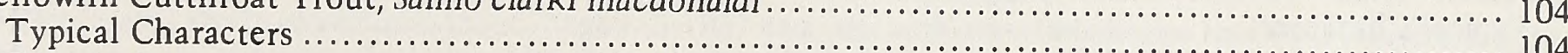

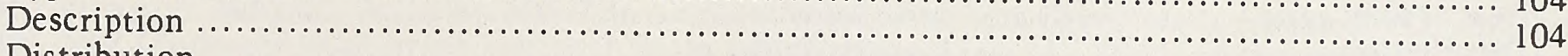

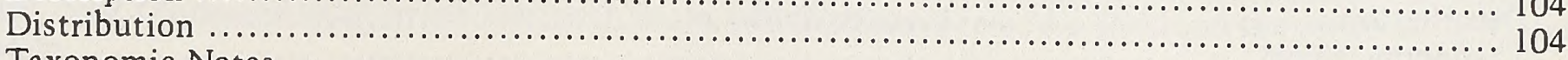

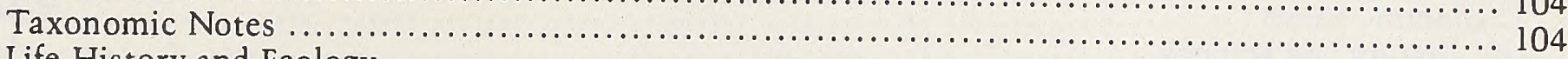

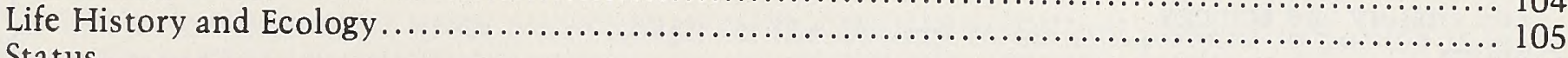

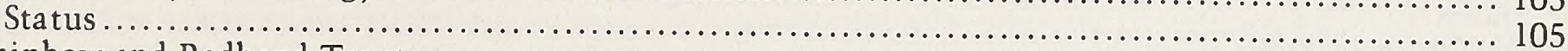

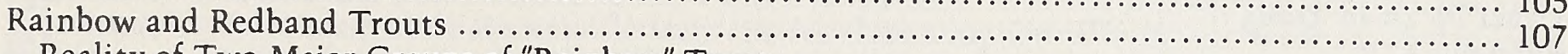

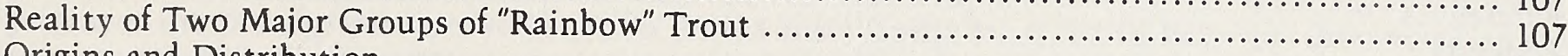

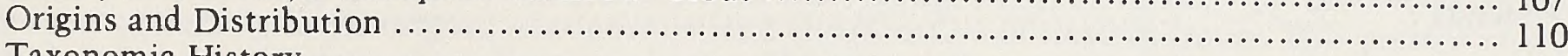

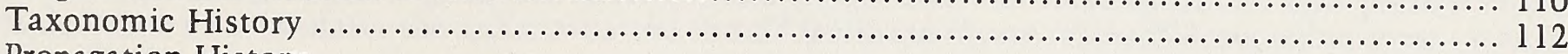

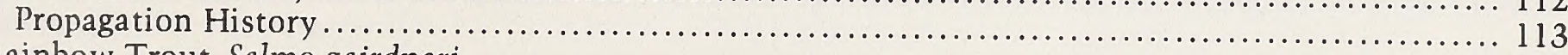

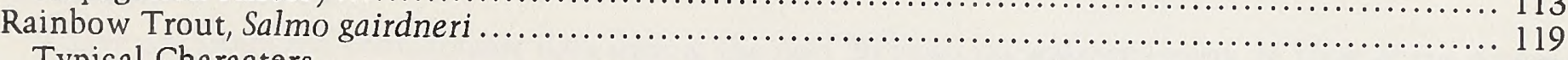

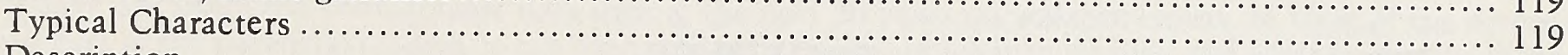

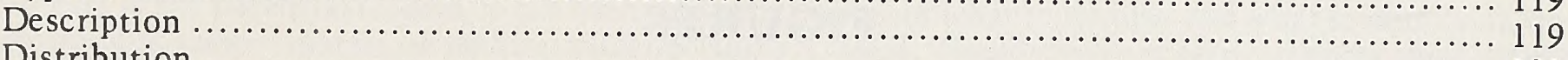

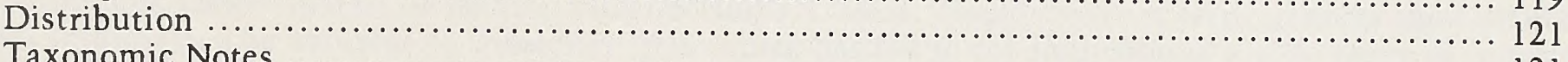

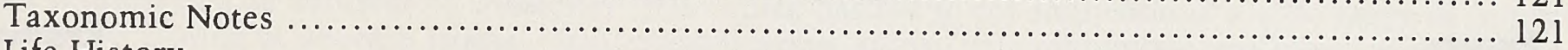

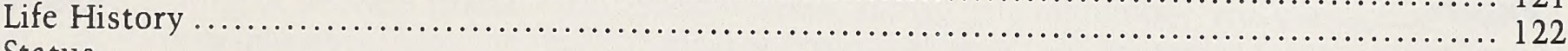

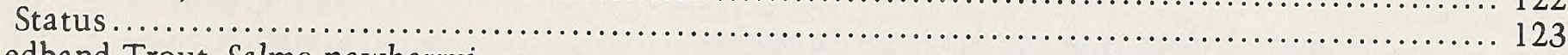

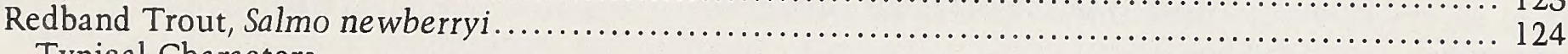

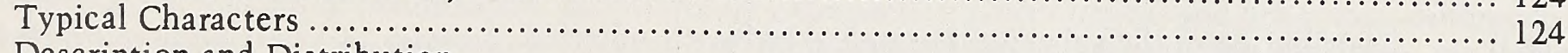

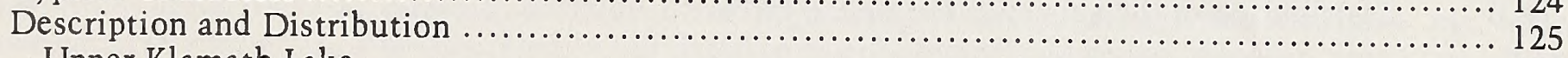

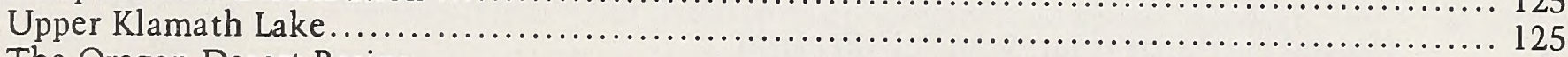

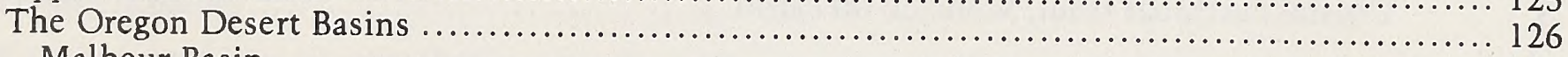

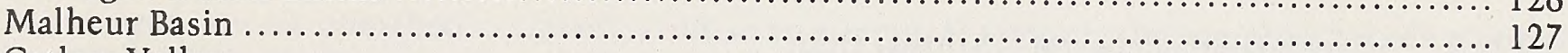

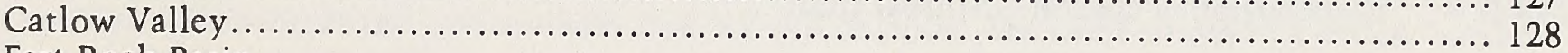

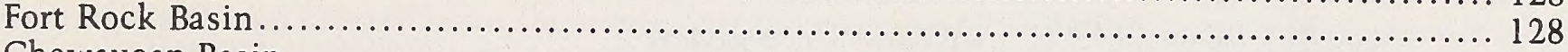

Chewaucan Basin.............................................................. 129

Warner Lakes Basin ............................................................... 129

Goose Lake Basin.............................................................. 130

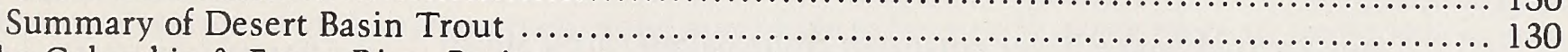

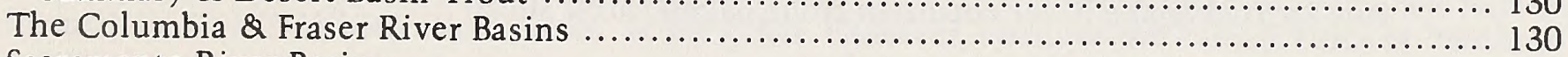

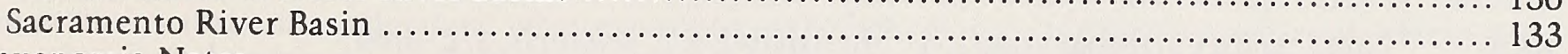

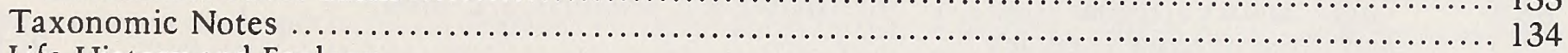

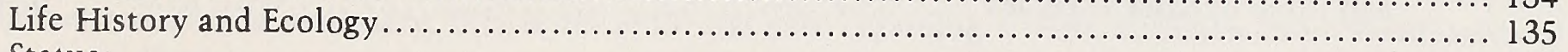

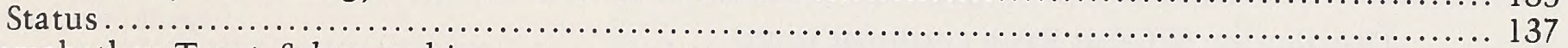

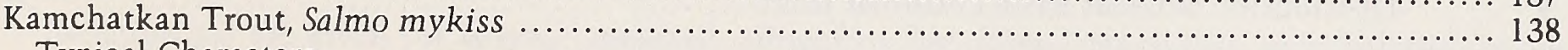

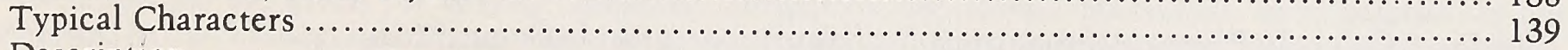

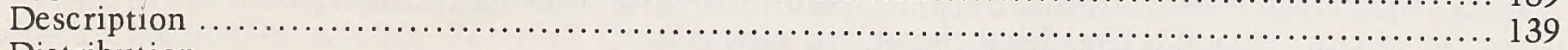

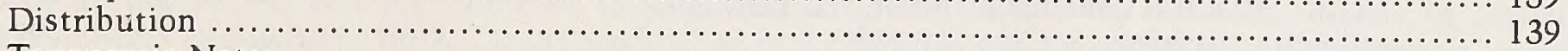

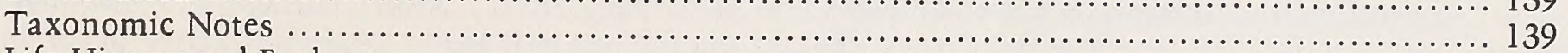

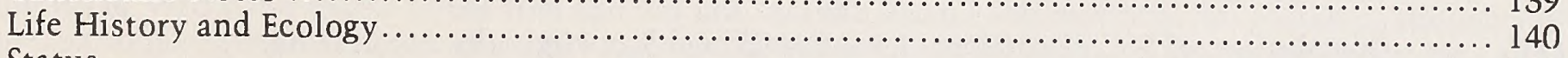

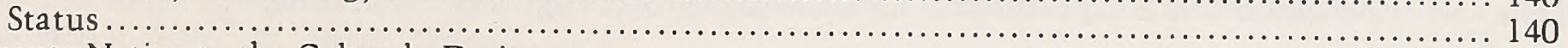

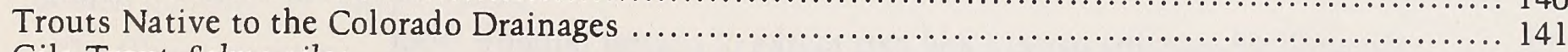

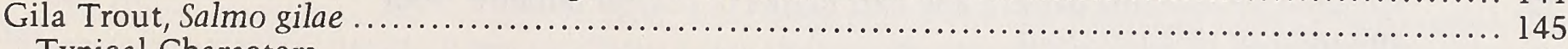

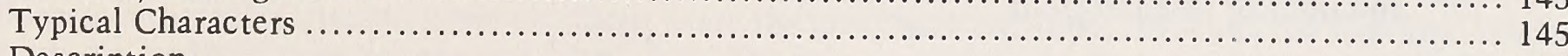

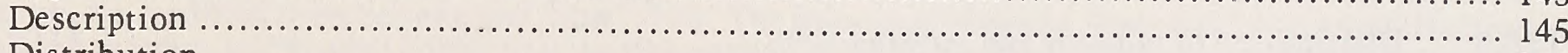

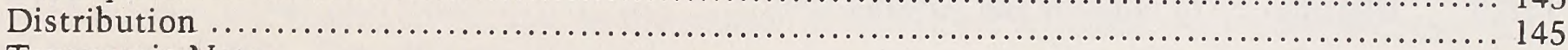

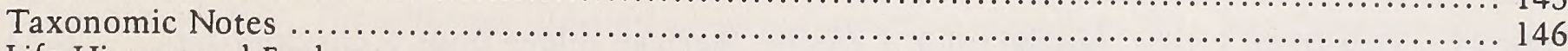

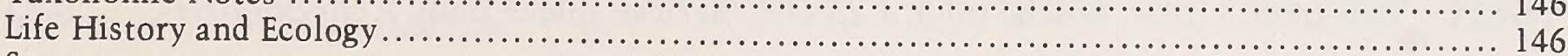

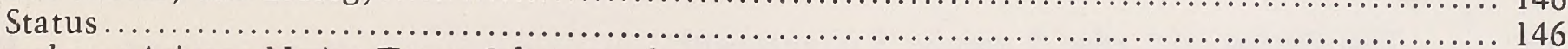

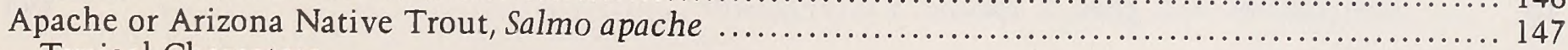

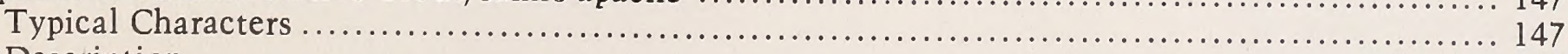

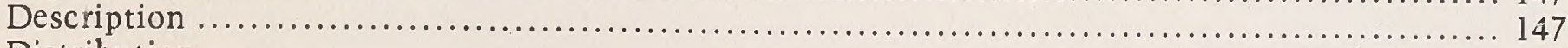

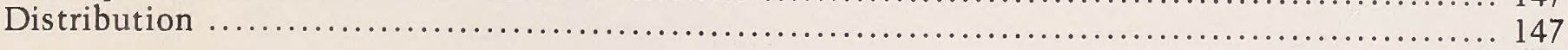


Taxonomic Notes

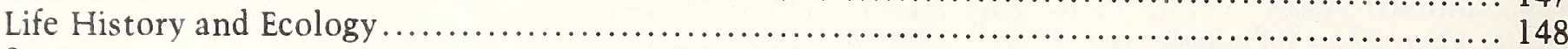

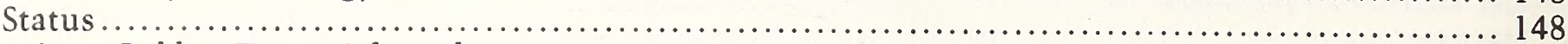

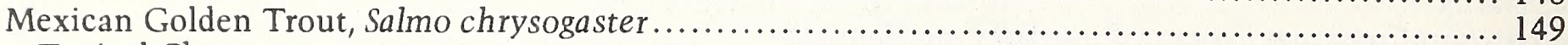

Typical Characters .................................................................. 149

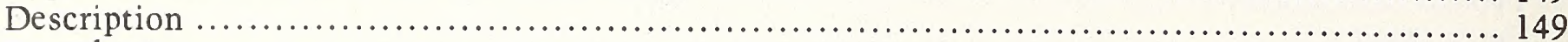

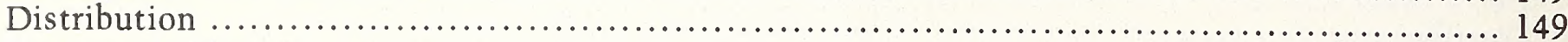

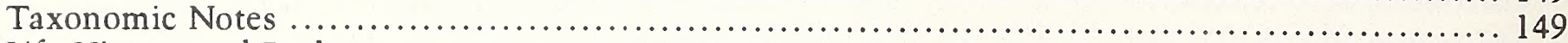

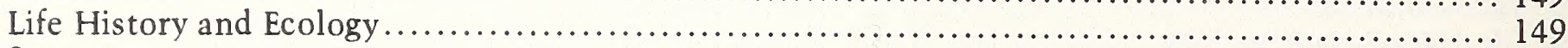

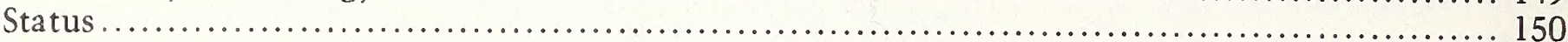

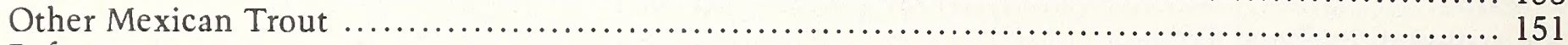

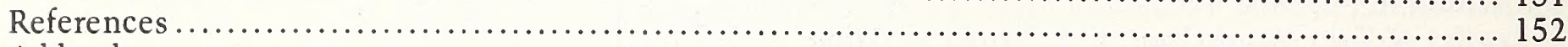

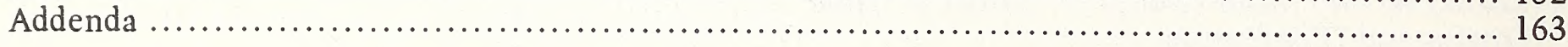

\section{FIGURES}

Figure

Page(s)

$1 \quad$ Assumed phylogeny of the subgenus Paraselmo

2A,B Distribution of the subgenus Paraselmo in North America..................... 9,10

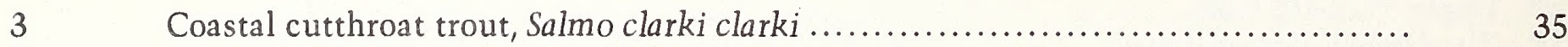

4A,B Distribution of coastal cutthroat trout ................................. 36,37

$5 \quad$ Spotting pattern of S. c. lewisi and S. c. bouvieri .............................. 45

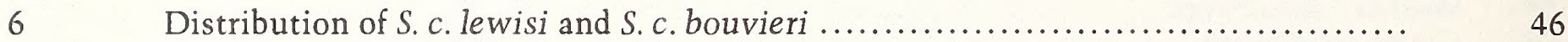

$7 \quad$ Fine-spotted Snake River cutthroat trout, Salmo clarki subsp .................... 60

8A-F Great Basin cutthroat trouts, S. c. henshawi, S.c. seleniris, S. c. utah, and three unnamed species

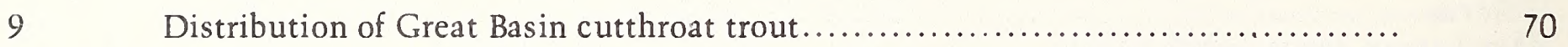

10A-D Colorado River cutthroat trout, S. c. pleuriticus; greenback cutthroat,

S. c. stomias; Rio Grande cutthroat, S. c. virginalis;

yellowfin cutthroat, S. c. macdonaldi

11 Distribution of S.c.pleuriticus, S. c. stomias and S. c. virginalis

12 Generalized spotting pattern and parr marks of coastal rainbow trout and interior redband trout

13A,B Distribution of rainbow and redband trout.

14A,B,C Gila trout, S. gilae; Apache trout, S. apache; Mexican golden trout, S. chrysogaster ...

15 Distribution of $S$. gilae, S. apache, S. chyrogaster. 
The basic intent of this monograph is to provide a source of information on the diversity present in the native trouts of western North America. This information includes identification, taxonomy, distribution, and present status. Also included are practical considerations pointing out how this diversity can be applied in fishery management programs.

My formal study of western trouts began in 1957 as a research assistant to the late Paul Needham at the University of California, Berkeley. Needham and I collected trout from California to Alaska in 1957. In 1958 and 1959, I collected trout in the Lahontan Basin, which resulted in a M.S. thesis on the trouts of the Great Basin.

In 1963, Needham and I wrote a monograph on the western trouts and planned to publish it in the University of California publications series. I was not satisfied with our monograph because too many questions were not adequately answered or were answered too simplistically. When Needham died in 1964, I withdrew the monograph from publication. In the intervening years, I still have not discovered all the answers pertaining to the origins, relationships, and classification of western trouts. This present monograph, however, articulates the unknowns and should facilitate future research designed to come up with more definite answers.

I have accumulated considerable data during the past 20 years on western trouts. In view of the diverse interests of the potential readers, it has been difficult to sort out what to include and what to omit from the voluminous subject matter. In making such decisions, I asked: Would someone want to know this? Would this information be valuable to someone? This course has led to the inclusion of a wide range of subject matter pertaining to western trouts - their classification, status, general biology, and management potential. The main emphasis is placed on the biological or ecological aspects of the native trouts, rather than on technicalities of their taxonomy in an attempt to underscore a theme of this work-that many of the most significant attributes of evolutionary adaptions are expressed in physiological and behavioral differences governing such traits as migration, tolerance of high temperatures, feeding specializations, etc. Such biological attributes are of ten completely unrelated to morphological and geographical attributes on which taxonomy is based.

I have indulged in some unorthodox classification in an attempt to simplify the complexities of a group of trout I call the rainbow-redband evolutionary line. As will be noted, the trout commonly called "rainbow" actually consists of such diversity that the term is virtually impossible to define. In order to emphasize what I believe is a major divergence between coastal rainbow trout and interior redband trout, I have arranged them into two species. This way, the assumed relationships of all forms can be more readily perceived by assigning them to either the coastal rainbow or the interior redband divergence. Such an arrangement may be an oversimplification of evolutionary reality and may prove to be in error, since there are forms that cannot confidently be classified with one "species" or the other. However, I believe the complexities of "rainbow" trout diversity are better understood when examined in the light of my classification, which also facilitates the testing of my hypotheses on degrees of relationships by future workers. Although it is a cliche to say that further research is necessary, this is certainly the case regarding a more authoritative classification of "rainbow" trout.

Descriptions are given for several unnamed subspecies, but formal taxonomic nomenclature is not proposed in this monograph. The monograph is not a formal publication, and any names proposed would be without taxonomic validity. Some of these unnamed forms were given scientific manes in Ernest Schwiebert's two-volume work, "Trout", published in 1978. Schwiebert's proposed names, however, were published with color plates of the fish and did not include formal descriptions. According to the rules of international zoological nomenclature, names published without descriptions are not valid, but are called "nomen nudems", or "naked names".

The illustrations of coastal cutthrout trout were prepared for the Needham and Behnke manuscript. The illustrations of the Colorado River cutthroat trout, the greenback cutthroat trout and the Gila and Apache trouts are modified from Behnke and Zarn (1976). The fine- spotted Snake River cutthroat trout illustration is from the thesis of Roscoe $(1974)$, and the illustration of the extinct yellowfin trout is adapted from Jordan and Evermann (1902). The other fish illustrations were drawn from specimens. Mrs. Joan Dorman assisted in the preparation of the illustrations. 



\section{INTRODUCTION}

The subject of this work is the trouts of the genus Salmo, native to western North America. Because of their ability to migrate in the ocean and a distribution influenced by climatic changes during the recent history of the earth, the little-known trouts of Asia, Salmo mykiss of Kamchatka and Salmo formosanus of Formosa, must also be discussed in order to bring all the pieces together.

The classification of this group of trouts is complex and confusing. About 50 species were described from 1792 to 1972 . Basic to this monograph is the question: How many species and subspecies actually merit taxonomic recognition? All the living forms of western Salmo are genetically closely related to the extent that no sterility barriers exist preventing generic exchange between any two species if they hybridize. Biochemical genetic differences as determined from electrophoretic studies between two western trout species, the rainbow trout and cutthroat trout, are more comparable to genetic differences between subspecies or local races of many other animal species. Yet there is not doubt that slight genetic differentiation, which might not be detectable by any other means than by observing its manifestation in life history differences, can be of enormous significance in fisheries management. For example, consider two populations of rainbow trout native to a single river system. One, an anadromous steelhead, ranges thousands of miles through the ocean before returning on its home migration at 10 to 20 pounds in weight to reproduce in the stream where it was born, while in a nearby tributary, a resident population of rainbow trout exists, reproducing and dying, perhaps never having moved more than a hundred yards from the site of birth and not growing to a size of more than $8-9$ inches.

The genetic diversity accumulated at the population level through the ages, under the direction of natural selection programmed by environmental cues and resulting in diverse and uniquely adapted local races, should be viewed as a resource to be studied, protected, and used.

The widespread introduction of nonnative trouts, including the ubiquitous disperal of rainbow trout and some subspecies of cutthroat trouts beyond their native ranges, and the deliberate crossing of rainbow and cutthroat trouts, along with the rapidly changing aquatic environments of the West, has led to a tremendous decline and even extinction of many of the unique forms of western trouts. Particularly in arid regions of the West, the notion that water flowing in a stream might have some intrinsic value as a medium to sustain native fish is of rather recent origin, and one that is certainly not yet generally accepted by many decisionmakers.

It is hoped that this monograph, by making information available on the numerous forms of native western trouts, will help save the remnants of the rapidly disappearing genetic diversity of western Salmo. For some taxa, such as Salmo clarki macdonaldi, the yellowfin cutthroat known only from Twin Lakes, Colorado, and an undescribed subspecies of cutthroat trout native to the Alvord basin of northern Nevada and southern Oregon, it is probably too late. They apparently have joined the dodo bird in extinction. 


\section{CLASSIFICATION: HISTORY AND PERSPECTIVE}

The close genetic relationship and lack of sterility barriers a mong all western trouts results in a gray area a mong species rather than clear-cut boundary lines. Thus, there is not likely to be general agreement on the recognition of species of western Salmo, nor on the degree of relationship among species. Despite some important contributions in recent years on chromosome evolution and genetics based on electrophoretic data, these techniques have limitations and, at present, cannot be used as a final answer for species and subspecies recognition.

As a starting point for assembling all the living forms into an evolutionary framework and to arrange the endpoints into a taxonomic scheme, western trouts can be segregated in to those that can be clearly assigned to the cutthroat trout and rainbow trout evolutionary lines and those that cannot, such as the golden trout of California, S. aguabonita; the Mexican golden trout, S. chrysogaster; the Gila trout, S. gilae; and the Apache or Arizona native trout, $S$. apache.

Even at this point, however, there is the problem of a distinctive but diverse group of trouts native to the upper Sacramento River Basin in northern California, extending through the upper Klamath Lake Basin and the desert basins of southern Oregon, eastward to the Steen Mountains and throughout much of the middle and upper Columbia River Basin east of the Cascade Range. This trout exists as both resident populations and andramous "steelhead" populations in the Columbia River Basin. For this diverse and geographically extended group, I have applied the name redband trout (Schreck and Behnke, 1971; Behnke, 1972). The diversity expressed by various geographically isolated populations of redband trout in characters, such as number of scales, vertebrae, pyloric caeca, presence or absence of basibranchial teeth, coloration and spotting pattern, is such that different geographical groups could be classified as S. gairdneri, S. clarki, or S. aguabonita.

In my opinion, the redband trout does represent an evolutionary line of its own that is distinct but closely related to that of the rainbow trout. The California golden trout, S. aguabonita, is a part of the redband phylogeny. Utter and Allendorf (1977) could find no unique genes as diagnostic for coastal rainbow trout, interior redband trout, or golden trout, but did find that when more than one form of a gene (alleles) was expressed, the frequencies were consistently different between the redband trout east of the Cascade Range and the coastal rainbow trout. Gold's (1977) phylogeny of western Salmo, based on chromosomes (karyotypes) indicating the close relationship of the redband trout to S. aguabonita, conforms to my interpretation, but the basis for Gold's evolutionary diagram -58 chromosomes in redband trout and S. aguabonita, and 60 chromosomes in rainbow trout-is not invariably true. Thorgaard (1977 and personal communication) found that coastal rainbow trout populations may be polymorphic for chromosome number. Within a single population, individuals with 58,59 , or 60 chromosomes may be found, and different populations have modal values ranging from 58 to 64 .

It is unlikely that in postglacial times the redband trout of interior regions and the coastal rainbow trout came into contact, hybridized, and obscured much of the distinctions between the two evolutionary lines in areas like the Columbia River Basin. Natural selection, however, preserved much of the genetic diversity between the two groups and avoided homogenization. Homing instinct is the mechanism that maintains reproductive isolation between the redband "steelhead" trout migrating east of the Cascade Range in the Columbia River Basin and the coastal rainbow steelhead west of the Cascades.

I cannot separate all redband trout from all rainbow trout with certainty; their distinguishing characters overlap. When rainbow trout of hatchery origin are introduced into redband trout populations, hybridization often occurs, leading to the virtual disappearance of pure populations of redband trout throughout much of their original range. The redband trout then is not a "good" biological species, comparable in genetic divergence to most animal species, but does represent a distinct evolutionary divergence from rainbow trout. Within this divergence, a multitude of genetically diverse forms adapted to diverse environments exist. Some redband trout have great potential value for fisheries management because of their resistance to high temperatures and because they are effective predators.

In July 1972, I took a sample of redband trout from Chino Creek, an isolated tributary of the Owyhee drainage of the Columbia River Basin in northern Nevada. I readily captured 15 specimens for taxonomic analysis by angling with an artificial fly, and was impressed by the sporting quality of their vigorous fight when hooked. Most impressive, however, was the fact that Chino Creek at the time was set in a barren landscape severely affected by livestock grazing and consisted of intermittent pools having a water temperature of $83^{\circ} \mathrm{F}$. These trout not only rose to a fly, but also exhibited a considerable energy reserve at a temperature lethal to most trouts. Undoubtedly this relict population of redband trout of Chino Creek constitutes a genetic resource of great potential value. It would be a serious mistake to deny such a population special consideration in land and water use decisions affecting its habitat because of the taxonomic uncertainty. Figure 1 presents my interpretation of the trouts of the genus Salmo. 


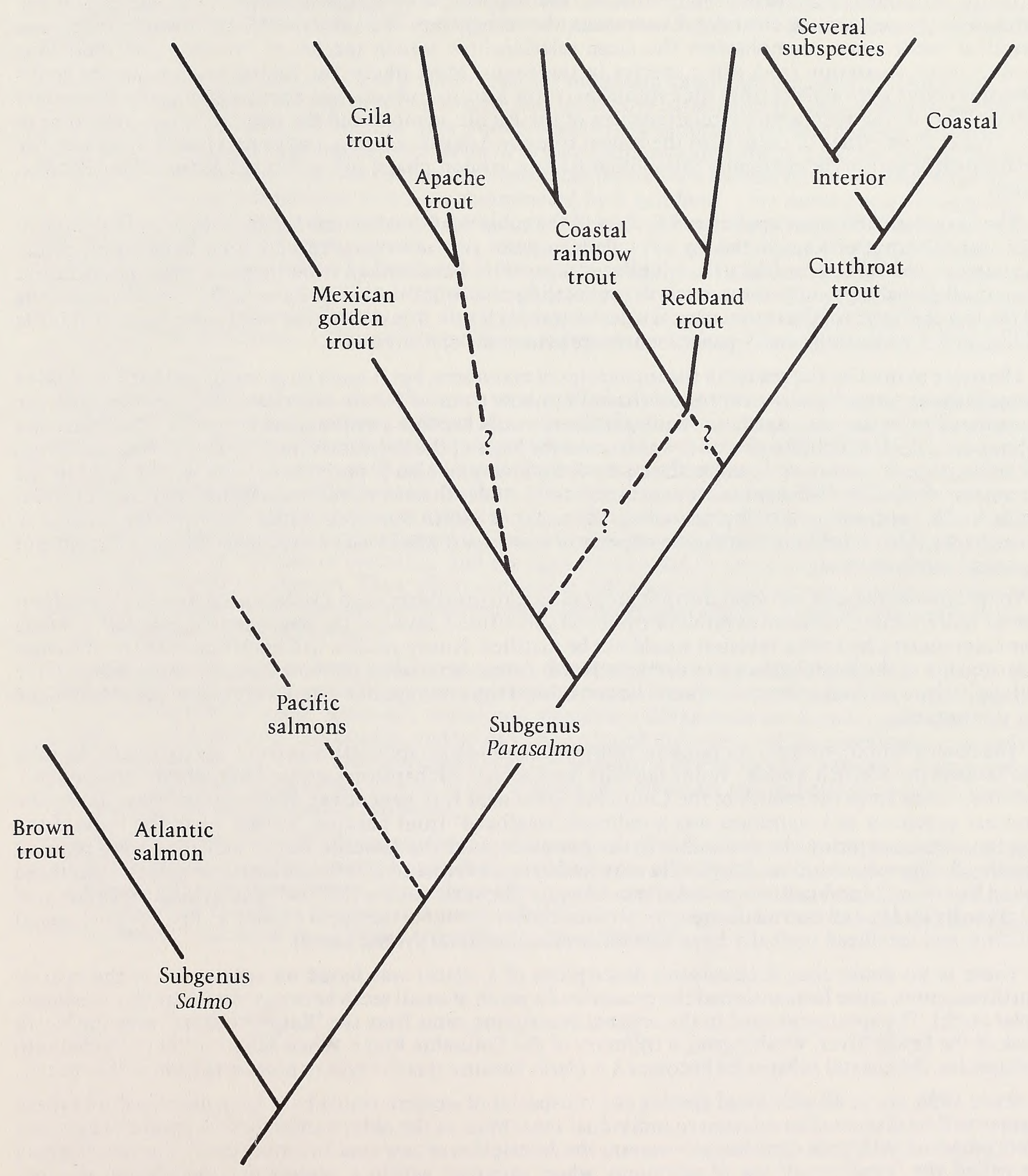

Figure 1. Assumed phylogeny of the subgenus Parasalmo. 


\section{TAXONOMIC HISTORY OF WESTERN TROUTS}

Vladykov (1963) set off the cutthroat and rainbow trouts as the subgenus Parasalmo to emphasize their distinctions from other species of the genus such as the Atlantic salmon, S. salar, and European brown trout, $S$. trutta. Although Vladdykov's main criteria, the expression of sexual dimorphism in males and the interorbital bones, are not clear-cut distinctions, the recognition of a subgenus for the western trouts has practical merit since it emphasizes the close relationships among species of Parsalmo and their long evolutionary separation from other species in the genus. Most likely, the Pacific salmons of the genus Oncorhynchus were derived from the evolutionary line leading to Parasalmo after its divergence from other Salmo. That is, the phylogenetic relationships of the Pacific salmons and the western trouts are closer to each other than either of them is to the brown trout or Atlantic salmon. I have previously discussed the relationships within the subfamily Salmoninae (trouts, salmon, chars) and within the genus Salmo (Behnke, 1968).

The first scientific name applied to a species of the subgenus Parsalmo was Salmo mykiss, by Walbaum in 1792 for the trout of Kamchatka. In 1814, Pallas named two additional species from Kamchatka, Salmo purpuratus and Salmo penshinensis. I published a paper on Kamchatkan trout (Behnke, 1964) pointing out that, in all probability, only one species of trout of the genus Salmo occurs on Kamchatka and that according to the law of priority of the international rules of nomenclature, S. mykiss is the valid name because it is the oldest, and S. purpuratus and S. penshinensis are synonyms of S. mykiss.

I hesitate to involve the reader in the intricacies of taxonomy, but it must be pointed out that S. mykiss of Kamchatka is virtually identical to the coastal rainbow trout of North America. If, as I believe, they are considered to be the same species, then S. gairdneri would become a synonym of S. mykiss. Mednikov and Akhundov (1975) concluded that this was true on the basis of the hereditary nucleic acid (DNA) similarity. The situation is confusing because the name S. mykiss (and also S. purpuratus) was widely used in the literature of the late 19 th century for cutthroat trout under the erroneous assumption that the cutthroat trout had a continuous distribution along the coast of North America across the Aleutian Islands to Kamchatka. Also, it is likely that the description of S. gairdneri was based on a redband "steelhead" trout, not a coastal rainbow trout.

For pragmatic reasons, however, I do not propose here to invalidate such a widely used name as $S$. gairdneri for the fish commonly known as rainbow trout and substitute $S$. mykiss. The chaos caused, especially among nontaxonomists, by such a revision would not be justified. Future studies will continue to affirm the close relationship of the Kamchatkan trout and the North American coastal rainbow trout to a point where there will be little or no doubt that they should be considered the same species-and S. mykiss is the oldest name for this species.

The names Salmo gairdneri for rainbow trout and Salmo clarki for cutthroat trout were given by Sir John Richardson in 1836 in his book, "Fauna Borealis Americana". Richardson's specimen for the description of $S$. gairdneri came from the mouth of the Columbia River near Fort Vancouver, Washington. Most likely, the original specimen of $S$. gairdneri was a redband "steelhead" trout because, at that time, the bulk of the steelhead runs entering the Columbia River passed beyond the Cascade Range and thus were redband steelhead. The redescription of S. gairdneri by Jordan and Evermann (1896) was based on redband steelhead taken from the Columbia River near Astoria, Oregon. The scale counts (137-177) and pyloric caeca count of 42 given by Jordan and Evermann are typical of the redband trout of the upper Columbia River Basin (coastal rainbow and steelhead typically have 120-140 scales and 50-60 pyloric caeca).

There is no doubt that Richardson's description of $S$. clarki was based on specimens of the coastal cutthroat trout, since he mentioned the presence of a patch of small teeth between the gill arches (basibranchial teeth). The specimens used in the original description came from the "Katpootl River", now the North Fork of the Lewis River, Washington, a tributary of the Columbia River. When Salmo clarki is divided into subspecies, the coastal subspecies becomes S.c.clarki because it is the type or nominate form of the species.

Since 1836, about 45 additional species and subspecies of western trouts have been described, and these names will be discussed in relation to individual taxa. Most of the older names for species and subspecies were proposed with little or no basis to warrant the description of new taxa. In former times, during what may be called the "typological" era of taxonomy when variation within a species or a population was not understood, slight differences were believed to denote distinction among species. Thus, one can realize how the great phenotypic variability of trout led to the description of many invalid species.

If the group I call the redband trout is recognized as a species, there is a problem in selecting the correct name for the species. The most commonly used name for an y group of redband trout is Salmo aguabonita for the California golden trout. The oldest name, however, is Salmo newberryi /the type specimen is in the National Museum|. Thus, under my revised classification, the California golden trout would become $S$. newberryi aguabonita. 
Dymond (1931, 1932) recognized the redband or "Kamloops" trout of the Upper Fraser River above Hell's Gate and of the Upper Columbia River in British Columbia, as Salmo kamloops. Jordan (1892) originally described it as "Oncorhynchus kamloops" from British Columbia, but later relegated it to a subspecies of $S$. gairdneri (Jordan and Evermann, 1896) and finally as a synonym of S. gairdneri (Jordan, Evermann, and Clark, 1930).

Dymond (1931) also described a new subspecies, the mountain kamloops, $S$. kamloops whitehousei, as an "extreme" form of the kamloops (or redband) trout, isolated above barrier falls in lakes of the Upper Columbia River Basin in the Selkirk Mountains. This trout probably represents the earliest invasion of redband trout into waters of the upper Columbia River Basin in British Columbia after the last glacial retreat. There they became isolated from subsequent contact and hybrid influence from coastal rainbow trout. Thus, they are similar to the ancestral redband trout, uncontaminated by $S$. gairdneri. This assumption is supported by a gross comparison between the mountain kamloops of British Columbia and another form of the redband trout, also long isolated from contact with rainbow trout, the golden trout of the Little Kern River, California, named Salmo whitei by Evermann (1906). Comparing the color illustrations of "S. k. whitehousei" in Dymond (1932) with "S. whitei" in Evermann's publication, the two are remarkably similar in coloration. It is not likely that these similarities are due to independent convergent evolution, but are the result of common ancestry. Schultz (1935) mentioned that anadromous runs (steelhead) of Kamloops trout occur in the Columbia River.

During the 1930's and 40's, several papers were published demonstrating that trout raised from eggs incubated at different temperatures exhibit significant differences in characters, such as the number of vertebrae and the number of scales. Because of this, it was assumed that most of the differences in characters used to separate taxa of trout, such as $S$. kamloops from $S$. gairdneri, were the direct result of different environments and lacked a genetic basis. Such an assumption ignores a simple fact. The experiments were conducted under laboratory conditions using extreme and constant temperatures. In nature, all members of the subgenus Parasalmo essentially respond to similar environmental temperature cues to initiate spawning no matter what the latitude or elevation, and the eggs are exposed to comparable diurnal fluctuations of temperature during incubation. Thus, when consistent differences in scale counts, numbers of vertebrae, and pyloric caeca are found among samples from different geographical areas, it can be assumed that there is a genetic basis for these differences.

For several years, my students and I have tested the amount of nongenetic change due directly to the effects of different environments by comparing parental populations with their derivatives introduced into different geographical areas. Although occasional significant differences are found, particularly in scale counts, most characters do not change, and we have never found differences of the magnitude reported from laboratory experiments. Thus, I am convinced that the diagnostic differences in characters among different groups of trout (species and subspecies) to be discussed in this report are real /genetic-based/differences, not artifacts of direct environmental influence.

Despite the large number of descriptions of species and subspecies of western trout, many distinct forms (subspecies) have never been named, including several forms of redband trout of the upper Sacramento drainage and of desiccating basins of southern Oregon; the cutthroat trouts native to the Alvord Basin of northern Nevada, southern Oregon, and the Humboldt River drainage of the Lahontan basin, Nevada; and the fine-spotted cutthroat trout of the Upper Snake River, Wyoming. 


\section{FOSSILS AND ANCESTORS}

Within the phylogenetic pathways of the genus Salmo, the branching point of the divergence giving rise to the present species of the subgenus Parasalmo must have separated from the rest of the phylogeny long ago-perhaps in the Miocene or early Pliocene times, about 10,000,000 years ago or more. The genetic divergence between the subgenus Salmo (brown trout, Atlantic salmon, etc.) and the subgenus Parasalmo is of sufficient magnitude that sterility barriers exist. Although some hybrids can be produced by crossing rainbow trout or Atlantic salmon, the hybrids are sterile.

Within the living species of Parasalmo, however, the fertility of hybrids (there is no data on hybridization of S. chrysogaster, the Mexican golden trout) and the general agreement in morphology and gene loci data from electrophoretic studies suggest the living species represent rather recent divergence in geological time from a common ancestor. The earliest divergence in Parasalmo, I suggest, may be the line leading to the Mexican golden trout S. chrysogaster (Fig. 1), which may have occurred in early Pleistocene or late Pliocene times, one to three million years ago. Miller (1972) mentioned that the earliest fossil with similarities to Parasalmo was found in Mexico and was estimated to be 3.5 million years old. I have since been told by Ted Cavender, Ohio State University, that the Pliocene Mexican fossil appears to be a Pacific salmon of the genus Oncorhynchus.

The dominant trout fossils of the Pliocene times that were found in North America represent a highly distinctive group characterized by a rod-like maxillary bone and are classified in the genus Rhabdifario (sometimes classified as Salmo). It is not known if Rhabdifario is a part of the Parasalmo phylogeney or represents a much earlier branch, perhaps diverging before the time of the separation of the subgenus Parasalmo from the subgenus Salmo. It is unlikely, however, that Rhabdifario was a direct ancestor of the living species of Parasalmo because of the distinctions in the maxillary bone. Also, basibranchial teeth have never been reported in the fossils. It is not very probable that species with basibranchial teeth could be derived from an ancestor that lacked these teeth.

La Rivers (1964) described a fossil from the upper Miocene of Nevada as Salmo cyniclope and later (La Rivers, 1966) described a Pliocene Nevada fossil as Salmo esmeralda. The material on which these names are based is too incomplete and has never been critically examined by a competent paleoichthyologist. Thus, judgment on their correct classification must be reserved. The earliest known salmonid fossil was discovered in British Columbia and dated from the Middle Eocene period (about 40 million years old). This fossil was named Eosalmo by Wilson (1977).

Most North American salmonid fossil specimens have been collected in Oregon and Idaho. Typical Pliocene associations found with Rhabdifario are fossil species of Pacific salmon, Oncorhynchus (Smith, 1975). A pparently, some highly unusual salmonids, which are completely different from any living salmonid fish, existed in North America in Miocene and Pliocene times. Cavender and Miller (1972) described a mid-Pliocene "saber-toothed" salmon from Oregon as Smilodonichthys rostratus. Smilodonichthys had no teeth except for massive teeth at the tip of the upper jaw. It had more than 100 gillrakers and probably reached a length of more than 6 feet based on the skull size. Kimmel (1975) described salmonid fragments from upper Miocene deposits in southeastern Oregon. Besides Rhabdifario, he described a new genus, Paleolox, for a salmonid with suggested relationships to the present Eurasian genus Hucho.

During changing climates and rearrangements of drainage basins in the Pleistocene period, ancestral representatives of Parasalmoapparently dispersed in North America, completely replacing earlier groups such as Rhabdifario. Since no fossils definitely assigned to the Parasalmo line of evolution are known from before Pleistocene times, the question is: Where were the ancestral species of Parasalmo before the Pleistocene?

The Miocene period would have provided climatic conditions favoring a holarctic dispersal in the Northern Hemisphere of the genus Salmo and subsequent isolation of European (subgenus Salmo) and North American/eastern Asia (Parasalmo) groups. The degree of speciation and wide dispersal of Parasalmo in North America would suggest North America as their center of origin. The presence of S. mykiss in Kamchatka and its separation from $S$. gairdneri is a relatively recent event, probably occurring no more than 11,000-12,000 years ago, or since the disappearance of the Bering Land Bridge at the end of the last glacial epoch.

There is, however, a most interesting and significant species, now perhaps extinct and known only from one river in the mountains of Formosa, named Salmo formosanus by Jordan and Oshima (1919). I have previously written about this fish (Behnke, 1959; Behnke, Koh and Needham, 1962). Only two specimens are known to exist: one formerly in the Stanford University collection and now in the California Academy of Sciences collection. Since I last wrote on Salmo formosanus, I have received further information from two 
Ja panese ichthyologists, Dr. Watanabe and Dr. Yasue, which leaves no doubt in my mind that $S$. formosanus is a distinct species. It has basibranchial teeth (like cutthroat trout), and may represent an early separation of the Parasalmo line or its direct ancestor which dispersed in Asia but became extinct except for a single river in Formosa. The first $S$. formosanus specimens were collected in 1917 near wild country controlled by fierce headhunters. The Japanese soon gained control of the area, cut the forests, and put the land into agriculture. Such land use changes caused environmental changes in the river system and, despite several collections since 1917, only Oncorhynchus masouhas been found. The apparent demise of $S$. formosanus demonstrates that small relict populations are highly vulnerable to extinction when man changes the environment. 


\section{DISTRIBUTION OF Parasalmo}

Other than the possible $S$. formosanus, the only indigenous distribution of the subgenus Parasalmo presently in Asia is S. mykiss, which is found from the lower Amur River and along the Okhotsk Sea coast to Kamchatka and the neighboring Commander Islands. All other subgenus members are restricted to western North America, although interior cutthroat trout have made short penetrations east of the Continental Divide several times.

The cutthroat trout exhibits the most widespread and primitive distribution pattern. Only cutthroat trout originally existed above barrier falls in the upper Columbia basin-in the upper Kootenay drainage above Spokane Falls (Spokane-St. Joe drainage), above the falls of the Pend Oreille (Clark Fork drainage) and above Shoshone Falls of the upper Snake River. From the headwaters of the Clark Fork, the cutthroat crossed the Continental Divide to gain access to the South Saskatchewan and upper Missouri rivers, but remained restricted to headwater areas and never penetrated much below Great Falls, Montana in the Missouri.

A separate crossing of the Continental Divide from the Snake River brought the cutthroat trout to the Yellowstone drainage (Pacific Creek to Atlantic Creek via Two Ocean Creek, a direct connection that is still operational). The natural distribution of cutthroat trout in the Yellowstone extended downstream to the Tongue River. An important point concerning correct classification of subspecies of interior cutthroat trout is that those crossing the Continental Divide giving rise to the upper Missouri River cutthroat trout, S.C. lewisi,and those entering the Yellowstone drainage were by two distinct ancestors, and the two derived groups (upper Missouri and Yellowstone) nevercame into contact. Thus, the Yellowstone cutthroat trout is recognizably distinct from S. c. lewisi.

From the upper Snake River, the cutthroat trout gained access to the Bonneville and Colorado River basins. From the Colorado, crossings of the Continental Divide by headwater stream captures allowed cutthroat trout to become established in the headwaters of the South Platte and Arkansas river systems and in the Rio Grande. The entire North Platte drainage was barren of native trout. Connections to the Columbia River basin provided access of interior cutthroat trout into the Lahontan basin. The coastal subspecies of cutthroat trout occurs from northern California to Prince William Sound in southern Alaska, but does not typically penetrate farther than 100 miles inland. There are no known instances where the distribution of coastal and interior cutthroat trout overlap.

The coastal rainbow trout (keeping in mind that I have segregated the native "rainbow" trout east of the Cascade Range in the Columbia Basin as a separate species-the redband trout) occurs both farther to the north and south than does the cutthroat. The northern limit is the Kuskokwim River of Alaska and the southern limit is the Rio del Presidio in Mexico. Throughout this range, various populations most likely exhibit varying degrees of redband influence from hybridization caused when the two forms came into contact in postglacial times. The rainbow trout native to the Mackenzie River system of Canada (upper Peace and upper Athabasca drainages) was derived from headwater transfer from the Frazer River drainage.

The redband trout is distributed in the Columbia basin east of the Cascade Range but has been blocked from access into much of the upper basin by the falls mentioned above in which only the cutthroat occurred naturally. It is native to the southern Oregon desert basins west of the Alvord basin and in the upper Klamath Lake basin where it may have once occurred with coastal rainbow steelhead trout. From Goose Lake basin, the redband trout entered the Sacramento basin via the Pit River. The distinctiveness of California golden trout and upper McCloud River redband trout indicates that another divergent group of redband trout, differing from the ancestral redband in the Columbia River basin by three to six fewer vertebrae, invaded the Sacramento River basin. The two ancestral lines of redband trout probably came together and hybridized in the upper Pit River-Goose Lake area.

By the end of the last glacial period, coastal rainbow trout were widely dispersed in the Sacramento system, and further hybridization probably occurred except in areas where the redband trout was isolated from contact, such as in the South Fork of the Kern and the Little Kern and in the headwaters of the McCloud River. Various degrees of intermediacy are found in present native trout of the Sacramento basin, but a strong redband influence is still apparent (yellowish or orange body colors; dorsal, anal, and pelvic fins tipped with white or yellow; faint yellow cutthroat mark; and high scale counts) in the trout of the Pit River drainage despite a long history of massive stocking with hatchery rainbow trout.

MacCrimmon's (1971) Figure 1, depicting distribution of S. gairdneri, includes the redband trout, as well as the California golden trout S. aguabonita, S. gilae, and S. chrysoogaster as S. gairdneri. The inclusion of the St. Joe River of northern Idaho as part of the original range of $S$. gairdneri in MacCrimmon's distribution map is in error. Only cutthroat trout are native above Spokane Falls in this drainage. Also, the redband trout is native in the Kootenay River drainage up to a barrierfalls between Troy and Libby, Montana. MacCrimmon's map shows the upstream limit of distribution in the Kootenay at the British Columbia-Idaho border. 


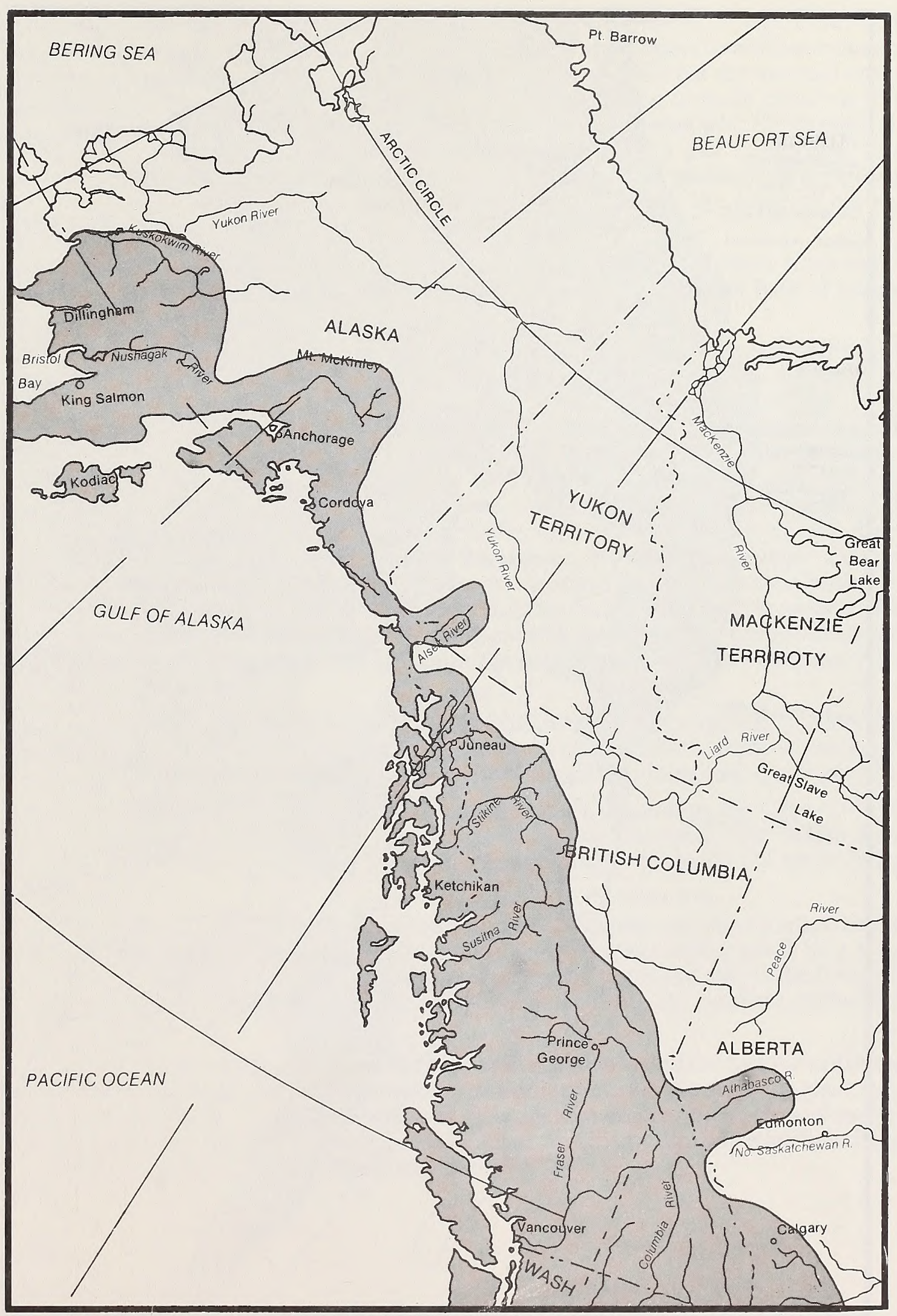

Figure 2A. Distribution of the subgenus Parasalmo in North America. 


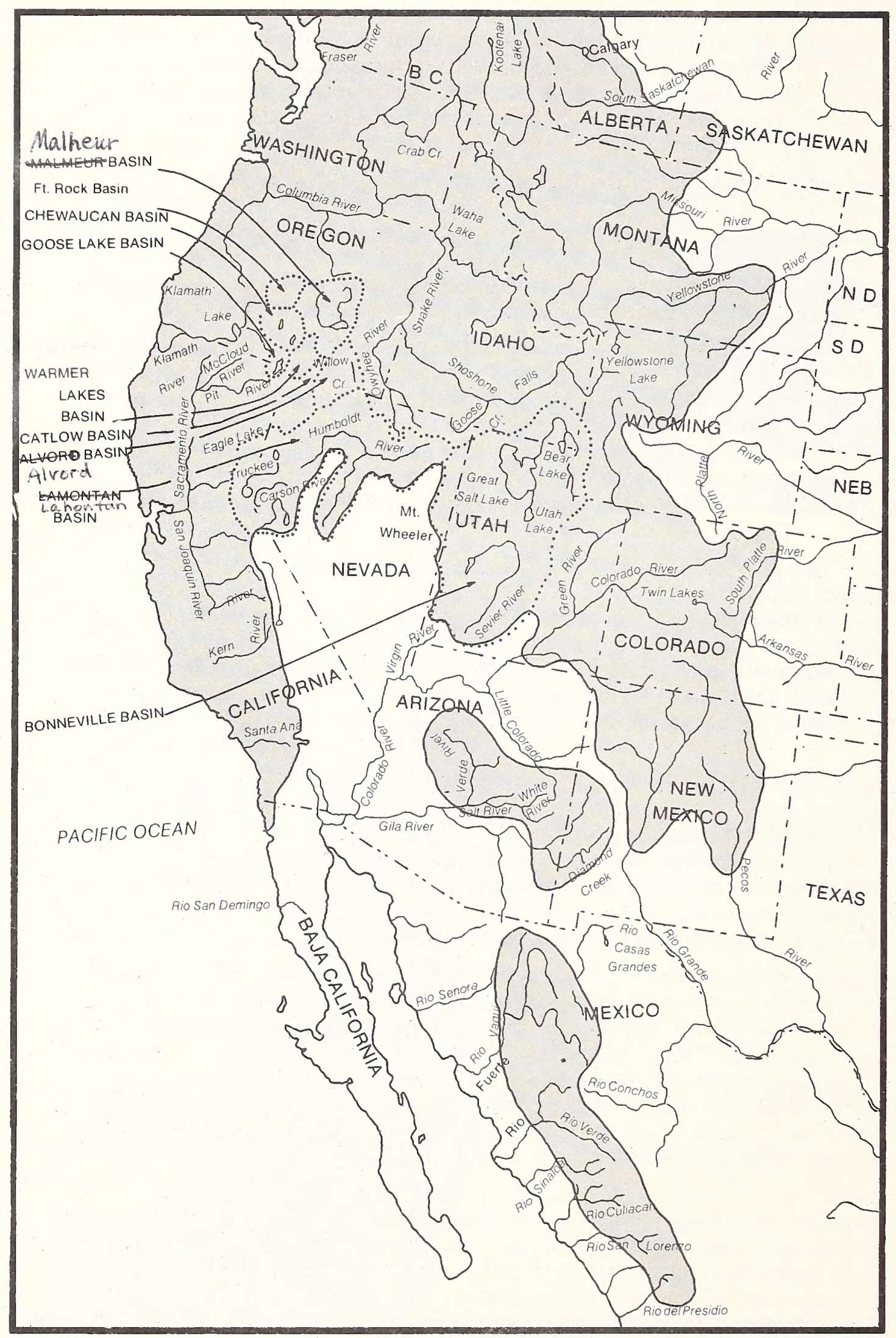

Figure 2B. Distribution of the subgenus Parasalmo in North America. 
I previously wrote that the original rainbow trout propagated by the U. S. Fish Commission from the McCloud River beginning in 1879 , was a mixture of the anadromous coastal rainbow trout and a resident, nonmigratory trout (Needham and Behnke, 1962). At that time, we believed the unusual characteristics of the resident McCloud River trout was the result of past hybridization from an ancestral cutthroat trout gaining access to the Sacramento basin from the Lahontan basin and mixing with the coastal rainbow trout. I had not realized that redband trout represent a distinct evolutionary line until more comprehensive collections were made in 1968 and 1972 demonstrating a common trend of character similarity in the trout throughout the northern section of the Sacramento basin and through the separate basins of southern Oregon and into the Columbia basin.

It is possible that the rapid selection and domestication of the hatchery rainbow trout were promoted by the original crossing of coastal rainbow and redband trout, providing a broad base of heretozygosity for selection to work on.

The geographic distribution and relative speciation expressed between coastal and interior cutthroat trouts and between rainbow and redband trouts had some similarities with the western char commonly known as the Dolly Varden trout, Salvelinus malma. Evidently, similar climatic and geological events influenced the isolation, distribution, and divergence of all these western salmonids in a similar manner during approximately the same time periods. Cavender (1978) demonstrated that the Dolly Varden char actually consist of two species - the typical coastal Dolly Varden, and a larger, more predaceous species, characterized by a broad, flattened head, an obtuse snout and the degree of denticulation of the gillrakers. This formerly unrecognized species is the "bull trout", Salvelinus confluentis. It apparen tly diverged from the ancestral Dolly Varden trout in the upper Columbia River Basin. Throughout the upper Columbia Basin, the bull trout has a distribution similar to that of S.c. lewisi. South of this range in the Owyhee system, upper Klamath Lake basin and the upper McCloud River of California, the distribution pattern of the bull trout followed the dispersal of the redband trout, but the bull trout is now limited to a few relict populations in the southern parts of its range. Apparently, the bull trout coexists better with cutthroat trout S.c. lewisi than it does with redband trout.

The distribution of trout associated with the Gulf of California (S. chrysogaster, S. gilae, and S. apache) is probably of ancient origin. These trout share some common traits with the redband trout group including yellowish body colors, a faint cutthroat mark, and white tips on the dorsal, anal, and pelvic fins.

The present distribution of Gila and Apache trouts indicates a disperal up the Colorado River to the Gila River system probably during one of the Pleistocene glacial epochs when the waters were colder. The establishment of $S$. chrysogaster in three Mexican river systems is probably the result of a more ancient dispersal.

These trouts associated with dispersal from the Gulf of California and their immediate ancestors have probably been isolated from the redband, rainbow, and cutthroat trouts of the north for a long time. If their range ever extended farther to the north to California along the coast and above the Grand Canyon of the Colorado River, they have long since been replaced or absorbed into the rainbow, redband, and cutthroat lines.

The historical distribution of S. apache was limited to the headwaters of the Salt River drainage of Arizona, the White and Black rivers, and to the headwaters of the Little Colorado River. S. gilae was more widely distributed in the headwaters of the Gila River of New Mexico and in the Verde and probably Agua Fria drainages tributary to the Salt River division of Gila River in Arizona. Both species have been reduced to a relatively few remnant populations (Behnke and Zarn, 1976). 


\section{GENERAL LIFE HISTORY NOTES}

Life history variability and the ecological adaptations of such traits as migratory behavior, feeding specializations, and other adaptations for survival beyond normal environmental limitations, including tolerance to high temperatures and alkalinity levels, are relatively rapidly evolved by local populations in particular geographical areas where all populations are exposed to similar environments and selective factors, and may not be characterisitc of a species or subspecies. That is, there is little or no correlation between ecological and life history traits and evolutionary divergence as expressed in a taxonomic arrangement. Thus, the ability of the redband trout of Chino Creek, Nevada, to flourish in 83 F. water, or the effective predation on Gila chubs by the redband trout of Catlow Valley, Oregon, cannot be extended to all redband trouts, such as the relict population in tiny Sheepheaven Creek near Mt. Shasta or the golden trout of the Kern River system. All have lived under quite different environments and selective pressures since separating from a common ancestor.

The slight genetic differences governing migratory (anadromous) vs. nonmigratory (resident) behavior have evolved independently probably thousands of times within widely distributed species of salmon, trout, and char under similar selective factors (convergent evolution). Similarly, variability in feeding, growth, age at maturity, maximum age, etc., are more characteristic of local populations than of a species or subspecies. For example, an en vironment offering the opportunity for rapid and sustained growth, such as a large lake or an ocean, will select for an older age at maturity and thus longer life span and greater maximum size because, despite the attrition from natural mortality, fewer older but larger females will spawn more eggs than will a greater number of smaller, younger females. Thus, again and again, genetically based intra-specific variability is exhibited independently and convergently in those populations long exposed to the selective factors involved with anadromy and large lake environments to delay sexual maturity until an older age and a larger size is attained as compared with populations of the same species or subspecies living in small river systems.

Some ecological generalities can be associated with at least parts of certain phylogenies, such as the better functioning of some interior cutthroat trout in cold water. Typically, the last remnants of several of the interior subspecies are found in small, cold headwater streams at high elevation where they dominate over introduced trouts such as the eastern brook trout, Salvelinus fontinalis, which has replaced the native cutthroat trout in so much of its original range. There are, however, many local exceptions. In the Humboldt Riverdrainage of the Lahontan basin and in the Bear River drainage of the Bonneville basin, fluvial-adapted native cutth roat trout have long been subjected to a harsh and unstable regime of flood and drought cycles. I have found these native trouts flourishing in waters that would be categorized as completely unsuitable for cutthroat trout. In these marginal waters, I have found brown trout, S. trutta, restricted to the colder, clearer tributaries with the native cutthroat trout dominant in the more unstable habitat.

Clearly, the most important ecological and life history attributes of significance to fisheries management are typically not those of a species or subspecies, but those of particular populations or groups of similar populations. For this reason, I have long stressed the practical reasons for perserving the natural genetic variablility that is still extant in the native western trouts (Behnke, 1968, 1972a, 1972b; Trojnar and Behnke, 1974; Behnke and Zarn, 1976).

Because of the general absence of correlation between life history and ecological characteristics on one hand and taxonomy on the other, it is fruitless to attempt to characterize a species or subspecies from intense life history studies of a single population unless the entire taxon consists of that population. 


\section{MANAGEMENT AND UTILIZATION OF NATIVE TROUTS}

Of concern here is the preservation of remnant populations of rare forms on one hand and the potential utilization of genetic diversity for fisheries management on the other, or the role of wild vs. domesticated races in fisheries programs.

More and more fisheries biologists and administrators are realizing that trying to satisfy the increasing demands of recreational angling by increasing hatchery production cannot continue indefinitely, if for no other reason than the simple economics of a fishery based on catchable trout, where six to eight trout may return for every ten stocked (in "good" catchable programs). The unequal distribution of the catch among license buyers in which 8 to 10 percent of the anglers harvest 50 percent of the trout caught (Butler and Borgeson, 1964; Marshall, 1973) results in "short-changing" the majority of anglers. It is also evident that anglers place a premium on a wild trout fishery over a fishery based on catchable stocking. Marchall (1973) evaluated the economics of wild trout and catchable trout fisheries in the Poudre River, Colorado, and found that the value of the wild trout fishery exceeded the value of the fishery based on what anglers are willing to pay for catchable trout by 1.8 to 1.0 .

The number of symposia in recent years indicates that there is a current awareness of the problem of overemphasizing catchable trout in fish management programs and a searching for alternatives to make better use of natural productivity. I would cite the symposia on wild trout management held at Yellowstone Park in 1975, at San Jose, California in 1977, at Eugene, Oregon in 1978 (wild trout-catchable trout symposiuml, and a wild trout symposium in Yellowstone Park in 1979, as examples of this awareness. However, the aspects of "wild" vs. native trout, particularly in relation to the use of native races in regular management programs, to demonstrate the practical values of preserving genetic diversity have not been adequately addressed or articulated in these symposia.

At present, the best known examples of management options using the natural productivity of native trout populations to sustain high quality fisheries (high catch-per-man-hour of fair to good-sized trout, 10 to 18 inches) are the fisheries for native cutthroat trout in the Yellowstone River of Yellowstone Park and in the upper St. Joe River and several other rivers of northern Idaho. There, special regulations take advantage of the cutthroat trout's vulnerability to angling by favoring the catching and releasing of an individual se veral times during its lifetime. Many subspecies of cutthroat trout and perhaps Gila, Apache, and redband trouts are highly vulnerable to angling, but this vulnerability also makes them ideal for fisheries designed to maximize catch-per-man-hour of large fish by bag limit, size, and gear restrictions (Behnke, 1978a). Despite a rather dismal history of special regulations to achieve the desired goals of more and larger fish, special regulations have been successful in greatly increasing survival and catch-per-man-hour in the native cutthroat trout populations of the Yellowstone River and streams of northern Idaho (Behnke, 1978a; Behnke and Zarn, 1976; Bjornn and Johnson, 19781.

In simplist terms, the efficacy of special regulations is based on the question: How many hours of angling per acre of water per year removes 50 percent of all catchable size trout from a body of water or a part of this water? With wide fluctuations, natural annual mortality of catchable size trout (age I , II, and older) will a verage about 50 percent even without angling mortality. Because angling mortality is largely compensatory (the more killed by fishermen, the fewer succumb to natural mortality), the reduction of angling mortality will not likely result in many more older fish the following year, unless angling mortality approaches or exceeds 50 percent of the catchable size fish.

The life history characteristics (growth rate and age structure) and vulnerability to angling exploitation make the interior cutthroat the ideal fish to maximize the success of a special regulation management option. In Rochet Creek, Idaho, Mc Phee (1966) reported that 32 angling hours (12 hours per acre) resulted in the catching of exactly 50 percent of all cutthroat trout 6 inches and over. In this same test, 25 percent of the brook trout were caught. In the Poudre River, Colorado, year-round angling pressure of up to 769 hours per acre could not remove more than 35 percent of the wild brown trout or more than 50 percent of the wild rainbow trout (Marshall, 1973; Klein, 1974).

These statistics show why the cutthroat trout populations have responded so dramatically in the Yellowstone River and in northern Idaho, and why special regulations have not been successful with other trout species.

Before protective regulations were imposed for Kelly Creek and the upper St. Joe River, Idaho, annual mortality rates of catchable size cutthroat trout were estimated at 75 percent. In 1971, a catch-and-release fishery was built on Kelly Creek and on the St. Joe River, with a size limit of 13 inches, a bag limit of 3 cutthroat trout, and with angling restricted to artificial lures. The results were quite rapid and dramatic. Actual abundance, based on transect counts, increased 4-fold in the upper St. Joe River(214 in 1969-70 to 878 
in 1975) and 13-fold in Kelly Creek (27 in 1970 and 355 in 1975) as annual mortality was reduced by eliminating most of the angling mortality. In the upper St. Joe River, the catch-per-man-hour of native cutthroat trout increased by 6 -fold $(.8$ to 4.8$)$, the number of trout over 10 inches in size increased by 10 -fold, and those over 13 inches increased by 30 -fold. With such quality fishing, angler use, after an initial decline following imposition of the special regulations in 1971, returned to pre-regulations levels by 1975 (Bjornn, 1975; Bjornn and Johnson, 1978).

Prior to the special regulations on the upper St. Joe River, large numbers of catchable trout were stocked to supplement the native cutthroat trout to meet angling pressure. Now this same angling pressure is being supported entirely by the native cutthroat population at no cost to the state. Fewer fish are killed, but the catch rate and number of larger fish has increased, and this fishery undoubtedly has significantly higher account values than a comparable fishery based on similar numbers of hatchery trout.

For those not familiar with the literature on the subject, I will briefly review the mortality associated with catching and releasing trout by various angling methods. Wide discrepancies can be found indicating differential mortality due to size, species, and time of the year. Warner (1976) found no significant difference in mortality between fly and bait-caught Atlantic salmon, but the angling occurred in a hatchery raceway where the small salmon swarmed at the fly or bait as soon as it hit the water and were immediately flipped out, typically hooked in the jaw before the bait could be swallowed. Bait-caught trout usually swallow the hook more deeply and die as a result of damage to the respiratory filaments of the gills. If swallowed into the esophagus or stomach and left in the fish, the hook eventually works its way into the heart (delayed mortality).

Thus, according to several researchers (Shetter and Allison, 1955; Mason and Hunt, 1967; Stringer, 1967; Klein, 1965; Hunsucker, et al., 1970|, mortality of bait-caught trout, using worms, salmon eggs, etc., ranges from 30 to 50 percent. Artificial lure-caught trout will suffer about a 5 percent mortality after release, and there are no reported significant differences between flies and hardware (spoons, spinners, etc.), barbed and barbless hooks, or single and treble hooks (Klein, 1966, recorded significantly less mortality from treble hooks than from single hooks). Mortality is highest in warmer water.

In Dutch Creek, Alberta, anglers harvested an estimated minimum of 78 percent of catchable size cutthroat trout, based on the actual recapture of trout previously caught, tagged and released to be caught again later in the season (Radford, 1977). Such high exploitation rates of cutthroat trout (I have roughly calculated that about 150 angling hours per acre were expended on Dutch Creek to harvest more than 75 percent of the catchable size fish/has led the province of Alberta to close their Rocky Mountain cutthroat trout streams to angling on alternate years.

Before special protective regulations were imposed on the northern Idaho streams, an angler preference survey was taken to determine the popular support of a strategy for protecting native trout by reducing the kill, eliminating catchable trout stocking, and limiting angling methods /Gordon, Chapman and Biornn, 1970|. Fishermen expressed overwhelming support for regulations designed to save a native cutthroat trout even though it meant they would kill fewer fish.

Establishing special regulation fisheries for native cutthroat trout in northern Idaho is a highly viable alternative to catchable trout stocking in situations where native trout populations still exist. State fishery agencies must now identify those waters where populations of native trout occur. If angling pressure exceeds 50 hours per acre per year on such waters, and if the native trout is a cutthroat trout, the population is likely to suffer from overexploitation and would benefit from protective regulations. By limiting angling methods to artificial lures and establishing a size limit allowing harvest of fish in their last one or two years span, virtually unlimited fishing pressure could be sustained entirely by natural reproduction. In such a fishery, the value of trout in the water exceeds its value in the creel.

A key issue for the future of trout fishing in America is to develop a more realistic approach for evaluating the worth of specific trout populations in relation to the fisheries they support. As discussed above, anglers place a higher value on wild trout than on hatchery trout. With proper publicity generating public awareness, wild native trout would have a premium value over wild nonnative trout, particularly where the native trout is rare and beautiful as is the case with most of the subspecies of native western trouts.

As demonstrated in the northern Idaho experience, when a native trout population exhibits relatively good growth, long maximum life span, and is highly vulnerable to angling to the extent that an individual can be caught and released several times, a high quality (catch-per-man-hour), high use fishery can be maintained on a stable but limited biomass. In situations where a native trout fishery, such as that of the upper St. Joe River, might be destroyed or modified by a dam, water diversion, channelization, etc., it would 
be completely wrong to accept mitigation in terms of an annual contribution of an equal biomass or hatchery trout to replace the loss of the native cutthroat. In no way are the values comparable.

Another area where I see the genetic resources of native trout having great value for fisheries management programs is in propagation (and the creation of new genotypes from hybridization/for stocking into lakes and impoundments where natural reproduction is not expected. Such environments now stocked with trout encompass millions of surface acres in the western United States. If the proper selection of those genotypes yielding the highest returns in particular environments, and the introduction of two or more genotypes together to take advantage of selective or interactive segregation (see Trojnar and Behnke, 1974) would increase total salmonid production and biomass by only a few pounds per acre, the net result would be significant in terms of producing more trout for more fishermen from present waters.

For more than 20 years it has been apparent that when stocked in natural waters, the offspring of several species of wild trout survive in greater numbers than do the offspring of domesticated hatchery trout (Miller, 1954; Vincent, 1960; Mason et al., 1967; Flick, 1971; Flick and Webster, 1964, 1976; Cordone and Nicola, 1970; Rawstron, 1977). The reasons are simple. As with any domesticated plant or animal, the domesticated trout has been rigorously selected for a hatchery environment and to thrive on an artificial diet. The genetic changes favoring success in hatcheries as expressed in behavioral and physiological traits are ill-adaptive in the wild and thus undergo negative selection and high mortality.

Some insight into the specifics of low survival of domesticated rainbow trout in the wild can be found in the physiological studies of Hochachka (1961) and Dickson and Kramer (1971). The reserve energy supply of domesticated trout is less than that of wild trout, particularly under high temperature stress. Whereas wild trout still have a considerable metabolic reserve to cope with the stress, hatchery trout do not. Also, the behavioral patterns of domesticated trout, al though a successful adaptation to ensuring their share of food in a crowded raceway, are wasteful of energy and ill-adapted in a natural environment (Jenkins, 1971).

As shown by Cordone and Nicola (1971, and much unpublished data developed by these authors), there is a direct negative correlation between the degree or length of time of domestication and survival in the wild in relation to the rigors of the selective factors (suboptimal temperatures, abundance of predators and competitors, etc.) of the environment. In water with a rich food supply, optimum temperatures, and an absence of competitors and predators (a benign environment which is essentially an extension of a hatchery raceway) trout would be expected to do as well, and perhaps even grow faster, than a wild strain of trout because universal selection of hatchery trout has produced a genetic basis for gluttony, the prediliction to increase caloric intake and develop a deep body contour. Even here, however, selection for rapid growth in a hatchery is typically negatively correlated with growth under natural conditions when compared with other hatchery strains. There is a lack of published data on this matter, but the unpublished reports support the negative correlation between hatchery growth and growth after stocking of selected hatchery strains of rainbow trout.

Dr. C. Stalnaker, U.S. Fish and Wildlife Service, supplied me with data collected by the Utah Cooperative Fishery Unit from two farm ponds in Cache Valley, Utah, where a domestic strain of rainbow trout, obtained from the Jones Hole National Fish Hatchery, was stocked with the most famous of all "fast growing" rainbow trout, the "Donaldson" rainbow, developed at the University of Washington. Samples were taken every six months for two years. At each sampling period, the rainbow trout from the Jones Hole Hatchery averaged 25 percent larger than the Donaldson rainbow in one pond, and 50 percent larger in the other pond. All were dependent on natural food.

Even in fish where hatchery propagation is not associated with domestication of brood stocks, such as anadromous salmonids, including the Atlantic salmon (Jessop, 1976), steelhead trout (Reisenbichler and McIntyre, 1977), and coho salmon (Suzumoto et al., 1976), una voidable selection occurs reducing survival after the fish are released. With the coho salmon, it was demonstrated that the selection of a rare allele for a certain type of transferrin (an iron bounding compound in the blood) was favored in the hatchery because it promotes resistance to a bacterial kidney dise ase, but fish with this rare type of transferrin have a markedly poor survival in the ocean.

In California, a "less domesticated" strain of hatchery trout, reputedly developed from a "Kamloops" trout, was developed at the Coleman National Fish Hatchery. When stocked into many lakes of diverse environments, the "Coleman rainbow" consistently produced significantly better yields in numbers and pounds compared with other "more domesticated" hatchery rainbow trout (Rawstron, 1977). However, when comparable plants of the Coleman rainbow trout and wild trout derived from Eagle Lake, California, were stocked into Lake Berryessa, the Eagle Lake trout produced 50 percent more biomass to the creel than did the Coleman rainbow (Rawstron, 1977). 
A significant increase in trout production from the millions of acres of reservoirs in the western United States is entirely feasible by the use of wild (native) genotypes and intelligent manipulation of genetic diversity to create ecological segregation by introducing two or more genetically diverse stocks. From a practical point of view, it is a matter of economics-how much return, or numbers and pounds of trout caught, can be obtained from a known investment (numbers, pounds, and costs) of trout stocked. Although initial investment costs are higher in the propagation of wild, native trout since they are more difficult and expensive to raise than domesticated strains, the returns can be much greater. With a better understanding of the practical values of preserving and using the genetic diversity of native trouts, more active and ambitious programs for imaginative and innovative management of our native trout resources should be forthcoming.

Certainly, no single genetic stock of native trout will be the "trout for all seasons" to exhibit superior growth and survival in very diverse environments. Each native stock is uniquely adapted through evolutionary programming for its own specific environment. Little consideration has been given to finding the "best fit" of wild genotypes for specific environments to obtain optimum results from introductions. It has long been known that the Lahontan cutthroat trout, S.c. henshawi, can thrive in high alkalinity water, such as Walker Lake, Nevada, which is lethal to all other salmonid fishes. Because of this, S. c. henshawi has been stocked into alkaline lakes in Oregon and Wyoming to produce trout fisheries not otherwise possible.

Among the remnant genetic diversity of native trouts, a potential wealth exists, waiting to be tapped by innovative fisheries management programs. A few of the obvious specialized adaptations possessed by various stocks of native trouts that could improve and increase angling opportunities in the future are: migratory and nonmigratory behavior, lacustrine specializations and effective predation on other fish, longevity, older age at sexual maturity, and resistance to high temperatures and to other environmental extremes. Particularly among various groups of cutthroat trout and redband trout, all these specializations can be found.

All these traits may be influenced to a large degree by nongenetic or environmental-acclimization factors, but it is wrong to assume that all taxa, such as all rainbow trout or all cutthroat trout, are ecologically identical and all genetically diverse stocks will respond identically when stocked into a new environment. Undoubtedly, the nongenetic component rate can be an enormous factor (length of growing season, availability and size of food, etc.) so that offs pring of the same parents reared under extreme conditions might show a 50 -fold difference in growth, which would be nongenetic.

For such characteristics as growth, the genetic basis governing the limitations are not of the simple Mendelian kind of dominant and recessives directly determining the color of pea flowers, but rather a whole series of genotype-environmental interactions influencing the behavior, physiology, and all life history aspects of the individual. For example, in Kookenay Lake, British Columbia, two distinct races of "Kamloops" or redband trout are native. One form feeds mainly in the littoral areas on invertebrates, spawning at an age of II or III and reaching a moderate size of about two pounds. The other race is a large predator feeding mainly on the native kokanee salmon. It spawns at an older age (IV-V), and attains a much greater size and greater maximum age (Cartwright, 1961; Hartman, 1969). The large trout of Kootenay Lake, when stocked into formerly barren Jewel Lake, B. C., attained a weight of 52 pounds (Scott and Crossman, 1973). The large race of trout from Kootenay Lake was the stodk of "kamloops" trout originally introduced into Lake Pend Oreille, Idaho, where introduced kokanee, O. nerka, had become abundant. In four years, trout of the original introduction reached weights in the catch of up to 32 pounds and up to 37 pounds in five years.

It is interesting to note that the native trout of Lake Pend-Oreille is the cutthroat trout, S. c. lewisi. Why did not the native cutthroat respond to the new food supply and use the kokanee salmon as did the introduced Kootenay Lake trout? In the lakes of the upper Columbia River basin (Pend-Oreille, Priest, Cour d' Alene, and Flathead Lakes of the Clark Fork and St. Joe River systems), the native cutthroat trout evolved with two native predator species, the Dolly Varden (or more correctly, the bull trout) and the Columbia River squawfish. Under this evolutionary programming, the cutthroat trout evidently specialized as an invertebrate feeder, rather than as a predator to minimize direct competition.

It would be wrong, however, to extrapolate from the feeding habits of the Columbia River basin cutthroat trout that all Salmo clarki are nonpredaceous. Perhaps the most highly predaceous of all trouts native to western North America is the cutthroat trout of the Lahontan basin. S. c. henshawi evolved as the only large predator species in Pleistocene Lake Lahontan (the size of present day Lake Erie) amid an abundance of minnows and suckers. The original Pyramid Lake population of $S$. c. henshawi was the only population continuing to evolve with a full complement of the native fish fauna after the desiccation of Lake Lahontan. It was this population that produced the official world record of 41 pounds, but the actual maximum size was probably greater than 60 pounds (Wheeler, 1969). 
Although not known from actual study, the main food supply of the Pyramid Lake trout probably was the abundant tui chub, Gila bicolor and G. pectinifer. No present stock of S.c. henshawi possesses all of the genetic attributes of the original Pyramid Lake population to so fully use the forage of the lake and to reach the maximum size of the original population, but certain atavistic traits, once evolved, such as prediliction for predation, might be dormant for thousands of years until the opportunity is presented to express the traits. For example, the redband trout of Catlow Valley, Oregon also was the only predator in a large Pleistocene Lake with Gila chubs. After the final desiccation of the lake several thousand years ago, this trout became restricted to a few small mountain tributaries. When a reservoir was constructed on one of these tributaries, Three Mile Creek, and a large population of Gila chubs became established in the reservoir, the redband trout developed a reservoir population and became an effective predator on the chubs. Kunkel (1976) found the reservoir to contain a biomass of chubs equal to 165 pounds per acre, and the trout biomass in the 15 acre area of habitable trout water was 76 pounds per acre. The redband trout in the reservoir a veraged 3.8 pounds at age III /the resident population in Three Mile Creek averaged 3 ounces at this age). The Oregon Department of Fish and Wildlife now propagates eggs from the redband trout of Three Mile Reservoir. Hopefully, studies on the performance of this trout in other waters will provide further insight into the potential use of this particular genotype in fisheries management.

Because many of the unique genotypes, such as the redband trout of Catlow Valley, are small populations, genetic heterozygosity may be slight. For introductions into new, nonnative waters, it may be advisable to make crosses between different isolated stocks to increase heterozygosity for natural selection to operate and increase survival and growth in the new environment.

For propatation and introduction into lakes and impoundments where maintenance of genetic purity of native trout is of no concern, bold and imaginative hybrid combinations should be experimented with to create a broad base of heterozygosity and to learn from experience what genotypes respond most favorably to certain types of environments. Such hybrid combinations might range from intraracial, such as crossings of the Catlow Valley race of redband trout from separate isolated streams, to interspecific crosses between coastal rainbow, redband, and cutthroat trouts. Hybridization resulting in a genotype incorporating aspects of Lahontan cutthraot trout, Eagle Lake "rainbow" trout, and the large "Kamloops" trout of Kootenay Lake, should have the genetic basis to become an effective predator in large, lacustrine environments on a variety of prey species under a variety of environmental conditons. Until now, the use of native trout in propagation for preserving and increasing the abundance of particular native stocks has been largely restricted to the propagation of steelhead trout, both the coastal anadromous rainbow trouts, and the anadromous redband trout (Salmon and Clearwater rivers of Idaho).

As was brought out in the symposium on the genetic implications of steelhead management (Hassler and Vankirk, 1977l, the potentially damaging aspect of steelhead propagation is that the genetic discreteness of the separate stocks has been largely ignored. The propatation of a stock from one river introduced into another river induces mixing of formerly isolated stocks with potential harm from unadapted genes being incorporated into some populations. The literature on the survival and return of native vs. nonnative stocks, however, indicates that natural selection rigorously selects against the introduced stock by differential mortality (Ricker, 1972).

Research by several students of the Oregon Cooperative Fishery Unit has shed some light on how negative selection operates at the level of a single gene against nonnative or hatchery stocks. For example, the transferrin allele in coho salmon is adaptive in a hatchery environment, but is virtually eliminated by negative selection when the fish are released in the ocean environment. Also, I would point out the works of the Oregon Fishery Unit group by Reisenbichler and McIntyre (1977) on the genetic basis governing growth and survival of hatchery and wild steelhead trout, and the thesis by Redding (1977) on the adaptive significance of different forms of the lactate dehydrogenase (LDH) enzyme in steelhead trout. Although it is theoretically possible to harm (reduced survival, growth, etc.) a native anadromous stock from introductions of nonnative stocks (here the term native is very narrowly used in reference to the separation of single interbreeding populations from each other even if both are native to the same river system), I believe natural selection will rapidly rectify the situation.

More intelligent management of anadromous stocks, based on recognizing the survival differences associated with slight genetic differences, will come about because of simple economics. When costeffectiveness analyses are conducted on all anadramous propagation programs and result in poor costbenefit ratios, such stocking will cease or be modified to recognize the genetic differences as the controlling factor governing the success of the program. 
Natural selection can work rapidly to modify a genotype exposed to a new environment by "weeding out" the ill-adapted genes. As mentioned in Behnke and Zarn (1976), an introduction of coho salmon from Puget Sound into the Lamprey River, New Hampshire, had only a 1.2 percent return from the ocean, but eggs taken and propagated from fish passing the test of natural selection in this new environment yielded a return of the next generation of 5.8 percent and at a 50 percent larger size.

Propagation of a few rare forms of native trout has been undertaken, such as the propagation of Lahontan cutthroat trout from Summit Lake for introduction into Pyramid Lake, Nevada, and the raising of S. apache for a recreational fishery in Christmas Tree Lake on the Fort Apache Indian Reservation, Arizona. Other more limited propagation programs have been used to expand the range of endangered taxa in an effort to change the status from endangered to threatened, such as the introduction of S. apache and S. gilae in Arizona and the introduction of the present brood stock of greenback cutthroat trout at the Bozeman, Montana Fish Cultural Development Center into Colorado. The Wyoming Game and Fish Department has initiated the propagation of the Colorado River cutthroat trout and the Bonneville Basin cutthroat trout to increase the abundance of these rare trout. Wyoming currently has a small brook stock of the redband trout of Chino Creek, Nevada. The severely degraded condition of Chino Creek indicated that this trout, with its potential to survive high water temperatures, might become extnict in the next few years. In 1973, the Nevada Fish and Game Department, in cooperation with the BLM, transferred some Chino Creek trout into the barren head waters of a small neighboring stream, Wolfe Creek. In 1975, 100 young-of-the-year redband trout from Chino Creek, Nevada, were transported to a private pond near Buffalo, Wyoming.

The Wyoming Game and Fish Department has effectively expressed concern for native trout to encourage better multiple-use management of Federal lands in relation to aquatic habitat values when conflicts with other uses arise. 


\section{HABITAT CONSIDERATIONS}

Once a state or Federal agency gets involved in projects specifically aimed at protecting and enhancing native trout, many problems result. As mentioned in Behnke and Zarn (1976), the first problem is one of proper identification. The next step is to do something to increase their abundance. At this stage, there is a great danger of getting involved in well-meaning but useless work, and wasting time and money. A logical first step would seem to be to research life history and ecology, by studying a single population from a small stream in order to exemplify the life history and ecological characteristics of the taxon. Because such characteristics are not correlated with taxonomy, the life history and ecological data obtained from such a study a re applicable only to the single population. In all likelihood, any trout of the genus Salmo in a similar habitat (for example, a small stream) would produce virtually identical life history and ecological data.

A common enhancement technique is to construct stream improvement structures. If properly designed, constructed, and placed, such structures can greatly increase trout production in streams lacking adequate depth and cover. Too often, however, the poor physical habitat of the stream is a symptom of waterhsed problems, and the effect rather than the cause of the problem is being treated. Under such circumstances, as where overgrazing by domestic livestock has destroyed riparian vegetation, destabilized the streambanks, and greatly accelerated erosion and peak runoffs in the watershed, instream structures will be silted in and cut around within one or two years and thus aggravate an already bad situation.

In contrast to lakes, where predictive indices of fish-like the morphoedaphic index-generally provide a good correlation between lake morphometry, nutrient levels, and fish production, the characterization of streams for predicting expected production and biomass of trout is much more complex. The Wyoming Game and Fish Department has been pioneering techniques for predicting trout biomass in streams with a "habitat quality index" (Binns and Eiserman, 1979).

Trout population abundance in streams can be considered "food limited" or "habitat limited". The physical environment of a trout stream is of great significance for controlling trout abundance. The basic physical attributes of a stream are expressed in depth, velocity and cover. Slower, deeper (more than 1 foot) waters with adequate cover produce more and larger trout than do shallow, high velocity flows without cover regardless of the food supply. Hung (1978) verified this fact, long know intuitively by biologists and trout fishermen, by man-made alterations of Lawrence Creek, Wisconsin, which converted fast, shallow water without cover into slower, deeper water with overhanging cover. The result was a dramatic increase in trout biomass and average size without influencing nutrient levels, water quality, or invertebrate production.

Thus, in streams with excellent physical habitat (ideal channel morphology and stable banks), trout populations will expand to the limit of their food supply (food-limited), and an increase in average size and abundance cannot be attained unless the food supply is somehow increased. More typically, however, and particularly in watersheds subjected to man's impact, the trout populations are habitat-limited because of poor bank stability, increased peak runoff, and erosion from denuded watershed which cause channel morphology to braid out or trench down. Both produce shallow, high velocity habitat similar to stream channelization. In such situations, watershed rehabilitation is necessary, particularly the establishment of vigorous riparian vegetation to stabilize the banks and to correct the changes in channel morphology before instream devices can be effective in creating better trout habitat.

At a livestock/fisheries symposium held in Sparks, Nevada in May 1977, three documented cases from streams in Oregon, Utah, and Montana were cited to demonstrate that trout biomass was three to four times higher in protected sections of a stream than in sections exposed to livestock overgrazing (Behnke, 1979). In my presentation, I stressed the danger of fisheries and land management agencies getting into the "research trap" by initiating research projects on water quality and invertebrate diversity that is unrelated to cause and effect relationships, to better understand how livestock affects trout populations. The obvious negative impact is a direct change in the physical environment caused by destruction of riparian vegetation and destabilization of stream banks. This triggers changes in channel morphology so that a habitat formerly characterized by slow, deep water with abundant cover, is converted to shallow, high-velocity flows without cover, causing a decline in trout abundance. The food supply and water quality, except for increased temperature and turbidity, have no correlation to the decline in such a situation.

Only by excluding livestock from the riparian zone or by establishing a grazing system to protect the riparian zone from damage can streams now suffering negative impact from grazing begin to recover.

Livestock grazing, however, is not always harmful to trout populations. If it were, there would be little public trout fishing available in the western states where Federal land constitutes one-half of the the total land mass, and where most of it is grazed by domestic livestock. The damage is most acute in the arid and semi-arid foothill regions where the grazing season is long and climatic conditions have produced grasslands 
but where precipitation is insufficient to promote rapid and vigorous growth and sustain high grazing levels. Such are the habitats of many rare forms of cutthroat trout and redband trout in the western states.

In many areas, the damage began more than 100 years ago during the time of the "open range" lor "tradegy of the commons"). All palatable vegetation was removed, and, without adequate vegetative cover, precipitation ran overground causing erosion and arroyos, greatly amplifying peak runoffs, and essentially destroying the streams of a denuded watershed as trout habitat. The streams with destabilized banks were unable to contain the increased flood peaks and were cut down to bedrock (30 to 40 feet or more in many cases). The water table of a watershed becomes proportionately lowered as the main channel cuts down. Eventually, what was originally grassland was converted to desert landscapes. In the longrun, livestock interests perhaps lost the most from this transformation of much of the foothills environment from grassland to cactus, sagebrush, and greasewood, and have the most to gain from rehabilitation of the degraded watersheds.

The above scenario is well documented in the literature of fluvial geomorphology (Schumm, 1969, 1977). A case history of the Douglas Creek watershed, once inhabited by S.c. pleuriticus, in western Colorado, is similar to the sequence of events discussed above (Womack, 1975). In 1883, 25,000 head of cattle were brought into the Douglas Creek watershed. Mr. James Rector, who accompanied the livestock and later resided in the area, related late in his life that the Douglas Creek watershed was the "best cattle country you ever seen-no brush and deep gullies like today, but lush grass up to the stirrups of a horse." Today, the watershed is a desolate expanse of barrenness and greasewood dissected by deep arroyos. A cabin built by Mr. Rector precariously teeters on the brink of a 40-foot deep arroyo cut by Doublas Creek.

The story of the Douglas Creek watershed has been repeated hundreds and perhaps thousands of times in the western states. The tremendous potential to increase native trout abundance and to restore it to large areas where no trout presently exists is obvious. Revegetation, restoration of riparian vegetation, stabilization of flows, and recovery of channel morphology can be relatively rapid in overgrazed watersheds once livestock have been excluded or properly managed (Heede, 1977). Prior to 1969, Otter Creek, a small tributary of Lake McConaughy, Nebraska, suffered from the effects of livestock grazing to the extent that the warm, shallow, silted stream was almost barren of trout. In 1969, the Nebraska Game and Parks Commission leased the headwaters area and fenced out the livestock. Rainbow trout eggs were stocked into Otter Creek in 1969. The stream rapidly recovered, vegetation flourished, the banks stabilized, the channel deepened, and the water cooled by 2 to 5 degrees. The water ran clear, exposing clean gravel beds. A migratory run of rainbow trout from the lake became established in Otter Creek and produced 20,000 seven to ten-inch smolts in 1974 to the lake fishery (Van Velson, 1977). 


\section{COMMENTS ON METHODS AND PRINCIPLES OF CLASSIFICATION}

As a prelude to the following section on the taxonomic arrangement of western North American Salmo, it is appropriate to discuss some of the principles of taxonomy and the methods used to obtain and interpret the information that is the basis for classification. Some understanding of taxonomic principles and of the methods available to obtain taxonomic information from specimens can be especially useful to biologists and administrators. Many have a naive faith that all taxonomic problems and confusion can be eliminated by modern technology, such as biochemical, cytogenetic, and computer techniques. Unfortunately, this is not the case at present. Unless a degree of understanding is attained sufficient to ask the correct questions regarding the efficacy of a certian technique, much time and money can be wasted in abortive efforts which ultimately add to the confusion.

The human mind has an aversion to confusion and a craving for orderliness. Nature, however, does not always conform to the standards of orderliness that we may desire. This lack of natural order is particularly characteristic of the evolution of western trouts. The relatively recent separation in geological time of the evolutionary lines leading to species and subspecies has not been of sufficient duration to produce sterility barriers. Thus, hybridization between taxa has likely occurred in the recent geological past and has been greatly accelerated in recent years by propagation and stocking practices.

For many, it is disconcerting to be told that there may not be clear-cut and consistently quantifiable distinctions between species and between subspecies. It is unlikely in most cases that a particular population can be deemed as a pure or unhybridized representative of a particular taxon with absolute certainty.

To facilitate an understanding of taxonomic methods and their limitations, it is useful to envision a phylogeny of the family Salmonidae with the probable branching points of its evolutionary network through geological time. A polyploid event (doubling of chromosome numbers and DNA content) occurred perhaps $100,000,000$ years ago in an ancestral species separating it from other fishes in the order Salmoniformes, such as the smelts of the family Osmeridae. From this origin, three major branches in the Salmonidae appeared, leading to the present subfamilies of whitefishes (Coregoninae), graylings (Thymallinae) and grouts, salmons, and chars (Salmoninae). Within the subfamily Salmoninae, the phylogenetic branching sequence represents various genera and subgenera, ramifying into species and subspecies.

The basis of a taxonomy attempting to reflect the actual but unknown evolutionary relationships is the detection of unique genetic events. An event occuring in one evolutionary line distinguishes it from its neighboring line (sister group), since the two lines separated from a common ancestor at a particular branching point in the phylogeny. The point is that no matter what method is used-the presence of basibranchial teeth, a particular coloration or spotting pattern, a rearrangement of the chromosomes, or the evolution of new genes replacing older ones which might be observed by electrophoresis of their products (protien molecules)-all have their bases of efficacy in their ability to detect unique genetic events distinguishing one evolutionary divergence from another.

Although evolutionary rates of change are highly variable, generally the longer the time period to reach any particular branching point, the more chance for genetic changes or unique events to accumulate in that line. The branching points leading to present subspecies of western trouts are, in most cases, associated with the fractioning and isolation of populations during the rearrangement of the landscape and drainage basins of the last glacial epoch about 25,000 to 50,000 years ago. Thus, the relative time periods involved in accumulating unique genetic events in various parts of the phylogeny of Salmonidae are about 2,000 times greater at the origin of the family level as at the origin subspecies level. With this in mind, it should be clear why it is unlikely that the relatively few unique genetic events differentiating subspecies will be detected by electrophoretic studies where only a relatively few genes of hundreds of thousands are amenable to observation.

Regarding the geological time period involved and the manifestation of the unique genetic events, there are many similarities between the evolution of subspecies of western trouts and the evolution of man, Homo sapiens. Anyone can distinguish Australian Aborigines from Scandanavian people. The genetic basis determining the conspicuous differences in color and morphology in this case is undoubted, yet no consistent difference in unique gene loci yet studied can be used to group or classify Homo sapiens. The human races are genetically closely related and have no sterility barriers, yet the genetically based differences may be clearly expressed in readily recognized morphological characters like skin color and stature. The situation is essentially similar with subspecies of western trout.

The major consistent difference among subspecies of western trout are found in coloration and spotting pattern, which can be easily learned with experience. If specimens in a population look like the native trout (have the typical spotting pattern and coloration of the trout native to the particular drainage basin), then they should be classified as the native trout. 
Binns (1977) developed a rating system for the purity of Colorado River cutthroat trout populations in Wyoming. The color illustration of Colorado River cutthroat trout on the cover of Binns' publication is a specimen from a "Grade C" population from Red Castle Creek. The trout in Red Castle Creek have been hybridized with rainbow trout, which is apparent from their internal characters. However, they are predominantly native Colorado River cutthroat trout, and the hybrid influence is not observable from external appearances. Thus, they are classified as Colorado River cutthroat trout. If this simple concept is applied, management and restoration programs would be greatly enhanced. For introductions into new waters, the purity of the parent population should be investigated in more detail.

The computer allows one to analyze tremendous amounts of data and to perform various permutations of the data to cluster and quantify degrees of similarity. It cannot, however, to create or discover new characters, and cannot differentiate genetic from nongenetic differences. For example, Koops and Mann (1975) raised genetically similar rainbow trout in three different environments with different food. The growth rates and relative body proportions of the three groups were significantly different. If a computer analysis were performed clustering these data on body measurements, it would lead one to believe that three distinct species, rather than a common gene pool, were involved.

Gold's (1977) computer analysis of meristic and morphological data on western trouts and his resulting phenogram may a pproximate evolutionary reality (except that $S$. apache should show greater similarity to $S$. gilae than to redband trout and S. aguabonita in his Figure 4l, but the redband trout's position in the phenogram is based on a sample from a single population (Sheepheaven Creek, Calfornia). If data from other redband populations from throughout their range were used to express their total range of variablilty, the orderliness of the phenogram would disintegrate.

Various types of multivariate analysis computer programs do offer effective ways to handle enormous amounts of data and to quantify similarities and differences in an impressive manner, but the resulting indices of similarity may not accurately reflect evolutionary reality. The danger of computer taxonomy is that a person inexperienced with the group under study can be led astray and arrive at highly erroneous conclusions concerning evolutionary relationships and classification.

In recent years, numerous publications have compared gene loci data to produce quantitative scores of similarities between subspecies of a species, species of a genus, and genera of a family. These quantitative scores, called indices of genetic similarity or genetic identity, would seem at first to offer some hope of placing quantitative limits for the recognition of species and subspecies in groups with taxonomic problems and confusion, such as the western trouts. There is general agreement for some groups of fish, such as the family Centrarchidae, between genetic similarity scores and their classification into genera, species, and subspecies. However, many conspicuous discrepancies are apparent. Two cyprinid genera, Hesperoleucas and Lavinia, show higher genetic identity scores than do subspecies of a single species of sunfish.

The most noted abberancy of genetic identity scores concerns the relationships of man and the chimpanzee. Man exhibits greater genetic similarity to the chimpanzee in gene loci comparisons than is found between differnt subspecies of species of the mouse genus Mus and the lizard genus Anolis. The problem with gene loci data is that only an infinitesimal portion of the total genome can be examined, and these genes may evolve at a different rate than the genes governing morphology and behavior. Also, only a fraction of the mutations present in a gene can be detected by electrophoresis. Siebenaller and Somero (1978) found significant functional differences in the lactate dehydrogenase (LDH) enzyme in several fish, correlated with the depths the fish lived at, but could find no differences in the LDH from electrophoretic analysis.

A relatively new technique, DNA hybridization, theoretically can compare genetic similarities by comparing the similarity of the bulk of genome/the redundant or regulatory DNA/ between two taxa. This method disassociates strands of DNA from cell nuclei representing two taxa (subspecies, species, genera, etc.) and recombines them (DNA hybridization). The more similar the DNA strands are to each other, the more tightly they bind and the more energy (heat) is needed to disassociate them (Gharrett et al., 1977). The temperature causing disassociation gives a quantitative score of relationships.

DNA hybridization data appears to reflect actual evolutionary relationships between evolutionary lines that have been separated for millions of years (clear-cut species, subgenera and genera), such as whitefishes of the genera Prosopium and Coregonus and the subgenera Coregonus and Leuchichthys (Mednikov et al., 1977). For more recent evolutionary lines diverging perhaps within the last million years, (closely related species and subspecies of Salmo and Salvelinus), however, the DNA hybridization scores do not, in my opinion, accurately reflect genetic relationships. 
Mednikov and Akhundov (1975) compared a steelhead rainbow trout imported into the USSR from Oregon with both the anadromous and resident forms of $S$. mykiss of Kamchatka and with hatchery rainbows, brown trout ( $S$. trutta), and Atlantic salmon (S. salar). As might be expected, the anadromous $S$. mykiss (called S. penshinensis in the publication/is virtually identical to $S$. gairdneri from Oregon. However, the hatchery rainbow trout's (called S. irideus in the publication/comparative score, based on hybridizing DNA of hatchery rainbow trout with Oregon steelhead DNA, lies half way between "S. gairdneri" and $S$. trutta $\mid S$. gairdneri $=100$ self-hybridization, "S. irrideus" $=61$, and $S$. trutta $=25 \mid$. This is not in accord with the actual degree of evolutionary relationships. Until the method is further refined and experimental errors reduced, I do not foresee DNA hybridization data contributing much to a better understanding of the relationships in the more recently evolved lines in the subgenus Parasalmo. It might, however, be a useful tool for testing the assumptions on relationsips between the major species group lines as illustrated in Figure 1. I do beleive, however, that some new biochemical/genetic technique will eventually provide the answers to the questios posed on relationships in this monograph.

The subfamily Salmoninae varies greatly in chromosome numbers. Within five species of Pacific salmon,

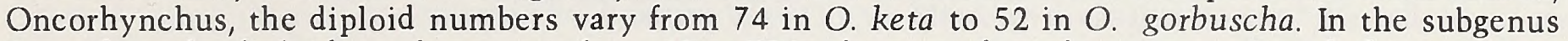
Parasalmo, the diploid number ranges from 68 to 70 in the coastal cutthroat trout, S. c. clarki, to 56 in $S$. apache. The general evolutionary trend is for a karyotype to progress from a higher number to a lower number by the fusion of two one-armed (acrocentric) chromosomes into a two-armed (metacentric) chromosome. However, in the rainbow-redband evolutionary line, I believe the trend for lower chromosome numbers was reversed.

The interior redband trout with the more generalized primitive features have 58 chromosomes. The coastal rainbow trout varies from 58 to 64 chromosomes. Evidently, the splitting of two-arm chromosomes into one-arm chromosomes, increasing the total chromosome number, has occurred in the recent evolutionary history of coastal rainbow trout. It was previously believed that rainbow trout are characterized by 60 diploid chromosomes and 104 arms, and cutthroat trout by 68 to 70 chromosomes with 106 arms in the coastal subspecies and 64 chromosomes with 106 arms in several interior subspecies. Gold et al. (1977)found that both coastal and interior cutthroat trout have 104 arms in their karyotypes, and that $S$. apache and probably S. gilae have 106 arms. Mexican golden trout have 60 chromosomes with 104 arms, and the trout native to the Rio Yaqui and Rio Mayo in Mexico have 64 chromosomes with $104 \mathrm{arms}$ (T. Uyeno and R. R. Miller, personal communication|. S. mykiss of Kamchatka is reported to have 58 to 60 diploid chromosomes (Vasilyev, 1975).

Thus, the chromosome picture of western trouts is confusing, and no clear pattern for interpreting relationships emerges. The number 64 must have evolved independently at least three times-in inland cutthroat trout subspecies, in some California populations of coastal rainbow trout, and in the trout of the Rio Mayo and Rio Yaqui, Mexico.

Until more refined techniques are developed that will allow clear banding patterns of the chromosomes so that homologous sections of the karyotypes can be determined among different species to interpret the evolutionary sequences of the rearrangements, chomomosome studies will play a limited role in interpreting evolutionary relationships.

First generation hybrids between rainbow and cutthroat trout have chromosome numbers intermediate of the parent species. However, a slight rainbow trout hybrid influence into a cutthroat trout population is not likely to be detected from chromosome analysis. If hybridization has progressed to the point where intermediate numbers of chromosomes are found in most of the population, the effects of hybridization will be obvious from the changes in coloration, spotting, and the influence on such characters as basibranchial teeth, number of scales, and pyloric caeca.

For groups like the western North American trouts, which represent relatively recent divergences without sterility barriers, the recognition of species and subspecies is, to a large measure, arbitary. The most common definition of a species is based on reproductive isolation-the ability of a species to coexist with its most closely related species without hyridizing. As I have previously pointed out (Behnke, 1972), the criterion of reproductive isolation cannot be uniformly applied to determine the validity of species of salmonid fishes - there are too many glaring exceptions. Resident and anadromous populations of rainbow trout or winter-run and summer-run steelhead trout inhabiting the same river system are not considered to be different species merely because they maintian reproductive isolation from each other. In salmonids, reproductive isolation may be maintained between more distantly related groups, such as rainbow trout and S. apache or S. gilae. My evidence of species and subspecies is based on several factors concerning evidence ofgenetic relatedness and zoogeography. 


\section{SYSTEMATIC ACCOUNTS OF WESTERN TROUTS}

\section{INTR ODUCTION}

It is apparent that there has been considerable disagreement about the "most" correct classification of western trouts, and it is not likely that a definitive resolution will be achieved in the near future.

Following the suggested relationships depicted in Figure 1, this section breaks down the subgenus Parasalmo into three species groups or series:

1. The cutthroat trout: one species with 15 subspecies.

2. The rainbow and redband trouts: two species provisionally recognized with many divergent forms.

3. The trouts associated with the lower Colorado River basin and Gulf of California: three species with no subspecies recognized at this time.

\section{CAUSES OF CLASSIFICATION CONFUSION}

The earliest attempt to a comprehensively classify American trouts is found in a manuscript written in 1861 by George Suckley, U.S. Army Surgeon and naturalist, who collected and studied trout while participating in the Pacific Railroad surveys of the 1850's. Suckley's manuscript, "On the North American species of salmon and trout" (often referred to as "Monograph of the genus Salmo"), was published in 1874 in the first report of the U.S. Fish Commission for 1872-73.

Suckley was the author of the name Oncorhynchus, devised to segregate the Pacific salmons from the trouts. He named a species, Salmo gibbsi, which, in part, refers to the redband trout of the middle Columbia River. Suckley recognized that the trout of the Upper Missouri River at Great Falls (S. clarki lewisi) was similar to the trout on the other side of the Continental Divide in the Clark Fork drainage of the Columbia River basin-a fact largely overlooked since then. Although of historical interest, Suckley's grouping of species is based mainly on ecological similarities, such as anadromous, nonanadromous, living in rivers, living in lakes, etc., and has little in common with current concepts of classification based on evolutionary relationships.

From about 1880 to 1930, the publications of David Starr Jordan and his associates completely dominated the literature and opinion on trout classification. Jordan, however, changed his mind several times about the classification of western trouts regarding the number of species recognized, their relationships, and nomenclature. Schreck and Behnke (1971) reviewed the details of Jordan's changing opinion. Very early in his career, Jordan realized that there are two clearly differentiated groups of western trouts, the rainbow and the cutthroat trout. His confusion began when he encountered specimens of the redband trout.

Jordan's diagnosis of Richardson's Salmo gairdneri, the steelhead trout of the Columbia River, was based on specimens taken from the Columbia River near Astoria, Oregon, which undoubtedly were specimens of the redband steelhead trout, not the coastal rainbow steelhead trout, as can be interpreted from the scale counts of 137-177 and pyloric caeca count of 42 given by Jordan and Evermann (1896). For many years, it was debated whether steelhead trout are coarse-scaled (120-140 scales) or fine-scaled (140-175), because all other steelhead, other than some of the Columbia River runs, were found to be coarse-scaled. The fact that has never been adequately recognized in the literature is that there are two distinct forms of steelhead trout, the coarse-scaled coastal rainbow steelhead and the fine-scaled redband steelhead, which runs up the Columbia River east of the Cascade Mountains.

In the early 20th century, Jordan decided that Richardson's original description of S. gairdneri was actually based on a specimen of sockeye salmon, and he substituted the name $S$. rivularis for $S$. gairdneri. Later, he changed his mind again and reinstated $S$. gairdneri as a valid name. The coarse-scaled coastal rainbow trout was recognized by Jordan as Salmo irideus. As previously discussed, if Jordan's diagnosis of Richardson's $S$. gairdneri, as found for example in Jordan and Evermann (1896), is considered a "first revision" (redefinition) of the name, then $S$. gairdneri would become the correct name for the redband trout, and $S$. irideus would be the name for the coastal rainbow trout (if we ignore the problem of the name Salmo mykiss of Kamchatka). For the purpose of this monograph, however, I believe such a course of action would further confuse nontaxonomists because the name $S$. gairdneri is firmly associated with the common name rainbow trout.

Jordan's ideas on western trout evolution can be summarized as follows. A cutthroat-like ancestral species dispersed from Asia to North America and spread throughout the Columbia River basin. The ancestral species was split by the creation of Shoshone Falls on the Snake River resulting in the isolation and 
evolution of the earliest form of interior cutthroat trout above the falls. The interior cutthroat trout crossed Two Ocean Pass to enter the Yellowstone drainage. From the Yellowstone, dispersion occurred in the Missouri River basin as far downstream as the Platte River. From the headwaters of the South Platte and Arkansas rivers of Colorado, other crossings of the Continental Divide, this time from east to west, established the present subspecies of cutthroat trout in the upper Colorado and Rio Grande basins. From the Colorado River Basin, the cutthroat trout somehow crossed the Sierra Mountains to evolve into the golden trout, S. aguabonita, a transitional form between the rainbow and the cutthroat trout. From the Kern River, the golden trout then dispersed along the Pacific Coast, evolving into the coarse-scaled coastal rainbow trout (Jordan's S. irideus), which in turn gave rise to the fine-scaled steelhead trout (Jordan's S. gairdneri).

Such a sequence of events may have appeared logical to Jordan, but they bear little semblance to reality. A diagram of evolutionary relationships based on Jordan's theory would place the most ancient separation of western trout between the coastal and interior cutthroat groups / the lower Colorado River basin and Gulf of California trouts were unknown to Jordan). No fish could have crossed Two Ocean Pass into the Yellowstone drainage until about 8,000 years ago because glacial ice would have blocked fish distribution on the Yellowstone Plateau. The cutthroat trout native to the upper Missouri drainages (Great Falls and above) are not derived from the Yellowstone cutthroat trout, but from a separate crossing of the Continental Divide from the headwaters of the Flathead River drainage. The separate crossings of the Continental Divide by two distinct ancestors-Snake River to Yellowstone and Flathead River to upper Missouri, is the cause of the present confusion over the correct usage of the subspecies $S$. c. lewisi.

The native trout of the Yellowstone River was never able to become established beyond the confines of the drainage until assisted by humans. This is apparent from the fact that trout are not native to the many excellent coldwater streams in the Black Hills of Wyoming and South Dakota. If trout had traversed the Missouri as far south as the Platte River, they would have certainly left remnants in the Black Hills. Also, trout (greenback cutthroat) are native to the South Platte, but not to the North Platte drainage.

It seems obvious then that Jordan's sequence here is reversed; the cutthroat trout of the Colorado River crossed the Continential Divide to give rise to the trouts of the South Platte, Arkansas and Rio Grande drainages. The Colorado River cutthroat trout could not have crossed the Sierras to give rise to the golden trout, although they are quite similar in coloration and spotting. Cutthroat trout native to the Colorado River basin never dispersed below the Grand Canyon. The San Juan River drainage is the southernmost natural distribution of cutthroat trout in the Colorado River basin.

Jordan and his associates, C. H. Gilbert and B. W. Evermann, performed many of the first scientific fisheries investigations in the West for the U.S. Fish Commission, the parent organization, in part, of the U.S. Fish and Wildlife Service. From their practical field experience and from examination of specimens, it was obvious that in coastal waters, both coastal cutthroat trout and coastal rainbow trout occurred, and each was perfectly distinct. Above Shoshone Falls of the Snake River and in interior waters, various forms of interior cutthroat trout were encountered. Below Shoshone Falls of the Snake River and in the middle Columbia River basin east of the Cascade range, they encountered nonmigratory populations of redband trout and became thoroughly confused. The redband trout appeared intermediate between cutthroat and rainbow trout, apparently bridging the gap betweeen the two species. They failed to connect the resident redband trout of the middle Columbia basin with the anadromous steelhead, $S$. gairdneri, from Astoria, Oregon, with 137-177 scales. Jordan and Evermann (1896) classified the resident redband trout of the middle Columbia Basin as a subspecies of cutthroat trout, using Suckley's name gibbsi, but in later works elevated gibbsi to full species status. It is now obvious that the steelhead trout Jordan characterized as $S$. gairdneri and the resident trout, classified as S. gibbsi, represent anadromous and non-anadromous stocks of the redband trout of the Columbia River basin.

Redband trout also caused considerable confusion in the upper Sacramento River drainage (particularly the McCloud River), the upper Klamath Lake, and the desert basin of southern Oregon. Jordan named S. gairdneri shasta and S. irideus stonei for McCloud River trout specimens. Most early references to the native trout of Upper Klamath Lake and the Oregon basins considered them to be cutthroat trout.

Jordan developed the idea that there are three major evolutionary lines, which he called "series" of western trout - the fine-scaled steelhead trout, the coarse-scaled rainbow trout, and the cutthroat trout. Earlierin his career (prior to 1900) he grouped all of the described forms as subspecies of the three "species" S. gairdneri, $S$. irideus, and S. mykiss (later S. clarki). After 1900, Jordan, evidently confused and frustrated over the correct classification of the diverse forms derived from the redband evolutionary line, recognized virtually all described forms as full species. His last opinion (Jordan, Evermann, and Clark, 1930) lists 32 full species of coastal rainbow, redband, and cutthroat trouts. 
I must admit that the redband group of trout long confused me and frustrated all attempts to develop a logical classification of western trouts reflecting evolutionary relationships. When I first examined the museum specimens Jordan had used to describe the McCloud River trout (S. "shasta" and S. "stonei") and museum specimens collected during early expeditions from the Oregon desert basins, I was also influenced by the fact that their characters are mostly intermediate between rainbow and cutthroat trout. On geographical grounds from the evidence of the distribution of other fish species, the Oregon desert basins and the upper Sacramento River drainage are areas where coastal and interior faunas have come together. It seemed logical to me at the time that the trout I now recognize as the redband trout originated from an ancient hybridization between an interior cutthroat trout and a coastal rainbow trout. This theory was mentioned in a paper I wrote with the late P. R. Needham on the origin of hatchery rainbow trout (Needham and Behnke, 1962). It is also presented in the unpublished manuscript Needham and I wrote on western trouts in 1963, and in my Ph.D. thesis of 1965.

It was not until many more collections had been made and examined between 1967 and 1972 that Ifinally realized that the redband trout is a unique evolutionary line that did not originate from hybridization between rainbow and cutthroat trout (Behnke, 1970, 1972; Behnke and Zarn, 1976; Schreck and Behnke, 1971). Recent chromosome analysis data also negates the possiblity that hybridization between rainbow and cutthroat trout could have produced the redband trout (Gold, 1977).

The U.S. Fish and Wildlife Service (USFWS) published a work on trout classification in 1949, Fishery Leaflet Number 355, titled "The trouts of North America-general remarks on classification". It was authored by S. F. Hildebrand, senior ichthologist of the USFWS. Hildebrand essentially based his classification of western trouts on that of J. O. Snyder, who was one of Jordan's associates at Stanford University. Snyder's (1940) classification as it appears in Fishery Leaflet 355, combined Jordan's steelhead "series" and coastal rainbow "series" into one "rainbow series", but with 12 full species listed. The "cutthroat series" contained nine recognized species.

The next major publication on western trout classification, by Miller (1950), described S. gilae, the first of the three currently recognized species of trout native to the lower Colorado River basin-Gulf of California area. Miller essentially followed Snyder's concepts of two evolutionary groupings or series, but relegated many of the species recognized by Snyder to subspecies status and increased the number of species or subspecies assigned to the cutthroat series from 9 to 12 .

Needham and Gard (1959) described collections of trout from California and Mexico. The major significance of Needham and Gard's work was the discovery of the Mexican golden grout, which they considered to be $S$. gairdneri, under the influence of the "two series theory" of trout evolution, whereby all forms could be assigned either to the cutthroat trout or to the rainbow trout evolutionary lines. As a research assistant to Needham at the University of California, Berkeley, at this time (1957-1964), I realized that the Mexican golden trout could not logically be assigned to either the cutthroat or the rainbow evolutionary lines; it represents a unique evolution, removed from both rainbow and cutthroat trouts. Needham and Gard (1964) named the Mexican golden trout as a new species, $S$. chrysogaster.

The last species to be named was Salmo apache by Miller (1972) for the trout native to a few headwaters of the lower Colorado River basin in Arizona. The trouts native to the lower Colorado basin-Gulf of California area (S. apache, S. gilae, S. chrysogaster) were discovered in relatively recent times and were unknown to Jordan. Their evolutionary relationships are still largely a matter of speculation, and it may be several years before sufficient genetic information is available on these trouts to validate or invalidate the relationships I have suggested in Figure 1. 


\section{CUTTHROAT TROUT, Salmo clarki}

\section{INTRODUCTION}

The common name "cutthroat" trout is now generally used in the literature for all forms of S. clarki and is the common name adopted by the American Fisheries Society's Committee for Common and Scientific Names. Evidently, the name was popularized by Charles Hallock, editor of "Forest and Stream", the leading sporting journal of the late 19th century. David Starr Jordan, America's most eminent ichthyologist, railed against the use of the name cutthroat for the trout he so greatly admired. Jordan believed the cutthroat trout was a much finer and more beautiful fish than the rainbow trout and stated that the cutthroat trout should be the predominant trout of fish culture rather than the rainbow. Goode (1888) wrote: "Hallock and other recent writers have applied to it the horrible name "Cut Throat Trout", which it is hoped will never be sanctioned in the literature." Goode alse objected to the "ridiculous name Dolly Varden trout", also to no avail.

The cutthroat trout has the greatest distribution of any of the species of western trouts. Along the Pacific Coast, the coastal subspecies occurs from southern Alaska to northern California. The interior forms are divided into many subspecies.

In many cases, subspecies of interior cutthroat trout are not "good" subspecies in that they may lack distinctive characters. In such cases, correct subspecific indentification is difficult without knowing where the specimens came from. For example, the greenback trout, S. c. stomias of the South Platte Basin, and the Colorado River cutthroat, $S$. c. pleuriticus, are so similar that predictable identification of specimens as stomias or pleuriticus cannot be made unless the drainage basin is known.

The use of subspecies is a practical device that facilitates management by dividing a highly variable, widely distributed species of unwieldy taxonomy into many smaller units associated with particular drainage basins or geographical areas. Although some of the subspecies, such as stomias and pleuriticus might logically be combined into one larger subspecies, I have not done so because the names are long established, and management and restoration programs are associated with the subspecies names. There would only be considerable confusion from name changes at this time.

\section{DISTRIBUTION AND TAXONOMY}

Interior cutthroat occur in the middle and upper Columbia River basin, the upper Colorado River basin, the Bonneville, Lahontan, and Alvord basins of the Great Basin. Several crossings of the Continental Divide established native cutthroat trout in the South Saskatchewan, upper Missouri (above Great Falls), Yellowstone, headwaters of the South Platte and Arkansas and in the Rio Grande. This distribution reflects a primitive pattern of dispersal. Of the trouts and salmons native to western North America, only the cutthroat trout was originally found above major barrier falls on major tributaries of the Columbia RiverKootenay River, Pend Oreille-Flathead drainage, Spokane River and Shoshone Falls of the Snake River (the "bull trout" or charr, Salvelinus confluentis, is native above the Columbia Basin barriers except for Shosone Falls).

It appears from the natural distribution of western salmonid fishes that the cutthroat trout was the "first on the scene" and populated the waters of the upper Columbia River basin prior to the formation of barrier falls. The later appearance of representatives of the rainbow-redband trout lines and the salmons of the genus Oncorhyncus, after the falls had formed, blocked them from further penetration.

There appears to be a considerable geographical gap separating coastal cutthroat trout from the interior subspecies. From chromosome studies, it is clear that the first major divergence in cutthroat trout evolution occurred between the coastal cutthroat trout and an ancestral interior form, which, in turn, gave rise to all other interior subspecies. The coastal cutthroat trout has the most chromosomes $(68-70)$ of any of the western trouts. Interior subspecies, studied to date, have 64 chromosomes (with the exception of S.c. lewisi which probably has 66). The coastal cutthroat trout's chromosomal complement (karyotype) is the primitive form. It gave rise to the karyotypes of interior cutthroat trout by a fusion of four pairs of one-arm chromosomes $(=8 \mathrm{chromosomes})$ into four two-arm chromosomes $|=4 \mathrm{chromosomes}|$, thus reducing the total number from 68 to 64 .

The interior cutthroat trout probably split into two diverging lines at an early stage of evolution during one of the glacial epochs of the Pleistocene. This earliest divergence of the interior cutthroat is represented 
today by the cutthroat native to the northern division of the upper Columbia (Kootenay, Clark Fork, and Spokane river basins|, upper Missouri, and South Saskatchewan drainages. I recognize this trout as S. $c$. lewisi. The cutthroat trout representing the other branch of this first major divergence is the trout native to the southern (Snake River) division of the Columbia River basin (although S. c. lewisi is the native cutthroat of the two largest tributaries of the Snake River, the Salmon and Clearwater rivers) and the Yellowstone drainage. It is commonly called the Yellowstone cutthroat. I recognize this subspecies as S. c. bouvieri, the first name unmistakeably applied to this form of cutthroat trout.

From southern parts of the Columbia River basin the "Yellowstone" cutthroat ancestor gave rise to the Great Basin cutthroat trout (Lahontan, Bonneville, and Alvord basins) on one hand, and to the Colorado River cutthroat on the other. From the upper Colorado River basin, crossings of the Continental Divide established native cutthroat trout in the South Platte and Arkansas drainages and in the Rio Grande basin.

Because of the great variablilty found in the different geographic races or subspecies (S. clarki is an excellent example of what is called a polytypic species in the systematic literature), and because of character overlap with redband trout, there is little in the way of absolute criteria, besides the chromosomes, to positively separate all cutthroat trout from all other western trouts.

The common name, of course, comes from the red, sometimes orange, slash mark found on each side beneath the lower jaw. Redband,Gila, and Apache trout often have a yellowish cutthroat mark, whereas true cutthroat trout, such as sea-run coastal cutthroat trout, may lose the mark. The presence of basibranchial ("hyoid") teeth is usually given in fish identification keys to separate cutthroat from rainbow trout. Although some pure cutthroat trout may lack basibranchial teeth (I have found cut throat trout specimens collected in the 1870 's, before any hybridization could have occurred, which lack basibranchial teeth|, the presence and development of these teeth is one of the most useful characters for evaluating the purity of a population and for estimating hybrid influences.

Although there are many exceptions that can only be learned from experience, basibranchial teeth should occur in more than 90 percent of the specimens in a pure population of cutthroat. A very slight hybrid influence from rainbow trout is detected most readily in the loss of basibranchial teeth. In most interior subspecies of $S$. clarki, the more obvious effects of hybridization resulting in changes of the spotting pattern and coloration are not apparent until basibranchial teeth are found lacking in more than 50 percent of the population. Some redband, Apache, and Gila trout have vestigial basibranchial teeth, but their occurrance is uncommon (they are absent in more than 50 percent of the population; usually present in 1-10 percent, if at all).

Typically, cutthroat trout have more scales than any other trout of the genus Salmo, but the California golden trout has more scales than most cutthroat trout. Some populations of cutthroat trout native to the Humboldt River drainage of Nevada have about the same number of scales typically found on the coarsescaled coastal rainbow trout. Cutthroat trout typically have 9 pelvic fin rays and coastal rainbow have 10, but redband trout have 9 and 10 . In practice, the lack of absolute criteria to separate all cutthroat trout from all other trout is not of great concern. A person or agency concerned with identifying native cutthroat trout from a specific geographical area or state would be dealing with particular subspecies whose differentiating characters can be more narrowly and precisely defined than can the species as a whole.

Most of the distribution of interior cutthroat trout occurs in areas where it is the only native trout. Below the barrier falls in the Columbia basin to the Cascade Range, where interior cutthroat trout came into contact with trout of the redband evolutionary line, the cutthraot was largely replaced by the later invaders. There, cutthroat distribution is sporadic and discontinuous, mostly characterized by isolation above barriers as depicted by Dymond (1932) for British Columbia.

The only areas where large-scale historical coexistence between interior cutthroat trout and a rainbow or redband trout has been maintained are the Salmon and Clearwater drainages (tributaries to the Snake River) of Idaho where resident interior cutthroat trout exist with anadromous, steelhead redband trout without hybridizing. This pattern of early occurrence of contact is exemplified by several independent basins of the Great Basin. In those basins with the longest isolation from direct connections to the Columbia River systems-Lahontan, Bonneville, and Alvord basins - the cutthroat trout is the native trout, but in several desert basins of southern Oregon, north of the Lahontan basin and west of the Alvord basin, with more recent connections to the Columbia River system, the redband trout is the native trout.

The coastal subspecies of cut throat trout does occur with coastal rainbow trout and, although hybridization between the two species does occur in some areas, they maintain their identity. Over many thousands of years of coexistence under natural selection, the coastal cut throat trout and the rainbow trout have evolved 
differences in behavior and ecological preferences to reduce competition where they occur together. In such a situation, natural selection favors the maintenance of two discrete species with discrete niches. Environmental changes, acting to break down niche separation and introduction of nonnative races of hatchery trout, can be important factors causing a breakdown of historical reproductive isolation.

\section{REASONS FOR DECLINE}

Except for the cutthroat trout native to the Salmon and Clearwater drainages, interior cutthroat trout have evolved in isolation from rainbow or redband trout and lack the innate isolating mechanisms that would allow for coexistence without hybridization. Where rainbow trout have been introduced into the interior waters in which cutthroat trout is the only native trout (which includes virtually the entire distribution of interior cutthroat trout), mass hybridization has almost invariably followed. Brown trout have commonly replaced interior cutthroat trout from the larger rivers and the eastern brook trout is now the most common small stream trout in the West. Of the 14 subspecies I recognize for interior cutthroat trout, 2 are extinct (Yellowfin trout of Twin Lakes, Colorado, and Alvord basin cutthroat), 10 have suffered ca tastrophic declines, and 2 still are "holding their own". The two subspecies not undergoing drastic declines are both undescribed. One is the fine-spotted cutthroat trout native to the Upper Snake River, Wyoming, where it is still the dominant trout in the drainage from Jackson Lake to Palisades Reservoir. The other is a trout native to Willow and Whitehorse creeks, two small streams that drain onto a high desert, just east of the Alvord sump of the Alvord basin, Oregon. No other fish live in these streams.

The extent of the interior cutthroat trout's decline throughout their entire range under man's impact can be appreciated by reading historical accounts of their great abundance by 19 th century travelers in the West. If one were to revisit the sites of most of these accounts (Bear River, Utah Lake, upper Colorado River, Green River, Rio Grande, Lake Tahoe, Truckee River, etc.), only nonnative trout would be found. The only large-scale occurrence of pure, interior cutthroat trout maintaining their original abundance, in a pristine environment and without nonnative trouts, is Yellowstone Lake and the Yellowstone River drainage above the falls in Yellowstone National Park.

It is difficult to understand how rapidly native cutthroat trout can vanish after the introduction of nonnative trouts. I personally observed the virtual replacement of cutthroat trout by brook trout within 5 years in a small stream. In 1967, Black Hollow Creek, a small tributary stream near Fort Collins, Colorado, was treated with rotenone to remove brook trout after a barrier dam was constructed. In 1968, greenback cutthroat trout, the original native trout, were stocked into Black Hollow Creek. The population increased and flourished. In 1972, two brook trout were found above the barrier. The numbers of brook trout increased each year, and the cutthroat population declined. When Black Hollow Creek was electrofished in the fall of 1977, we could not find a single cutthroat trout among the dense population of brook trout. A few greenback trout, evidently from an upstream refuge, were sampled from Black Hollow Creek in 1978.

There are still many high altitude headwater areas where cutthroat trout appear to have a selective advantage over nonnative trouts, evidently because of their better functioning in colder waters. Although most of these populations have been exposed to hybridization and are not "pure" native trout, they do maintain the appearance of native trout and should be recognized and managed as such. In such situations, the remnant native trout populations may be extremely vulnerable to replacement after environmental disturbance.

In 1972, I made a collecting trip in Montana with Mr. George Holton, Montana Fish and Game Department, in search of $S$. c. lewisi populations. In a small stream tributary to the Smith River cutthroat trout were found in its headwaters and brook trout were found farther downstream during a 1968 survey. The watershed was clearcut in intervening years. All vegetation was removed from the stream banks and erosion and sediment load greatly increased along with higher water temperatures. In 1972, electrofishing the stream to its source, we found only brook trout. A neighboring watershed was also clearcut, but a small segment of the very headwaters was not cut. We found only native cutthroat in the pristine section and predominently brook trout where the stream flowed through the barren wasteland of the clearcut.

Such incidents of habitat change and nonnative trout introductions multiplied thousands of times throughout the West during the last 100 years, provide some insight in to why interior cutthroat trout are so rare today. 


\section{PROPAGATION OF CUTTHROAT TROUT}

A brief review of the history of cutthroat trout propagation reveals that indiscriminant mixing of various subspecies of cutthroat trout and hybridization with rainbow trout in many hatcheries has been a major cause of the rapid decline of pure native subspecies.

Artificial propagation of cutthroat trout began about 1870 by private hatcheries. Livingston Stone, an early fish culturist and a founder of the American Fish Culturist Association (predecessor of the American Fisheries Society/ was dispatched to California in 1872 by the newly created U.S. Fish Commission to find a source of salmon eggs for propagation and distribution. Stone's western experiences during 1872 are recorded in the first report issued by the U.S. Fish Commission for 1872-73. Stone was impressed by Salt Lake City's municipal hatchery, propagating the native cutthroat trout of the Bonneville basin (Salmo clarki utah has not been propagated to any extent since that timel. The Lahontan cutthroat trout was also propagated in 1872 by private hatcheries and by the California Acclimatization Society. A private operator was hatching rainbow (or redband) trout on a tributary of the McCloud River, California.

The earliest shipments of rainbow and cutthroat trout beyond their native ranges and to foreign countries, including Japan and New Zealand, were largely by private enterprise. The completion of a transcontinental railroad in 1869 stimulated interstate shipment of trout eggs and fry.

The first rainbow trout eggs in the Federal hatchery system were taken in 1880 at the Baird Hatchery on the McCloud River by Livingston Stone. The first cutthroat trout propagated in a Federal hatchery were from eggs of the greenback trout of Twin Lakes, Colorado, in 1891, by Leadville National Fish Hatchery personnel. The annual reports of the U.S. Fish Commission of the late 19th and early 20th centuries, indicate that all the presently recognized subspecies of cutthroat trout were treated as a single entity-the "black-spotted" trout. Almost from the beginning of cutthroat trout propagation at the Leadville Hatchery, two Colorado subspecies, the greenback trout of the Arkansas River drainage (Twin Lakes) and the Colorado River cutthroat trout from the western side fo the Continental Divide, were mixed together as "black-spotted" trout to be stocked out and shipped to other states.

The Bozeman, Montana, National Fish Hatchery was constructed in 1898 and began the propagation of two additional subspecies of cutthroat trout from eggs taken at Henry's Lake, Idaho /large-spotted cutthroat native to Snake River and Yellowstone drainages), and from trout of the Madison River, Montana (S. c. lewisi)-again mixed together for propagation and distribution as black-spotted trout.

In 1902, personnel of the Spearfish, South Dakota, National Fish Hatchery, discovered the tremendous potential for obtaining vast numbers of cutthroat trout eggs from Yellowstone Lake in Yellowstone National Park, where all the spawning trout from this 77,000-acre body of water ascend a relatively few, small tributary streams and can be readily trapped. From about 1905 to 1955, the Yellowstone Lake cutthroat trout was the dominant form of cutthroat propagated. A peak number of $38,000,000$ eggs were taken in 1935 , and were distributed to all the western states via both state and Federal agencies and to private individuals and organizations. Because of such large-scale propagation and widespread distribution, the common name "Yellowstone" cutthroat has become broadly established for virtually all interior cutthroat trout.

All the western states with native cutthroat trout established their own propagation programs, typically taking the eggs from wild populations in lakes or reservoirs. The problem is that these brood stock lakes were usually stocked with Yellowstone cutthroat trout and rainbow trout so that hybrids, scarcely resembling the native trout, have been widely stocked as "native" trout throughout the West. Most of the interior subspecies of cutthroat trout were propagated (as block-spotted trout) in hatcheries at one time or another. Exchanges between Federal hatcheries, between state hatcheries, and between Federal and state hatcheries thorougly mixed the races from different geographical areas.

After fish culturists learned how relatively simple it was to obtain and hatch millions of eggs of trouts and salmons in the late 19th century, fisheries in the United States entered an era of what might be called the "Johnny Appleseed" mentality. All that needed to be done was to "seed" baby trout and salmon in waters all over the country with the Biblical admonition to be fruitful and multiply. Environmental limitations governing a species distribution and abundance were not given much thought. The articles, correspondence, and comments found in the reports of the U.S. Fish Commission during this period make for interesting reading. Chinook salmon were stocked into the Mississippi River near New Orleans, and the return of great salmon runs from the Gulf of Mexico were eagerly awaited. Miners in Nevada pleaded to have carp sent to them so they could stock their waters with this fine new fish they had heard so much about. Their urgency to stock carp was vividly emphasized by pointing out that the native trout, $S$. $c$. henshawi, which is now a 
threatened species, sold for the outrageous price of up to 40 cents a pound, and they would do their best to control the trout population and make the waters safe for the carp.

One had only to write one's congressman or the U.S. Fish Commissioner and free fish would be delivered. The U.S. Fish Commission and some states had their own railroad cars to transport and deliver fish. The recipient had only to take a bucket to the station and meet the train. Obviously, during this period, which lasted until World War II, innumerable unrecorded introductions were made by individuals and clubs with varieties of cutthroat (mainly from Yellowstone Lake), rainbow, brook, and brown trouts supplied by the U.S. Fish Commission and state agencies.

The U.S. Forest Service and National Park Service also ran their own fish propagation and distribution programs in some areas. The "seeding" of headwater streams with eyed eggs or fry became a standard part of fisheries management programs in western states, and this practice continued in some areas into the 1970 's. The string of pack horses and mules transporting their cargo through remote mountain areas became a sandard public image of fisheries management in action. The loss of the Paiute cutthroat trout from its type locality, Silver King Creek above Llewellyn Falls in the Lahontan basin of California, was due to an inadvertent stocking of rainbow trout fingerlings during a headwater "seeding" operation in 1949.

Because of such large-scale and indiscriminant introductions, we now have the acute problem of finding pure native trout populations in many areas of the West. So much unrecorded stocking took place that there is hardly a water in the country where it can be said with certainty that it has never been stocked. A few of my own experiences can illustrate the consideration which must be given to the influence of past stocking in regard to native trout.

During my M.S. thesis research on the Lahontan cutthroat trout, I noted that the three "type" specimens of "Salmo evermanni" in the Stanford University collection were, in fact, Lahontan cutthroat trout. S. evermanni was named for a trout fuond in 1907 in the headwaters of the Santa Ana River, California, above a barrier falls. Old stocking records, found in the biennial reports of the California Fish Commission, revealed that 6,000 Lahontan cutthraot trout from eggs taken at Lake Tahoe were stoked into the Santa Ana River in 1895 , and 17,500 were stocked in 1896 with a notation that 15,000 of these were stocked "above the falls". Thus, Salmo evermanni is not a valid species, but a synonym of S. c. henshawi (Benson and Behnke, 1961).

In 1958, there was much excitement over the discovery of the greenback cutthroat trout in the headwaters of the Big Thompson River of Rocky Mountain National Park. The greenback had been believed extinct at the time. No one knew how to recognize a greenback trout, but it was believed that the fish in the Big Thompson River headwaters must be the greenback because the site is part of the historical range (South Platte Basin), the site is isolated, and no stocking records indicating this area had ever been stocked could be found. The bubble of excitement was burst by the finding of hand written notes in Park Service files relating the stocking of 140,000 "spotted native" trout in 1922 and of 130,000 trout in 1923 into the Big Thompson headwaters by the Estes Park Sportsman's Association. The "native" trout were given to the Sportsman's Association by the Estes Park State Fish Hatchery and most likely originated from Yellowstone Lake.

My files reveal that this incident, emphasizing the problems that can arise from native trout studies that lack an understanding of the taxonomy of the subspecies in question, considerably dampened the enthusiasm and support of the U.S. Fish and Wildlife Service for further studies and restoration projects on native trout.

When I examined specimens from the present population in the headwaters of the Big Thompson River, I was surprised to find that the trout are not Yellowstone cutthroat trout, but are a relatively "good" greenback trout (slightly hybridized). I concluded that these isolated waters already had an abundant native trout population when the hatchery fry were stocked, and there was virtually no survival of the nonnative fry. If this is true, why then were the waters stocked? Richard DeLong, one of my former graduate students, once interviewed an elderly resident of Estes Park who participated in the stockings of 1922 and 1923 . The route at that time, from Estes Park to the headwaters of the Big Thompson River, required a difficult journey of two days with two crossings of the Continental Divide by the pack train carrying the fish. No one knew if trout were native to the stream because the area was so remote that none of the sportsmen had ever fished it. This stocking, conforming to the common belief at the time, was motivated by the pbjective of "seeding" all headwater areas with fry, trusting that they would grow, multiply, and increase the trout abundance throughout the entire watershed. 
In 1967, personnel of Wyoming Game and Fish Department, surveying waters on National Forest lands, found a series of lakes with only cutthroat trout in the Green Riverdrainage near Pinedale, Wyoming. A falls on the drainage isolates the watershed from invasion of fish from the Green River. Wyoming records revealed no stocking of these lakes, and it was assumed that a stronghold of the rare, native Green River cutthroat trout had been discovered. In 1969, I examined specimens collected from these lakes and, from their appearance and taxonomic characters, recognized that they were introduced Yellowstone cutthroat trout, not S. c. pleuriticus, the native trout of the Green River Basin. Subsequently, notes were located in the local office of the U.S. Forest Service revealing that these lakes were originally barren of fish and had been stocked with Yellowstone cutthroat in 1937 by the Civilian Conservation Corps.

Occasionally a situation arises in which past introductions have present value because a unique race of trout, now extinct in its original environment, was transplanted and has persisted. Hickman and Behnke (1979) describe what we believe to be the discovery of the original Pyramid Lake race of the Lahontan cutthroat trout. During the summer of 1977, Mr. Hickman, collected specimens in the Bonneville basin of Utah as part of the research on Bonneville cutthroat trout sponsored by the U.S. Bureau of Land Management and found an unusual trout in a small stream on Pilot Peak on the Utah-Nevada border. I identified the specimen as Lahontan cutthroat trout, which undoubtedly was introduced since Pilot Peak is part of the Bonneville basin. It was determined that the se Lahontan cutthroat trout had been in this small stream since prior to 1950, having been introduced during a period when the only source of Lahontan cutthroat trout used in propagation came from Pyramid Lake. The significance of this discovery is that the Pyramid Lake race of Lahontan cut throat trout was probably the largest of all trout native to western North America. It is genetic resource of great potential value.

In recent years, interest in endangered and threatened species and in the preservation of rare native fauna has stimulated some attempts to propagate pure, native subspecies of cutthroat trout. The interior cutthroat trout now most commonly raised (mainly in Federal hatcheries and Wyoming state hatcheries) is the fine-spotted cutthroat trout native to the upper Snake River, Wyoming. Most cutthroat trout propagation is based on eggs taken from wild fish, but the Wyoming Game and Fish Department has developed a "semi-domesticated" race of the fine-spotted cutthroat trout at its Auburn Hatchery with a brood stock maintained for more than 20 years and selected for early spawning.

The coastal cutthroat trout has fared better than the interior subspecies has in regard to maintaining its integrity under propagation. Virtually all propagation of coastal cutthroat occurs in Washington and Oregon where the coastal and interior subspecies have historically been separated in propagation practices. In areas where coastal cutthroat trout are known to hybridize with rainbow trout, however, the stocking of hatchery trout may be a significant factor causing the breakdown of reproductive isolation between rainbow trout and coastal cutthroat trout. Crescent Lake, on the Olympic Peninsula, Washington, was once famed for its fishery of large native rainbow and cutthroat trouts. In the 1950's, after many years of introducing great numbers of hatchery rainbow trout and Yellowstone cutthroat trout, hybrid specimens became common. The implications of the Crescent Lake situation are discussed later.

The cutthroat trout, in contrast to the rainbow trout, has not become naturalized much beyond its original distribution. Nilsson (1971) wrote that "a couple" of stocks of cutthroat trout are maintained in Sweden. It is true, however, that within their native range, many headwater lakes at high elevations were isolated by falls and barren of fish. Much of the present cutthroat trout propagation is designed for stocking mountain lakes. This association of cutthroat trout with originally barren, high mountain lakes, has given rise to the erroneous belief by anglers that the natural distribution of interior forms of cutthroat trout is restricted to remote, high-elevation lakes. 


\section{COASTAL CUTTHROAT TROUT, Salmo clarki clarki}

\section{TYPICAL CHARACTERS}

Coloration silvery to brassy with yellowish tints; spotting profuse; spots irregular in outline (not rounded).

Scales in lateral series typically 140-180, but with some coarse-scaled (120-140) resident stocks; $30-40$ scales above lateral line.

Gillrakers $15-21$, typically $17-18$ short, blunt in structure.

Pyloric caeca 25-55, mean values about 40.

Vertebrae 59-64, typically 61-62.

\section{DESCRIPTION}

The coastal cutthroat trout differs from all other trout by its profusion of small to medium size spots of irregular shape (not rounded in outline as in most interior subspecies) distributed more or less evenly over the sides of the body onto the head and often onto the ventral surface and on the anal fin. Of all interior subspecies, only the Lahontan cutthroat trout has the distribution of spots similar to the coastal cutthroat, but the spots of Lahontan cutthroat are larger, rounded in outline, and fewer in number compared with coastal cutthroat. The spots on coastal cutthroat trout are dense and closely set in relation to one another. Quadri (1959) demonstrated that complete separation between specimens of coastal and interior cutthroat trout (S.c. lewisi) could be obtained from a quantification of the differences in spotting pattern. Snyder (1940) also counted the spots on coastal cutthroat trout and found 26-71 spots on the head and 322-577 on the body.

The coastal cutthroat trout does not develop brilliant colors as do some of the interior subspecies. Sea-run individuals are silvery, with the silvery deposits in the skin of ten obliterating or masking the spots on the body. Resident freshwater fish tend to be darker, with a coppery or brassy sheen. Pale yellowish colors may appear on the body, and the lower fins may be yellow to orange-red. A faint rose tint might be apparent on the sides and ventral region of sexually mature fish, especially in lake-dwelling stocks.

The distinctive spotting pattern is the only character, other than the number of chromosomes mentioned earlier, that consistently differentiates the coastal subspecies from the interior subspecies of cutthroat trout. There are some trends in differentiation, however, by which most coastal cutthroat trout differ from most interior cutthroat trout (and also from rainbow and redband trouts).

The gillrakers of coastal cutthroat trout are typical of predaceous species. They are slightly fewer in number (typically 17-18 vs. 18-20, but with much overlap) than the gillrakers of other trouts (both cutthroat and rainbow-redband), but the most diagnostic feature is the more rudimentary development of the gillrakers, which are short and blunt rather than long and attenuated. The parr marks of juvenile cutthraot are typically more narrow or oblong compared to the typical round parr marks of coastal rainbow juveniles (McConnell and Snyder, 1972).

I have not studied the coastal subspecies as intensively as I have the interior forms. My taxonomic data are based on examination of 277 specimens from 22 localities scattered throughout the range of the subspecies from northern California to southern Alaska, and are supplemented by the works of Hartman (1956), Quadri (1959), Schultz (1936), DeWitt (1954), and Snyder (1940). I have compared samples from sea-run populations, populations isolated in small streams above barrier falls, and lacustrine (lake-dwelling) populations to assess the amount of variablity found within a subspecies of such broad geographical distribution and with different ecological forms.

I have found that coastal populations with direct access to the sea (typical sea-run cutthroat) are quite similar throughout the entire range of the subspecies with no evidence of clinal variation in characters between northern and southern populations. Evidently, wandering from stream to stream along the coast has maintained a mixing and gene flow sufficient to dampen significant divergence between northern and southern stocks. In some isolated populations, however, considerable divergence is apparent in such characters as the numbers of scales and basibranchial teeth. The case of these divergent, isolated populations is similar to the situation of most of the interior subspecies, in which many populations within the subspecies' geographical range may have been isolated from each other for several thousands years, resulting in considerable variability within the subspecies. 
The scale count in the lateral series (counted two rows above the lateral line) ranges from 140-180 in coastal cutthroat trout that are free to migrate to and from the sea. Mean values are consistently between 150 and 160, typically about 155 . In two Oregon streams isolated by barrier falls, I took samples that differed from each other by 40 scales. Thirty specimens from Grassy Lake Creek, Clatsop County, have 117-138 (126.3) scales in the lateral series. Fifteen specimens from Bible Creek, Tillamook County, have 148-184 (166.5) scales. Hatchery rainbow trout have been stocked into the Grassy Lake Creek watershed, and some hybridization has probably occurred. Two of the 30 specimens lack basibranchial teeth, but the vertebrae count of 59-62 (60.4) is the lowest of any of my samples of coastal cutthroat trout, indicating that hybrid influence from rainbow trout is slight.

Another sample from an isolated population in Penn Creek, Patrick's Point State Park, northern California, which appears to be pure cutthroat trout in all other respects, has scale counts similar to the Grassy Lake Creek fish. Eleven specimens from Penn Creek have 118-135 (126.1) lateral series scales. Schultz (1936) mentioned that in the Puget Sound drainages of Wahington, two forms of coastal cutthroat trout have been observed-a "normal" cutthroat with 143-180 scales in the lateral series and 30-36 scales above the lateral line, and a coarse-scaled cutthroat with 120-140 (usually 125-130| lateral series scales and 25-29 scales above the lateral line. It was not stated whether the two forms were found living together.

It can be difficult and frustrating to set arbitrary limits of variability for the diagnostic characters of a subspecies of such broad distribution and expect all populations to conform to expectations. All that can be done with the coastal cutthra ot trout is to give the typical values found in the sea-run populations that form a genetic continuum and point out the exceptions that will likely be encountered in small, isolated populations. Situations comparable to the populations of Grassy Lake Creek, Bible Creek, and Penn Creek must be duplicated hundreds, perhaps thousands of times throughout the range of the subspecies. If one would apply quantitative taxonomic methods and then describe new subspecies for all those populations that exceed the normal range of variation of the sea-run populations, chaos would result.

Scale counts above the lateral line (counted from the scale at the origin for the dorasl fin in a diagonal row to the lateral line, but not including the lateral line scale) range from 30-40, typically 34-36. These typical scale counts of coastal cutthroat trout (150-160 in lateral series and 34-36 above the lateral line) are lower than are found in any of the interior subspecies except the cutthroat trout native to the Humboldt River drainage of the Lahontan basin.

Vertebrae numbers typically range from 60 to 64, with mean values of 61-62, which is characteristic of $S$. clarki as a whole.

Gillraker numbers range from 15 to 21 , with most mean values of about 18 . My lowest counts are from the Penn Creek sample, 15-18(16.5), and the highest counts are from museum specimens of the Crescent Lake, Washington, cutthroat trout, "S. crescentis". Thirteen of those specimens, including the type specimen of "S. crescentis", have 18-21 (18.9) gillrakers.

Pyloric caeca numbers range from about 25 to 55 , with mean values of about 40 , which is comparable to other subspecies of cutthroat trout except for the Lahontan cutthroat. DeWitt (1954) found 23-60 (40.3) caeca in 71 specimens from several northern California localities.

Basibranchial teeth are usually well-developed in coastal cutthroat trout, but are not readily observable. These teeth are very small and lie between the gill arches on the floor or the phyrynx on the membranous basibranchial plate. I stain the area with Alizarin-red stain and allow the specimens to stand overnight before examining them under a binocular microscope. Basibranchial teeth may not appear until the specimen is about $100 \mathrm{~mm}$ in length. The absence of basibranchial teeth indicates a hybrid influence from rainbow trout.

DeWitt (1954) found 6 out of 79 California coastal cutthroat specimens lacking basibranchial teeth (called hyoid teeth by DeWitt), but mentioned that some specimens had an appearance suggestive of hybridization. DeWitt found from 1 to $34(8.8)$ basibranchial teeth in the 73 specimens with these teeth, which is about what I found in my samples from California to Alaska /means ranged from about 5 to 15 with only one notable exception). The highest number of basibranchial teeth found in any coastal cutthroat sample was found in nine museum specimens from Lake Sutherland, Washington. Two species, S. jordani and S. declivifrons, were described from Lake Sutherland (Meek, 1899). In my examination of Lake Sutherland specimens, I could not detect "two species", but found them typical of coastal cutthroat trout except for the high number of basibranchial teeth, 15-52 (29.2), about twice the number found in any other sample of coastal cutthroat. 

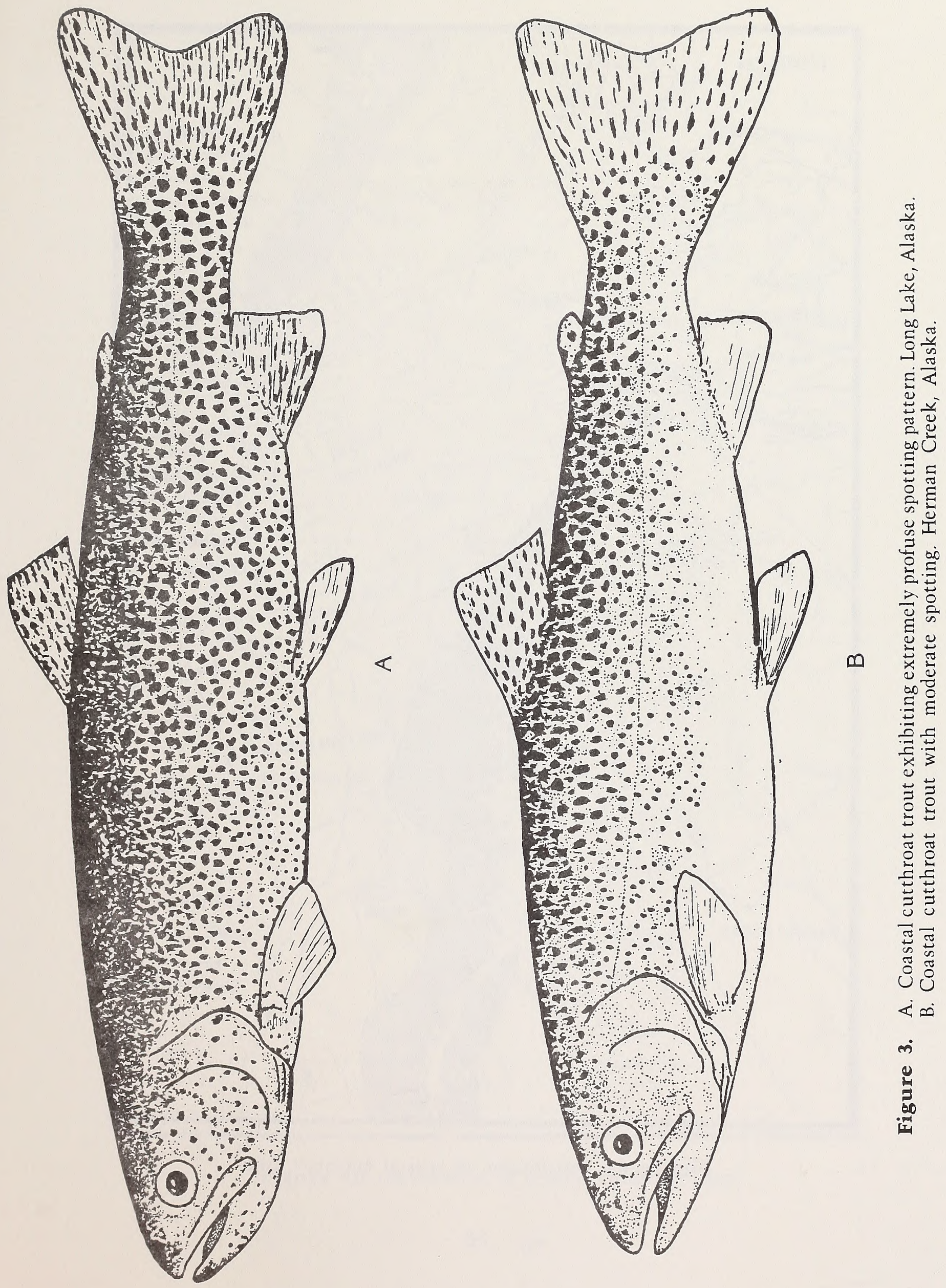


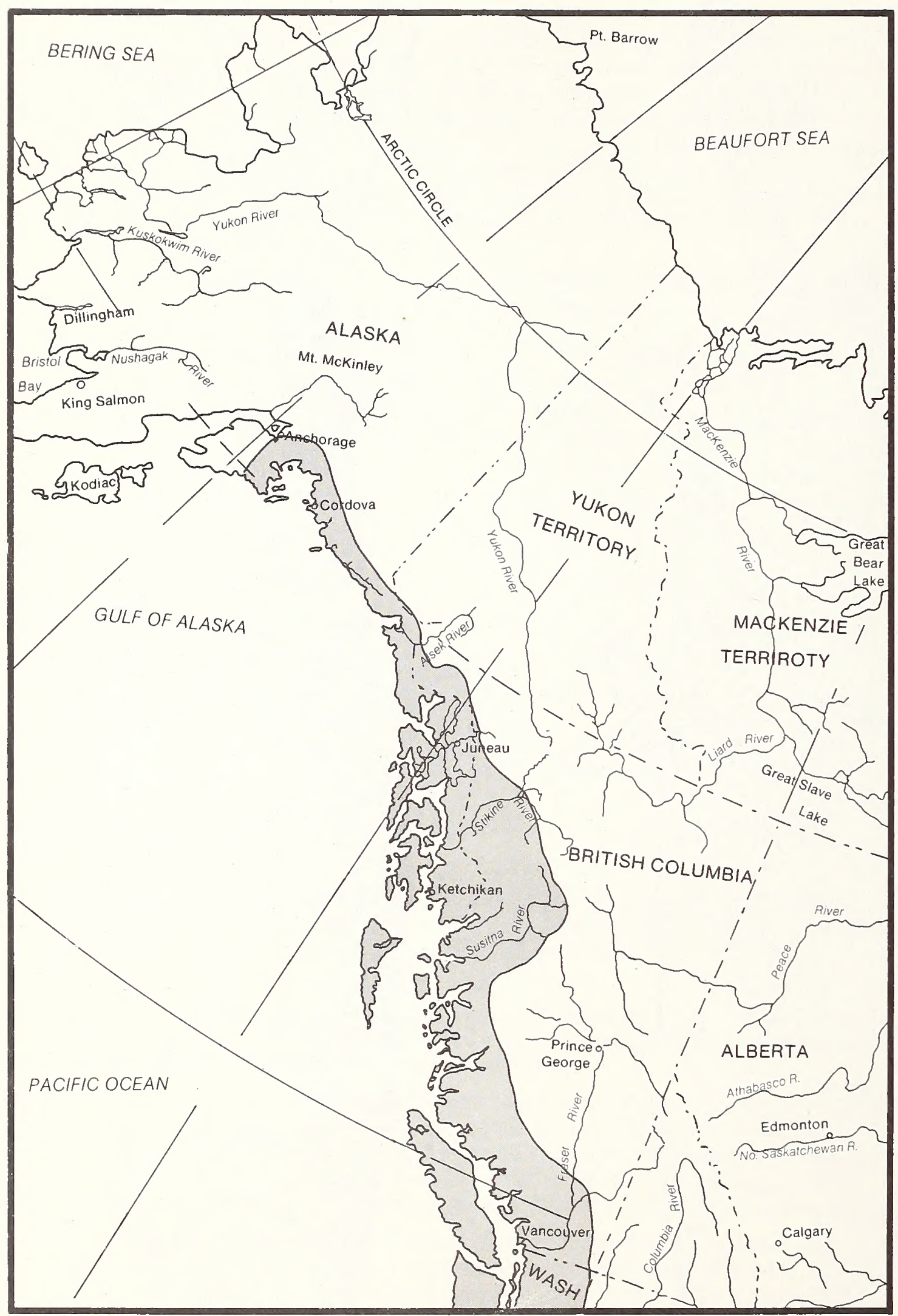

Figure 4A. Distribution of coastal cutthroat trout. 


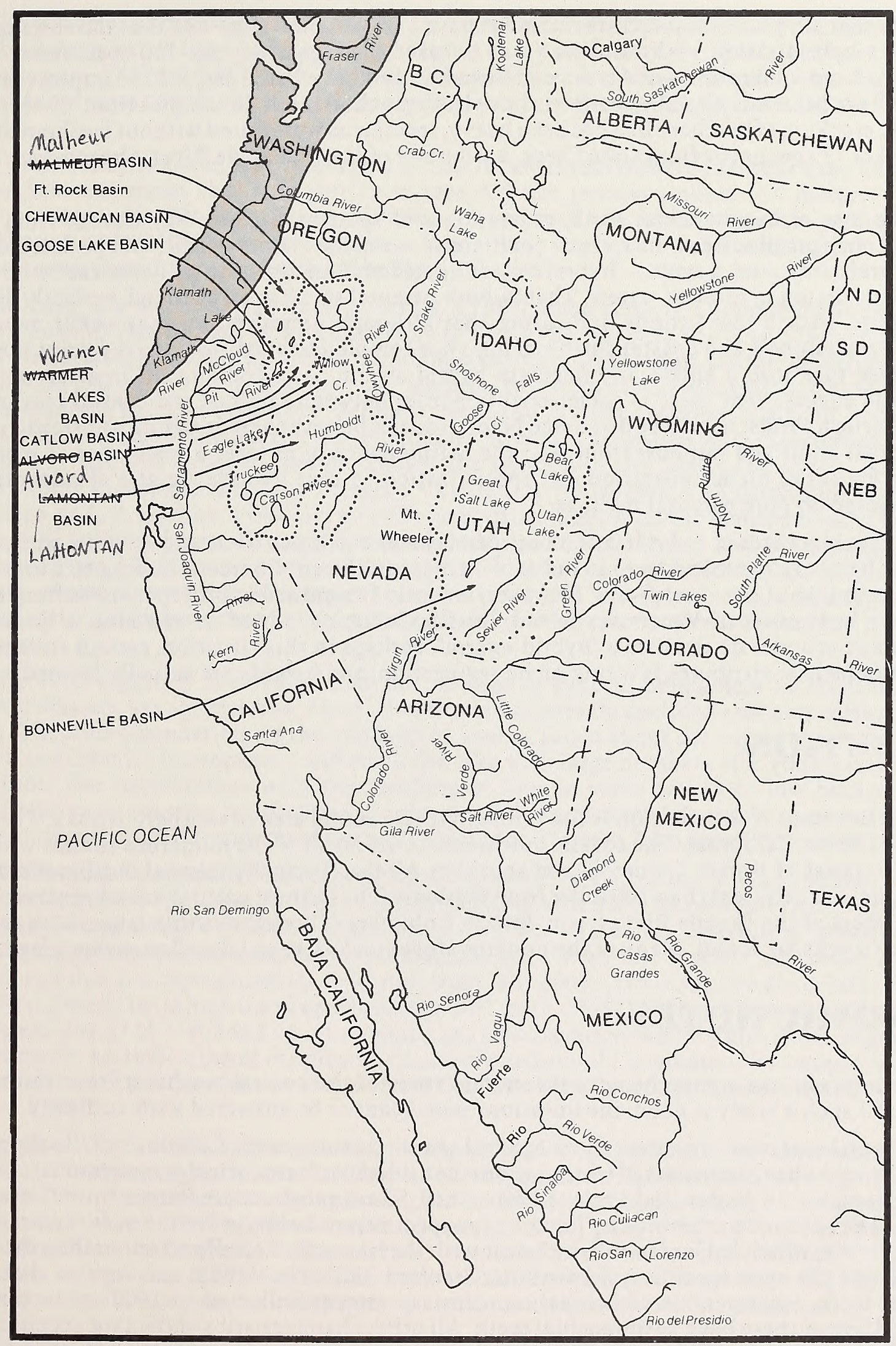

Figure 4B. Distribution of coastal cutthroat trout. 
My opinion that all "pure" coastal cutthroat trout have basibranchial teeth and that the absence of these teeth indicates hybridization with rainbow trout is based on separating out 110 specimens of coastal cutthrout trout from remote areas of Alaska and British Columbia where I assume the impacts of stocking hatchery fish have been nil. All 110 specimens have basibranchial teeth. In samples from Washington and Oregon, where stocking of hatchery fish has been heavy, specimens were found without basibranchial teeth. For example, 4 of 17 specimens from Gate Creek, a tributary of the McKenzie River, Oregon, lack basibranchial teeth.

Besides the loss of basibranchial teeth, coloration and spotting pattern may change from a hybrid influence, and changes in scale counts, caeca counts, and vertebrae counts usually can be detected. Where suspected hybrids are found, a typical "hybrid swarm" is seldom found, as is usually the case with rainbowcutthroat hybridization in interior waters. That is, both parental species can be found, perfectly distinct, in the same stream with a few hybrids, indicating that although hybridization may occur, reproductive isolation between rainbow and coastal cutthroat does not completely break down to the point that the two parental species fuse into a single, intermediate hybrid swarm as is common in interior waters. This evidence would suggest that there is some sterility barrier between rainbow and coastal cutthroat trout resulting in sterile hybrids. As will be discussed below, I do not believe there is significant sterility between coastal cutthroat trout and rainbow trout, and the maintenance of at least a semblance of reproductive isolation is a matter of niche separation and specialization so that hybrids are at a disadvantage and a "premium" is place on pure parental matings.

I believe most instances of hybridization between coastal cutthroat trout and rainbow trout is caused from stocking hatchery trout and by man-induced changes in the environment leading to a breakdown of ecological segregation of the two species. However, recently I examined hybrid specimens from two small streams on the west coast of Vancouver Island, British Columbia, where no stocking is known. These Vancouver Island samples do indicate a "hybrid swarm". Perhaps in this situation, certain stream sections lack the environmental attributes favoring niche segregation, and hybrids are actually favored.

\section{DISTRIBUTION}

The northern extent of distribution is the Prince William Sound area of southern Alaska. The southern limit is the Eel River, California. The coastal cutthroat occurs on all of the numerous islands with suitable habitat off the coast of British Columbia and southern Alaska. Typically, coastal cutthroat trout do not occur far inland-usually less than 100 miles from the coast. The farthest natural inland penetration occurs in the headwaters of the Skeena River basin, British Columbia. Throughout this range, both sea-run and nonmigratory stocks are found. Many of the nonmigratory stocks live in lakes (lacustrine-adapted stocks).

\section{TAXONOMIC NOTES}

There has never been a comprehensive taxonomic study of the coastal cutthroat trout throughout its range, and until such a study is done, the questions posed cannot be answered with authority.

All coastal cutthroat trout are currently recognized as a single subspecies, S. clarki clarki. In the past, other species or subspecies have been named which are now considered to be identical (synonymous) to S.c. clarki. Jordan and Beardslee (in Jordan and Seale, 1896) named Salmo gairdneri crescentis from Crescent Lake, Washington. The specimen examined by Jordan (type specimen or holotype for the name crescentis) lacks basibranchial teeth, which led Jordan to associate it with the fine-scaled steelhead rather than the cutthroat trout. I examined the type specimen of crescentis(Stanford Univ. No. 11863) and verified that it has no basibranchial teeth. However, six additional crescentisspecimens collected in 1909 are in the Stanford collection and five of these have basibranchial teeth. All other characteristics of the type specimen and the six specimens collected in 1909 are typical of coastal cutthroat trout. I also examined six specimens of Crescent Lake cutthroat trout collected in 1899, borrowed from the Chicago Natural History Museum. All of these specimens have basibranchial teeth [2-12 (8.8)].

Grouping all the Crescent Lake cutthroat specimens reveals scale counts of $150-162$ (155), gillraker counts of 18-21 (18.9), and vertebrae counts of 62-65 (63). The gillraker and vertebrae counts are the highest values I have encountered in any sample of coastal cutthroat trout. A rainbow trout ("S. beardslei") is also native to Crescent Lake, and it is probable that some hybridization historically occurred. 
Meek (1899) named another species of trout from Crescent Lake as Salmo bathoeceter, which was reputed to live only in deep water. I can find nothing in Meek's description or in the specimens borrowed from the Chicago Museum (collected by Meek) that shows any difference between bathoceter and crescentis. I conclude that only one population of cutthroat trout is native to Crescent Lake, and it should be classified as S. c. clarki.

I would emphasize, however, that classifying the native cutthroat trout of Crescent Lake with the coastal subspecies does not mean that this particular race did not possess unique life history and behavior characteristics specialized for the Crescent Lake environment. Thus, for management purposes, the stocking of hatchery S.c. clarki into Crescent Lake would not likely duplicate all of the desirable attributes of the native stock even though they are both of the same subspecies.

Crescent Lake is a deep body of water covering 4,700 surface acres in Olympic National Park on the Olympic Peninsula, Washington. It is isolated from the sea by barrierfalls. In the late 19th century, the lake was famed for its fishing for large (to at least 15 pounds/ native rainbow trout and for the native cutthroat (to about 5 pounds $\mid$. During the 20 th century, man's attempts to improve on nature included a massive stocking program introducing millions of hatchery rainbow trout, Yellowstone cutthroat trout, and kokanee salmon, along with blocking and polluting the major tributary stream. The results were disasterous to the native trouts. The U.S. Fish and Wildlife Service studied the sitution in the 1940's and 1950's. A report, titled "Report of fishery investigations, Lake Crescent, Olympic National Park with management recommendations", written by L. R. Garlick, 1949, and a 1953 report titled "Report on the management of the Beardsley trout fishery of Lake Crescent, Olympic National Park", by Z. E. Parkhurst and M. A. Smith, reveal that rainbow $x$ cutthroat hybrids were common among the Crescent Lake trout. Color photographs accompanying the latter report, however, show a typical rainbow trout (the "Beardsley" trout) and a typical cutthroat trout ("crescentis") taken from the spawning run, indicating that reproductive isolation had not completely broken down.

From the 1953 report, it is obvious that the concept of genetic uniqueness in relation to fisheries management was not yet appreciated. The native trouts had greatly declined and were difficult to raise in hatcheries. The recommendations of the 1953 report were to forget about the native trouts since they were hybridizing and difficult to propagate, and stock the lake with large numbers of a "good strain" of hatchery rainbow trout. The implications were that nothing of unique value would be lost because the native "Beardsley" rainbow trout was classified as S. gairdneri and the "crescentis" cutthroat trout as S.c. clarki. How much of the original genetic resources of the native trouts of Crescent Lake presently remains is not known.

Meek (1899) named two additional species, S. jordani and S. declivifrons, for what I believe to be a single coastal cutthroat trout population native to Lake Sutherland, which lies immediately to the east of Crescent Lake. Examination of Meek's data and of the specimens he used in his description (borrowed from the Chicago Natural History Museum), does not indicate more than one form of cutthroat trout in Lake Sutherland, and that is a typical coastal cutthroat trout, S. c. clarki. However, the Lake Sutherland trout is slightly differentiated in its high number of basibranchial teeth [15-52(29.2) in 10 specimens] and lower than average scale counts [131-158(146)]. Much stocking has since occurred, and the fate of the original cutthroat trout is unknown. An indication of the present degree of purity could be obtained by comparing the number of basibranchial teeth in a present day sample from this lake with the counts I made from the 10 specimens collected in 1898 .

I have assumed that hybrids between rainbow and cutthroat trout are fertile, but there is little in the way of experimental evidence to prove this. Based on numerous experiences with interior cutthroat trout where hybrid swarms are common, there is no other logical conclusion to explain these swarms /that is, only an intermediate hybrid population is found without specimens of "pure" rainbow trout or "pure" cutthroat trout), except to assume that the hybrids are fertile. For coastal cutthroat trout, with 68 or 70 chromosomes, however, there is a greater difference in chromosome numbers from rainbow trout $(58-60)$ than there is between rainbow trout and interior subspecies of cutthroat trout with 64 chromosomes.

The only "scientific" hybrid experiment using coastal cutthroat trout of which I am aware, was the M.S. thesis research of Hartman (1956). Hartman crossed coastal cutthroat from Chilliwack Lake with the interior "Kamloops" trout from Cultus Lake, British Columbia, which was actually a redband trout. With this hybrid combination, I assume that the chromosome numbers of the parent species were 68 or 70 , and 58 , the maximum difference between members of the cutthroat trout species and the rainbow-redband group of trouts. Hartman actually found slightly higher viability and survival in the hybrid crosses than in the pure parental crosses. For his thesis, however, Hartman did not have time to make second generation crosses to determine the fertility of the hybrids. Hartman told me in 1961 that the hybrids were backcrossed with both 
rainbow trout and cutthroat trout and were fully fertile. In Hartman's hybrids, there was no difference in the sex ratios between the hybrids and the pure parental matings. Typically, in evolutionary divergence, before sterility evolves, one sex or the other is dominant in hybrids (unisexual hybrids).

Mr. Donald Campton, currently a Washington State Game Department employee studying the genetic structure of coastal cutthroat trout populations of the Puget Sound region, wrote to me that his electrophoretic studies have detected hybrids between rainbow and cutthroat trout in some streams.

The ecological differences between coastal cutthroat and rainbow trout where they occur toge ther act to separate the two species at spawning by the preference of the cutthroat for the smaller tributary streams and the rainbow for the main river channels. The introduction of domesticated hatchery rainbow trout could bridge the historical spatial separation of the two species in some streams and bring about hybridization and gene flow between them that did not occur originally. There is much to be learned about hybridization between coastal cutthroat trout and coastal rainbow trout -its extent, the fertility of the hybrids, the factors stimulating hybridization, why hybrid swarms rarely form, the impact of hatchery trout, etc.

Perhaps the most basic question concerning the classification of all coastal cutthroat trout as a single subspecies is that of the separation between "normal" |140-180 scales/cutthroat and coarse-scaled cutthroat trout. As discussed, I found two populations isolated by falls in California and Oregon that average only 126 scales in the lateral series. Schultz (1936) claimed cutthroat trout with similar low scale counts were found in the Puget Sound drainages. Do these coarse-scaled cutthroat trout represent relicts of an early divergence which were replaced or hybridized by a later invading form? Or, are they the result of independent, convergent evolution in each of the separate, isolated populations and/or a hybrid influence from rainbow trout? If the former is true, then a separate subspecies should be recognized for the coarse-scaled coastal cutthroat trout; if the latter is correct, only one subspecies should be recognized. Gene loci studies, such as those currently being performed by Mr. Campton, may shed some light on the matter.

If the coarse-scaled coastal cutthroat trout does represent a distinct evolutionary divergence, the question would then be: do the two forms live together without hybridization? That is, can they coexist and maintain reproductive isolation? I have reviewed the two cases, Crescent Lake and Lake Sutherland, in which the native cutthroat trout was described as two species in each lake. The evidence does not support the notion that two "species" of cutthroat trout occurred in each lake, but rather that each lake had a single stock of $S$. clarki clarki.

Dr. Carl Bond, Oregon State University, told me of a case where two populations of coastal cutthroat trout do occur together in the same lake. In Triangle Lake of the Suislaw River drainage, Oregon, one population spawns in late winter (typical coastal cutthroat trout spawning) and another spawns in May. It is not known if this is a completely natural situation or if one of the populations is the result of introductions from a stock with a genetic basis for a spawning time different from that of the native population. Odell Lake, Oregon, has two populations of kokanee salmon, both introduced, which do not hybridize because of differences in the time and place of spawning (Averett and Espinosa, 1968). The taxonomy and life histories of the two cutthroat populations in Triangle Lake should be studied in detail to gain a better understanding of the systematics of the coastal cutthroat trout as well as the implications for the use of intraspecific genetic diversity in fisheries management as discussed by Trojnar and Behnke (1974).

Hopefully, genetic research will provide new insights into the coastal cutthroat trout and its relationships to the in terior cutthroats and to the rainbow-redband group. Utter et al. (1973), compared the products of 22 genes between coastal cutthroat trout and rainbow trout and found them to be similar labout 95 percent similarity). Mr. Campton's research found 4 of 30 gene loci to be distinct among the rainbow and cutthroat trout of the Puget Sound area. Modern genetic studies of trout are still in an early stage of development. It will take several years of obtaining data from gene loci from many populations of diverse geographical areas before a reasonable interpretation of evolultionary relationships and divergence can be made.

\section{LIFE HISTORY AND ECOLOGY}

The coastal cutthroat trout is not as popular as the larger more "glamorous" steelhead trout and salmons of the Pacific Coast. This is reflected in the amount of literature, both popular and scientific, about the coastal cutthroat. 
Detailed life history data were not published until Sumner's $(1953,1962)$ papers on the Sand Creek, Oregon, cutthroat. Hartman and Gill (1968) discussed the ecological preferences of juvenile rainbow and cutthroat trouts, providing some insight into the mechanisms of niche separation. Giger (1972) gave comprehensive life history data on the cutthroat trout populations of several Oregon rivers. Armstrong (1971) discussed the age, growth, feeding habits, and migrations of the cutthroat in Eva Lake, Alaska. Andrusak and Northcote (1971) and Schutz and Northcote (1972) studied the feeding and spatial distribution of cutthroat trout occurring with Dolly Varden trout (Salvelinus malma) in British Columbia. Idyll (1942) studied the feeding of cutthroat, rainbow, and brown trout in the Cowichan River, British Columbia. Bustard and Narver (1975) delineated the winter habitat preference of coastal cutthroat. Nicholas (1978a, 1978b) provided considerable information on cutthroat trout in the Willamette River watershed and their interactions with rainbow trout.

The sea-run cutthroat trout of Oregon typically migrate to saltwater in late spring, early summer at an age of II or III and at a size of 7 to 9 inches, although some may never go to sea. Evidently, coastal cutthroat do not travel in the open ocean, but rather concentrate in bays, estuaries, and along the coast. In saltwater, the cutthroat feeds intensively on crustaceans and fish and grow at the rate of about 1 inch per month. After 2 to 5 months in the sea, the cutthroat returns to rivers. The typical spawning period is late winter, early spring, but may extend to May. The timing of the migrations, age at migrations, length of time spent in the sea, and spawning time vary among stocks.

The much lesser degree of anadromy in coastal cutthroat trout compared to steelhead rainbow trout may not be due to osmoregulatory problems of living in seawater. Giger (1972) claimed that cutthroat trout only 100 to 125 days old, weighing a fraction of an ounce ( $4-5 \mathrm{gms}$.), had complete survival in full salinity ocean water.

The maximum age of sea-run coastal cutthroat trout is about 10 years and they grow slowly after their first spawning at age III or IV. The fall runs of cutthroat trout, as they congregate off the mouths of rivers and run up the rivers, provide a highly popular fishery for West Coast anglers. These cutthroat are popularly known as "harvest" trout because most of the runs coincide with the harvest season. Washington (1977) believes that the cutthroat trout is the third most populargamefish caught in marine waters of the Pacific Northwest after the coho and chinook salmons (virtually all steelhead are caught in fresh water). The fish making up the fall run range from about 10 to 18 inches, and the maximum size is about 22 inches and 4 pounds, with exceptional cases of 6 to 7 pounds.

Like cutthroat trout in general, the coastal cutthroat is vulnerable to overexploitation by angling. In Sand Creek, with little angler use, survival from first to second spawning was 39 percent, from second to third spawning was 71 percent, and from third to fourth spawning was 12 percent. In five Oregon rivers subjected to heavy angling pressure, the estimated survival ranged from 5 to 26 percent between the first and second spawning. Johnson (1979) discussed the problem of angler overexploitation of coastal cutthroat trout and the need for more regulations on the Stillaguamish River, Washington. Predation in the sea may be a significant cause of natural mortality. Giger (1972) reported 58 percent of the wild cutthroat and 67 percent of the hatchery cutthroat trout taken from the Alsea River estuary in 1970 had scarring indicative of predator attacks.

Although the coastal cutthroat trout has been propagated in large numbers in Oregon and Washington, it is only in recent years that some thought has been given to making more effective use of genetic diversity in the subspecies for fishery programs. It has long been known that different stocks have different life history characteristics governing the timing of migrations and length of time spent in the sea.

Johnson (1976) and Johnson and Mercer (1976, 1977) discussed the Washington Department of Game's cutthroat propagation program that uses two stocks. One returns from the sea in September and October, and the other in December and January. If successful, such an innovative program would greatly extend the popular fall fishery. Undoubtedly, hatchery rearing and widespread stocking has stimulated mixing among stocks.

My taxonomic analysis failed to reveal any detectable genetic divergence between sea-run stocks of different geographical areas. Giger (1972) indicates considerable natural straying between streams. The problem of genetic mixing of coastal cutthroat stocks from propagation and stocking practices is probably not such a potentially critical matter as it might be with steelhead rainbow and salmon propagation programs. Of more significant impact may be the stocking of hatchery rainbow trout in streams where both cutthroat and steelhead trout exist. This could be a significant factor causing some breakdown in reproductive isolation by the domestic rainbows by bridging the spatial gap and any spawning time gap between the steelhead and cutthroat, thus stimulating hybridization. 
Donaldson et al. (1957) crossed a hatchery strain of coastal cutthroat with a wild strain, which, when stocked into Echo Lake, Washington, returned from three to six times more fish than the parental races. These interesting results demonstrating the practical use of genetic diversity have not been followed up.

The coastal cutthroat trout can be highly predaceous. Idyll (1942) found the cutthroat had a higher percentage of fish in its diet than either the rainbow or the brown trout in the Cowichan River, British Columbia. Studies by Armstrong in Alaska and Northcote in British Columbia reveal that when coastal cutthroat live with Dolly Varden trout, the cutthroat is the more predaceous species by far. Ricker (1941) found the cutthroat trout to be the major predator on young sockeye salmon in Cultus Lake in 1940. Nilsson (1971, Fig. 2) showed a more rapid growth and more predaceous feeding habits in cutthroat trout compared to rainbow trout living together in a British Columbia lake. The interaction between coastal cutthroat trout and rainbow trout when both are resident (non-migratory) in the same stream or lake is variable. In the Willamette River, Oregon, Nicholas (1978b) found the rainbow trout was dominant and grew more rapidly than the cutthroat. In British Columbia, it appears that the coastal cutthroat is dominant over rainbow trout when they reside in the same lake and the cutthroat attains a larger size. The noted author, the late Roderick Haig-Brown, mentioned this in his book, "The Western Angler". In view of their predatory nature and long

In view of their predatory nature and long maximum life span (to at least 10 years), it is strange that "trophy" coastal cutthroat trout of 15 to 20 pounds or more are unknown. Dymond (1932) gives a maximum size of 17 pounds for coastal cutthroat trout living in a lake. This size has been repeated in the literature, but the lake in question has never been identified or the record size verified. The coastal cutthroat, as the interior subspecies, appears to be highly vulnerable to environmental impacts. Clearcutting of forests in Oregon, causing increased sediment, reduced cover resulting in a greater maximum water temperature that depressed cutthroat trout abundance for 6 to 8 years, although coho salmon abundance rebounded rapidly (Ringler and Hall, 1975; Moring and Lantz, 1975).

The cutthroat trout species in general seems to act like the canary in the mine-it is a sensitive indicator of environmental change.

\section{STATUS}

Until evidence is presented to the contrary, the coastal cutthroat trout can be considered a single subspecies throughout its entire range. Although coastal cutthroat abundance has drastically declined in many areas because of environmental alterations (mainly logging), and the threat of hybridization exists for many stocks, it is by far the most widely distributed and abundant of any subspecies of $S$. clarki. Hopefully, the increased appreciation of cutthroat trout, apparent in state and Federal agencies in recent years, will result in better environmental protection and more scientifically based propagation programs designed to increase the abundance of this long neglected fish. 


\section{THE INTERIOR CUTTHROAT TROUT NATIVE TO THE COLUMBIA AND UPPER MISSOURI BASINS}

The cutthroat trout native to the middle and upper Columbia River basin, the South Saskatchewan drainage, and the upper Missouri and Yellowstone systems present a confusing array of diversity that has never been adequately explained or correctly classified. The trend has been to lump all these native trouts into one subspecies, S. c. lewisi, typically with the common name "Yellowstone" cutthroat.

Schultz (1941), observing the trout of Glacier National Park, where the headwaters of the Flathead River (Clark Fork of the Columbia system), the South Saskatchewan drainage, and the upper Missouri tributaries are in close proximity, found such variation in spotting pattern that he was led to believe a complete transition from coastal to Yellowstone cutthroat trout was represented. Schultz (1935) also believed he had found intermediates (hybrids) between coastal and interior cutthroat trout in the middle Columbia basin, east of the Cascade Mountains in Washington, and that it was fruitless to attempt to delineate subspecies of interior cutthroat trout of the Columbia and upper Missouri basins, except to group them as S. C. lewisi. Schultz did not realize that S.c. lewisi and Yellowstone cutthroat trout are different subspecies, or that S. C. lewisi is native to the upper Columbia River basin. He also failed to correctly distinguish the Yellowstone cutthroat introduced into Glacier Park.

The stocking history of Glacier National Park waters was repeated throughout the West and led to the extermination of the native trout from vast areas. In 1918, the National Park Service and U.S. Bureau of Fisheries built a hatchery near the Park boundary. The 1922 U.S. Bureau of Fisheries report mentions that "... the National Park Service is now engaged in intensive fish culture in cooperation with Bureau hatcheries in Yellowstone and Glacier Parks." Referring to Glacier National Park, the 1923 report states: "An interesting and important feature of the work in the region was the planting of eyed black-spotted trout eggs in the almost inaccessible waters in that part of the Park lying along the Continental Divide and the Canadian border. More than 1,000,000 eggs were planted in the head waters of numerous lakes and streams." That same report tells of 1,332,000 Yellowstone cutthroat trout eggs being delivered to Glacier Park and of 1,389,700 eggs being taken from Park waters. At that time, Park waters contained introduced Yellowstone cutthroat trout, the native $S$. c. lewisi, and most likely, hybrid combinations of the two in addition to rainbow and brook trout.

A memorandum written by a Glacier National Park employee in 1925 discussed the intensive fish stocking of Park waters which were "... attaining the results (of which/we are all justly proud", mentions that "... the increasing number of tourists means that we must expand these activities." Thus it is not surprising that Schultz was confused when he attempted to identify subspecies of cutthroat trout in Glacier Park in 1939.

Several years ago, as I examined more and more specimens of cutthroat trout collected from an area encompassing the upper Columbia and upper Missouri and Yellowstone basins, I noted consistent differences in the spotting of the trout in specific areas. It was clear that the native cutthroat trout in question were derived from two distinct ancestral groups. One group, native to the northern sections of the upper Columbia River basin (Kootenay, Clark Fork, and Spokane river systems) is characterized by small spots that are irregular in outline and somewhat similar those of coastal cutthroat trout, except for the distribution of spots on the body and in coloration. This same form of trout crossed the Continental Divide and is native to headwaters of the South Saskatachewan drainage and to the upper Missouri basin. The oldest name for this subspecies is S. c. lewisi.

The living representatives of the other evolutionary line resulting from this probable first divergence of the interior cutthroat trout ancestor after its isolation and separation from the coastal cutthroat trout are the native cutthroat trouts of the Snake River drainage and the Yellowstone basin. They consistently differ from S.c.lewisi by having fewer, larger spots that are rounded in outline and by their coloration. For this, the "true Yellowstone" cutthroat, I use the name $S$. c. bouvieri.

In the Snake River system, two mysteries have yet to be adequately explained. One concerns the origin of an undescribed subspecies, the fine-spotted Snake River cutthroat, whose distribution is completely circumscribed by the "Yellowstone" cutthroat. The two subspecies are not separated by physical barriers to prevent hybridization, yet they remain distinct despite past stocking practices forcing them to mix. The other mystery is why the two major tributaries of the lower Snake, the Salmon and Clearwater rivers, have $S$. c. lewisi as the native trout, not S. c. bouvieri. The entry of le wisi into the Salmon River from stream capture from the Clark Fork drainage is quite plausible, but what happened to the bouvieri ancestry that is assumed to have been the original trout of the Salmon and Clearwater drainages? Possibly it was eliminated by redband trout prior to the establishement of S. c. lewisi. 
Below the barrier falls on the major upper Columbia tributaries and west to the Cascade Mountains, cutthroat trout are found as disjunct, isolated relict populations. Almost nothing is known about the correct classification of these trout. The subspecies S.c.alpestris was named for the few isolated populations known from the upper Columbia basin and Upper Fraser River system of British Columbia. The validity of this subspecies is yet to be determined.

From 1967 to 1974, I accumulated more than 1,300 specimens from more than 100 localities in Idaho, Montana, and Wyoming for the study of the systematics of S. c.lewisi, S. c. bouvieri, and the fine-spotted Snake River cutthroat. Research grants from Yellowstone National Park and the U.S. Forest Service funded two graduate student theses on these trout. Murphy (1974) studied the fine-spotted Snake River cutthroat trout and the Yellowstone cutthroat and compared the similarities between the two and between those and the Bonneville basin cutthroat, S. c. utah, derived from the upper Snake River. Roscoe (1974) studied S. c. lewisi from the upper Columbia, upper Missouri, and South Saskatchewan basins, comparing them with S.c. bouvieri.

Dr. Richard Wallace, University of Idaho, has kindly provided me with copies of his data based on examination of several hundred $S$. c. lewisi specimens from Idaho, particularly from the Salmon and Clearwater drainages. I also analyzed 19 th century specimens to determine the native trout of areas where they no longer exist. 

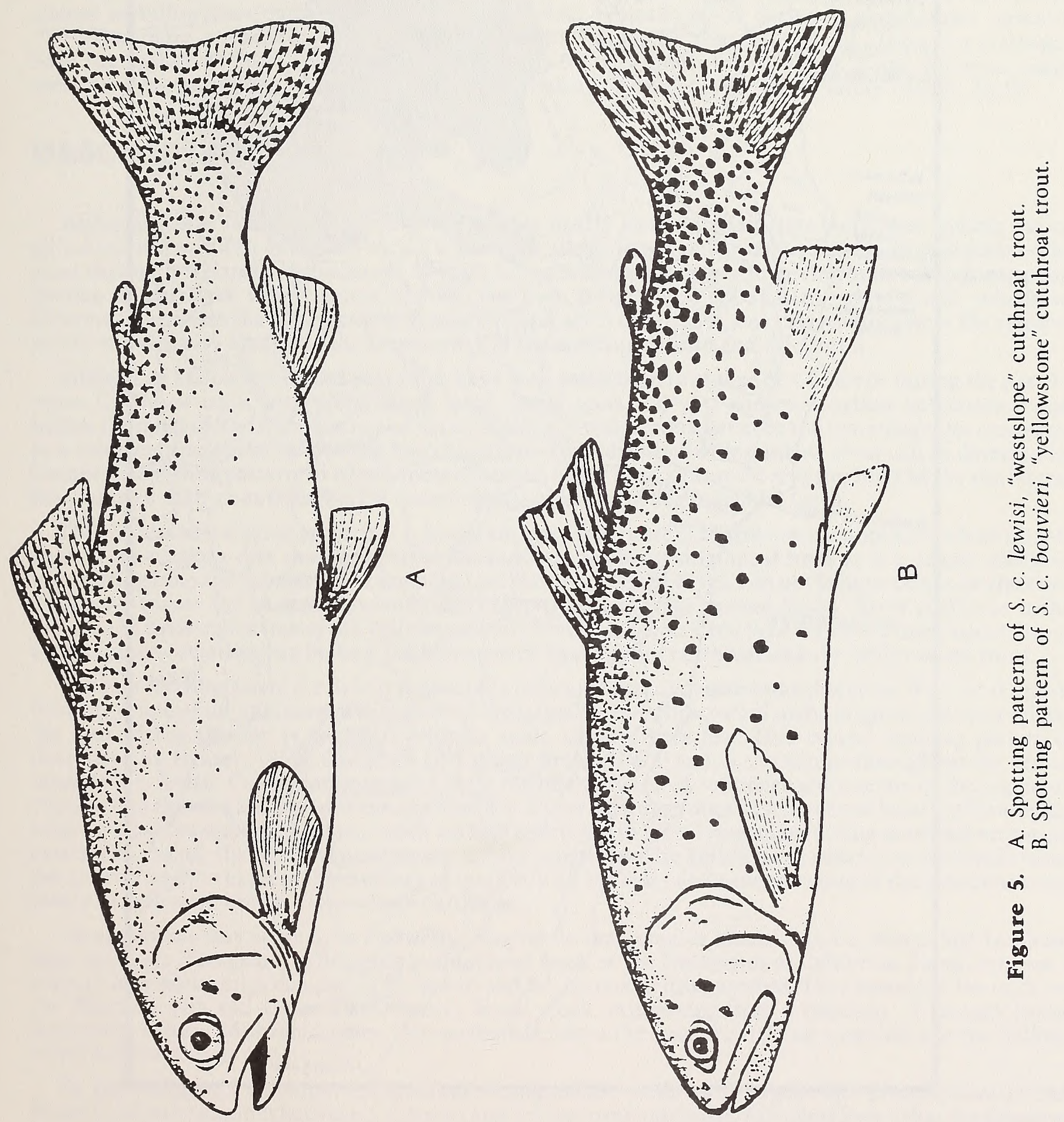


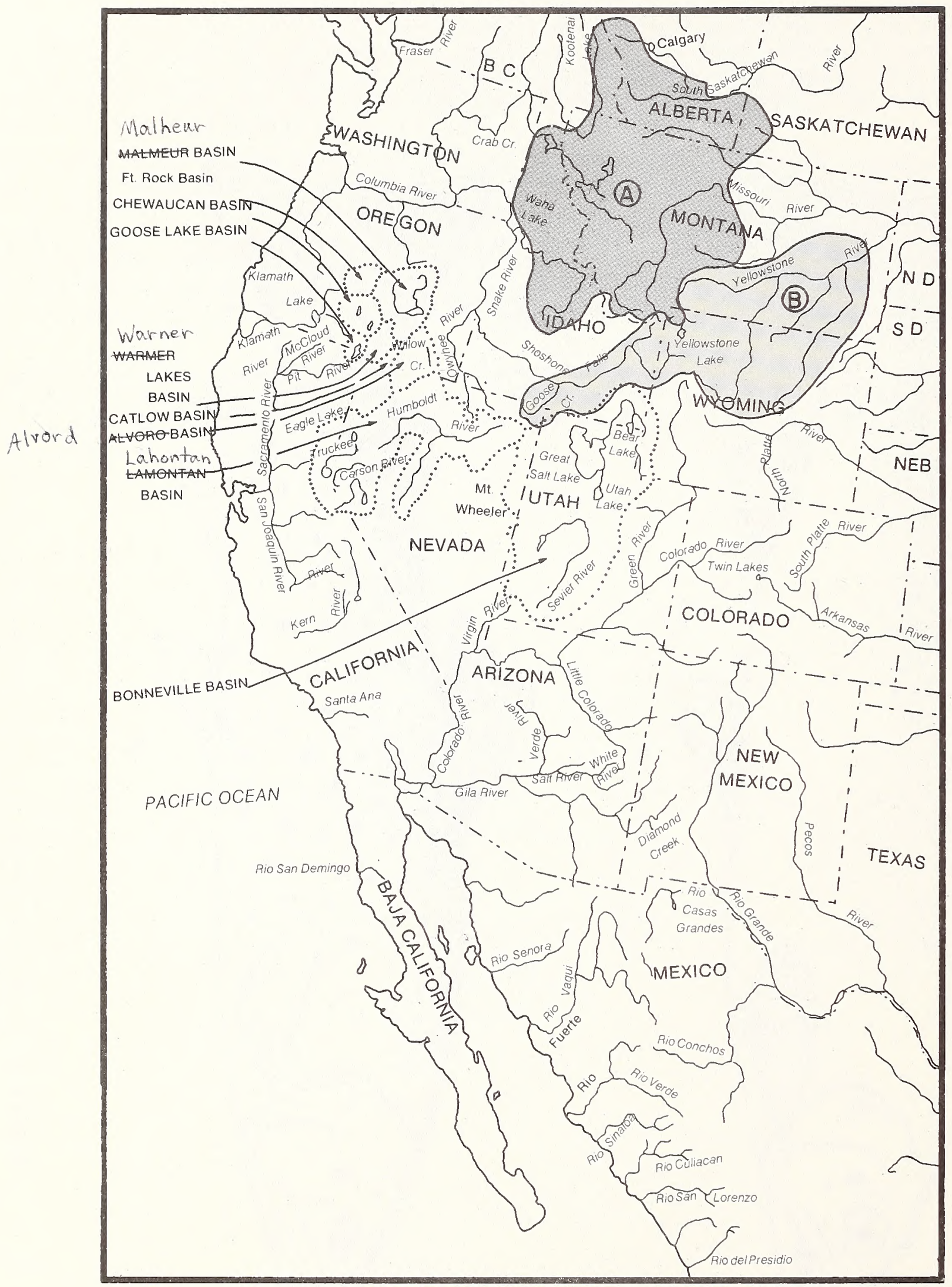

Figure 6. A. Distribution of S.c.lewisi.

B. Distribution of S. c. bouvieri. 


\section{"WESTSLOPE" CUTTHROAT TROUT, Salmo clarki lewisi}

\section{TYPICAL CHARACTERS}

Spots small, irregular in outline (non-rounded), similar in shape to the spots of coastal cutthroat trout. Few spots on anterior part of body below lateral line. Coloration variable, generally silver with yellowish tints, but has genetic basis to express bright yellow, orange, and red colors to a much greater extent than is found in coastal or Yellowstone cutthroat trout. Vertebrae 59-63, typically 60-61. Scales in lateral series typically 150-200 or more, with mean values generally 165-180. Specimens from Salmon and Clearwater drainages have the highest counts. Pyloric caeca typically 25-50, with mean values 30-40. Upper Missouri basin specimens generally have lowest caeca counts. Gillrakers typically 17-21, mean values usually 18-19.

\section{DESCRIPTION}

Although there is a trend toward lower counts in the meristic characters /vertebrae, pyloric caeca, gillrakers) of S. c. lewisi compared with S. c. bouvieri, the geographical distribution of both subspecies is so great that with isolation of thousands of years between major drainages involving both subspecies, much overlap in character values exists between the two. Fortunately, the spotting pattern and coloration differences between the subspecies is distinctive and, with experience, one can readily assess the relative purity of a stock by observing the consistency of the spotting pattern and coloration.

Millions of Yellowstone cutthroat trout have been stocked in the range of S.c. lewisi during the past 75 years. Cutthroat trout with pronounced, large, round spots and with brownish-yellow coloration found within the range of lewisi are due to past introductions. Hybridization between the two subspecies can result in a complete transition in spotting and coloration. Hybridization with rainbow trout can be detected by changes in spotting pattern, in which spots appear on top of head and on the anterior body below the lateral line, reduced scale counts, increased caecal counts, and loss of basibranchial teeth.

The size and shape of the spots on S.c. lewisi are similar to those of the fine-spotted Snake River cutthroat trout. This suggests that the fine-spotted Snake River cutthroat originated from an S. c. lewisi ancestor, transferring from the Salmon River drainage into the upper Snake River. I do not believe this to be the case, however, because the basic yellowish-brown coloration of the fine-spotted Snake River cutthroat is the same as the basic coloration of the Yellowstone cutthroat. Gene loci data, to be discussed later, also indicate a close genetic relationship betwen the fine-spotted Snake River cutthroat and the Yellowstone trout.

The spot distribution of S.c. lewisi is generally typical of interior cutthroat subspecies. If an arc is drawn from the origin of the anal fin extending above the lateral line and downward to the origin of the pectoral fin, the area within this arc is generally without spots, or with very few. This typical spotting pattern is illustrated by Hanzel (1959), Campbell (1971), and Brown (1971) and is consistent throughout the entire range of S. c. lewisi. Coloration is under a more direct environment influence since many of the pigments deposited in the skin are derived from the food. S.c. lewisi, however, does have a genetic basis for developing bright yellow, orange, or red colors, which are best developed in lake-living males during spawning season. In extreme examples, the whole ventral region may be bright red. The Yellowstone subspecies evidently lacks the genetic basis to express these colors so intensely on the sides and ventral region of the predominantly brassy or yellowish-brown Yellowstone cutthroat.

Chromosomes may prove to be a powerful diagnostic character for identifying S. c. lewisi. Eric Loudenslager and Gary Thorgaard, performing postdoctoral work at the University of California, Davis, sent me a copy of their manuscript comparing S. c.lewisi and S. c. bouvieri chromosomes. They found S. c. lewisi lfrom the Montana Fish and Game Department's brood stock, originating from a tributary of Hungry Horse Reservoir|, to have 66 chromosomes, intermediate between the coastal cutthroat trout $(68)$ and the Yellowstone cutthroat trout (64).

Dr. Fred Allendorf, University of Montana, examined the products of 50 gene loci (electrophoresis) and found 8 loci to be distinct between S.c.lewisi and Yellowstone cutthroat. Allendorf found that the degree of distinction in these loci was much less between $S$. c. lewisi, coastal cutthroat, rainbow, and redband trout than between lewisi and Yellowstone cutthroat - Which is not in accord with my interpretation of evolutionary relationships. Analysis of gene loci, however, does offer additional characters for assessing the purity of lewisi stocks where hybridization with Yellowstone trout is suspected.

As mentioned, there are trends in differences in the taxonomic characters between lewisi populations 
because of long isolation between the drainage basins where they occur. Dr. Richard Wallace's data, based on 12 samples, or 124 specimens, from the Salmon and Clearwater drainages, indicate that the $S$. c. lewisi of these drainages typically have more lateral series scales than do other populations. The highest counts were obtained from 10 specimens from Elizabeth Creek, a tributary to the North Fork of the Clearwater River. Their scale counts ranged from 187 to 232 , with a mean value of 209 . The other 11 samples have mean values of 185 and 195.

The extreme values of scale counts found in Salmon and Clearwater specimens where lewisi occurs with redband trout may be, in part, an example of "character displacement", where differences between two species isolated from each other become accentuated in areas where they are in contact. The increased divergence in characters is a reflection of evolutionary mechanisms acting to lessen competition. In eight samples from the St. Joe River drainage of Idaho /part of the Spokane River division of the upper Columbia basin|, Wallace obtained mean values ranging from 164 to 180 lateral series scales, comparable to Roscoe's (1974) counts of lewisi specimens from the Clark Fork drainage.

\section{DISTRIBUTION}

The original distribution of S.c. lewisi is not known for certain, particularly in the western limits of its range. Future research may find that the mountain cutthroat trout of British Columbia, S.c.alpestris, should be classified as $S$. c. lewisi, which would call for a considerable range extension. The known range includes the upper Missouri basin where original distribution of cutthroat trout occurred in the main Missouri and all tributaries downstream to below Great Falls, Montana, probably to Fort Benton labout 35 miles downstream from Great Falls). Cutthroat trout are also native to the headwater areas of the Judith, Musselshell, Milk, and Marias rivers, which join the Missouri downstream from Fort Benton.

Almost the entire distribution of S. c. lewisi in the Missouri basin is in Montana. The headwaters of the Madison and Callatin rivers are in the extreme north west corner of Wyoming in Yellowstone National Park, where a few lewisi populations still exist and where the Milk River extends into Alberta, Canada. In the South Saskatchewan River drainage, the range of S.c. lewisiincludes mountain tributaries in Montana and Alberta from the Bow River southward. On the west side of the Continental Divide (Columbia River basin), the natural distribution includes the Kootenay River drainage from its headwaters downstream below the confluences of the Moyie and Elk rivers (upstream from Kootenay Lake), in British Columbia, Montana, and Idaho. The known distribution in the Clark Fork drainage of Montana and Idaho includes the entire drainage downstream to the falls on the Penn Oreille River.

S.c. lewisi is native to the Spokane River (Coeur d'Alene, St. Joe drainages) system in Idaho above Spokane Falls. An apparent anomaly in the distribution is its occurrence in the Salmon and Clearwater drainages of the Snake River system of Idaho, where S. c. bouvieri would be assumed to be the native cutthroat trout. Perhaps lewisi replaced bouvieri from the Salmon and Clearwater drainages, or bouvieri was replaced by the redband trout, and a later transfer from the Clark Fork drainage in to the Salmon River established S. c. lewisi in coexistence with anadromous redband trout. No cutthroat trout are definitely known to be native to most other major Snake River tributaries below Snake River, such as the Wood, Weiser, Boise, Payette, Owyhee, and Malheur rivers. There the redband trout is the only known native trout.

Below the barrier falls, which originally isolated S. c. lewisi in the upper Columbia basin, and westward to the Cascade Mountains, cutthroat trout occur only rarely and sporadically. The origins and relationships of these "middle" Columbia basin cutthroat trout remain a mystery. Are they derived from S. c. lewisi, S. c. bouvieri, both of them, or do they represent a distinct subspecies? The questions are difficult to answer because of past introductions.

S. c. lewisi is probably the native trout of the isolated Lost River group of streams of the Snake River Lava Plateau, Idaho, which originate in the Lost River Mountains. The headwaters intertwine with the headwaters of the Salmon River drainage, and the streams sink in to the ground before they reach the Snake River so are completely isolated systems. The native trout of these streams are unknown, and any current study will have to deal with the problem of introductions. Hayden (1872) mentioned a small-spotted cutthroat trout in one of these isolated streams (Medicine Lodge Creek), and Evermann (1896) mentioned small-spotted cutthroat in the headwaters of the Wood River near Sun Valley (redband trout are native to the lower Wood River, which enters the Snake River below Shoshone Falls but contains some upper Snake River species). Hubbs and Miller (1948) believed the cutthroat trout of the Snake River Lava Plateau represents an undescribed subspecies. 
I examined 10 specimens collected in 1934 from one of these isolated drainages (Irving Creek) in the University of Michigan collection. Since the Irving Creek specimens appear to be hybrids between a native trout, rainbow trout, and/or Yellowstone cutthroat trout, and the question of the native trout of the lava plains streams remains open. The other fish species native to these streams, the bull trout, Salvelinus confluentis, and sculpins, Cottus, are also found in the Salmon River drainage, but not in the upper Snake River. My interpretation is that volcanic eruptions eliminated all fish life from these streams when they were direct tributaries to the upper Snake River. After isolation from the Snake River, headwater stream transfers from the Salmon River system established the present fauna. If this is true, S.c. lewisi should be the native trout of these isolated drainages. The occurrence of native cutthroat trout in the Wood River system and their correct identification is also open questions. I have never been able to locate native trout populations in the lava plains streams or in the Wood River drainage.

During the last glaciation of the Pleistocene period about 7,000 to 70,000 years ago, large glacial lakes formed throughout the present range of S.c. lewisi. These lakes played a role in the historical distribution of the subspecies. Lake Missoula, the largest, is of particular significance. Several times the ice dams creating Lake Missoula failed, and great floods swept across eastern Washington resulting in the present terrain, commonly called the "scablands". It would seem logical that S.c.lewisi occurred in glacial Lake Missoula and was transported by flood waters westward to the Cascade Mountains. I have often entertained the thought that the cutthroat trout native to Lake Chelan, Washington, in the Cascade Range is S. c. lewisi and was perhaps derived via an ancient flood from glacial Lake Missoula.

The present status of the cutthroat trout native to Lake Chelan is doubtful. They may no longer exist there, at least as pure populations. The Lake Chelan cutthroat trout was propagated in hatcheries during the early 20th century. Dr. Richard Wallace and I attempted to track down a source of the Lake Chelan cutthroat in 1974. An article in the Washington State Game Bulletin (1967, Vol. 19, No. 3), titled "Twin Lakes cutthroat", discussed the egg-taking operation at this brood stock lake in Chelan County, Washington. The article states, "The fish in Twin Lakes are of probable fry obtained from eggs taken from cutthroat trout in the Stehekin River at the head of Lake Chelan."

Dr. Wallace obtained 11 specimens of cutthroat trout from Twin Lakes and 19 specimens from Kings Lake, the other source of interior cutthroat trout eggs for propagation in Washington (the Kings Lake trout were derived from Priest Lake, Idaho, and were S.c.lewisi). The Twin Lakes specimens are S. c.lewisi. The spotting pattern and general appearance are so wholly typical of lewisi that they could serve as a model for the subspecies. However, I do not consider this identification of the Twin Lakes cutthroat as S. c. lewisi to be proof that its range extended westward to Lake Chelan in the Cascade Mountains. As previously discussed, the common mixing of races of cutthroat trout in propagation casts doubt on the assumption that the present Twin Lakes trout represents a direct continuity of the native trout of Lake Chelan. To answer this question with more authority, "true" native trout of the Lake Chelan watershed would have to be discovered and critically analyzed.

If indeed the natural range of S. c. lewisi extends to the Cascade Mountains, the mystery of the Crab Creek cutthroat becomes even more puzzling. Crab Creek, near Ritzville, Washington, is an isolated scabland stream in an area innundated by the floods from glacial Lake Missoula. On this basis, a native trout should be S. c. lewisi. The trout collected in 1908 and named Salmo eremogenes by Evermann and Nichols (1909), however, is characterized by few, large, round spots-quite typical of S.c. bouvieri. Possibly, the trout named S. eremogenes is not native to Crab Creek, but was stocked by man.

\section{TAXONOMIC NOTES}

The subspecies of S. c. lewisi represents the probable first divergence of interior cutthroat trout from a coastal cutthroat ancestor. I characterize S. c. lewisi mainly by its distinctive spotting and group all cutthroat trout native to the upper Columbia, South Saskatchewan, and upper Missouri basins, which share this spotting, as the same evolutionary group or subspecies. I believe the identification based on spotting pattern will be verified in the future by a distinctive karyotype (66 chromosomes) associated with this particualr evolutionary line.

The earliest name for any member of this wide-ranging group is "Salar lewisi", used by Girard (1856) for specimens caught in the Missouri River near Great Falls, Montana. Salmo clarki lewisi (Girard) then is the correct subspecific name and applies not only to the Missouri drainage trout, but also to this same cutthroat trout native to the South Saskatchewan and upper Columbia basins. 
Biologists in Montana long ago recognized that the cutthroat trout native to the Clark Fork drainage, S.c. lewisi, was different in appearance from the Yellowstone Lake cutthroat trout, S. c. bouvieri, which was so widely propagated in hatcheries. The common name "westslope" cutthroat was used to differentiate the Clark Fork cutthroat from the Yellowstone cutthroat, but the mistaken belief that S. c. lewisi is the correct name for the Yellowstone cutthroat resulted in the assumption that the "westslope" cutthroat is an undescribed species or subspecies.

Hanzel (1959) studied the distribution of both lewisi and bouvieri cutthroat trout in Montana and presented photographs depicting the difference in spotting between Yellowstone and upper Missouri cutthroat, but did not discuss the taxonomic implications of these differences. Zimmerman (1965) demonstrated that the cutthroat trout on both sides of the Continental Divide in the Clark Fork and upper Missouri drainages are identical (this observation was also made by George Suckle in the 1850's), but did not compare S.c. lewisi with Yellowstone cutthroat trout. Weisel (1955) considered the Yellowstone and upper Missouri cutthroat to be S. c. lewisi, but classified the "westslope" cutthroat as S. clarki clarki (coastal cutthroat). Brown (1971) listed Salmo clarki without subspecies designation for all the native cutthroat trout of Montana, but presented photographs of a Yellowstone cutthroat and a westslope cutthroat clearly showing the spotting distinction.

Idaho biologists also recognized the clear distinction between S. c. lewisi native to the Spokane River system (Coeurd'Alene Lake, St Joe River) and to the Pend Oreille-Clark Fork system (Priest Lake, Lake Pend Oreille) on one hand, and hatchery cutthroat (S.c. bouvieri) stocks derived from Henry's Lake, Idaho or from Yellowstone Lake on the other hand. In Idaho, S. c. lewisi has been called the "north Idaho" cutthroat.

It is understandable why there has been so much confusion over the separation and correct classification of S.c.lewisi and the Yellowstone cutthroat. However, the distinctions in spotting and coloration between the two subspecies are consistent and easily recognized with experience.

\section{LIFE HISTORY AND ECOLOGY}

There are three basic life history forms found in S.c.lewisi throughout its range: migratory between lakes and streams, migratory between small tributaries and main rivers, and nonmigratory tributary stocks. S. c. lewisi is native to all the large lakes of the upper Columbia basin in Idaho and Montana /Coeur d'Alene, Priest, Pend Orielle, and Flathead Lakes). These lake stocks of lewisi have a life history somewhat similar to that of migratory coastal cutthroat trout. Spawning migrations from the lakes may travel as far as 100 miles to the spawning grounds where spawning occurs from March to July. The young typically spend from 2 to 3 years in the stream before migrating to the lake at a size of 7 to 9 inches. After 1 to 3 years in the lake, sexual maturation occurs typically at age IV or V and a size of 14 to 16 inches. Typical maximum age is VII, and typical maximum size is 18 to 20 inches and about 3 pounds.

The migratory stream fish spawn in tributaries and often remain there during the summer months. In the fall, they leave to overwinter in the main river channels. Tagged fish have shown movement of 100 miles or more (Bjornn, 1971; Bjornn and Mallet, 1964). This type of river migragory life history is particualrly prevalent among stocks of S. c. lewisi native to the Salmon River drainage and may be influenced by natural selection as a mechanism for partitioning niches to facilitate coexistence with the steelhead redband trout.

In contrast to the coastal cutthroat trout and most other subspecies, S. c. lewisi does not appear to be highly predaceous. Roscoe (1974) summarized the literature on the feeding habits of lewisi. Most food studies have been on lewisi stocks living in large lakes where forage fish are abundant, yet fish are rarely found in the diet. This lack of predatory feeding is illustrated by the establishment of kokanee salmon in all the large upper Columbia lakes of Idaho and Montana. In Lake Pend Oreille, where introduced kokanee became extremely abundant, the native cutthroat trout did not feed on the kokanee, but drastically declined in size because of competition with kokanee. In contrast, the native bull trout, Salvelinus confluentis, attained record weights, and the race of large "Kamloops" trout from Kootenay Lake, British Columbia, where kokanee are native and a natural predator Kamloops - prey kokanee relationship evolved, attained weights of 32 pounds in 4 years, and 37 pounds in 5 years when introduced into Lake Pend Oreille.

I attribute the weak development of piscivorous feeding by S.c.lewisi to its evolution with two predatory species, the bull trout, and the Columbian squawfish, Ptychocheilus oregonesis. By specializing as an invertebrate feeder, direct competion was avoided and more harmonious coexistence developed under natural selection. The introduction of nonnative fishes, in addition to environmental degradation, has 
disrupted the historical interactions of the native trout with its physical and biological environment and has caused tremendous declines in the distribution and abundance of $S$. c. lewisi throughout most of its range.

Kokanee salmon and lake trout, Salvelinus namaycush, are two species that are particularly detrimental to lacustrine stocks of cutthroat trout in general. The kokanee with its numerous gillrakers monopolizes the zooplankton of lakes, and the lake trout is an effective predator. Besides kokanee and lake trout, the Great Lakes whitefish, Coregonus clupeaformis, has become established in several lakes in Glacier National Park. This whitefish species is an effective feeder on both zooplankton and benthos. These nonnative species combinations have all but eliminated the native cutthroat trout from lakes once famous for abundant populations of S. c. lewisi.

Spokane and Clark Fork drainages in Idaho and Montana has been wrongly interpreted in my opinion. It is not a direct cause and effect relationship. If cutthroat trout were abundant in a particular area 100 years ago but gone today, it is not from competition or predation by squawfish. The squawfish were there many thousands of years ago also. The warming, pollution, and siltation of the streams caused by land use practices and the establishment of brook trout in tributary streams of brown and rainbow trout and an assortment of nonnative warm-water fishes in main streams have caused the decline.

As is common of the species in general, S.c.lewisi is vulnerable to angling exploitation. All the examples of special fishery regulations to protect native trout in Idaho and Alberta discussed earlier deal with $S$. $c$. lewisi. With regulations protecting the bulk of a population exposed to angling, and by allowing the catching and releasing of fish below a certain size, an intensive, high quality fishery can be maintained entirely on natural reproduction.

The success of special regulation fisheries with S.c. lewisi, as documented by Dr. Ted Bjornn and students of the Idaho Cooperative Fishery Unit, is evidence that $S$. c. lewisi has significant fishery management values. None of the nonnative trouts is so vulnerable to angling that they can be caught and released several times, which is necessary to support a high catch-per-man-hour on a limited stock of fish. It is likely that angling pressure of no more than 50 hours per acre per year will overexploit $S$.c. lewisi in a stream, and the population will respond markedly to protective regulations at such angling intensity.

Another management potential for S.c. lewisi is the use of intraspecific diversity as discussed by Trojnar and Behnke (1974). In 1971-1972, John Trojnar, then a graduate student, and I studied the interactions of two subspecies of cutthroat trout, the fine-spotted Snake River cutthroat and a partially hybridized stock of S.c. stomias, in a Colorado lake. The two avoided direct competition by partitioning the food supply. The implication was that two or more differentiated stocks of a species, when living together tend to specialize, making more effective use of the food supply and producing more total biomass than one stock could alone.

In 1972, Mr. Goerge Holton, Montana Fish and Game Department, arranged to duplicate the Colorado lake study by stocking five Montana lakes with both S. c. lewisi and Yellowstone cutthroat trout. Unfortunately, there was no adequate follow-up on these lakes. The only information on this experimental stocking was obtained by Dr. John Clark, a former Colorado State University graduate student now employed by the Alaska Fish and Game Department, in 1973 and 1974 during two brief visits to three of the lakes. Clark's preliminary observations indicate that there was no obvious difference in the growth or survival of the two subspecies in the lakes, but they were feeding on different groups of invertebrates and the angler catch at any one time would be predominantly one subspecies or the other. The implication is that lewisi and bouvieri, when stocked together, will produce more fish and more biomass than either one could alone, and that the interaction between the two will result in a more consistent fishery in mountain lakes for anglers. Of course, such introductions should not be made in watersheds where pure lewisi populations exist and where there would be a danger of contamination.

\section{STATUS}

From 1966 to 1973, the U.S. Department of Interior issued an annual "redbook" of endangered species. In the early volumes, the Montana westslope cutthroat trout, "Salmo sp.", is listed as an endangered species, but that was changed to "status undertermined" in later editions because of taxonomic confusion. It should now be clear that the Montana westslope cutthroat trout is S. c. lewisi, and the range of the subspecies is much greater than the Clark Fork drainage of Montana.

Although S. c. lewisi has vanished from most of its range, there are areas where essentially pure native trout are yet relatively common because of its great original range. Even though they have been exposed to 
hybridization, the native stocks show little or no outward sign of hybridization; that is, phenotypically they are S.c. lewisi. Such areas include tributaries to the Salmon and Clearwater drainages, the upper St. Joe River of Idaho, and the South Fork of the Flathead River (Hungry Horse Reservoir and above), Montana. The term "relatively common" is indeed relative. The areas where $S$. c. lewisi is still the dominant trout are small compared to its original distribution. For example, Platts (1974) in the Salmon River drainage of Idaho, found cutthroat trout common only in undisturbed stream sections at the highest elevations. Although lewisi may be relatively common in such sites, there are few such undisturbed habitats.

Despite its rarity in the Kootenay River drainage and most of the Clark Fork and Spokane drainages, S. C. lewisi has fared better on the west slope of the Continental Divide than on the east slope. Pure populations of S. c. lewisi are rare in the upper Missouri and South Saskatchewan basins.

Determining the purity of $S$. c. lewisi populations is a problem of degree. All transitional forms may be found from typical (unhybridized) lewisi to hybrid swarms of typical rainbow trout within a segment of a particular drainage. Pure populations are usually restricted to remote, isolated areas. However, the bulk of the population that can be classified as $S$. c. lewisi from outward appearance are not isolated and have been exposed to hybridization, but natural selection has favored the maintenance of the native genotype with some slight introgression (inflitration of few nonnative genes into the gene pool, but not forming hybrid swarms|from rainbow trout and/or Yellowstone or Henry's Lake cutthroat trout. For management purposes, any population closely resembling lewisi (not obviously hybridized) in its coloration and spotting pattern, should be recognized and classified as such, and hair splitting over nuances of purity should be avoided.

For the establishment of a brood stock for propagation and reintroductions, however, identification as S.c. lewisi would call for more intensive taxonomic study to be as certain as possible that the trout being propagated is a pure lewisi. The Montana Fish and Game Department has developed a large-scale propagation program with $S$. c. lewisi to stock Hungry Horse Reservoir and other waters in its native range. Fortunately, the orignal stock chosen as S. c. lewisi, from a tributary to Hungry Horse Reservoir, appears to be a virtually pure S. c. lewisi (Roscoe, 1974). The introduction of nonnative trouts (including Yellowstone cutthroat trout) within the range of lewisi, where possible contamination may occur, has ceased in Montana.

The cutthroat trout most widely stocked in Idaho is S. c. bouvieri of Henry's Lake, which have been slightly hybridized with rainbow trout. Millions of Henry's Lake cutthroat have been stocked into lewisi populations throughout most of the range of lewisi for many years in Idaho, and there are few populations of lewisi that have not been exposed to hybridization. 


\section{YELLOWSTONE CUTTHROAT TROUT, Salmo clarki bouvieri}

\section{TYPICAL CHARACTERS}

Spots are medium-large, pronounced, rounded in outline, and much larger and fewer than those of S.c. lewisi. Distribution of spots on body somewhat similar to lewisi with concentration on caudal penduncle except in Yellowstone Lake trout, which has spots more evenly distributed over sides of body.

Coloration is yellowish-brown, silvery, or brassy. Bright golden-yellow, orange or red colors absent. Rose tints may appear on body of mature fish.

Vertebrae 60-63, typically 61-62. Scales in lateral series $150-200$, typically $165-180$. Pyloric caeca $25-50$, typically 35-43. Gillrakers 17-23, typically 19-20 (highest in Yellowstone trout).

\section{DESCRIPTION}

The trout native to Yellowstone Lake has been stocked by the millions from about 1905 to 1955 in many waters outside the range of S.c. bouvieri and may be encountered as a "nonnative" cutthroat in many states. The Yellowstone Lake cutthroat differs from other bouvieri populations in a tendency for the spots to be more or less evenly distributed over the sides of the body (sometimes on the ventral region), by more gillrakers '18-23 (21)] with well-developed rakers on the posterior side of the first arch, and by more basibranchial teeth (average of 22). Evidently these distinctive traits are lacustrine selected characters.

An example of sharp divergence that can be expressed by a local isolated population of a subspecies is the cutthroat trout of Sedge Creek in Yellowstone National Park. Sedge Creek is tributary to Yellowstone Lake, but geothermal activity creating Turbit Lake effectively blocks any communication between the Lake and Sedge Creek. The isolation of the Sedge Creek trout from Yellowstone Lake trout could not be of great geological age. No fish could have inhabited the Yellowstone Plateau until the glacial ice melted within the last 8,000 years. The Sedge Creek cutthroat have only a few spots on the caudal penduncle and closely resemble the "type specimens" of S. bouvieri from Waha Lake. In nine specimens from Sedge Creek, I counted 52-63 |58| pyuloric caeca, which, except for some Lahontan cutthroat, are the highest caeca counts ever recorded for pure cutthroat trout (Sedge Creek has never been stocked according to Park records).

Bulkley (1963) discussed the differences in spotting, coloration, and basibranchial teeth he found among the Yellowstone Lake trout and the Sedge creek trout. The graduate research of Mr. Eric Loudenslager at the University of Wyoming could not find a single difference in 22 gene loci between Yellowstone Lake trout and Sedge Creek trout. The slight genetic differentiation that must be present results in a conspicuous difference in spotting pattern and in the number of pyloric caeca.

In Rocky Mountain National Park lakes, trout populations derived from introduction of Yellowstone Lake cutthroat can be recognized and differentiated from populations in neighboring lakes derived from "native" cutthroat (predominantly greenback cutthroat and/or Colorado River cutthroat genotypes) by the coloration. Yellowstone cutthroat are silvery, brassy, or yellowish-brown, while the predominantly greenback of Colorado River cutthroat develops brilliant coloration. With experience, the distinctive spotting pattern and coloration of Yellowstone Lake cutthroat trout can be readily used for field identification of populations introduced outside their native range.

The stream-living populations of S.c.bouvieri in the upper Snake River and Yellowstone drainages do not differ much from S.c. lewisi in their meristic characters. As previously discussed, this early divergence in the evolution of interior cutthroat trout resulting in the lewisi and bouvieri lines may be reflected in chromosomes and gene loci data.

\section{DISTRIBUTION}

As with S. c. lewisi, the western extent of the range of the Yellowstone cutthroat trout is not known for certain. The type locality for the name bouvieri is Waha Lake, Idaho, an isolated lake in the lower Snake 
River system near the Washington border. I have also examined specimens collected in 1893 from the Wallowa River, a tributary to the lower Snake River, Washington, which are typical of this subspecies. From this, it can be assumed that the Yellowstone cutthroat trout, S.c. bouvieri, was the original native trout of the entire Snake River system, but was replaced by redband trout where they came into contact below Shoshone Falls of the Snake, and was replaced by S.c. lewisi as the native cutthroat trout of the Salmon and Clearwater drainages. S. c. bouvieri may have expanded its distribution beyond the confines of the Snake River as evidenced by "Salmo eremogenes", a typical S. c. bouvieri of Crab Creek, Washington.

I would expect that S. c. bouvieri persists in the Snake River drainage (Owyee, Payette, Wood, Weiser, Boise rivers) in waters isolated from contact with the later invading redband trout, but this assumption has yet to be verified.

Above Shoshone Falls, the Yellowstone cutthroat is native to all the Snake River system, except for a section of the main Snake River and its tributaries between Jackson Lake and Palisades Reservoir where the fine-s potted Snake River cutthroat exists. Before Palisades Reservoir was constructed, the native trout of the main Snake River from Palisades to Shoshone Falls could have been either the fine-spotted subspecies or the Yellowstone cutthroat or both. The evidence is not definitive on this matter. All the tirubutaries to the Snake River between Palisades and Shoshone Falls (Henry's Fork, Portneuf, Raft and Goose rivers) have S.c. bouvieri as the native trout.

Undoubtedly bouvieri invaded the Yellowstone drainage from Pacific Creek of the Snake River, over Two Ocean Pass, to Atlantic Creek of the Yellowstone, an access route that is still open. The description of Two Ocean Pass found in the literature and based on Evermann's observations in 1893 as recounted in Jordan and Evermann (1896) and many other publications, is somewhat in error. On the Continental Divide, North Two Ocean Creek precisely divides with one branch becoming Pacific Creek, a Snake River tributary, and the other, Atlantic Creek, a Yellowstone tributary. There are no barriers between the Snake River and Yellowstone Lake via this route. However, from age/size distribution, I noted during my visit in 1967 that the Yellowstone Lake trout run up to the head of Atlantic Creek for spawning but do not enter Two Ocean Creek or Pacific Creek. The trout of Two Ocean and Pacific creeks are resident or nonmigratory stream fish.

On the southern side of Two Ocean Pass, South Two Ocean Creek flows through a complex network of beaver ponds, but the main flow goes into Atlantic Creek. Transcontinental movement of trout could only occur during high flows. Evidently, Evermann, following Pacific Creek to its headwaters, was led astray by a dead-end spring-fed branch and did not see the connection between Pacific and Atlantic creeks via North Two Ocean Creek. Evermann believed the passage route was via South Two Ocean Creek.

Once the ice on Yellowstone Plateau melted some 8,000 years ago, the cutthroat trout became established in Yellowstone Lake. Since that time they have established several subpopulations, isolated from each other by homing to partental tributaries for reproduction. In the Yellowstone drainage, the native cutthroat spread in all tributaries as far as the Tongue River. The Powder River drainage, the next downstream tributary after the Tongue River, was barren of native trout. Thus it can be concluded that S. c. bouvieri never spread in the Missouri basin beyond the confines of the Yellowstone drainage.

\section{TAXONOMIC NOTES}

If it is accepted that the Yellowstone cutthroat trout is derived from a different ancestor and should be recognized as a different subspecies from the cutthroat native to the upper Missouri system, then the name $S$. c. lewisi goes with the upper Missouri cutthroat, and another subspecies name must be found for the Yellowstone cutthroat. The cutthroat trout of the Bonneville basin, recognized as S. c. utah, is derived from the Yellowstone cutthroat of the upper Snake River and is not much differentiated from the Yellowstone cutthroat. That is, there are no characters by which S.c. utah can be consistently separated from Yellowstone cutthroat trout with high accuracy, and it could logically be concluded that the name $S$. c. utah should also apply to the Yellowstone cutthroat of the Snake and Yellowstone River systems.

From a practical point of view, I have rejected such a classification because of the the confusion it would cause. The name utah has been long associated with the trout of a specific basin and, to retain this classification in its present sense, another name must be used for the large-spotted cutthroat trout of the Snake and Yellowstone drainages. The earliest name that applies to the cutthroat characterized by large, rounded spots of either the Snake River or Yellowstone basins is "Salmo purpuratus bouvieri", named by Bendire (1882) for the cutthroat trout native to Waha Lake, Idaho. Waha Lake is isolated from the Snake 
River and represents one of those localities where the native cutthroat trout evidently gained access before the isolation occurred and persisted as a relict population, protected from contact with the later invading redband trout which evidently replaced bouvieri from the entire Snake River drainage below Shoshone Falls.

Jordan and Evermann (1902) published an illustration of "Salmo bouvieri" of Waha Lake, showing a cutthroat trout with a few large, round spots, mainly on the caudal peduncle area. A scale count of 173 was given. I examined one ancient specimen of bouvieri from Waha Lake from the collection of the California Acadamy of Sciences and counted only 157 scales in the lateral series. This specimen has 17 gillrakers, 61 vertebrae, and a spotting pattern conforming to the illustration in Jordan and Evermann. I have no doubt that the cutthroat trout native to Waha Lake is of the same evolutionary line (subspecies) as the large-spotted cutthroat of the upper Snake River and Yellowstone River. Thus, the "Yellowstone" cutthroat trout becomes S. c. bouvieri.

Unfortunately, the diagnosis of bouvieri from the type locality, Waha Lake, cannot be more clearly defined. Very few museum specimens exist, and the native trout is now certainly extinct in Waha Lake. A 1961 letter from Mr. James Simpson, Idaho Fish and Game, to P. R. Needham, related that to rid the lake of carp and other rough fish, Waha Lake was twice treated with rotenone to kill all fish.

The cutthroat trout of Crab Creek, Washington, named Salmo eremogenes by Evermann and Nichols (1909) appears to be identical to bouvieri, and I consider the names to be synonymous. Crab Creek, an isolated stream on the scablands of eastern Washington, is also an isolated drainage within the Columbia basin where, apparently a cutthroat trout persisted as a relict, protected from contact with the later invasion of redband trout. If the trout named eremogenes is truly native to Crab Creek, it is an anomalous distribution because the Crab Creek drainage is north of the Snake River and in the path of the great floods emanating from glacial Lake Missoula, which would have been expected to carry S. c.lewisi, not the S.c.bouvieri to this region. Some unknown events during or since the last glacial period must have rearranged trout distribution to put bouvieri in the expected range of lewisi (Crab Creek) and to establish lewisi within the range of bouvieri (Salmon and Clearwater drainages of the Snake River system).

\section{LIFE HISTORY AND ECOLOGY}

Most of what is known of the life history of S.c. bouvieri is based on the cutthroat trout of Yellowstone Lake (Bulkley, 1961); Cope, 1956, 1957a, 1957b). Because of the widespread propagation and stocking of Yellowstone Lake cutthroat, the typical consensus on the role of cutthroat trout in fisheries management is largely based on the performance of Yellowstone Lake cutthroat. This has led to misconceptions on the ecological variability found in the species as a whole. For thousands of years, the cutthroat trout evolved in Yellowstone Lake, essentially without other fish species (besides the trout, only a race of the genus Rhinichthys is native above the falls of the Yellowstone). This lack of evolutionary programming regarding interaction with a variety of fish species in their recent history, and the highly stable, oligotrophic environment of Yellowstone Lake makes the Yellowstone Lake cutthroat ill-adpated to successfully coexist with other fish species or to thrive in diverse environments where it has been introduced.

The longnose sucker and the redside shiner have been introduced by man are abundant in Yellowstone Lake. The present fishing regulations governing the cutthroat fishery requiring the release of all trout over 13 inches is designed to favor cutthroat predation on the nonnative sucker and minnow. It remains to be seen how effective a predator the Yellowstone Lake cutthroat can become after an evolutionary history of several thousand years during which it had little opportunity to feed on fish except its own young.

I believe that S. c. bouvieri, in general, is more of an innate predator than is S. c. lewisi. Above Shoshone Falls, the bull trout and squawfish were absent, and the cutthroat historically was the only large predator species. In Goose Creek, Nevada, the last major tributary to the Snake River above Shoshone Falls, I found that fish remains made up almost 100 percent of the stomach contents of the cutthroat trout over 12 inches. In the main Snake River, just upstream from Shoshone Falls, cutthroat trout in the 15 pound size range have been reported by anglers and Idaho Department of Fish and Game personnel.

Ionce examined two specimens from this area that weighed about 4 and 5 pounds. My attention was called to these trout because it was claimed that normally spring-spawning trout enter the fall-winter period with gonads at an advanced state of maturity, ready to spawn as soon as water temperatures rise in the spring. The two specimens sent to me on November 19, were taken from a spawning redd in a spring-fed tributary of a constant temperature of 48 degrees. Evidently, the movement from the colder Snake River into the warmer 
waters of the tributary initiated the November spawning. These large trout above Shoshone Falls are cutthroat $x$ rainbow hybrids (based on my specimens), but the cutthroat phenotype predominates. The fish were large and silvery, obscuring the spotting pattern to such an extent that I could not decide if the orignal cutthroat ancestor of this area was S. c. bouvieri or the fine-spotted subspecies.

Other reports from Colorado, Wyoming, Idaho, and Montana of "Yellowstone" cutthroat reaching 12 to 16 pounds may be based on hybrids. Yellowstone Lake cutthroat were stocked into Strawberry Reservoir, Utah, soon after its creation, and a 27 pound "cutthroat" is recorded from this reservoir (Platts, 1957). Strawberry Reservoir trout are still used for the bulk of cutthroat trout eggs propagated in Utah. I examined a series of specimens taken from the spawning run in 1972 and determined that the Strawberry Reservoir cutthroat trout is a hybrid between Yellowstone Lake cutthroat and rainbow trout, but is predominantly Yellowstone cutthroat.

In lake environments, S. c. bouvieri, as does the cutthroat species as a whole, suffers a high mortality after spawining, and if a female survives to spawn a second time, it typically occurs two years later. It takes that long to accumulate sufficient energy reserves to develop the ova. This is comparable to the spawning regime of anadramous salmonids. Small, resident stream trout typically spawn every year.

The maximum age is variable and greatly influenced by environmental factors. In Yellowstone Lake the maximum age appears to be VII, though few fish attain this age. This maximum age is comparable to most cutthroat trout subspecies recorded in the literature. However, in South Gap Lake, Wyoming, I examined introduced Yellowstone Lake cutthroat trout of age X and XI. South Gap Lake is in the Snowy Range at an elevation slightly over 11,000 feet. It probably has only about 90 ice-free days per year. Under this frigid regime, metabolism and growth processes are slowed and the life span is extended. At age X and XI, these trout were only 11 to 13 inches long.

Another interesting phenomemon observed in the Yellowstone Lake trout in South Gap Lake is that the average number of basibranchial teeth increased from the parental average of 22 in Yellowstone Lake to 33 in the fish stocked into South Gap Lake. Evidently this is due to the extremely slow growth that greatly extends the time it takes to reach 80 to $100 \mathrm{~mm}$ when the definitive number of teeth is attained. This is the only example of many comparisons showing a significant difference between a parental and introduced population in basibranchial teeth number.

I know of two examples in which Yellowstone cutthroat trout coexist with rainbow trout without massive hybridization. In the Yellowstone River below the falls in Yellowstone National Park, both rainbow and native cutthroat trout coexist and remain distinct. Although some of the characters of the cutthroat indicated that they are not pure, a hybrid swarm has not developed here. Evidently in this big river environment, niche diversity is such that the maintenance of both species is favored. In a small tributary stream, Elk Creek, I found a typical hybrid swarm.

The other example is in Buffalo Bill Reservoir on the Shoshone River, a tributary of the Yellowstone in Wyoming. The angler's catch from this reservoir includes native Yellowstone cutthroat, rainbow trout, and fine-spotted Snake River cutthroat trout, which are stocked annually. Natural reproduction occurs in the Shoshone River drainage above the reservoir, but obvious hybrids are not common. It will be interesting to note if the fine-spotted Snake River cutthroat trout can maintain itself from natural reproduction and remain distinct from both the Yellowstone cutthroat trout and the rainbow trout. Such situations where native cutthroat trout do coexist with introduced rainbow trout in interior waters without massive hybridization are rare.

\section{STATUS}

S. c. bouvieri, compared with most other subspecies, is doing well. In the upper Snake river drainage it is still relatively common above Jackson Lake, but has been largely replaced or hybridized in most of the downstream tributaries below Palisades Reservoir. The cutthroat trout is still the dominant trout in Henry's Lake and the Teton River, Idaho, although these populations have been slightly hybridized. In the Yellowstone drainage above the falls, the native cutthroat is still the only trout. As previously mentioned, the upper Yellowstone area has the greatest concentration of interior cutthroat trout still existing in their natural environment with no nonnative trouts. The vulnerability of the cutthroat trout to angling is the basis for a popular catch-and-release fishery on the Yellowstone River below the lake. Before 1974, a 14 inch size and 3 trout per day limit resulted in virtually no trout more than 14 inch left by the end of the season. Presently, 16 to 20 inch cutthroat are common in this same stretch of water (Yellowstone River below Mud Volcano). 
Below the falls of the Yellowstone, rainbow and brown trout soon become dominant, and pure populations of S. c. bouvieri are rare in both Montana and Wyoming.

Since the egg-taking operations at Yellowstone Lake ended about 1955, the propagation of pure bouvieri nearly came to an end. In recent years in Wyoming, interest in restocking of the Wind River lakes (Big Horn drainage of the Yellowstone/ with native trout has led the Wyoming Game and Fish Department to take fish from South Paintrock Creek, an isolated tributary of the Big Horn River, to establish a brood stock of S.c. bouvieri. I identified the South Paintrock Creek trout as a pure population in 1972. The Montana Fish and Game Department maintains a small brood stock, originally derived from Yellowstone Lake, for stocking lakes in the Yellowstone drainage. 


\section{FINE-SPOTTED SNAKE RIVER CUTTHROAT TROUT, Salmo clarki subsp.}

\section{TYPICAL CHARACTERS}

The most diagnostic trait of this undescribed subspecies is the unique spotting pattern. This trout has the smallest spots found in any of the trouts native to western North America. The spots are profuse and resemble a heavy sprinkling of ground pepper on the sides of the fish. Other characters are similar to Yellowstone cutthroat trout, except for a tendency for more yellowish colors and orange or red lower fins.

\section{DESCRIPTION}

When I first compared samples of the Yellowstone cutthroat trout, S. c. bouvieri, from the headwaters of the Snake River (Heart Lake) with samples of fine-spotted cutthroat from more isolated localities, I found significant differences in some characters. However, as more and more samples from throughout the ranges of the fine-spotted and Yellowstone cuttrhoat in the upper Snake River drainage were analyzed, all clear-cut distinctions broke down except for the consistent difference in spotting between the two subspecies.

Heavy stocking of rainbow trout and Yellowstone cutthroat trout has historically occurred within the range of the fine-s potted trout, and, in more recent times, the fine-spotted cutthroat has been propagated in large numbers by the Jackson, Wyoming, National Fish Hatchery and by Wyoming Game and Fish Department hatcheries and stocked into the range of the large-spotted Yellowstone cutthroat in the upper Snake drainage. Thus, it can be assumed that some hybridization has occurred and some of the variability in taxonomic characaters are not completely natural.

Despite introductions of rainbow trout and forced mixing between the two cutthroat trout subspecies, the two forms of native cutthroat trout remain phenotypically distinct and are still the dominant trouts in most of their native ranges above Palisades Reservoir in the Snake River. Murphy (1974) found lateral series scale counts ranging from 136 to 188, with mean values of 153 to 176 in six samples of fine-spotted cutthroat. Pyloric caeca numbers ranged from 32 to 51 , with mean values of 39 to 46 . Vertebrae number ranged from 60 to 65 , with means of 61.4 to 62.9. Basibranchial teeth ranged from 4 to 30 with means of 12 to 18 . This high degree of variation indicates some hybrid influence on the stock samples. The degree of differences between samples and observations on size-age groups from different localities shows clearly that the fine-spotted Snake River cutthroat is not a single homogeneous entity, but consists of many discrete stocks, reproductively isolated from each other, although all living in a continuous environment.

The basic coloration of the fine-spotted cutthroat is similar to that of the Yellowstone cutthroat trout with predominantly yellowish-brown, sometimes silvery colors. Faint rose tints may appear on mature fish, and the lower fins can develop orange or red colors. The distribution of the spots on the body is similar to that of interior cutthroat trout in general with the greatest concentration of spots on the caudal peduncle area and above the lateral line anterior to the dorsal fin.

\section{DISTRIBUTION}

The distribution of the fine-spotted Snake River cutthroat is most unusual in that it is not isolated from another subspecies (the Yellowstone cutthroat). All other subspecies are geographically isolated from each other.

The present distribution extends in the Snake River from below Jackson Lake to Palisades Reservoir in all tributaries from the Gros Ventre to the Salt River. Below Jackson Lake, the first three tributaries, Pacific Creek, Buffalo Fork and Spread Creek, have Yellowstone trout as the native trout, and populations of both subspecies occur in the Gros Ventre drainage (Yellowstone cutthroat in headwater tributaries and finespotted cutthroat in rest of drainage). I have not encountered an area where the two forms exist together year-round. Somehow they are able to partition the upper Snake River drainage between them and avoid massive hybridization.

Before a dam was constructed to raise the level of Jackson Lake, there was no barrier from the Snake River below the lake into the lake. It is not known if the Yellowstone cutthroat, fine-spotted cutthroat, or both were native to Jackson Lake. Only Yellowstone cutthroat appear to be na tive above the lake. Large numbers of fine-spotted cutthroat of hatchery origin have been stocked into Jackson Lake and the Snake River above 
the lake. Cutthroat trout became scarce in Jackson Lake after the lake trout, Salvelinus namaycush was established.

Before the dam creating Palisades reservoir was constructed, it was not known how far downstream the original distribution of the fine-spotted cutthroat extended. In all the tributaries to the Snake River below Palisades Reservoir to Shoshone Falls, from which I have examined specimens, the Yellowstone cutthroat is the native trout.

How this distribution between two distinct forms of closely related cutthroat trout originated, and how it has been maintained without hybridization into a single intermediate form despite forced mixing, is one of the most fascinating questions yet to be explained concerning the systematics and biology of cutthroat trout.

\section{TAXONOMIC NOTES}

The ability to maintain reproductive isolation when occurring in a continuous environment conforms to most definitions for recognizing species. Recognizing distinct, but related groups as species or subspecies is generally based on the degree of reproductive isolation between them. If the two related groups are geographically isolated, but known or assumed hybridization occurs if they live together, the two groups are recognized as two subspecies of one species. If the two groups maintain their distinctions when together in a continuous environment, as do the fine-spotted and Yellowstone cutthroat trouts in certain areas of the Snake River drainage, they are usually recognized as separate species.

I do not believe reproductive isolation is complete because of the transition and overlap in taxonomic characters and the occasional specimen with intermediate spotting indicate some hybridization does occur. Because of the close genetic relationships shown by Eric Loudenslager's research at the University of Wyoming, where not a single one of the 22 gene loci examined differed between the fine-spotted cutthroat and the Yellowstone cutthroat of both the upper Snake River and Yellowstone Lake, I believe it prudent to consider the fine-spotted cutthroat as a subspecies of $S$. clarki, rather than as a distinct species. It is undoubtedly derived from the cutthroat trout evolutionary line, probably in recent geological times from the Yellowstone subspecies ancestor. I have previously discussed (Behnke, 1972) the problem of recognizing species solely on the basis of reproductive isolation. There are countless examples of Salmonid fish, with strong homing instincts, in which minute genetic divergence has resulted in reproductive isolation.

When I first became familiar with the fine-spotted Snake River cutthroat trout, the striking difference in spotting led me to consider that the direct ancestor of the fine-spotted cutthroat may have been a coastal cutthroat trout that penetrated the upper Snake River before Shoshone Falls was formed, but after the Yellowstone trout had become establishd there. A check of the chromosomes of the fine-spotted trout proved them to be identical to those of Yellowstone cutthroat, and that theory of origin was discarded (Behnke, 1970). I then considered that the direct ancestor may have been S. c. lewisi, derived by stream transfer from the upper Salmon River, across the present Snake River Lava Plateau. From Loudenslager's gene loci study, indicating the close relationship between the fine-spotted and Yellowstone cutthroat trouts, and Dr. Allendorf's work indicating a much more distant relationship between Yellowstone cutthroat and S.c. lewisi, I have concluded that the fine-spotted cutthroat trout originated from the Yellowstone cutthroat during the last glaciation in the upper Snake River area.

Dr. J. D. Love, U.S. Geological Survey, University of Wyoming, is an authority on the geological history of the upper Snake River and Yellowstone area. Dr. Love explained that there were several opportunities during the late Pleistocene period for an ancestral cutthroat trout stock to fraction into isolated units in glacial ice dam lakes and landslide lakes in the upper Snake River system. Evidently, after some thousands of years of isolation, the ancestral Yellowstone trout and the new form, slightly differentiated by its isolation, came together again, but instead of freely hybridizing, were able to establish reproductive isolation and maintain their distinctions. Once in contact, evolutionary mechanisms governed by natural selection, probably greatly emphasized the spotting differentiation.

Why has such a distinctive trout never been officially described as a new species or subspecies? The answer seems to be that because of their restricted distribution, the fine-spotted trout was overlooked by early ich thyologists. Jordan, Evermann, and Gilbert collected fish in the upper Snake River drainage between 1889 and 1895. Jordan came down the Snake River from its headwaters (Heart Lake) to "President Camp" above Jackson Lake. Evermann came over the Continental Divide and down Pacific Creek. In these localities, 


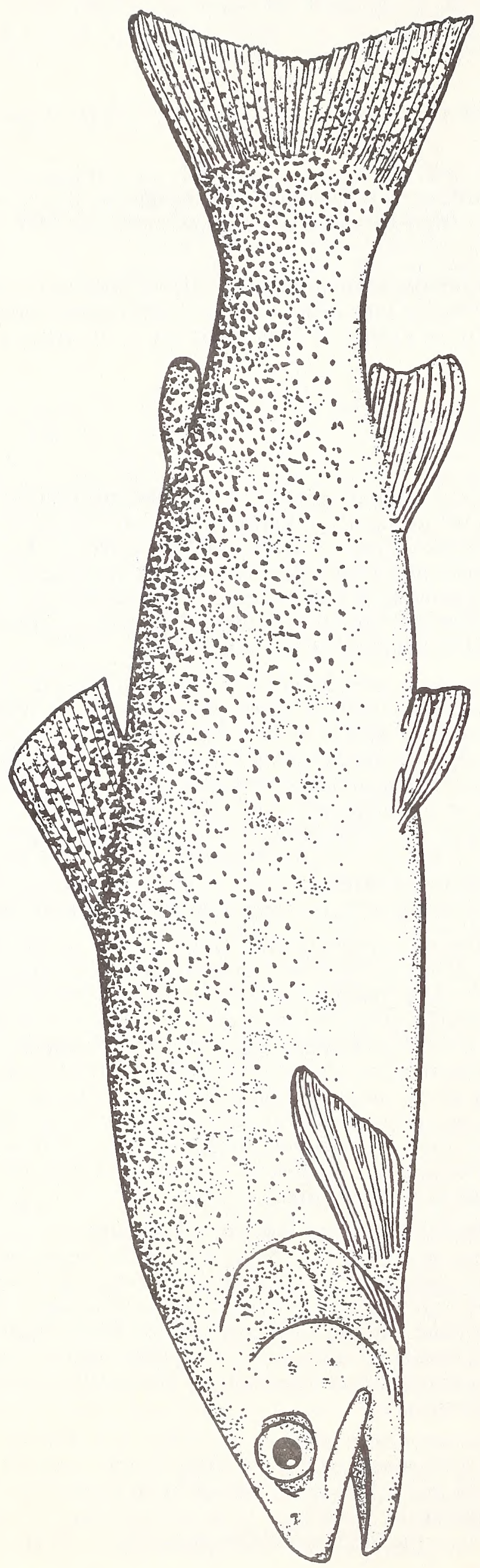

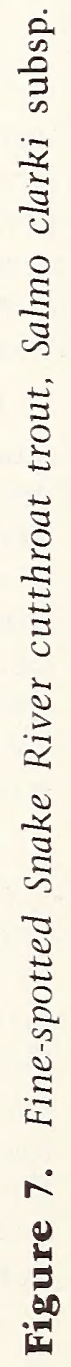


only the Yellowstone cutthroat trout collected by Jordan and Evermann are native. Evermann and Gilbert collected farther downstream, but those localities too (Portneuf and Henry's Fork drainages) have only the Yellowstone cutthroat.

Baxter and Simon (1970) presented a photograph of the fine-spotted Snake River cutthroat trout and mentioned that it has never been formally described, but is worthy of recognition.

\section{LIFE HISTORY AND ECOLOGY}

Kiefling (1978) has comprehensively reviewed the life history and ecology of the fine-spotted cutthroat.

In the Snake River from Jackson Lake to Palisades Reservoir, the fine-spotted cutthroat trout supports a major sport fishery. Formerly, it made up about 97 to 99 percent of the trout catch of the Palisades Reservoir, but an outbreak of infestation by a nematode parasite of the genus Philonema, has severely affected the reservoir population in recent years. According to the 1975 Palisades Reservoir Fisheries Investigation of the Idaho Department of Fish and Game, the cutthroat trout still made up 84 percent of the catch. Since the outbreak of the parasite, the brown trout, $S$. trutta, which suffers much less infestation because it does not feed on the zooplankton crustacean intermediate host of the parasite to the extent that the cutthroat does, has greatly increased its numbers.

The greater vulnerability of the cut throat to angling is illustrated by comparing the angler catch of the gill net samples of Palisades Reservoir in 1975. The cutthroat trout made up 84 percent of the anglers catch and brown trout made up 15 percent, but in the gill nets, the cutthroat made up on 28 percent of the trout caught. As mentioned, the fine-spotted trout is not a single homogeneous stock in the Snake River drainage, but consists of discrete populations. There are two basic life history types. In the main Snake River, the trout migrate to tributaries for spawning, with the young moving to the main river for growth and maturation. Also in tributary streams, resident (nonmigratory) stocks are found. The population structure and interaction between discrete stocks to make the most effective use of the total environment is complex and perhaps of a delicate balance that could be upset by environmental modifications.

The importance of the fine-spotted Snake River cutthroat trout to Wyoming's fishery program has resulted in a series of studies on the ecology of this trout by the Wyoming Game and Fish Department, such as the works of Wiley (1969), Kiefling (1973), and the definitive report by Kiefling (1978).

As discussed by Troinar and Behnke (1974), the evolutionary programming of the fine-spotted Snake River cutthroat trout, influenced by its historical coexistence with a variety of fish species in a big river environment, has resulted in a trout with a wide range of adaptive responses that allow for successful introductions into diverse environments. After the study by Trojnar of the Snake River cutthroat in a Colorado Lake, Paul Sekulich, one of my former graduate students, continued the study of the fine-spotted trout's adapatability to new environments by following their growth and feeding habits in three reservoirs on the Uinta Indian Reservation, Utah (Sekulich, 1974). In different environments, the Snake River cutthroat opportunistically exploits the major food resources and readily changes from benthic to pelagic or to surface feeding. At a size of 12 to 14 inches, large organisms like fish and crawfish dominate the diet, if available, and the growth rate rapidly increases. I have raised the fine-spotted cutthroat trout in a small pond on my property in Fort Collins, which, with an abundance of crawfish, have reached 21 inches and over 4 pounds at age III.

The fine-spotted Snake River cutthroat may not be well adapted to life in small streams, Mullan (1975) demonstrated a poor condition factor for these trout stocked in small streams on the Uinta Indian Reservation.

This trout is now widely propagated in hatcheries and widely distributed outside its original range. I believe that as more studies are made on introduced stocks of Snake River cutthroat trout, along the lines of the research of Trojnar and Behnke (1974) and Sekulich (1974), the stereotyped image of "cutthroat trout" in fisheries management, based on Yellowstone Lake cutthroat, will change. It will then be realized that the tremendous genetic diversity found within the species $S$. clarki can be manifested in more practical ways than merely as criteria for identifying one subspecies from another by the differences in spots and coloration. 


\section{STATUS}

The fine-spotted Snake River cutthroat trout is the only subspecies of $S$. clarki that is presently more abundant than it was historically. There has been no marked reduction in abundance within its known historical range, and the widespread propagation and introduction outside its native range has increased its historical abundance.

Probably all fine-spotted cutthroat stocks have been exposed to hybridization with both Yellowstone cutthroat trout and rainbow trout, but they have resisted the effects of hybridization to an amazing degree. Hybrid-appearing specimens are most common in disturbed habitat like the unstable environment at the mouth of Spread Creek. For all practical purposes, the "purity" of any particular stock of fine-spotted cutthroat trout can be judged on the basis of uniformity and consistency of the spotting pattern. 


\section{THE MOUNTAIN CUTTHROAT TROUT, S. c. alpestris}

\section{TYPICAL CHARACTERS}

Typical characters are not definitely known because taxonomic data is based on only five specimens from two localities. From my examination of four specimens, I found S. c. alpestris to be similar to S. c. lewisi except for higher than average scale counts (195-210), more pored scales in lateral line (145-150), and numerous basibranchial teeth (15-40).

\section{DESCRIPTION}

S. c. alpestris, named by Dymond (1931), is the most recently described subspecies of cutthroat trout. Dymond described the Mountain cutthroat trout form a few isolated localities in the Upper Columbia basin and a few sites in headwater tributaries of the Fraser River basin, British Columbia. Virtually all of these localities are isolated by falls, and relict interior cutthroat trout populations were found above the falls but have been replaced in intervening waters by the redband or "Kamloops" trout (Dymond, 1931, 1932). However, Dymonds's description of the taxonomic characters is based on only a few specimens from Canyon Creek and Isaac Creek, near Revelstoke, British Columbia, and it is not known if the distinguishing characters apply to all of the populations considered to be alpestris by Dymond.

The most diagnostic trait differentiating alpestris from other subspecies, according to Dymond, is the high number of scales in the lateral series (200-230). I examined four specimens from Isaac Creek, borrowed from the University of British Columbia and from the Royal Ontario Museum. Although the specimens are faded and the precise spotting pattern is difficult to determine, I would consider these specimens to be $S$. $c$. lewisi. My lateral series scale counts (195-207) are lower than those given by Dymond, but higher than found in most S. c. lewisi (except for the sample previously mentioned from the Clearwater drainage in Idaho). The four Isaac Creek specimens have numerous basibranchial teeth (15-40), but the most distinctive trait is the high number of lateral line pored scales, which lie along the lateral line and bear pores from the lateral line system. Almost all western trouts have 120-125 scales in the lateral line, seldom more than 130 . The Isaac Creek specimens I examined have 145, 146, 149, and 150 lateral line scales.

Using the example of the trout of Sedge Creek in Yellowstone National Park, small, isolated populations may rapidly evolve highly divergent characters. It is not known if the distinctive scale counts and high number of basibranchial teeth are characteristic of all of the populations considered to be alpestris by Dymond or if they are restricted to the Isaac Creek trout.

\section{DISTRIBUTION}

Dymond's complete list of British Columbia localities for alpestris includes three small streams near Revelstoke, small lakes and two stream tributary to Kootenay Lake, two lakes in the Nelson area, and three streams and a lake in the Shuswap area of the upper Fraser River basin. This distribution pattern, represented by sporadic and disjunct occurrence of relict populations of interior cutthroat trout below the major barrier falls of the upper Columbia basin, eastward to the Cascade Mountains, is also found in Washington and Oregon. Are all of these disjunct populations derived from a single ancestor (lewisi, bouvieri), or from a hybrid combination of the two? The natural distribution of cutthroat trout of this vast region and their correct classification remains essentially unknown. Introductions of nonnative trouts and mixing of races of cutthroat trout in hatchery propagation will make any future study of the distribution and taxonomy of these relict cutthroat trout exceedingly difficult.

\section{TAXONOMIC NOTES}

S. c. alpestris has not been generally accepted as a valid subspecies. Quadri (1959) and Carl et al. 91971) considered alpestris to be a synonym of S.c.lewisi. On zoogeological grounds, such an assumption is logical. S. c. lewisi is native to all of the upper Kootenay River drainage where it was historically isolated from contact with redband trout. It would be expected that the disjunct, isolated populations of cutthroat trout in tributaries to Kootenay Lake and in other upper Columbia River basin localities are part of a once 
continuous distribution of S. c. lewisi that was replaced by the redband trout. If this distribution was once continuous along the glacier fronts during the last ice age, there has been no opportunity for "alpestris" to be long isolated in geological time from the continuous distribution of S. c. lewisi.

During the last ice age, about 10,000 to 50,000 years ago, the maximum extent of the Cordilleran Ice Sheet reached into northern Washington and completely covered the entire range of "alpestris" in British Columbia. It is possible that a third evolutionary group (subspecies) of interior cutthroat trout, derived from an early branching of either the lewisi or bouvieri evolutionary lines was associated with the waters of the middle Columbia basin east of the Cascades Mountains and moved northward into the present range of alpestris after the glaciers retreated. Until known native populations of cutthroat trout are found and critically analyzed from this area in Oregon, Washington, and British Columbia, the validity of alpestris and the correct classification of cutthroat trout from this whole middle-upper Columbia basin area, outside the known range of lewisi and bouvieri, can only be a matter of speculation.

A specimen of the Oregon State University collection (3329) from the John Day River drainage is of interest. The Deschutes and John Day rivers are the first major tributaries of the Columbia River east of the Cascade Mountains. It is uncertain whether cutthroat trout are native to the John Day drainage, but the specimen collected in 1953 from Indian Creek east of the town of John Day, Grant County, Oregon, has a distinctively high scale count of 217 scales in the lateral series. The specimen is small (about 6 inches) and faded, but the spotting pattern is more typical of le wisi than of bouvieri. This specimen has 13 basibranchial teeth. If true native cutthroat trout populations could be found in the John Day, Umatilla, Walla Walla, Yakima, and Lake Chelan drainages of the middle Columbia basin from lower Snake River tributaries such as the Imnaha, Grand Ronde, and Palouse drainages, and from the Columbia basin of British Columbia, the riddle of the correct classificaiton of the middle Columbia basin cutthroat trout could be solved and the validity of alpestris determined.

\section{LIFE HISTORY AND ECOLOGY}

All that can be said has been mentioned by Dymond (1932) based on some limited observations. The diet of specimens from small streams was made up entirely of insects. The populations are abundant and the growth rate is slow. The largest observed specimen of alpestris was about 14 inches long.

\section{STATUS}

If the name "alpestris" is provisionally used to include all of the disjunct relict populations of the middle Columbia basin, then little is known about the original distribution and abundance. The taxonomic status and present survival status of this group or groups of cutthroat trout is also unknown. Any future study will have to determine whether a population is truly native or introduced, and if native, whether or not it has been influenced by hybridization.

Undoubtedly, most of the original native populations of cutthroat trout of the middle Columbia basin have been replaced or hybridized by nonnative trouts. In the Oregon State University collection, five specimens from Canyon Creek, a neighboring tributary to Indian Creek in the John Day drainage, are rainbow $\mathrm{x}$ cutthroat hybrids. If the middle Columbia basin cutthroat should prove to represent one or more valid subspecies, they would likely qualify as a "threatened species" under the Endangered Species Act. Their historical occurrence was always rare and sporadic since their replacement by redband trout after the last glacial period, and propagation practices and introductions have likely pushed them to the brink of extinction. 


\section{CUTTHROAT TROUT OF THE GREAT BASIN}

The Great Basin of the western United States as defined by Hubbs and Miller (1948) consists of many separate, internal drainage basins without present connections to the ocean. The major area of the Great Basin with native cutthroat trout is roughly bounded by the Sierra Mountains of California on the west, the Columbia River basin on the north, and the Colorado River basin on the east and south. During the last ice age, about 8,000 to 75,000 years ago, large lakes existed in these separate basins. The largest of these ancient lakes were Lake Bonneville, which at maximum level, was approximately the size of present day Lake Michigan, and Lake Lahontan, about the size of present day Lake Erie. My formal research on Salmonid fishes began with a study of the cutthroat trouts of the Great Basin for my M.A. thesis (Behnke, 1960). When I began my study of Great Basin trouts in 1958, it was commonly believed that the Lahontan cutthroat, S. $c$. hewshawi, and the Bonneville cutthroat, S. c. utah, were extinct as pure populations.

An interesting group of cutthroat trout, which I have divided into six subspecies, are native to three basins of the Great Basin: the Lahontan basin with three subspecies, the Alvord basin with two subspecies, and the Bonneville basin with a single subspecies. These three basins have been long isolated from direct contact with the Columbia River basin. An interior cutthroat trout ancestor gained access to these basins before they became completely isolated from contingous drainages. The subsequent isolation protected the Great Basin cutthroat trout from contact with redband trout. In several separate basins of the Great Basin in Oregon, north of the Lahontan basin and west of the Alvord basin, redband trout evidently completely replaced cutthroat trout.

The bull trout, Salvelinus confluentis, and the Columbia River squawfish did not become established in Great Basin waters; thus, the cutthroat trout was the only large predatory fish amid many species of minnows and suckers in the ancient lakes. This evolutionary programming to specialize as a large lake predator is particularly imprinted in the genotype of the Lahontan cutthroat, S. c. henshawi.

About 8,000 years ago, the large lakes of the Great Basin dried up to about present conditions, with a few remnant waters such as Pyramid Lake, Nevada, and Great Salt Lake, Utah. The evolutionary specialization as large, lacustrine predators made the Lahontan cutthroat trout, henshawi, the Bonneville cutthroat trout, S.c. utah, and the two undescribed subspecies native to the Alvord basin ill-adapted to life in small stream environments where these subspecies were mainly restricted after the desiccation of the ancient lakes. Under these circumstances, the cutthroat trouts of the Great Basin were extremely vulnerable to replacement by nonnative trouts and rapidly disappeared form streams once nonnative trouts were stocked.

I have noted two exceptions to this general rule of replacement of native Great Basin trout by nonnative trouts: the cutthroat trouts native to the two largest river systems in the Great Basin, the Humboldt River drainage of the Lahontan basin, and the Bear River of the Bonneville basin. Evidently the native trout of the Humboldt and Bear river drainages were river specialized rather than lake specialized trout. I believe they were nonmigratory stream trout, even during the time of the ancient lakes. The semiarid climate characterizing much of the Humboldt and Bear river drainages during the past several thousand years resulted in unstable and highly fluctuating environments in regard to flows and temperatures. The native cutthroat trout still found in areas of the Humboldt and Bear River drainages have successfully resisted replacement or hybridization by nonnative trouts. Many of the habitats where native cutthroat trout still flourish in the Humboldt and Bear river drainages would be considered marginal or submarginal trout waters by most standards.

The native cutthroat trout of the Humboldt River drainage of Nevada is sufficiently differentiated from the Lahontan cutthroat, S. c. henshawi, to be recognized as a separate subspecies. The Bear River cutthroat trout is only slightly differentiated from the rest of the Bonneville basin cutthroat trout, and I believe it represents a river specialized form of S. c. utah.

The other subspecies of Great Basin cutthroat trout include the Paiute trout, native to only one tributary to the East Fork of the Carson River of the Lahontan basin, and two undescribed subspecies native to separate sections of the Alvord basin. One of these subspecies is presumed extinct and the other survives in two streams.

The basic dull coloration (absence of bright red, orange or golden yellow) and rounded spots on the body of the Great Basin cutthroat trouts indicate that they all originated from a "Yellowstone cutthroat, S. $c$. bouvieri, kind of ancestor.

The Lahontan basin cutthroat trout exemplifies the need to preserve genetic diversity regardless of taxonomic status. The ecological adaptations of the native trout of the Lahontan basin are diverse. Only the original Pyramid Lake population probably retained the full range of genetic adaptations to be an effective predator that were acquired by their ancestors in Lake Lahontan. The Humboldt River cutthroat is adapted 
to survive in harsh and highly unstable stream environments. This diversity points out a serious flaw in the General Accounting Office's Report to Congress on endangered species (July 2, 1979). The GAO report recommends that the Endangered Species Act be amended to protect only those species that are endangered or threatened throughout all or a significant portion of their range. That is, local populations and subspecies would not be considered unless the species as a whole were endangered or threatened. The fallacy of such a course of action in relation to preserving the genetic diversity within a species is apparent from considering the components of the cutthroat trout species. 

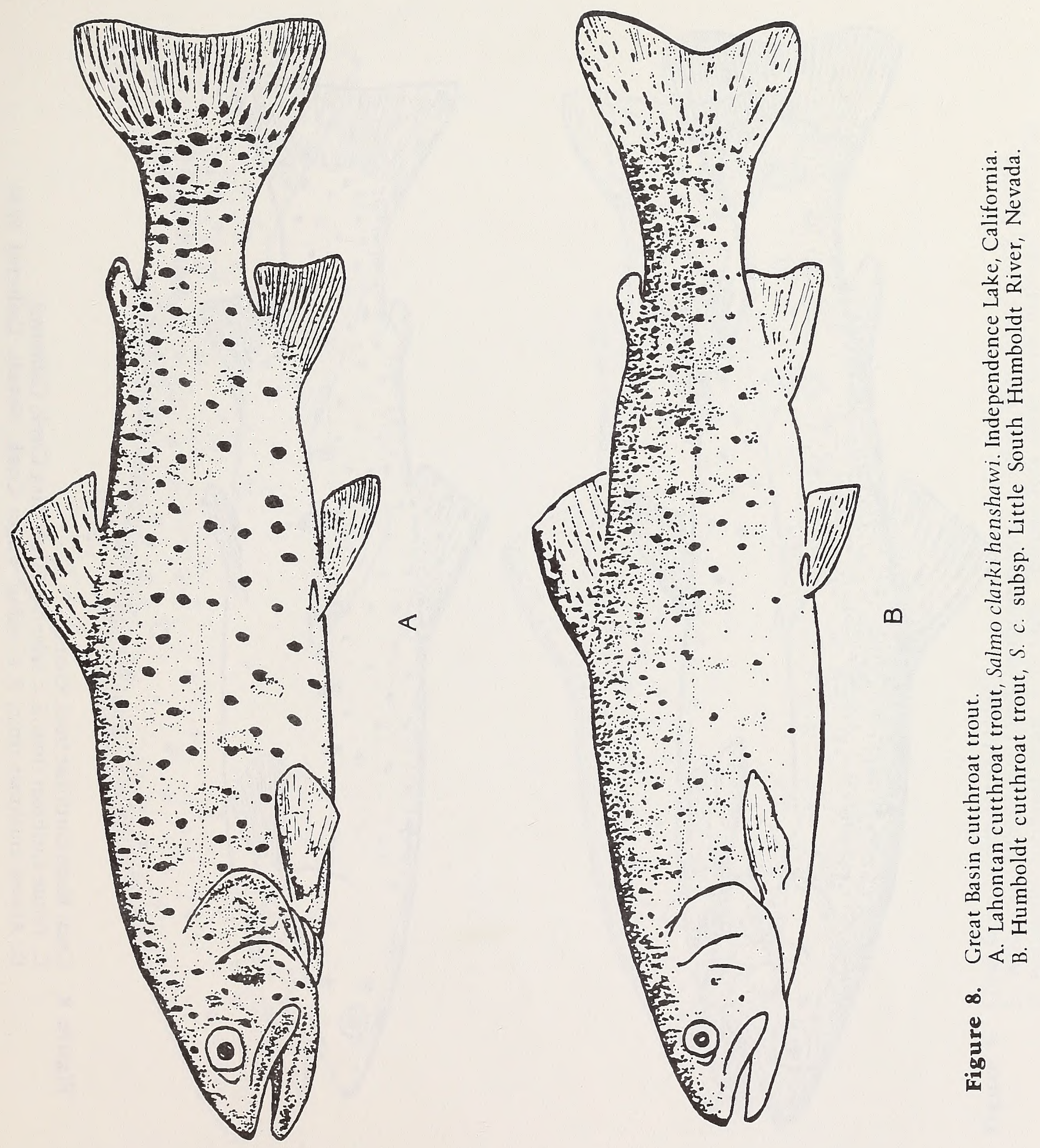

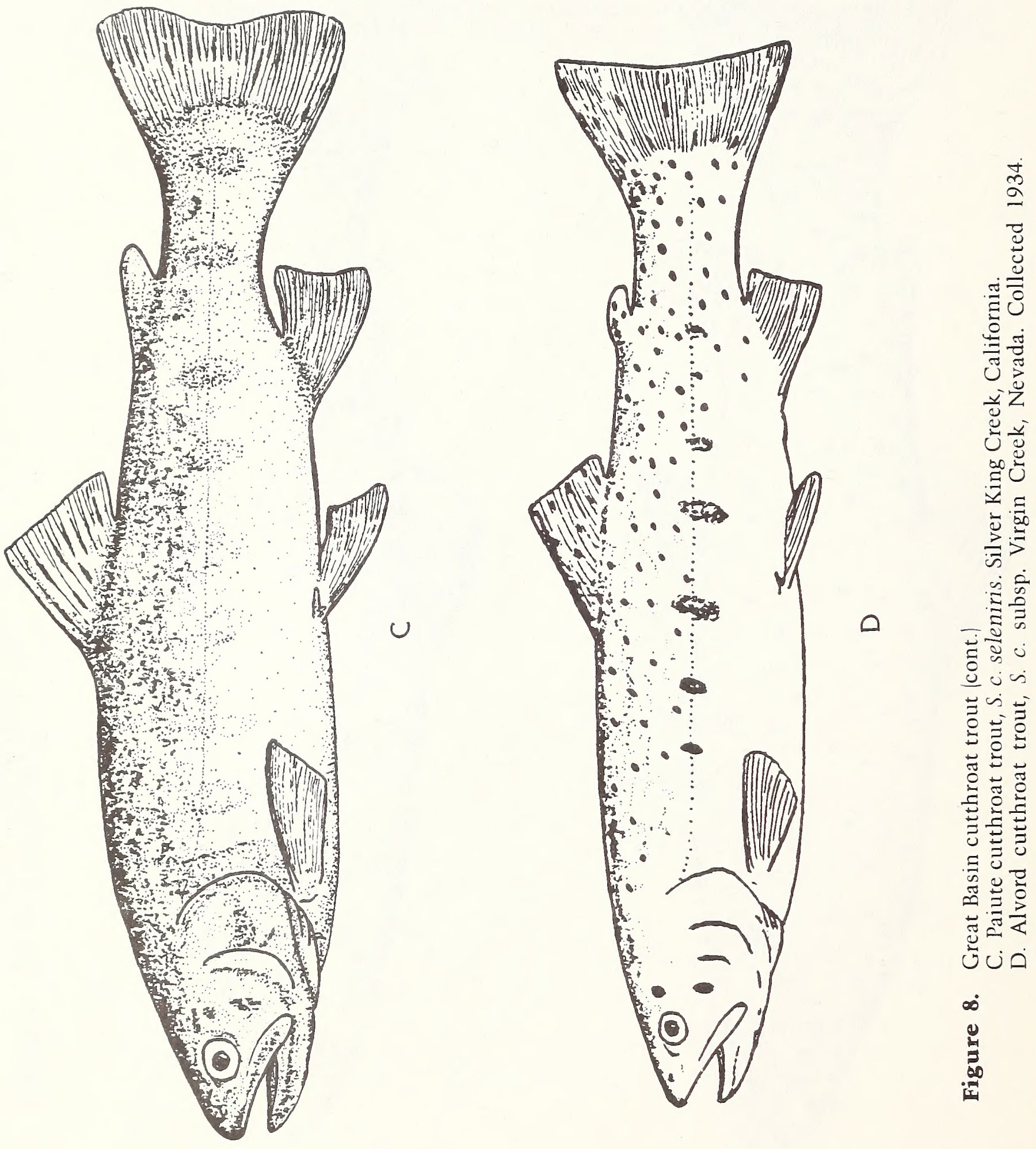

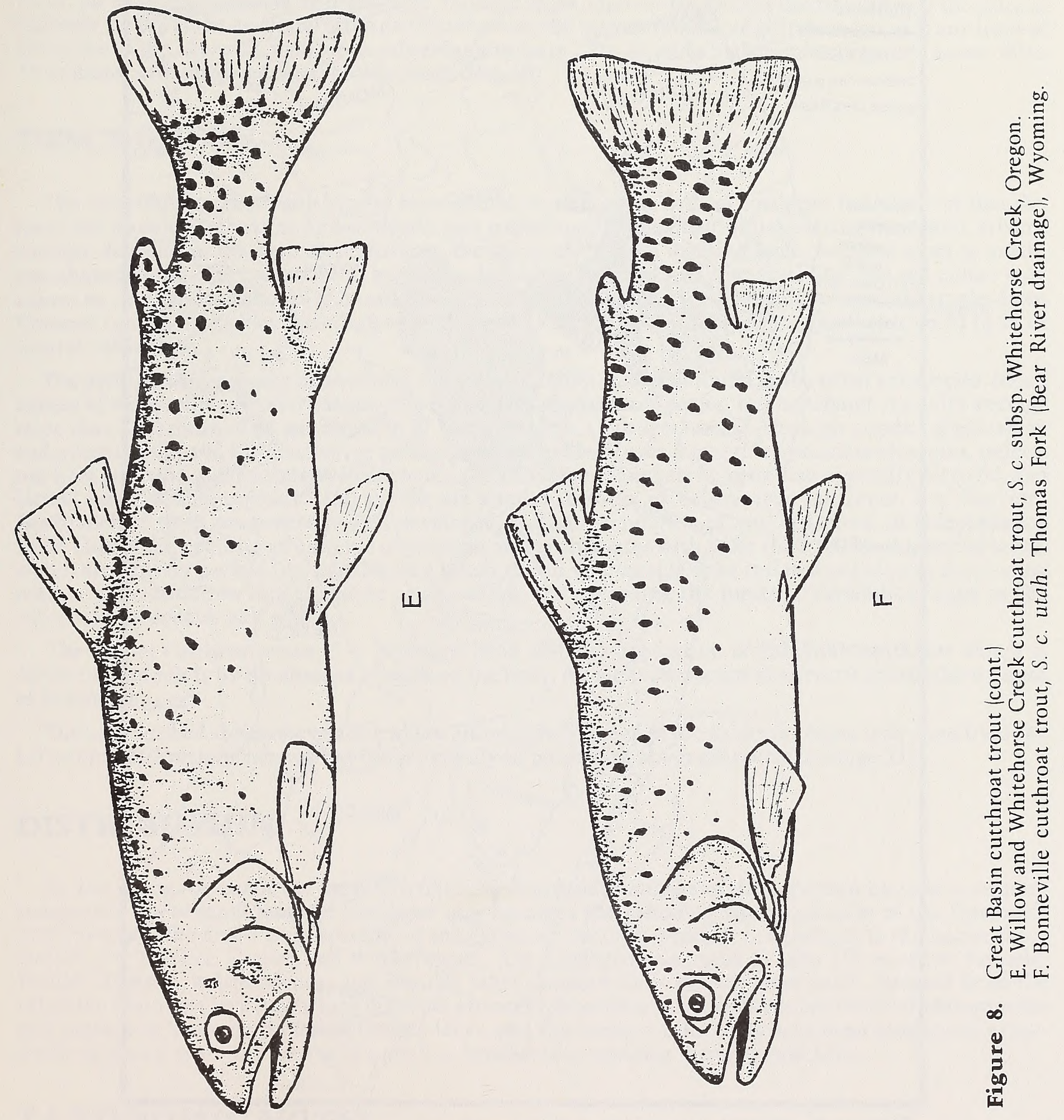


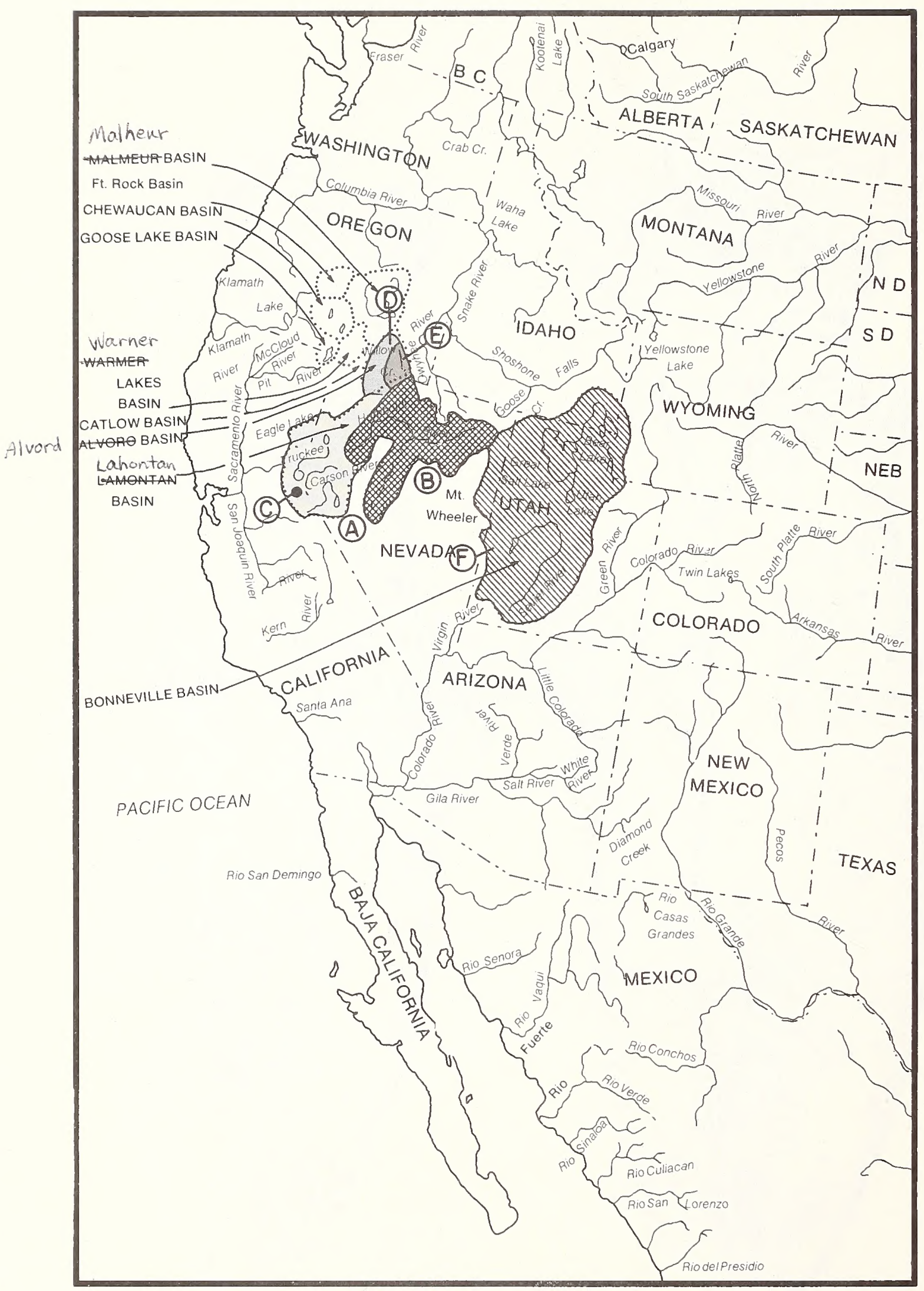

Figure 9. Distribution of Great Basin cutthroat trout. Three subspecies are native to Lahontan basin: Lahontan cutthroat [A] ; Humboldt cutthroat $[\mathrm{B}]$; Paiute cutthroat [C] $\bullet$. Two subspecies are native to Alvord basin: one (presumed extinct) subspecies is native to Alvord sump drainage [D] ; and the other is restricted to Willow and Whitehorse creeks [E] Only one subspecies is recognized for the Bonneville basin $[F]$ iltmill. 


\section{LAHONTAN CUTTHROAT TROUT, Salmo c. larki henshawi}

\section{TYPICAL CHARACTERS}

A combination of three characters distinguishes S. c. henshawi from all other subspecies of cutthroat trout: the spotting pattern of medium-large, rounded spots, more-or-less evenly distributed over the sides of the body, on top of the head, and often on the abdomen; the highest number of gillrakers found in any trout of the genus Salmo -21 to 28 , with mean values ranging from 23 to 26 ; and a high number of pyloric caeca - 40 to 75 or more, with mean values typically more than 50 .

\section{DESCRIPTION}

The spotting pattern of henshawi is most similar to that of the coastal cutthroat trout, except that the spots are rounded in outline and typically less numerous in henshawi. In lake-living henshawi, silvery guanine deposits in the skin can transform the spots, them from medium-large, rounded spots to small, star-shaped spots. The coloration is generally dull, similar to Yellowstone cutthroat, but red colors may appear on the sides and cheeks of henshawi. Snyder (1917) described the operacula of spawning males from Pyramid Lake as being like "glowing coals". The gillrakers are well developed and number from 21 to 28 in several collections.

The pyloric caeca number in henshawi is generally higher than that found in any other subspecies. Mean values of 45 or more are rarely found in populations of other subspecies, but henshawi typically average more than 50 (a mean of 66 was found in 17 Donner Creek, Utah specimens). The high number of gillrakers and pyloric caeca and the distinctive spotting pattern evidently are lacustrine specialized features, reflecting long isloation and evolution in ancient Lake Lahontan. Numbers of vertebrae, typically 60 to 63 , and lateral series scales, typically 150 to 180 , are similar to those of Yellowstone cutthroat, $S$. c. bouvieri. Basibranchial teeth are generally well developed, but one population of $S$. $c$. henshawi, in Independence Lake, California, exhibits an extreme expression of this character with more than 100 basibranchial teeth, which are densely packed like bristles on a brush. Again, an example of an isolated population developing marked differentiation in a character or characters and exceeding the limits of variability found in the subspecies or species as a whole.

The Paiute cutthroat trout, S. c. seleniris, is an isolated population of Lahontan cutthroat which is differentiated solely by the absence of spots on the body. All other characters of seleniris are similar to those of henshawi.

The undescribed subspecies native to the Humboldt drainage of the Lahontan basin is derived from the Lahontan cutthroat, henshawi, but differs mainly in possessing fewer gillrakers (average 21 ).

\section{DISTRIBUTION}

By describing the cutthroat trout native to the Humboldt drainage of the Lahontan basin as a separate subspecies, the original range of henshawi now becomes the Lahontan basin exclusive of the Humboldt River system. The major river systems of the Lahontan basin in which $S$. c. henshawi is the native trout include the Truckee, Carson, and Walker rivers. S. c. henshawi was found in Lake Tahoe arid in Pyramid, Walker, Donner, Independence, and Summit lakes. Summit Lake is a separate basin, isolated from the Lahontan basin by a lava flow which diked off a former Lahontan tributary stream. Native cutthroat trout are still present in Summit and Independence lakes, and the Summit Lake trout have been propagated extensively in recent years as a source of pure S. c. henshawifor stocking into Pyramid Lake.

\section{TAXONOMIC NOTES}

The genetic basis for attaining the largest size of any subspecies of cutthroat trout could be considered a taxonomic character of S.c. henshawi. The original Pyramid Lake population of henshawi probably reached the greatest size of any western North American trout. The first published report on trout of the Lahontan basin (Fremont, 1845), reports how, in January 1843, Fremont's expedition reached Pyramid Lake and the 
Indians brought trout to his camp. The long trek across an expanse of barren desert may have influenced Fremont's opinion of the Lahontan cutthroat trout, which he referred to as "Salmon-trout", and about which he wrote: "Their flavor was excellent - superior, in fact, to that of any fish I have ever known. They were of extraordinary size - about as large as the Columbia River salmon - generally from 2 to 4 feet in length."

By 1870, the large size of Lahontan cutthroat trout had attracted the attention of fish culturists in California, and trout from Independence Lake and the Truckee River were being propagated in private hatcheries and by the California Acclimatization Society. The earliest literature indicates a general belief that there were two forms or species of Lahontan cutthroat trout in all of the lakes, a brown or black trout and a silver trout. One of the first tasks of the newly created California Fish Commission in 1870 was to attempt to classify the Lahontan cutthroat trout. Specimens of "Brown" and "silver" trout from Lake Tahoe and the Truckee River were sent to Seth Green, a noted fish culturist, who found them to be landlocked salmon, not trout.

The name "Salmo henshawi" was given by Gill and Jordan in 1878 in the second edition of Jordan's textbook, "Manual of the Vertebrates", based on a specimen from Lake Tahoe sent by the naturalist, H. W. Henshaw. Following the common belief that there were two species of Lahontan cutthroat trout, Jordan at first used the name henshawi to designate the "silver" trout of Lake Tahoe. He recognized the "black" Tahoe trout as "S. tsuppitch" (the name tsuppitch is a synonym of Oncorhynchus kisutch, the coho salmon). Later, Jordan and Evermann (1896) designated the "black" trout as S. mykiss henshawi, noting that the "silver" trout of Lake Tahoe did not deserve taxonomic recognition. Shortly thereafter, however, the "silver" trout was named S. clarki tahoensis (Jordan and Evermann, 1898). Snyder (1917) described two distinct spawning runs of cutthroat trout from Pyramid Lake up the Truckee River, but believed only one species was involved.

The question of the "black" and "silver" trout and whether more than one form of Lahontan cutthroat trout was native to Lake Tahoe and Pyramid Lake has never been definitely answered. The history of ancient Lake Lahontan was characaterized by several long-term fluctuations in lake level, which could have provided opportunities for isolation and incipient speciation, such as is found in the Humboldt River drainage subspecies. Thus, the possibility that the Lahonan cutthroat trout of Lake Taho and Pyramid Lake actually consisted of two groups, henshawi and tahoensis, must be recognized.

Based on my examination of specimens, I conclude that only a single group, henshawi, should be recognized. The type specimen of tahoensis does not differ in any way from henshawi (Jordan's gillraker count of 18 for tahoensisis in error; there are actually 25 gillrakers on the first left gill arch in the type specimen/. I can find no real indication of more than one form of cutthroat trout in many collections examined form the Truckee (including Lake Tahoe and Pyramid Lake specimens), Carson, and Walker river drainages. The belief that there were two "species" of native trout in Lake Tahoe was based on the difference in size between first spawning and repeat spawning fish, and differences in appearance between sexually mature and immature fish. Until 1931, California Game and Fish Department hatcheries separately propagated both henshawi and "tahoensis". 
As previously mentioned, "Salmo evermanni", described from the headwaters of the Santa Ana River, California, was based on S. c. henshawi introduced from Lake Tahoe. Snyder $(1914,1917)$ described three additional species of trout from the Lahontan basin, $S$. regalis, the "royal silver" trout of Lake Tahoe; $S$. smaragdus, the "emerald" trout of Pyramid Lake; and S. aguilarum, the Eagle Lake trout. I have published my opinion that $S$. smaragdus is based on an introduced rainbow trout, and that $S$. regalis is based on hatcheryproduced cutthroat $\mathrm{x}$ rainbow hybrids (Behnke, 1972).

The Eagle Lake trout is of particular interest. Eagle Lake is isolated from the Lahontan basin but was once tributary to it, and the native fish fauna are all Lahontan species except for the trout, which belongs to the rainbow-redband evolutionary lineage. The most logical explanation of this distribution is that the original trout of Eagle Lake was S. c. henshawi, but during a period when the climate was warmer and drier than at present, trout were eliminated because of a lack of suitable spawning tributaries. A later head water transfer established a form of redband or rainbow trout from the Pit River drainage described as S. aquilarum.

\section{LIFE HISTORY AND ECOLOGY}

Behnke and Zarn (1976) summarized the pertinent literature and studies of henshawi life history. Like most trout of the genus Salmo, S. c. henshawi is opportunistic in its feeding, and its life history characteristics are greatly influenced by its environment. This can be illustrated by comparing life history characteristics and feeding habits of the parental population of henshawi (slightly hybridized with rainbow trout) in Blue Lakes, California, with the population in Heenan Lake, derived from the Blue Lake stock. Clear-cut differences in condition, growth, age at maturity, and feeding were demonstrated in the same genotype exposed to different conditions. Thus, caution must be exercised when attempting to delineate the genetic basis of the subtle ecological and life history specialization which may produce such a large size in $S$. $c$. henshawi.

There is a genetic basis for maximum size, but there is also an enormous environmental influence on size. Only the original population of Pyramid Lake continued to coexist with the full array of Lahontan basin fish after the desiccation of Lake Lahontan. Summit Lake had no native fish other than the cutthroat trout. The stock of henshawi most commonly propagated in hatcheries is from Heenan Lake, California. The original source of this stock was the Carson River (a river, not a lake population), which was hybridized with rainbow trout while the stock was maintained in Blue Lakes (Behnke, 1960).

I believe that only the original Pyramid Lake population of henshawi possessed all the genetic attributes to make maximum use of the Pyramid Lake environment and food resources to attain such a great size. The Heenan Lake and Summmit Lake races do not have the precise genetic basis to duplicate the life history and growth potential of the original Pyramid Lake henshawi. In the last spawning run from Pyramid Lake in 1938, trout averaged 20 pounds (Sumner, 1940). The "world record" cutthroat trout from Pyramid Lake weighed 41 pounds, but when I first visited the Paiute Indian Reservation at Pyramid Lake in 1958, it was a common belief among the older tribal members that trout larger than 40 pounds were regularly caught in the Indian commercial fishery. Wheeler (1969) cited the testimony of Mr. Fred Crosby, who acted as an agent for the tribal fishery, that a 62 pound trout was caught in 1913.

During the last 20 years, millions of Heenan Lake and Summit Lake Lahontan cutthroat trout have been stocked into Pyramid Lake, but few trout of more than 20 pounds have been produced.

Concerning the practical management application of using the genetic diversity in remnant stocks of henshawi to create a large lake predator, I discussed in Behnke and Zarn (1976) the idea of crossing the Walker, Independence, and Summit Lake stocks to produce a broad base of heterozygosity to stock into Pyramid Lake (or any other lake) where the the genotypes would be subjected to natural selection, and to then take the eggs from the fish surviving in the new environment. In selecting for maximum size, the oldest fish at first maturity should be considered. That is, a fish spawning for the first time at age Vor VI will reach a much greater maximum size than will a first spawning at II or III in the same environment.

The most exciting information I can add since preparing the Behnke and Zarn manuscript two years ago is that I believe a small part of the source of the original Pyramid Lake genotype is extant and available for use. The population in Donner Creek on Pilot Peak, Utah-Nevada border, is probably derived from the stocking of Pyramid Lake cutthroat trout into this stream 50 to 75 years ago. The trout in Donner Creek is S. c. henshawi, and was introduced by man since Pilot Peak is in the Bonneville basin. It was established prior to 1952, probably around the turn of the century according to local testimony. Until the 1950's when the Nevada Fish 
and Game Department began propagating S.c. henshawi from Walker, Summit, and Heenan lakes, the only source of henshawi propagated in Nevada was from Pyramid Lake.

Undoubtedly the present Donner Creek population, discovered by the Utah Division of Wildlife Resources and the Utah BLM in 1977, does not carry the complete evolutionary heritage of the original Pyramid Lake race of henshawi. The original stocking was probably made with relatively few fish and the selection factors exerted by survival in tiny Donner Creek are very different from those of the original Pyramid Lake environment. The obvious next step is to obtain eggs from the Donner Creek trout and establish a brood stock, preferably in a natural environment, from which large numbers of eggs can be taken in the future.

I can see no way that the purity of henshawi can be maintained in Pyramid Lake if the trout spawn naturally in the Truckee River as discussed by Bailey (1978). Thus, unless the fishery is maintained entirely by artificial propagation, there should not be a great concern over mixing of stocks (for example, crossings using Summit Lake, Independence Lake, Walker Lake, and Donner Creek trout) to produce the genetic basis for future selection. I have some doubts on the purity of the Walker Lake stock of henshawi maintained at the Verdi, Nevada hatchery; they have never been adequately examined. The other stocks, Summit Lake, Independence Lake, and Donner Creek, can be considered pure henshawi. Considerable information on the cutthroat trout currently stocked into Pyramid Lake was gathered during a four-year study (1975-1978) on the ecology of Pyramid Lake by W. F. Sigler and Associates, Inc. The results of this study have not yet been released.

\section{STATUS}

S. c. henshawi was formerly listed as an "endangered species" under the 1973 Endangered Species Act. Its status was changed to "threatened" in 1975 to legally allow angling and facilitate management. Very few pure populations of henshawi exist. The Walker Lake cutthroat, of doubtful purity, has been maintained in a hatchery since 1948 when flows in the Walker River were so reduced from irrigation diversions that natural reproduction was impossible. The original Pyramid Lake population became extinct as a result of the first Bureau of Reclamation project ever constructed - the Newlands Project - and the closure of Derby Dam on the Truckee River, 30 miles above Pyramid Lake in 1906. Until about 1920, sufficient water passed over Derby Dam to maintain natural reproduction in the river below the dam. As more and more water was diverted by Derby Dam, reproduction diminished, and the last spawning run took place in 1938 . Since no native trout was found thereafter, the Pyramid Lake race of henshawi was presumed extinct. The native trout of Lake Tahoe became extinct about 1940 after most of the suitable spawing tributaries were blocked.

S. c. henshawi still exists in Independence Lake, despite a long history of introductions of nonnative salmonids. In recent years, the California Department of Fish and Game has propagated the Independence Lake cutthroat in hatcheries, and a new brood stock is now established in Martis Lake, a tributary to the Truckee River, California. Walt Disney Productions has had plans for several years to develop a major resort at Independence Lake, but there has been considerable opposition to this, and its future is not known.

The U.S. Fish and Wildlife Service has been propagating the Lahontan cutthroat trout of Summit Lake mainly for stocking in to Pyramid Lake. The Summit Lake trout was in peril from the effects of overgrazing on BLM lands in the watershed. The only spawning tributary was so affected by a large sediment burden that a delta built up at the mouth, and a bulldozer was required to open the stream to spawning (Behnke and Zarn, 1976). After some embarrassing publicity, fencing and grazing controls were imposed, and the situation has dramatically improved (Dahlem, 1979).

The California Department of Fish and Game's "Threatened Trout Committee" has discovered some new populations of henshawi and made some transplants. The major restoration project to date in California is the introduction of the Independence Lake cutthroat trout into Martis Lake after the eradication of nonnative trouts. Although planned as a brood stock lake, catch-and-release angling will be permitted in Martis Lake, and anglers will have the opportunity to catch pure Lahontan cutthroat trout of good size.

The BLM in Utah and the Utah Division of Wildlife Resources in 1979 approved the Pilot Peak Habitat Management Plan (HMP) which will provide in part for future management and protection of S.c. henshawi and its habitat in Donner Creek and other suitable waters in the Pilot Peak Mountain Range. The U.S. Fish and Wildlife Service is also cooperating in the management of this species. 


\section{THE PAIUTE CUTTHROAT TROUT, Salmo clarki seleniris}

\section{TYPICAL CHARACTERS}

The only trait distinguishing seleniris from henshawi is the absence of spots on the body. All other characters are typical of S. c. henshawi.

\section{DESCRIPTION}

The Paiute trout was derived in relatively recent geological times from S. c. henshawi after isolation in Silver King Creek, a tributary of the East Carson River, Alpine County, California. The Paiute trout can be described as a Lahontan cutthroat trout without spots, but even the lack of spotting is not an absolute character. Up to nine faint spots were found on the specimens of Paiute trout used by Snyder (1933) to name "Salmo seleniris" (Ryan and Nicola, 1976). I have observed specimens of a remnant henshawi population isolated in the very headwaters of the East Carson River that have almost no spots on the body. These specimens would be classified as seleniris if found in Silver King Creek.

All the meristic characters of seleniris are typical of henshawi-lateral series scales, 150-180; vertebrae, 60-63; pyloric caeca, 50-70; and gillrakers, 21-27 (24). The assumption that the genetic rela tionships between seleniris and henshawi of the Carson River drainage are closer to each other than are the affinities between Carson drainage henshawi and henshawi from other than Lahontan basin drainages is supported by the recent graduate research of Busack (1978). Electrophoresis of the products of several gene loci showed complete identity between seleniris of Silver King Creek and two henshawi populations in the East Carson drainage. Greater dissimilarity was found between the seleniris of the Silver King drainage and an introduced population of seleniris in Cottonwood Creek, southern California, than between seleniris of Silver King Creek and henshawi of the East Carson drainage.

Thus, from a genetic relatedness point of view, S.c. seleniris does not represent a "good" subspecies, but the slight difference it does have is expressed in an unusual way. It is the only species or subspecies of western trout that consistently has no obvious spots on the body.

\section{DISTRIBUTION}

The distribution of the Paiute trout is unique in that it is not native to its type locality above Llewellyn Falls in Silver King Creek, but was introduced above the falls in 1912 by sheepherders (Behnke and Zarn, 1976; Ryan and Nicola, 1976; Busack, 1978). When Snyder (1933) described seleniris, he believed it was native only to the headwaters of Silver King Creek isolated by Llewellyn Falls. He was not aware of the information later provided by Mr. Virgil Connell, a stockman who pastured sheep in the Silver King watershed, that no fish existed above Llewellyn Falls until transplanted from below the barrier in 1912. Another transplant was reputedly, but doubtfully, made in 1924. Fortunately, these transplants were made because by 1933, the trout below Llewellyn Falls represented a rainbow x cutthroat hybrid swarm (Behnke, 1960). No one would have ever heard of the Paiute trout if the sheepherders had not moved them above the barrier before hybridization with rainbow trout got underway.

Two isolated tributaries to lower Silver King Creek, Coyote Valley and Corral Valley creeks, were found to have Paiute trout (Vestal, 1947), but the streams were probably stocked from lower Silver King Creek as early as the 1860's by loggers. In 1946, Paiute trout, mainly collected from Corral Valley and Coyote Valley creeks, were transported and stocked into the North Fork of Cottonwood Creek, Mono County, California (Vestal, 1947). From Cottonwood Creek, a few subsequent transplants have been made.

In 1949, an inadvertent stocking of rainbow trout was made in Silver King Creek above Llewellyn Falls. When I examined specimens in 1964, a hybrid swarm had developed. The trout in Corral Valley and Coyote Valley creeks were also thoroughly hybridized by 1964. Fortunately, two small headwater tributaries to upper Silver King Creek, Four Mile Canyon, and Fly Valley creeks still had unhybridized Paiute trout, which were used to restock Silver Creek after a rotenone treatment in 1964. Some hybrids survived the treatment and the effects of hybridization gradually spread through the population, indicated by spots on the body. The rotenone treatment was repeated in 1978. 


\section{TAXONOMIC NOTES}

Snyder (1933) described the Paiute trout as a full species, Salmo seleniris. As discussed, the genetic relationship of seleniris is so close to that of henshawi that, on a quantitative basis, the henshawi and seleniris of the Carson River drainage appear to be more closely related to each other than do the henshawi of the Carson drainage and the henshawi of the Truckee Riverdrainage. The subspecies category as used with cutthroat trout is more of a practical device to associate a name with a unique group of trout than it is a measure of evolutionary divergence. From what is now known about Paiute and Lahontan cutthroat trout, I would probably not recognize the Paiute trout as a distinct subspecies if it had not already been named and long recognized as such. I would consider it to be a unique race of S.c. henshawi. However, the name seleniris has been widely used in the literature and has been entered into the Federal Register, first as an endangered species and later as a threatened species. It has been incorporated into the management plans of the California Department of Fish and Game and of the the U.S. Forest Service. Undoubtedly, the Paiute trout has benefited from its own subspecies recognition, more so than if only considered as a race of henshawi.

\section{LIFE HISTORY AND ECOLOGY}

Behnke and Zarn (1976) reviewed ecological aspects of the Paiute trout, and Diana and Lane (1978) published a paper on its movement and distribution in Cottonwood Creek. The only unique thing about the life history of Paiute trout is that they carry the evolutionary imprinting of their Lahontan cutthroat trout ancestor from ancient Lake Lahontan which makes them vulnerable to replacement or hybridization by nonnative trouts. Paiute cutthroat trout must be maintained in isolation if they are to be preserved.

\section{STATUS}

In 1975, the "endangered" species status under the 1973 Endangered Species Act was changed to "threatened" to facilitate manangement. For several years, an attempt to control the hybrid population in Silver King Creek, which reappeared after the 1964 rotanone treatment, was made by electrofishing the stream and removing all fish with more than five spots on the body. This proved to be ineffective, and the stream was again treated in 1978 to eliminate hybrids. The California Department of Fish and Game has demonstrated a sincere commitment to preserving the Paiuite trout. A monitoring program continues on Silver King Creek and on the North Fork of Cottonwood Creek. A few small populations have been established in southern California in Cabin Creek, Birchim Lake, and Stairway and Sharktooth creeks.

Since the native range of the Paiute trout was always small /the smallest of any currently recognized subspecies of cutthroat trout), it will not take much in the way of introduction into new waters to increase its abundance. On the other hand, with so few viable populations, it would not take much in the way of inadvertent or illegal introductions of nonnative trouts to cause extinction. 


\section{THE HUMBOLDT CUTTHROAT TROUT, Salmo clarki subsp.}

\section{TYPICAL CHARACTERS}

Similar to S.c. henshawi except for fewer gillrakers '18-24(21) vs. 21-28(24)] and a trend for fewer scales in the lateral series and above the lateral line.

\section{DESCRIPTION}

The Humboldt River drainage subspecies had not been formally described. The only mention of this trout in the published literature is found in the Lahontan cutthroat trout section of Behnke and Zarn (1976). I became aware of a group of native trout differentiated from $S$. $c$. henshawi when I examined museum specimens collected by J. O. Snyder from the Lahontan basin from 1911 to 1915 . There are four major river systems in the Lahontan basin, the Truckee, the Walker, the Carson, and the Humboldt drainages. Since the desiccation of ancient Lake Lahontan about 8,000 years ago, these river systems have been isolated from each other. From examination of specimens during the early period of my research, I noted that the trout native to the Truckee, Walker, and Carson drainages, S. c. henshawi, consistently differed from Humboldt River drainage specimens in the number of gillrakers.

Synder (1917) made the first comprehensive collections of Lahontan basin fishes. His collection contained 19 specimens of trout from the Humboldt drainage, but he examined only specimens from the Truckee drainage (Pyramid Lake and Lake Tahoe) and did not recognize the distinction between henshawi and the Humboldt trout.

At the time I completed my M.A. thesis, I believed the Humboldt trout was extinct as pure populations. Soon after, however, Mr. William Nisbet, Nevada Fish and Game Department biologist in the Elko region, collected several samples of native trout from small streams in the Humboldt drainage. With the assistance of Mr. Nisbet, I made collections in 1961,1962, and 1963, which were summarized in the unpublished work coauthored with the late P. R. Needham. Mr. Patrick Coffin, Mr. Nesbit's replacement as the Elko regional biologist, continued to find new sources of the Humbold t native trout. I joined Mr. Coffin on a collecting trip in 1972. My total material on the Humboldt trout consists of more than 200 specimens from 27 locations.

To show the difference in gillraker number between S. c. henshawi and the Humboldt cutthroat trout, a table was prepared in the Needham and Behnke manuscript presenting the gillraker counts of all Lahontan basin cutthroat trout examined to 1964. Grouping all 161 specimens of S.c. henshawi and 137 specimens of Humboldt trout from 20 localities revealed S.c. henshawi with from 21 to 18 gillrakers and a mean of 24.2 , and the Humboldt trout with from 18 to 24 gillrakers and a mean of 21.0. Collections of both henshawi and Humboldt trout since 1964 have also agreed with this separation.

For a more quantitative analysis, Hickman (1978) used a discriminant function computer analysis to analyze 16 characters to quanitfy the differences between Bonneville basin cutthroat trout, S. c. utah, and several other subspecies. He included 35 specimens of $S$. c. henshawi and 32 specimens of Humboldt cutthroat. The computer separated henshawi specimens from Humboldt drainage specimens with 100 percent accuracy (complete separation).

Besides gillraker numbers, the Humboldt cutthroat tends to have fewer scales in the lateral series and above the lateral line. Most mean values for lateral series scale counts range between 140 and 150 in Humboldt sample. The Ganz Creek tributary in the North Fork Humboldt drainage, however, has a particularly coarse-scaled trout. In 17 specimens, I counted $117-140(126)$ scales in the lateral series. It must be recognized that tremendous numbers of nonnative trout were stocked into the Humboldt drainage, and for many years it was considered an almost sacred obligation to "seed" all headwater streams with trout fry.

All the populations of Humboldt trout have probably been exposed to hybridization, first with $S$. $c$. henshawi, stocked in large numbers until the 1920's, and later with Yellowstone Lake cutthroat trout and rainbow trout. Unlike most other regions where native subspecies of interior cutthroat trout have been replaced or thoroughly hybridized by nonnative trouts, the Humboldt cutthroat has resisted the encroachments of nonnative trouts to an a mazing degree. Basibranchial teeth are usually the first character to reflect hybridization with rainbow trout. In interior cutthroat trout in general, the more obvious effects of hybridization (changes in spotting and coloration) are not apparent until about 50 percent or more of the population lacks basibranchial teeth. In 121 specimens of Humboldt cutthroat that are more than 4 inches in length, basibranchial teeth are present in 115 , or 95 percent. 
The pyloric caeca number is similar to that of $S$. c. henshawi, with from 40 to 70 caeca, and most mean values range between 50 and 60. Six specimens from Hanks Creek, a tribuary to the Marys River (eastern head waters of Humbold t drainage/ have the highest number of caeca, 55 to 69 , with a mean value of 65 . The vertebrae number, 60 to 63 , is also similar to that of S. c. henshawi.

There are subtle but not clear-cut differences in spotting patterns and coloration between Humboldt cutthroat and henshawi. The spots are typically fewer on Humboldt trout and are more concentrated posteriorly on the body. Only rarely are spots found on the abdomen. The coloration is generally dull, with typically brassy, copper, or burnished silver colors predominating. Light yellow with some pink tints may appear on the side. The ventral region is white or gray, and the lower fins are brownish but may develop faint pink tints.

\section{DISTRIBUTION}

Originally, this trout was native throughout the Humboldt River drainage of eastern Nevada, but is now restricted to several small streams. The greatest concentration occurs in the headwaters of the Marys River. All present known localities of Humboldt cutthroat trout are in Elko County, with the exception of two headwater tributaries to the Reese River in Nye County. A transplant from Frazer Creek established a new population in Sherman Creek north of Elko. The basins immediately to the south of the Humboldt drainage of the Lahontan basin were barren of trout, and early settlers stocked many barren streams in the Toiyabe Mountains with Humboldt cutthroat trout from the Reese River (Hubbs and Miller, 1948). I have not been able to verify the present existence of these early introductions.

Although most of my samples contain fewer than 10 specimens from any locality, Inote a consistent trend for the specimens from the southern part of the drainage (Lamoille area, South Fork of the Humboldt) to have the highest scale counts. To determine the validity of "sub"-subspecies differentiation by the native trout within the Humboldt drainage requires much more intensive study.

\section{TAXONOMIC NOTES}

Lake Lahontan's size fluctuated greatly from the time of its origin about 75,000 years ago to its final desiccation about 8,000 years ago. Broecker and Kaufman (1965) detailed a sequence of four major periods of alternating high and low lake levels. It is likely that the ancestral cutthroat trout gained access to the Lahontan basin during an early phase of the creation of Lake Lahontan. A subsequent lowering of the lake level could have isolated the cutthroat trout in the Humboldt drainage from the rest of the basin to initiate genetic differentiation (about at the stage when the ancestral trout had an average of 21 gillrakers). With the next rising of the lake level, contact between the two diverging groups of cutthroat trout would have occurred, but because of selective pressures to maintain a river-specialized form of trout to use the large Humboldt drainage environment, massive hybridization did not occur, and differentiation was preserved.

I do not believe the Humbold t cutthroat trout acquired all its genetic differentiation from S. c. henshawi since the dessication of Lake Lahontan, or during the last 8,000 years. The Truckee, Walker, and Carson river drainages have been isolated from each other as long as they have been from the Humboldt drainage, yet S.c. henshawi is essentially undifferentiated in the Truckee, Carson, and Walker drainages. The henshawi populations, restricted to streams during the last 8,000 years or so in the Truckee, Walker, and Carsons drainages, all average about 24 gillrakers. It is unlikely that the Humbold cutthroat reduced the gillraker number from 24 to 21 . Instead, the present gillraker number was established long ago during an early phase of Lake Lahontan and has not changed since the earliest isolation of the ancestral stock in the Humboldt drainage.

\section{LIFE HISTORY AND ECOLOGY}

An evolutionary history of survival in the arid lands watersheds of the Humboldt drainage, where the native trout has been subjected to a harsh and unstable environment characterized by flood-drought cycles for the past several thousand years, has produced an adaptable genotype well suited to environmental 
extremes. This evolutionary heritage appears to be the most logical explanation for why the native Humboldt cutthroat trout has so successfully resisted replacement and hybridization by nonnative trouts. Nonnative brook, brown, and rainbow trouts are mainly established in the "best" trout streams in the Ruby Mountains, characterized by well-vegetated watersheds and relatively stable year-round flows.

The native cutthroat dominates those streams in the poorer watersheds where flows are highly unstable. I have taken the native trout from small streams in late summer with no flowing water, only intermittant pools between long reaches of dry streambed, where flood debris from spring floods could be observed in tree branches 5-6 feet above the streambed. The native cutthroat thrives in Frazier and Sherman creeks where summer temperatures of 78 degrees F. have been recorded. Native cutthroat trout often enter two irrigation reservoirs in the Humboldt drainage, Willow Creek Reservoir (between Tuscarora and Midas) and Jiggs Reservoir south of Elko, from headwater tributaries during high runoff years. These reservoirs are turbid, eutrophic bodies of water, seemingly completely unsuited for cutthroat trout. The native cutthroat, however, attain weights of 5 to 7 pounds in these unlikely environments. Brook and rainbow trout stocked into Willow Creek Reservoir had low survival rates, and the few that survived for one year lost weight (personal communicaiton from William Nisbet and Pat Coffin). Although I know of no direct evidence on the matter, it could be assumed that the Humboldt cutthroat is similar to S. c. henshawi in its tolerance of waters of high alkalinity and high $\mathrm{pH}$ (a trait of the Lahontan fish fauna in general).

The Humboldt cutthroat trout appears to represent a valuable genetic resource for fisheries management. A brook stock should be established in a pond or reservoir so that large numbers of eggs may be taken and propagated. If large numbers of Humboldt cutthroat could be stocked into a variety of new environments, much could be learned about its life history and ecological variability and its potential role in fisheries management programs. It is much easier to sell a program to save a rare, native trout if some attributes of practical economic value can be demonstrated.

\section{STATUS}

Although known from 27 sites, not all of these populations can be considered pure. None of the sites contain large populations because of the size of the habitat. Many streams are reduced to a few seep pools by late summer. Others are affected by mining activity. Most of the watersheds are badly overgrazed by livestock and suffer from heavy irrigation diversions. Long-term survival of native cutth roat populations in most of the 27 sites is judged as precarious. The most secure population, inhabiting the largest area, is found in the headwaters of the Marys River, where the drainage originated in the Jarbidge Primitive Area of the Humboldt National Forest.

In arid land watersheds, characteristic of much of the Humboldt drainage, irrigation demands begin to dry up many streams soon after permanent flow is established in the headwaters leaving little habitat for native trout. All of the sites where Snyder (1917) collected native trout during 1911 and 1915, an area along the main Humboldt River, including a few tributaries from Carlin to Deeth, are now barren of trout because of the highly degraded envrionment.

The Humboldt cutthroat trout is listed as one of the world's rare fishes in the Red Data Book of the International Union of Conservation of Nature. 


\section{BONNEVILLE CUTTHROAT TROUT, Salmo clarki utah}

\section{TYPICAL CHARACTERS}

Similar to Yellowstone cutthroat trout, but differs mainly in the typical spotting pattern with larger, more evenly distributed spots on the sides of body.

\section{DESCRIPTION}

The cutthroat trout native to the Bonneville basin consists of three slightly differentiated groups associated with: 1) the Bonneville basin proper including the Jordan, Provo, Weber, Sevier river drainages, 21 the Snake Valley region of Utah-Nevada on the western extremity of the basin, and 3/ the Bear River drainage. Because of the high degree of variability and the close relationship to S.c.bouvieri, the Bonneville cutthroat trout cannot be clearly defined. The major difference from S.c. bouvieri is the tendency to develop larger, more pronounced spots on the sides of the body, and for these spots to be more evenly distributed and not concentrated posteriorly. The Snake Valley cutthroat trout typically has smaller, more profuse spotting, but the spots are usually more-or-less evenly distributed.

Scale counts in the lateral series are typically 140 to 180 , with mean values ranging between 150 and 170 . The lowest counts are in Snake Valley trout, and the highest counts are in Bear River drainage specimens. Pyloric caeca numbers range from about 25 to 55 , with mean values of about 35 , except for the Bear River drainage samples that typically average more than 40 . Gillraker numbers typically range from 16 to 21 , with mean values of 18 or 19 , except the Snake Valley cutthroat trout which have 18 to 24 gillrakers with means of 20-22.

The Snake Valley cutthroat trout is also characaterized by a profusion of basibranchial teeth $(6$ to 90$)$ with mean values from 20 to 28 . Most other samples of $S$. $c$. utah average 5 to 10 basibranchial teeth, except for a collection from Willow Creek, a small, isolated stream south of Salt Lake City, which has an average of 19 basibranchial teeth. Vertebrae counts in S.c. utah tend to be slightly higher (typically 62-63 vs. 61-62) than in other subspecies. The generally dull coloration of Bonneville trout is shared by all Great Basin cutthroat trouts.

It was formerly believed that S.c. utah was extinct (Cope, 1955; Platts, 1957; Singler and Miller, 1963). An adequate description of S. c. utah has never been published, and the only illustration of this subspecies (Jordan, 1891) was based on a specimen from Utah Lake in which the silvery pigmentation induced from living in this alkaline environment modified the spotting pattern and resulted in a specimen with few small speckle-like spots - a typical S. c. utah.

In all, I examined 27 ancient museum specimens from the Bonneville basin in an attempt to diagnose this subspecies for my M.A. thesis. The problem was clouded by a collection of cutthroat trout I made in 1958 from Pine Creek on the western slopes of Mt. Wheeler, Nevada. The Pine Creek cutthroat were belived to be introduced from the Bonneville basin and to represent $S$. c. utah, but I noted sharp differences between the Pine Creek trout and the museum specimens of Bonneville trout, particularly in the numbers of gillrakers and basibranchial teeth.

During the succeeding years, I collected numerous specimens and also received many specimens from several state and Federal agencies. From 1973 to 1978, I prepared several reports on Bonneville and Snake Valley cutthroat trout: two for the U.S. Fish and Wildlife Service, two for the Bureau of Land Management, one for the U.S. Forest Service, and three for the Wyoming Game and Fish Department. The M.S. thesis of Murphy (1974) compared Bonneville trout with Yellowstone trout, demonstrating their close similarities. The most comprehensive work on the Bonneville cutthroat trout is the recently completed M.S. thesis of Hickman $\mid 1978$, funded by the BLM Utah State Office.

When I first compared the Pine Creek cutthroat trout from Mt. Wheeler, Nevada, with the museum specimens of S. c. utah, I believed that a new subspecies should be described for the Snake Valley cutthroat (the same conclusion was reached independently by Dr. R. R. Miller, University of Michigan). As more populations of native cutthroat trout were discovered from the Snake Valley region and from other sections of the Bonneville basin, as summarized in Hickman's thesis, it became apparent that differentiation between all Snake Valley trout and all other S.c. utah was not as clear-cut as is found between the Lahontan cutthroat, henshawi, and the Humboldt River cutthroat. For example, using a discriminant function computer analysis of 16 taxonomic characters, 35 specimens of $S$. c. henshawi and 32 specimens of Humboldt cutthroat were 
separated with 100 percent accuracy. That is, the computer correctly assigned every specimen to its respective subspecies (Hickman, 1978). The Snake Valley cutthroat trout should be considered a unique race of S. c. utah.

The lack of clear-cut distinctions between S.c. bouvieri and S. c. utah indicates that the cutthroat trout native to the Bonneville basin has not been isolated as long as has the Lahontan basin cutthroat trout.

\section{DISTRIBUTION}

The Bonneville basin with 34 million acres is the largest basin of the Great Basin and once contained the largest of the ancient lakes of the Great Basin. Lake Bonneville, at maximum size of 19 million acres, was approximately the size of present day Lake Michigan, with a maximum depth of about 1,000 feet. The present site of Salt Lake City was once under about 700 feet of water.

The Bonneville cutthroat trout are not well differentiated from the Yellowstone trout native to the Snake River, and it can be assumed that the ancestral cutthroat did not gain access to the Bonneville basin until relatively recent geological times $(20,000$ to 30,000 years ago). The other fish fauna, such as the genera lotichthys, Chasmistes, Gila, and Prosopium of the Bonneville basin, indicate much greater antiquity, with isolation perhaps established in Pliocene times or millions of years ago.

Since the Bear River was originally tributary to the upper Snake River, it can be assumed that it also contained "Yellowstone" cutthroat trout at that time. From about 20,000 to 35,000 years ago, volcanic activity caused the Bear River to change coarse and become part of the Bonneville basin, thus transferring Snake River fish species into the Bonneville basin. The greatly augmented flow from the Bear River increased the size of Lake Bonneville until it spilled over to connect to the Snake River at Red Rock Pass at the northeastern tip of ancient Lake Bonneville. Because the bulk of the Bear River drainage and Bear Lake were never submerged by ancient Lake Bonneville, the Bear River drainage cutthroat trout are slightly differentiated from other S. c. utah (higher pyloric caeca number and scale counts).

The differentiation of the Snake Valley cutthroat trout is likely explained by the fluctuating levels of Lake Bonneville. Like ancient Lake Lahontan, it is believed that Lake Bonneville had four major fluctuations during its existence. Snake Valley was a bay of ancient Lake Bonneville during the stage of maximum level, but was isolated from the rest of the basin at all other times.

The native cutthroat was distributed in all suitable waters in the basin. About 100 years ago, cutthraot trout from the Snake Valley region were stocked into previously barren streams in neighboring isolated basins between the Bonneville and Lahontan basins (Hubbs et al., 1974). One of these early introductions persisted in Pine Creek on Mt. Wheeler, and several more recent introductions of Pine Creek stock have established a few additional populations in small streams in these separate basins.

A population of S. c. utah also existed in the headwaters of the Santa Clara River of the Virgin River drainage of the lower Colorado River basin. It is not known whether the S.c. utah of the Santa Clara drainage is native or introduced. Miller (1961) cited an "old timer" who claimed cutthroat trout were in the Santa Clara River at Pine Valley, Utah in 1863. I visited Pine Valley in 1958 and 1973 . There is only a slight and gentle divide separating the Bonneville basin from the Santa Clara drainage, and a headwater transfer in the 1860's by pioneers is a plausible explanation for the occurrence of S. c. utah in the Santa Clara drainage. On the other hand, none of the early fish collections from the Virgin River basin reported trout. If trout were native to the headwaters of the Santa Clara drainage, they should have spread in all suitable waters throughout the Virgin Riverbasin. The Santa Clara cutthroat trout near Pine Valley persists in two small head water streams (Reservoir Canyon and Water Canyon creeks) and are among the few populations of typical S. c. utah still extant.

\section{TAXONOMIC NOTES}

In the early literature, Bonneville cutthroat trout were referred to as "Salmo virginalis", which was first used to describe specimens of cutthroat trout from the Rio Grande basin, Colorado. Its use is restricted to designating the Rio Grande subspecies. This error was pointed out by Snyder (1919) in a footnote to his paper on Bear Lake whitefishes and by Jordan (1920). The earliest name given to a trout strictly of the Bonneville basin is "Salmo utah" by Suckley (1874). Suckley merely wanted to differentiate the cutthroat trout of Utah 
Lake from the rest of the Bonneville cutthroat, which he identified as S. virginalis. The trout from Utah Lake, due to their silvery coloration and large size, appeared quite distinct from the the trout in mountain streams. Suckley meant to apply the name "utah" only to the Utah Lake trout, but because Utah Lake is in the Bonneville basin, and if all Bonneville cutthroat trout are recognized as one subspecies, the correct name is $S$. c. utah.

The Domingeze-Escalante Expedition (1776) noted trout used by the Indians of th Utah Lake region. The first description of the basin's native trout was made by the naturalist Townsend in 1833 on a trip through the Great Basin to California.

Many common names have been applied to the Bonneville cutthroat. It is often referred to as the "Utah" cutthroat. The common name Bonneville cutthroat is more accurate because three subspecies of cutthroat trout are native to the state of Utah (utah, pleuriticus, and bouvieri), and the native range of the Bonneville cutthroat trout extends into Wyoming, Idaho, and Nevada.

Studies of gene loci, carried out by the Utah Cooperative Fishery Unit (Wydoswki et al. 1976), failed to find any unique or differentiated genes associated with S. c. utah that could be used to separate Bonneville cutthroat trout from other subspecies. These studies did discover a unique form of the lactate dehydrogenase enzyme in some specimens of Snake Valley cutthroat trout from isolated populations, which supports the assumption that the Snake Valley cutthroat trout represent a natural evolutionary group, genetically differentiated from other S. c. utah.

\section{LIFE HISTORY AND ECOLOGY}

In the few lakes left in the Bonneville basin after the final desiccation of ancient Lake Bonneville, such as the Bear, Utah, and Panguitch lakes, the Bonneville cutthroat continued to exist in an environment with the native Bonneville fish fauna. In these lakes, the native cutthroat reached a size of up to 15 to 20 pounds and were abundant. Large-scale commerical and sustenance fisheries heavily exploited these lake populations, and they were also of great significance to the early Mormon settlers of Utah. Warnings of overexploitation appeared in the earliest literature. A single haul of a net could yield 3,500 pound s of trout from Utah Lake in 1864 , but no more than 500 pound sy 1872 (Yarrow, 1874), and only 100 pounds by 1889 (Sigler and Miller, 1963). The last native cutthroat trout was taken from Utah Lake in 1933. Yet, even if not a single native trout were ever killed by fishermen or poachers, there would be no native trout in Utah Lake today, nor would the rare status of $S$. c. utah be in any way influenced. Overfishing had nothing to do with the present status.

Since Bear Lake was less affected by pollution and loss of spawning tributaries, the native cutthroat trout persisted. However, during the last 75 years, millions of nonnative rainbow trout, Yellowstone Lake cutthroat trout, and Strawberry Reservoir cutthroat trout (Yellowstone rainbow $\mathrm{x}$ hybrid) have been stocked into Bear Lake and hybridization has influenced the present genotype. How much of the original native trout genotype is still present in the Bear Lake cutthroat population is not known. I would assume that natural selection has favored the original Bear Lake cutthroat trout over nonnative cutthroat and rainbow trouts and that a large measure of the orignal genetic resource is still present. Despite annual introductions of rainbow trout, this species has never become established, and a rainbow trout fishery in Bear Lake can only be maintained by stocking catchable fish. The cutthroat trout of Bear Lake then represents, with only a minute hybridization, a genotype of the original lacustrine stock of the Bonneville cutthroat from ancient Lake Bonneville.

Recognizing the practical economic advantages of propagating the native cutthroat of Bear Lake for at least wild fish that look like native cuthroat) for stocking into Bear Lake, the current management policy for this lake takes eggs from wild Bear Lake trout, selected on general apperance as "native" cutthroat, for the propagation program (Nielson and Archer, 1977). More than 2,000,000 eggs were taken during 1975 and 1976. The average size of the cutthroat trout used in the egg-taking operation in 1975 was 24 inches and 6.5 pounds.

Almost nothing has been published on the life history and ecology of S. c. utah. Some data on age, growth, and food habits were given by Nielson and Archer (1977) for the Bear Lake cutthroat. Insects make up the entire diet of smaller trout, and fish enter the diet when the trout reach a size of about 10 to 12 inches. At a size of 18 to 20 inches, they feed exclusively on fish.

The fish fauna on Bear Lake is unusual with several relict species from ancient Lake Bonneville. Four species of whitefishes of the genus Prosopium and a sculpin, Cottus extensus, are endemic to Bear Lake/they 
are found nowhere else in the world). The association of the native trout with this peculiar species for thousand of years has likely given the advantage to the native over nonnative trouts because of their more specific predator-prey relationships. The major prey species is the Bear Lake "cisco", Prosopium gemmiferum.

The greatest "stronghold" of native S. c. utah (slightly hybridized, but typical of the subspecies in out ward appearance) is in the Thomas Fork and Smith Fork drainages of the Bear River system in southwestern Wyoming. The general habitat in these drainages is poor because of land use practices. Yet, native cutthroat trout completely dominate nonnative trout. A few brook trout are found in some tributaries, but the cutthroat is numerically dominant. Brown trout occur in two streams with the best habitat (clear, cold water in well-vegetated watersheds), but the cutthroat is the only trout found in the warmer, turbid main streams.

Until recent years, large numbers of fine-spotted Snake River cutthroat trout were stocked in to both the Smith Fork and Thomas Fork drainages. In 1907, I collected fish in the Smith Fork and found many hatchery-reared Snake River cutthroat. I "wrote off" the Smith Fork as a site containing S.c. utah at the time, but further collections in 1976, after stocking had ceased, yielded only cutthroat trout with large, pronounced spots on the body, typical of S.c. utah. No evidence of hybrid influence from the fine-spotted Snake River cutthroat trout was detected. Evidently, these Bear River cutthroat of the Thomas Fork and Smith Fork drainages bear an evolutionary heritage of adaptions for the highly unstable environments of the arid foothills region - similar to the evolutionary history and adaptability of the Humboldt cutthroat trout of the Lahontan basin.

The cutthroat trout of the Snake Valley region also has some useful fisheries management traits. It inhabits very small streams but consistently attains a greater size than do brook trout or rainbow trout in comparable streams. For example, in tiny Trout Creek in the Deep Creek Mountains of western Utah, cutthroat trout of up to 10 inches are found above a barrier. Below the barrier, rainbow trout are found; almost none of the rainbow trout exceed 6 inches. This favorable size comparison between native and nonnative trouts in several small eastern Nevada streams containing Snake Valley cutthroat was first called to my attention by Mr. Frank Dodge, a Nevada Fish and Game Department biologist. Because it is a much more appealing trout to the angler, Nevada has attempted to establish the Snake Valley cutthroat in many more small streams in the region.

\section{STATUS}

In its pure, unhybridized form, S.c. utah is one of the rarest of the subspecies of cutthroat trout. It was long believed extinct until the discoveries of the Snake Valley cutthroat trout in Pine Creek on Mt. Wheeler and the S. c. utah in Reservoir Canyon Creek in the headwaters of the Santa Clara drainage. In 1953, 44 trout from Pine Creek were transplanted into Hampton Creek, a tributary to Snake Valley of the Bonneville basin, Nevada, to establish a new population. In 1960, 54 trout from Pine Creek were transplanted into Goshute Creek in an isolated basin, White Pine County, Nevada. In 1977, trout from Goshute Creek were stocked into Water Creek and Clear Creek, White Pine County, Nevada. In 1972, Mr. Frank Dodge discovered a pure population of Snake Valley cutthroat trout in their natural range, in the uppermost mile of the headwaters of Hendrys Creek, a tributary to Snake Valley.

In my former reports, I believed the native cutthroat trout was extinct in the Deep Creek Mountains of Snake Valley because there was no known record of it since 1932, and all subsequent collections found only rainbow trout. In 1974, Utah BLM biologists Don Duff and Josh Warburton found cutthroat trout in the upper mile of Trout Creek above a barrier and in the very headwaters of neighboring Birch Creek. The Utah BLM funded Mr. Hickman's study to investigate the Deep Creek Mountains more thoroughly for native trout. During Hickman's field work in 1976, he discovered the barrier had washed out on Trout Creek and rainbow trout and hybrids were found where only cutthroats had been collected from Birch Creek in 1974. A new barrier was constructed by BLM on Trout Creek and another on Birch Creek, but only about a quarter mile of habitat is left for the cutthroat trout in Birch Creek, and it appears that rainbow trout influence is now present in the remnant Birch Creek stock.

In 1977, Trout Creek below the barrier was treated with rotenone by personnel of the Utah Division of Wildlife Resources in an attempt to eliminate rainbow trout and reestablish the native cutthroat throughout the stream. Although prospects appear brighter for the continued survival of the Snake Valley form of $S$. c. utah, its total present habitat consists of only a few miles of tiny streams of marginal trout habitat, and most a re subjected to degradation from grazing, mining, and irrigation diversions so that a sudden cloudburst 
could wipe out any population (all of the streams where the Snake Valley trout has been introduced were barren due to complete loss of all fish from former floods). The total habitat consists of only a few surface acres of water.

The Trout Creek watershed was threatened in 1977 by proposed uranium exporation. A BLM emergency land withdrawal protected the Deep Creek Mountains from mining exploration until 1980. This protection for an area of critical environmental concern was made by the Secretary of the Interior under Section 204(e) of the Federal Land Policy and Management Act of 1976.

Populations of pure, native cutthroat trout are also rare in the rest of the Bonneville basin. A small population of typical S. c. utah is found in Birch Creek, in the Sevier Riverdrainage near Beaver, Utah. Birch Creek also suffers from land use problems, mainly livestock overgrazing, and much of this population was lost during a severe drought in 1977. A small population of cutthroat trout exists in about a quarter mile isolated section of Willow Creek, tributary to Cottonwood Creek in the Jordan River drainage, Salt Lake County, Utah. The Willow Creek trout has smaller spots than typically found in S. c. utah and averages 19 basibranchial teeth. It has long been in a protected watershed (domestic water supply) and the stream was probably never stocked. The divergence expressed in the Willow Creek population is probably an example of a small, isolated population initiating genetic divergence (genetic drift) from the rest of the subspecies.

In the headwaters of the Santa Clara drainage near Pine Valley, Utah, typical S. c. utah still exist in the headwaters of Reservoir Canyon and Water Canyon creeks. The "stronghold" of trout typical of S. c. utah in appearance occurs in the Smith Fork and Thomas Fork drainages of the Bear River system in Wyoming. Only two streams, however, have populations judged to be pure S.c. utah - Raymond Creek and the headwaters of Giraffe Creek. When I visited Raymond Creek in 1976, I was astounded to see strange vehicles, the likes of which I had never seen before, strung out along the stream with mineral exploration people setting off blasting charges and busily recording seismograph readings. This whole general area of the Bear River system lies in a geological area called the "overthrust belt", believed to contain tremendous reserves of petroleum and natural gas. It seems as though the discovery of rare native trout is always just one step ahead of some impending disaster to the population.

In 1977, the Wyoming Game and Fish Department took trout from Raymond Creek to its Daniel Hatchery to establish a brook stock for the propagation of S. c utah. In a 1978 report prepared for the Wyoming Game and Fish Department, I presented the results of my examination of 17 specimens of cutthroat trout from Lake Alice, Wyoming. Lake Alice is a natural body of water, 231 surface acres in size, formed in the distant past from a landslide across a head wa ter tributary to Hobble Creek (Smith Fork drainage). It has always had native trout, but some introductions (s pecies unknown, but probably Yellowstone cutthroat trout) are known. I found the Lake Alice specimens different from the stream-living cutthroat of the Smith Fork drainage in their spotting pattern (fewer spots) and lower scale counts. The differentiation, however, cannot be logically explained from a hybrid influence from either Yellowstone cutthroat trout or rainbow trout. I believe the Lake Alice cutthroat is a pure or virtually population of S. c. utah.

Hickman (1978) estimated the total stream habitat where pure S. c. utah are known to exist to comprise about 30 surface acres of water. The identification of the Lake alice trout as pure /no examination or test can define "pure" S.c. utah with absolute certainty) Bonne ville cutthroat trout, tremendously increases the size of the range of the subspecies from about 30 acres to about 260 acres. The Bonneville cutthroat was listed in the USDI "Redbook" of rare and endangered species as "status undetermined" until 1973. It is listed as "rare" in the Red Data Book of the International Union for the Conservation of Nature. Holden et al. (1974) considered it endangered. Miller (1972) listed the Snake Valley cutthroat trout as one of the threatened fishes of the United States. The American Fisheries Society's Committee on Endangered Species $(1979)$ lists it as "threatened". At the present time, the Bonneville cutthroat trout is undergoing a "status review" to ascertain all available information of the species and its habitat to determine if a proposal to officially list it is appropriate. 


\section{ALVORD BASIN CUTTHROAT TROUTS}

The Alvord basin of northwestern Nevada and southcentral Oregon is bounded by the Lahontan basin to the south, the Owyhee drainage of the Columbia River basin on the east and north, and is sharply separated from the Catlow Valley and Harney desert basins to the west by the impressive Steens Mountains.

Contemporary with Lake Lahontan and Lake Bonneville, Alvord Lake filled a trough of the Alvord basin in late Pleistocene times. Alvord Lake extended about 75 miles along its north-south axis and was 5 to 10 miles wide. U.S. Geological Survey Map I-416, "Pleistocene lakes in the Great Basin", depicts Alvord Lake and its relationships to other Great Basin lakes as it appeared during the Pleistocene.

Evidently, the Alvord basin has long been separated from direct aquatic connection to any contiguous basin. Besides the cutthroat trout, only one species of fish, an endemic chub, Gila alvordensis, is native to this basin.

Almost nothing can be found in the literature regarding the Alvord basin cutthroat trout. Trout were first collected in the Alvord basin by Dr. Carl Hubbs and his family in 1934, and Hubbs and Miller (1948) mentioned it as an undescribed, endemic subspecies. Bond $(1961,1966)$ listed the Alvord cutthroat trout as $S$. c. henshawi. Behnke and Zarn (1976) pointed out that the native cutthroat associated with the Alvord basin represented two undescribed subspecies: one native to the drainage and presumed extinct, the second native to Willow and Whitehorse creeks, which are not strictly part of the Alvord basin, but drain to a desert plateau to the east. Willow and Whitehorse creeks probably never connected to ancient Alvord Lake (USGS Map I-416 shows complete isola tion between Willow and Whitehorse creeks and Alvord Lake). The absence of the chub, Gila alvordensis, from the Willow and Whitehorse drainages also supports the theory that these drainages were never part of the Alvord Lake basin proper.

I borrowed the specimens collected from the Alvord basin by Hubbs in 1934 from the University of Michigan collection and noted that in 30 specimens collected from Virgin Creek, Nevada |Alvord sump drainage), the gillraker numbers are 20-26 (23.4). In 14 specimens collected from Willow Creek, Oregon, these counts are 18-23 (20.8) (Behnke, 1960). I obtained further specimens in recent years and made a collecting trip to the Alvord basin and Willow and Whitehorse creeks in 1972. Specimens from Willow and Whitehorse creeks are similar to each other except that Willow Creek specimens have an average of about 10 more lateral series scales than do specimens from Whitehorse Creek. I found only typical rainbow trout in several isolated sites in the Alvord sump drainage, and it is doubtful that a population of cutthroat trout native to this drainage still exists.

The origin and relationship of the two subspecies native to the Alvord basin are matters for speculation, but I beleive they were derived from a cutthroat trout of the Lahontan basin, probably via Summit Lake. Dr. Hubbs once pointed out that a lava flow cut off a head water tributary system in the Lahontan basin to create Summit Lake. The lake level rose until it spilled over into the Virgin Creek drainage tributary to Alvord sump, or to ancient Alvord Lake during the late Pleistocene. Such a sequence of events would explain why a trout with gillraker numbers so similar to that of S. c. henshawi would be found in the Virgin Creek drainage.

This theory fails, however, to adequately explain why trout native to Willow and Whitehorse creeks average 21 gillrakers native. The spotting pattern characteristic of the Virgin Creek cutthroat trout (few large, round spots, more concentrated posteriorly) feeble development of basibranchial teeth (10 of 19 specimens more than 4 inches in size collected in 1934 lacked basibranchial teeth, and most of the rest have only one or two teeth|, and low scale counts (average of 135 lateral series scales), suggest that the ancestral cutthroat trout native to the Alvord basin has long been separated from its Lahontan cutthroat trout ancestor.

With so many unknowns, one must keep an open mind, although the following sequence of events suggests a plausible explanation of the origins and affinities of Alvord cutthroat trouts. During an early phase of Lake Lahontan, an ancestral Lahontan cutthroat, characterized by about 21 gillrakers and perhaps 150 lateral series scales, was isolated in Summit Lake by a lava flow. A maximum lake level was reached in Summit Lake, and it spilled over into the Virgin River drainage tributary to ancient Alvord Lake, transferring the cutthroat trout from Summit Lake to the Alvord Lake basin. The headwaters of Willow Creek intertwine with those of Trout Creek (tributary to ancient Alvord Lake). An early transfer of trout (before the gillraker number was increased under selection in ancient Alvord Lake) occurred between Trout and Willow creeks. During cooler, wetter climatic periods, the lower reaches of Willow and Whitehorse creeks would have come into contact allowing the trout to become distributed throughout the Willow and Whitehorse creek drainages.

In both Summit Lake and ancient Alvord Lake, convergent evolution produced a trout similar to S. c. henshawi in gillraker number. Summit Lake still exists, and its native trout have slightly more gillrakers (25) 
than are typically found in S.c. henshawi. The trout isolated in Willow and Whitehorse creeks followed a course of evolution that paralleled that of the cutthroat trout native to the Humboldt River drainage of the Lahontan basin. That is, both subspecies (Humboldt and Willow-Whitehorse) remained little changed from the assumed ancestral Lahontan cut throat trout, with about 21 gillrakers and about 150 scales, that gave rise to both of them.

I have noted some basic similarities between Summit Lake cutthroat trout and the Virgin Creek specimens of the Alvord basin collected in 1934, which suggests a common evolutionary heritage. These basic similarities shared by Summit Lake and Virgin Creek cutthroats, differentiating them from typical S.c. henshawi are: reduced fin ray counts, particularly a trend toward having eight pelvic rays (almost all cutthroat trout have ninel; fewer spots on the body; lower scale counts labout 155 in the lateral series in Summit Lake cutthroat trout and 135 in Virgin Creek specimensl; the occurrence of fused vertebral centra, noted from examination of X-rays; and the trend toward more feeble development of basibranchial teeth.

If my assumptions are correct, the cutthroat trout of Summit Lake, presently considered to be one of the few remaining pure stocks of $S$.c. henshawi, may be genetically closer to the trout once native to the Alvord Lake basin (Virgin Creek cutthroat) than to present S. c. henshawi - or intermediate between henshawi and the Alvord Lake basin subspecies. 


\section{CUTTHROAT TROUT NATIVE TO ALVORD LAKE BASIN, Salmo clarki subsp.}

\section{TYPICAL CHARACTERS}

Differs from S.C. henshawi in typical spotting pattern. Spots fewer, not evenly distributed over sides of body. Lateral series scales 122-152 (135). Feeble development of basibranchial teeth; absent in 50 percent or more of specimens, and typically only one or two teeth in those specimens with basibranchial teeth.

\section{DESCRIPTION}

My data is based on the examination of 30 small (less than 6 inches) specimens collected in 1934 from Virgin Creek, Nevada (University of Michigan, Museum of Zoology Number 130532). There are fewer than 50 relatively large, round spots on the body, and very few spots on caudal fin. Spots not evenly distributed; concentrated posteriorly and above lateral line.

Gillrakers 20 to 26 (23.4). Basibranchial teeth absent in 10 of 19 specimens more than 4 inches in size. Scales in lateral series 122 to 152 (135); scales above lateral line 33 to 37 (35). About 30 percent of specimens have eight rather than nine pelvic fin rays. Branchiostegal rays typically fewer than other western trouts (8-9 vs. 9-12). Pyloric caeca, 34 to 49 (42). Vertebrae, 59-63 (61.2).

In 1934, Dr. Hubbs collected trout specimens from Trout creek, Oregon, in the Alvord Lake basin. The Trout Creek specimens represent various stages of hybridization with rainbow trout, which is obvious from their appearance, reduced number of gillrakers, absence of basibranchial teeth and 9 and 10 pelvic rays. This raises the question of possible hybrid influence in the Virgin Creek specimens (feeble basibranchidl teeth, low scale counts|. From the distinctive and uniform spotting pattern exhibited by the Virgin Creek specimens, I believe that if this population had been hybridized by rainbow trout prior to 1934 , the effects were very slight and the characters little influenced. After 1934, rainbow trout replaced or "absorbed" the native cutthroat trout in Virgin Creek. A 1971 collection from approximately the same site contained only typical rainbow trout.

\section{DISTRIBUTION}

I assume that the Alvord Lake basin trout was originally a lacustrine-adapted trout existing in ancient Alvord Lake and spawning in tributary streams. After the desiccation of Alvord Lake, it was restricted to tributary streams. The two major tributary systems to Alvord Lake (the present Alvord sump) are the Virgin-Thousand Creek drainage, originating in Humboldt County, Nevada, north of Summit Lake, and the Trout Creek drainage originating in the Trout Creek Mountains, Harney County, Oregon, at the Nevada boundary. The Alvord Lake basin cutthroat trout was native to both the Virgin-Thousand Creek and the Trout Creek drainages. Like S. c. henshawi and S. c. utah, its lacustrine evolutionary heritage made it vulnerable to replacement and hybridization from nonnative trouts in small stream habitat. Collections made in 1971 in Virgin Creek and in 1972 in the Trout Creek drainage to the headwaters found only rainbow trout.

\section{TAXONOMIC NOTES}

I believe that the cutthroat trout native to the Alvord Lake basin was sufficiently differentiated from both S. c. henshawi and from the cutthroat of Willow and Whitehorse creeks to deserve separate subspecific designation. If by some remote chance an extant population were to be discovered, it would undoubtedly be a small population, probably in a precarious survival status. If such an unlikely even occurs, formal subspecies designation should be published so this subspecies could be listed under the Endangered Species Act. 


\section{LIFE HISTORY AND ECOLOGY}

Nothing is known except that this trout was a relict of Alvord Lake and its lacustrine-specialized heritage made it vulnerable to rapid replacement and hybridization once rainbow trout were introduced into its habitat.

\section{STATUS}

This trout is probably extinct. The collection made in 1934 was from the canyon area just above the junction of Virgin Creek with Thousand Creek (just above the Thousand Creek Gorge, T44N, R25E). A collection of six specimens in the Oregon State University collection (3834) made in 1971 from Virgin Creek in this area (T34N, R25E), are rainbow trout with 62-63 vertebrae, 17-20 (18.7) gillrakers, 116-130(122) lateral series scales, $9-10$ pelvic fin rays, $10-12$ branchiostegal rays, basibranchial teeth absent in all specimens, and no trace of the distinctive spotting pattern of the trout found here in 1934.

In the Trout Creek drainage, hybridization was already underway in 1934, but specimens from other headwater localities still bore a strong resemblance to the Virgin Creek trout. In 1972, I collected from the Trout Creek drainage to the uppermost headwaters and found only typical rainbow trout. In 15 specimens examined in an attempt to find some trace of the original cutthroat trout genotype in the present rainbow trout population, I found 60-64 (63) vertebrae, 15-20 (18.6) gillrakers, 41-66 (53) pyloric caeca, 9-12 branchiostegal rays, and no basibranchial teeth-no trace of the native cutthroat trout can be detected.

Ialso sampled the head waters of Cottonwood Creek, a western drainage from the Trout Creek Mountains to Pueblo Slough (Thousand Creek drainage) and again found only rainbow trout.

The Alvord basin is desert country with few perennial streams and little opportunity for the native cut throat trout to exist in some isolated locality. The area has not been thoroughly surve yed for native trout, however, and the remote possibiltiy exists that the Alvord Lake basin cutthroat trout is not extinct. The high elevation area immediately north of the Summit Lake basin, such as the western drainages from the Pine Forest Mountains, should be surveyed.

Rediscovery of the Alvord cutthroat trout would be a significant event. 


\section{CUTTHROAT TROUT OF WILLOW AND WHITEHORSE CREEKS, Salmo clarki subsp.}

\section{TYPICAL CHARACTERS}

Differs from Alvord Lake basin subspecies by fewer gillrakers (typically 19-23 vs. 22-25), more scales in lateral series (typically 140-155 vs. 125-145), more pyloric caeca (typically 40-58 vs. 35-48), and better development of basibranchial teeth (averaging 5-6 and present in about 95 percent of specimens).

\section{DESCRIPTION}

The description of the trout of Willow and Whitehorse creeks is based on 59 specimens collected from 1934 to 1972 from Willow Creek, 51 specimens collected from 1969 to 1972 from Whitehorse Creek, and 15 specimens collected in 1972 from Little Whitehorse Creek.

Willow Creek and Whitehorse Creek are compeltely isolated from each other, but it is assumed that at some time during the past few thousand years, a period of wetter climate allowed connections between the drainages and the trout moved from Willow to Whitehorse Creek. As might be expected, there are some slight differences between the populations native to the two isolated drainages. A dirt road crosses Little Whitehorse Creek, and if nonnative trouts were ever stocked, Little Whitehorse Creek would be the most probable site for introductions. Little Whitehorse Creek connects to Whitehorse Creek during high flows, and trout can move throughout the drainage where perennial flows occur.

In 59 specimens from Willow Creek, I counted 59 to 64 vertebrae $(61.8), 18$ to 23 (21.0) gillrakers, 39 to 59 (48) pyloric caeca, 36 to 45 (41) scales above the lateral line, and 141 to 163 (152) scales in the lateral series. Virgin Creek specimens a verage 35 scales above the lateral line and 135 in lateral series. Fifty-six of the 59 specimens had basibranchial teeth (95 percent), which range in number from 1 to 13 (6). Almost all specimens have 9 pelvic fin rays, and branchiostegal rays range from 9 to 11 .

The data from 51 specimens from Whitehorse Creek are essentially similar to the Willow Creek samples: vertebrae, 60-63 (61.9); gillrakers, 18-24 (21.6); pyloric caeca, 37-52 (46); scales above lateral line, 34-43 (38); in lateral series, 127-164 (142); basibranchial teeth present in 40 of 41 specimens over 4 inches (97 percent), ranging from 1-14 (5).

In the specimens from Little Whitehorse Creek, a slight hybrid influence might be reflected by the absence of basibranchial teeth in 2 of 15 specimens ( 87 percent with teeth), and a specimen with a pyloric caecal number of 76 . The spotting pattern is similar to that of the Virgin Creek speicmens, being relative large and sparsely distributed with a tendency for concentration posteriorly and above the lateral line anteriorly. The coloration is similar to that of Lahontan and Hummboldt cutthroat trout, with dull silvery or brassy coloration and indistinct rose tints in the region of the lateral line in sexually mature fish.

\section{DISTRIBUTION}

In historical times, this trout had been restricted to the Willow and Whitehorse Creek drainages, Harney County, Oregon. No other species of fish is found in Willow or Whitehorse creeks, indicating a long period of isolation from all surrounding drainages. The absence of the Alvord chub, Gila alvordensis, and the position of the shoreline of ancient Alvord Lake at its maximum elevation, which is below the desert plateau receiving the waters of Willow and Whitehorse creeks, indicate that those creeks never directly connected to ancient Alvord Lake. To the northeast there is only a slight divide separating the desert plateau from the Owyhee River drainage of the Columbia basin. Evidently, this desert plateau never contained an ancient lake connecting with either the Owyhee drainage or with Alvord Lake. The obvious conclusion is that the ancestral trout entered Willow Creek from a headwater stream transfer. The most likely place for this to have occurred is in the Trout Creek Mountains where the headwaters of Willow Creek and Trout Creek (Alvord Lake basin) are in close proximity. 


\section{TAXONOMIC NOTES}

Hubbs and Miller (1948) recognized "Alvord" cutthroat trout as an undescribed subspecies, but their material included specimens of both of the subspecies recognized here -from Virgin and Trout creeks of the Alvord Lake basin and from Willow Creek of the desert plateau basin. They did not examine the taxonomic characters of the specimens and failed to recognize the distinctions between the two groups. The graduate research of Wilmot (1974) included data on the cutthroat trout of Whitehorse Creek. He found this trout to have 64 chromosomes, similar to Lahontan and Yellowstone cutthroat.

\section{LIFE HISTORY AND ECOLOGY}

There has been no formal study made on the Willow or Whitehorse Creek cutthroat trout. In 1972, I observed these trout existing in warm, silty sections of their drainages, in atypical cutthroat trout habitat. Their evolutionary adaptations to an unstable arid land environment is probably comparable to the Humboldt cutthroat of the Lahontan basin and to the Bear River cutthroat of the Bonneville basin.

\section{STATUS}

Although there has been no replacement by nonnative trout in the original range of this subspecies, their populations were limited by the effects of livestock grazing when I visited the area in 1972 . Most of the Willow Creek and Whitehorse Creek watersheds are on BLM lands and are grazed by domestic livestock. The problem, typical of arid regions in general, is that all water and pala table vegetation are limited to the stream bottom areas by mid-summer, and the cattle concentrate along the streams causing damage to trout habitat by eliminating riparian vegetation, destabilizing stream banks, and silting the water. A livestock exclosure fence on a section of Whitehorse Creek demonstrated what the stream habitat might be throughout the drainage if protected from livestock. Within the fence, lush riparian vegetation stabilized the banks and provided cover. Outside the fence was a barren wasteland. Mr. Robert Borovicka, BLM fisheries biologist, Portland, Oregon, has since informed me that livestock have been excluded from the canyon areas to enhance the environment of the cutthroat trout. 


\section{COLORADO RIVER CUTTHROAT TROUT, Salmo clarki pleuriticus}

\section{TYPICAL CHARACTERS}

Differs from previous subspecies by higher scale counts 170-205+ in lateral series and 38-48+ above lateral line) and by the genetic basis to develop brilliant red, orange, and golden yellow coloration. S. $c$. pleuriticus cannot be differentiated from S. c. stomias on the basis of these characters however.

\section{DESCRIPTION}

A striking change in the coloration of native cutthroat trout occurs between the Bonneville basin, upper Snake River, and the Yellowstone River drainage on one hand, and the Green River - Colorado River basin on the other. Although some of the headwater tributary streams may be only a few miles apart, it would be possible to know that one had crossed a divide and was in the Green River drainage when the somber, dull hues of S. c. utah or S. c. bouvieri gave way to the brilliant coloration of S. c. pleuriticus.

The coloration is best developed on sexually mature males from lakes. Beside the red colors along the lateral line, the entire ventral region may be bright crimson, or bright orange, with golden yellow colors on the lower sides of the body. The spotting pattern is variable. Typically, in tributaries of the upper Green River in Wyoming, the spots are relatively small or moderate in size las small or smaller than the pupil of the eye) and are distributed on the sides of the body mainly on the caudal peduncle area and above the lateral line anterior to the dorsal fin, which is typical of interior cutthroat trout in general. The spots are pronounced and rounded in outline. In the Yampa River drainage, the native cutthroat have larger spots, quite similar to the greenback cutthroat S. c. stomias (Binns, 1977).

The Colorado River cutthroat trout and the greenback cutthroat trout consistently exhibit the highest scale counts of any of the subspecies, with the possible exception of S.c. alpestris. Lateral series scale counts range from 170 to well over 200. Pure populations of pleuriticus should average more than 180 scales in the lateral series and more than 43 scales above the lateral line. Vertebrae numbers typically range from 60 to 63 , with mean values of about 61 or 62 . Gillraker numbers range from 17 to 21 , with mean values of about 19 . Pyloric caeca numbers typically range from 25 to 45 and average from 30 to 40 . So few populations of what can be considered pure S.c. pleuriticus are known to exist that a valid diagnosis of this subspecies is difficult. Wernsman (1973) summarized the taxonomic data on Colorado River cutthroat trout in his thesis on the native trouts of Colorado. Some additional data based on reports I wrote for the Wyoming Game and Fish Department were given by Binns (1977).

\section{DISTRIBUTION}

The cutthroat trout native to the upper Colorado River basin has a large range, but it is a discontinuous distribution and probably has been for several thousand years because of the warm, sediment-laden waters in the Green River from above the town of Green River, Wyoming, and in the Colorado River below the town of Rifle, Colorado (these are about the present continuous downstream limits of rainbow and brown trout in the basin).

This discontinuous distribution probably explains the differences in the size of the spots from specimens from different parts of the drainage. S. c. pleuriticus is native to the upper Colorado River basin above the Grand Canyon. On the west, the downstream limits are the Dirty Devil River of Utah and on the east, the San Juan River drainage of Colorado, New Mexico, and Arizona. Although S. c. pleuriticus is not generally recognized as a native fish of Arizona, it almost certainly occurred in a few streams of the San Juan drainage in the Chuska Mountains on the New Mexico border. Mr. Charles Sanchez and Mr. Terry Merkel, USFWS biologists, sent me a specimen from one of these border streams in the Chuska Mountains. Although hybridized with rainbow trout, it still retained some of the strong coloration of pleuriticus. "Old timers" in this area agree that cutthroat trout are native to these streams. Old records of $S$. c. pleuriticus from the headwaters of the Little Colorado River and from the White River, Arizona, are based on S. apachespecimens (Miller, 1972). 


\section{TAXONOMIC NOTES}

No adequate description of the Colorado River cutthroat was published until the work of Behnke and Zarn (1976). Cope (1872) named S. pleuriticus from specimens he examined from the Green River, Fort Bridger, Wyoming; the South Platte River; and the Yellowstone River. Cope also listed pleuriticus from the Rio Grande and Bonneville basins. The basis for Cope's naming of a new species was a keel he observed along the midline of the skull in the specimen he grouped as pleuriticus. This character is not a natural trait, but was due to improper preservation of the specimens. They had become partially dried out, forcing the frontal bones of the skull together to form a ridge. Because a name had not been previously proposed for the cutthroat trout of the Colorado-Green River basin, Cope's name of pleuriticus became the valid name. Jordan (1891) fixed the name pleuriticus solely with the Colorado River basin cutthroat trout, and this usage has continued to the present.

\section{LIFE HISTORY AND ECOLOGY}

We can only speculate on the life history of pleuriticus, based on historical notes and recent observations. S.c.pleuriticus rapidly disappeared from the mainstreams of the upper Green and upper Colorado Rivers and their major tributaries after nonnative trouts were introduced. From this it can be surmised that they are not well adapted to coexist and compete in large river environments. Rainbow trout were first stocked into the Gunnison River, Colorado, in 1888 with 10,000 fry. By 1897, the Gunnison was famous for its rainbow trout fishing, with fish up to 12 pounds being caught, and the native cutthroat had virtually disappeared.

Trout that resemble pleuriticus are typically found in isolated head water streams today. In the foothill regions of the Green River drainage in Wyoming, however, several populations of "good" native cutthroat trout (slightly hybridized) are found in badly degraded stream habitat (Behnke and Zarn, 1976; Binns, 1977). The "purest" native lake population that still exists is in Trappers Lake, Colorado (Gold et al., 1978). Evidently, the Trappers Lake population of pleuriticus is well adapted for this environment by virtue of thousands of years of evolution in this lake (Trapper Lake watershed has not been modified much by man). Despite the stocking of millions of nonnative trouts over the years, the present Trappers Lake cutthroat trout shows no sign of hybridization.

The historically unstable environment characterizing the foothill streams of the Green River drainage of Wyoming may have exerted the same evolutionary selection on the S.c. pleuriticus of this area as was discussed for the Humboldt and Bear River cutthroats.

Historically, cutthroat trout reached a large size in the Colorado River basin with unverified reports of 20 pounds or more. An anonymous article in "Forest and Stream" magazine, published in 1878 (9/25:268-69), titled "Trout in the Rocky Mountains", mentioned that although the greenback cutthroat trout, S.c. stomias, was abundant on the east slope of the Rockies in Colorado, anglers would travel to the west slope to the Colorado River basin if they desired large trout.

\section{STATUS}

Pure populations of S.c. pleuriticus are gone from the great area they inhabited 100 years ago. I have little new information to add concerning the status of this trout other than what I wrote in Behnke and Zarn (1976).

Slightly hybridized populations resembling pleuriticus can still be found in many areas, but these areas in total represent less than one percent of the original range. These "good representative" populations should be recognized, protected, and managed as pleuriticus, which they primarily are. Based on my analysis of specimens and evaluation of the relative purity of many collections of cutthroat trout from Wyoming, Binns (1977) developed a rating system ranging from " $\mathrm{A}$ " (pure) to " $\mathrm{F}$ " (obvious hybrids), to facilitate the protection and management of S. C. pleuriticus in Wyoming. As discussed previously, there is no way "purity" can be certified. An "A" rating should be based on collections from isolated streams in which the specimens show no indication of a hybrid influence. 
In Wyoming, I have identified two such sites in the upper Green Riverbasin: upper Rock Creek, tributary to the Labarge Creek, and North Beaver Creek, tributary to Piney Creek. In 1978, Dr. Binns sent me 17 specimens from Lead Creek, a tributary of Horse Creek. The Lead Creek cutthroat sample have the most uniform and "ideal" pleuriticus spotting pattern of any sa mple yet examined. Each specimen is a mirror image of the others. Two of the 17 specimens lack basibranchial teeth, and the scale counts are marginal for what I would consider "pure" pleuriticus (average of 43 above lateral line and 181 in lateral series).

I would hesitate to declare the Lead Creek cutthroat trout as "pure", but in matters relating to management decisions about fisheries or land use, any population bearing such a strong resemblance to the native subspecies should be recognized as that subspecies. That is, the populations rated as A, B, or C by Binns (1977) should be recognized as S. c. pleuriticus without quibbling over the degree of purity. The cutthroat trout selected to illustrate $S$.c. pleuriticus in the color photograph on the cover of Binn's publication is from Red Castle Creek, a grade " $\mathrm{C}$ " population with 5 of 15 specimens examined lacking basibranchial teeth and with scale counts of 174 and pyloric caecal counts of up to 52, definitely indicating an influence from past hybridization with rainbow trout. Yet this hybrid influence cannot be detected from the spotting pattern and coloration-they look like typical S. c. pleuriticus.

In Colorado, a pure population of pleuriticus exists in Northwater Creek, a headwater tributary to Parachute Creek on the Naval Oil Shale Reserve lands. Records reveal a long stocking history of both "native" cutthroat trout and at least one introduction of rainbow trout. Yet, all 41 specimens examined from Northwater Creek have basibranchial teeth and average 47 scales above the lateral line and 186 scales in the lateral series. They appear to be a typical population of $S$.c. pleuriticus, with no evidence of hybridization. The Trappers Lake, Colorado, cutthroat trout also shows no evidence of hybridization from past introductions of nonnative trouts, and is propagated by the Colorado Division of Wildlife for stocking into high elevation lakes.

Because there are no populations of pleuriticus that have not been exposed to hybridization, the question of purity is relative. Management agencies should document the occurrence of populations that still resemble pleuriticus in outward appearance and then evaluate their characters in a ranking system similar to that of Binns' (1977). Those populations judged to have the least hybrid influence could be used to establish new populations in a restoration program.

Miller (1972) listed pleuriticus as one of the threatened fish of the United States. The Bonneville chapter of the American Fisheries society considered it endangered (Holden et al., 1974). It is listed as threatened by the Colorado Division of Wildlife. The 1979 Endangered Species Committee of the American Fisheries Society lists this cutthroat trout as one of "special concern". 


\section{THE GREENBACK CUTTHROAT TROUT, Salmo clarki stomias}

\section{TYPICAL CHARACTERS}

Similar to S.c.pleuriticus, but with a tendency to have larger spots and more scales/typically more than 45 scales above lateral line and more than 185 in lateral series).

\section{DESCRIPTION}

As with S.c.pleuriticus, there are so few pure or "good" stomiaspopula tions available for examination, and ancient museum specimens of this subspecies are also rare, that a valid diagnosis is difficult. From examination of available specimens, I find that the cutthroat trout native to the South Platte and Arkansas drainages have emphasized the basic spotting pattern and the high number of scales of their pleuriticus ancestor to produce a trout that typically has the largest spots and the most scales of any subspecies of cuthroat trout.

Scale counts in what I consider "pure" stomias collections average from 44 to 57 above the lateral line and from 189 to 217 (mean values) in the lateral series. Vertebral and caecal numbers are about the same as in S.c. pleuriticus. In its potential to develop brilliant coloration, stomias is similar to pleuriticus.

There is broad overlap in characters between specimens of pleuriticus and stomias. Two of my graduate students, Terry Hickman and David Miller, worked for the Colorado Division of Wildlife in the summer of 1977 and 1978 in an attempt to find new populations of greenback trout. They prepared a report on their work in 1977, in which they compared data from 16 taxonomic characters of previous collections of $S$. c. stomias with several other subspecies of cutthroat trout in a multidiscriminant function analysis. This analysis quantified the close relationship between stomias and pleuriticus.

Based on the taxonomic characters, 16 percent of the stomiasspecimens were incorrectly classified as pleuriticus, and 8 percent of the pleuriticus specimens were incorrectly classified as stomias. Thus, from a purely taxonomic viewpoint, stomias and pleuriticus might be considered a single subspecies. However, the names have been long recognized to designate the cutthroat trout native to the upper Colorado basin on one hand and to the South Platte and Arkansas drainages on the other.

\section{DISTRIBUTION}

The native distribution of the greenback cutthroat is in the headwaters (mountains and foothills) of the South Platte and Arkansas river drainages. The range lies almost entirely within the state of Colorado except for a few headwater tributaries of the South Platte in a small area of southeastern Wyoming. No trout are native to the North Platte drainage.

\section{TAXONOMIC NOTES}

There is considerable confusion about the origin of the name stomias for the original (type) specimens. It is possible that the specimens on which the name is based were not greenback trout taken from the South Platte drainage. In the same publication in which he named S. pleuriticus, Cope (1972) named S. stomias from specimens collected from what he considered the "South Platte River at Fort Riley", Kansas. The South Platte River drainage does not enter the state of Kansas. In later publications, Cope stated that the "type locality" of stomias is the Kansas River at Fort Riley. The Kansas River, however, has no native trout.

The confusion originated with an Army expedition under the command of Lt. F. T. Bryant, traveling from Fort Riley, Kansas, to Fort Bridger, Wyoming, and back again in 1856. A surgeon, Dr. W. R. Hammond, accompanied the expedition and made natural history collections. Among his collections were two specimens of cutthroat trout. The expedtion traversed parts of the Knasas, North Platte, South Platte, and Green River drainages in Kansas, Nebraska, Wyoming, and Colorado. Cutthroat trout could have been collected only in the Green River or South Platte drainages. The problem is that all of the specimens collected on the expedition were simply labeled "Fort Riley, Kansas", the terminus of the expedition, and shipped to the Philadelphia Academy of Sciences where Cope later saw the cutthroat trout specimens and named Salmo stomias. 
Jordan (1891) redefined stomias and limited its use to the cutthroat trout native to the South Platte and Arkansas river drainages. Jordan also appears to be the first to use the common name "greenback" for this trout in the literature. Actually, stomiasspecimens do not have any more green on their backs than do any other subspecies of cutthroat trout.

There is little genetic differentiation between stomias and pleuriticus because of their probable recent separation from each other. Undoubtedly, cutthroat trout invaded the South Platte basin from a stream transfer from the Colorado River basin. Thus, pleuriticus gave rise to stomias. A later transfer form the South Platte to the Arkansas drainage established greenback trout in that basin. It is likely that because of the great degree of isolation between different groups of S.c. pleuriticus in different areas of the Colorado-Green River basin, some pleuriticuspopulations share closer genetic affinities to some stomias populations than they do to other pleuriticuspopulations.

\section{LIFE HISTORY AND ECOLOGY}

The rapid disappearance of greenback trout after the introduction of nonnative trouts suggests the greenback is one of the most vulnerable of all cutthroat trouts to replacement by nonnative trouts. The historical range of the greenback has been well surveyed by my students and me during the past several years. We have neverfound an area with a concentration of several streams containing a trout that could be called a "good" greenback cutthroat trout. The three known populations that I consider pure stomias all occur in small headwater streams, protected from contamination from nonnative trouts by barrier falls.

The greenback trout seldom attained a large size. About one to two pounds seems to be a typical maximum size given by "old timers". Jordan (1891) mentioned that the greenback fed on invertebrates and when held in a hatchery, were reluctant to accept fish flesh as food. In Twin Lakes, Colorado, the greenback trout coexisted with the "yellowfin" cutthroat trout when Jordan visited the lake in 1889. The greenback did not exceed a foot in length, but the yellowfin cutthroat attained a size of 10 to 12 pounds.

In small headwater habitat, however, the greenback can attain a relatively large size of 14 to 15 inches (headwaters of Little South Poudre River), which is much larger than that attained by brook trout, Salvelinus fontinalis, in similar habitat. The brook trout is now the dominant trout in small, headwater tributary streams in the Rocky Mountains. A practical objective of replacing brook trout with greenback trout as part of a greenback restoration program is the replacement of stunted brook trout populations with a trout that can attain a much greater size and is more attractive to the angler.

\section{STATUS}

S. c. stomias was listed as "endangered" under the 1973 Endangered Species Act until 1978 when its status was changed to "threatened". Actually, the survival status of the greenback trout had deteriorated since 1976 (Behnke and Zarn, 1976). In Hidden Valley Creek in Rocky Mountain National Park, the greenback was reintroduced in 1973 after chemical treatement of the stream to eliminate the brook trout. Successful reproduction was noted in 1974 and 1975, but in the fall of 1976, brook trout were found in Hidden Valley Creek. It is probably only a matter of time before the greenback is eliminated by the brook once again in Hidden Valley Creek, although brook trout are actively being removed.

Black Hollow Creek, a small tributary to the Poudre River west of Fort Collins, Colorado, was transformed into a greenback trout sanctuary in 1967 by construction of a barrier dam and chemical treatment of the stream above the barrier to remove the brook trout.

Greenback trout from Albion Creek (the last 10 specimens found among hordes of stunted brook trout in 1968) and from Como Creek (40 specimens) were introduced into Black Hollow Creek. They reproduced and were flourishing until brook trout were found there in 1973. In the fall of 1977, my students and I thoroughly electrofished Black Hollow Creek for more than a mile above the barrier and found only brook trout. In 1978, a few greenback trout were found in a head water area above a partial barrier falls where brook trout had not yet reached. Black Hollow Creek was chemically treated again in 1979.

Behnke and Zarn (1976) mentioned that a 1971 transplant of greenback trout from Como Creek into a barren section of the North Fork of Big Thompson River failed (no greenback trout were found above the barrier in 1972). However, Bruce Rosenlund, USFWS biologist, found a healthy population of greenback trout above the barrier in October 1978. 
The change in status from endangered to threatened will benefit the greenback recovery program because the streams into which they are reintroduced will not have to be closed to angling. A state agency is not enthusiastic about banning angling in a stream on public lands. The Greenback Recovery Team is an active program which should greatly increase distribution and abundance within a few years. West Creek, in Rocky Mountain National Park, was treated in August 1978 to remove brook trout, and greenback trout from Hidden valley were stocked in June 1979. A small brood stock of greenback trout from Como Creek has been established at the Bozeman, Montana, Federal Hatchery to facilitate introductions.

In their search for greenback trout populations in the summers of 1977 and 1978, Terry Hickman and David Miller failed to find any pure populations, verifying the observation of Behnke and Zarn (1976) that it is unlikely many pure populations remain. They did, however, find a "relatively good" (partially hybridized) population in South Apache Creek (Arkansas River drainage) and identified several potential sites for introductions. Also, collections have been made in the North Park region (headwaters of North Platte drainage) where trout are not native but were introduced by the early settlers. To date, all North Platte drainage cutthroat trout specimens examined represent hybrid populations. If a "pure" population of cutthroat trout is found in the North Platte drainage, it will be a problem to identify whether it is stomias or pleuriticus. It would be assumed that the earliest introductions of trout into the North Park region were packed in from the nearest, most easily reached source. The south and west areas of North Park are contiguous with the Colorado River basin (pleuriticus), the east side of North Park is continguous with the South Platte basin (stomias).

I have already encountered the problem of identifying trout of unknown origins as stomias or pleuriticus. In the headwaters of the Poudre River drainage in the South Platte basin, I found what appears to be a virtually pure population of cutthroat trout in a small tributary to Long Draw Reservoir. This trout was brightly colored, averaged 48 scales above the lateral line and 198 scales in the lateral series, and showed no sign of a hybrid influence. Downstream in the Poudre River drainage, two barrier falls exist. It seems probable that no fish were native to this head water area. Before the turn of the century, an irrigation project tapped several tributaries at the source of the Colorado River with a ditch more than 20 miles long to transport water across the Continental Divide to Long Draw Reservoir. The population presently inhabiting this tiny tributary stream may have become established in the Colorado River basin via the Long Draw Ditch and therefore is pleuriticus, not stomias. The spots on this trout are smaller than is typically found in stomias specimens.

Behnke and Zarn (1976) believe that only two pure natural populations of stomias are known, and are found in the headwaters of the Little South Poudre River in Larimer County, Colorado, in a small habitat above a barrier, and in about two miles of stream in Como Creek, Boulder County, Colorado. The two populations exhibit considerable differences in some characters, including average lateral series counts of 190, with an average of 48 scales above the lateral line in Como Creek specimens, and counts of 217 and 57 in the Little South Poudre specimens. These differences are most likely due to selection or genetic drift acting on small, isolated poulations. They both exhibit large, pronounced spots on the body.

Behnke and Zarn (1976) mentioned that the "best" known greenback population still extant in the Arkansas River basin occurred in the headwaters of South Huerfano Creek. In 1976 and 1977, this area was investigated. Although some greenback trout still exist here, brook trout are now dominant. However, another population of greenback trout was discovered in Cascade Creek, a small tributary to the South Huerfano River head waters. Cascade Creek is isolated from the Huerfano River by a falls about 30 feet high. Above the falls only cutthroat trout are found. The taxonomic characters of 15 specimens from Cascade Creek lead me to believe they are a pure population of S. c. stomias. They average $194 \mathrm{scales}$ in the lateral series, 44 scales above the lateral line, 38 pyloric caeca, and all possess basibranchial teeth.

The fate of the greenback population native to Twin Lakes parallels the fate of the greenback trout in general. Twin Lakes was noted for its abundance of greenback trout in the 19th century. In the 1890's, rainbow, brook, and lake trout (Salvelinus namaycush) and Atlantic salmon were introduced. When Juday sampled Twin Lakes in 1902 and 1903, rainbow trout were dominant (Juday, 1906). Although Juday collected specimens of greenback trout, some of which I identified as hybrids when I examined Juday's specimens at the National Museum, he found no "yellowfin" cutthroat trout. The greenback disappeared from Twin Lakes shortly thereafter. Twin Lakes is now primarily noted for its lake trout fishery. 

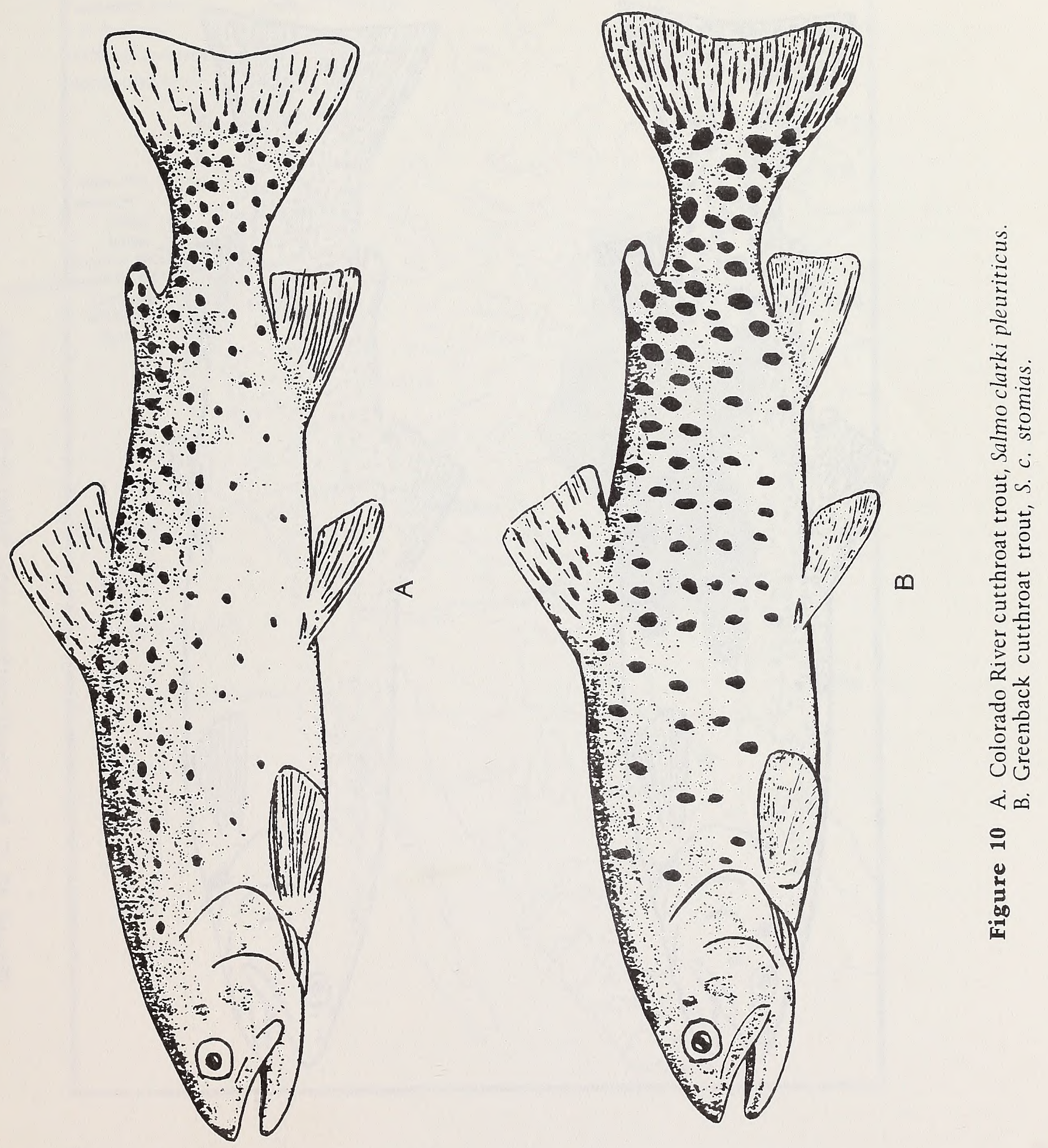

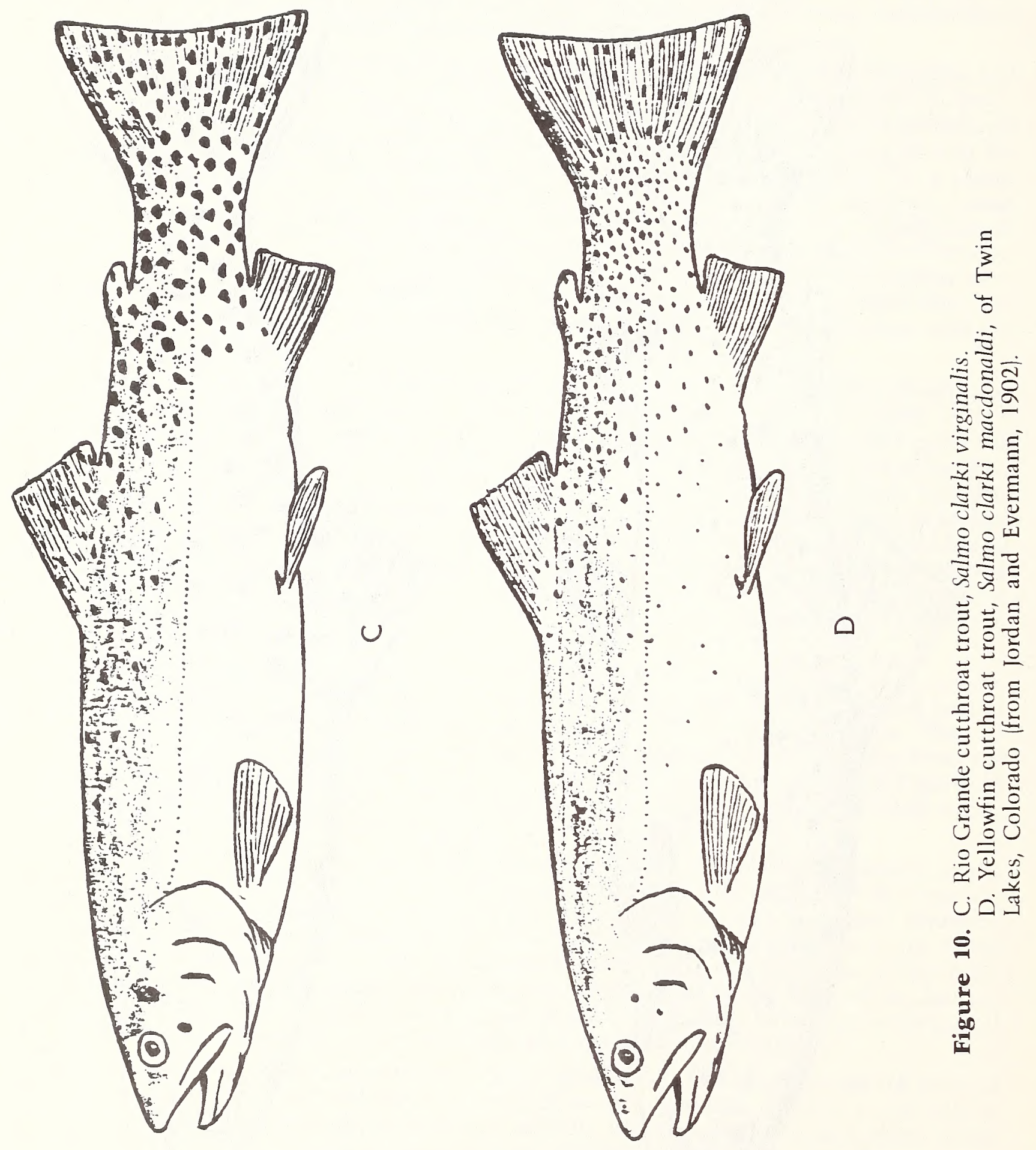


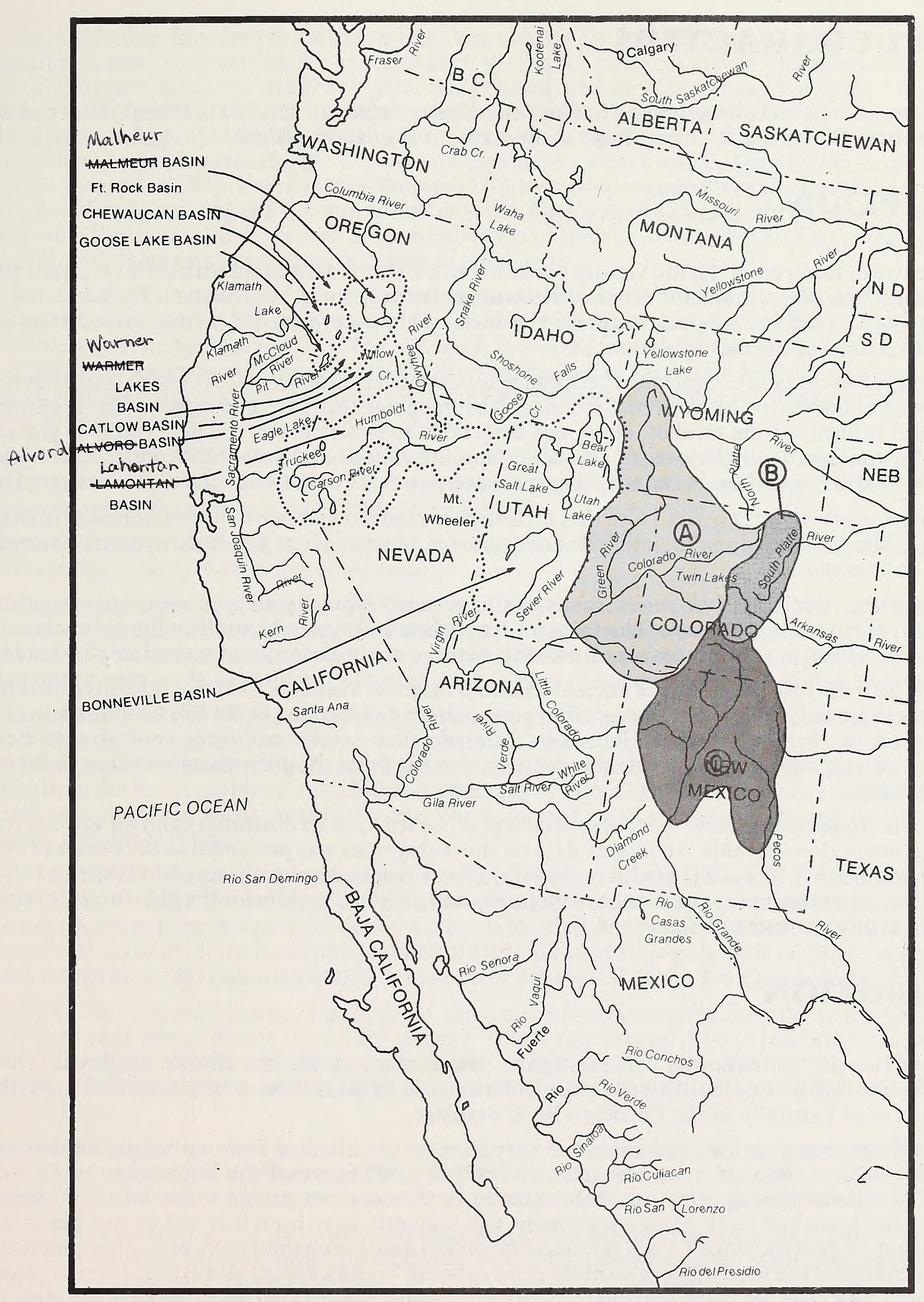

Figure 11. Original distribution of Colorado River cutthroat trout $[\mathrm{A}]$; Greenback cutthroat trout $[\mathrm{B}]$; and Rio Grande cutthroat trout $[\mathrm{C}]$ 


\section{RIO GRANDE CUTTHROAT TROUT, Salmo clarki virginalis}

\section{TYPICAL CHARACTERS}

Differs from stomias and pleuriticus by having fewer scales, typically 150-180 in lateral series and 35-45 above lateral line, and by the different shape of the spots on the caudal peduncle (irregular in outline).

\section{DESCRIPTION}

There are two basic forms of the Rio Grande cutthroat trout. One is associated with the Rio Grande proper of Colorado and New Mexico, and the other with the upper Pecos River in New Mexico. The cutthroat trout of the Pecos drainage differs by having larger spots, which are almost typical of S.c. stomias, and more scales in the lateral series - an average of about 175.

The number of vertebrae are typically 61-62, and pyloric caeca are typically 30-50, which is slightly higher than the caeca counts of pleuriticus and stomias. Basibranchial teeth are typically feebly developed. A slighty hybrid influence from rainbow trout, not detectable in other characters, may cause 50 percent or more of the population to lack these teeth. One of two specimens collected from the Rio Pureco, New Mexico in 1872 lacked basibranchial teeth, and the other specimen possessed only two microscopic vestiges of teeth.

The coloration of virginalis is similar to that of pleuriticusand stomias, with the development of rich red, orange, and golden yellow colors, but typically not expressed as intensely as is found in extreme examples of pleuriticus and stomias.

The most distincitive trait of virginalis is the spotting pattern. Typically, all spots are concentrated on the caudal penduncle in adult specimens. The spots form a profuse and close-set patch on the peduncle, and are not rounded in outline, but are "club" shaped, probably because of a coalescence of several small, round spots.

Although there is little in the way of ancient museum material available to base a valid diagnosis of S.c. virginalis, there are still several pure, or "good" representative populations in the Rio Grande basin of New Mexico and on the Forbes Trinchera Ranch in Colorado that exhibit sufficient general agreement in characters to provide a description of this subspecies and to recognize the differences between the Pecos and Rio Grande forms.

My graduate students and I have written several reports on Rio Grande cutthroat trout for various Federal and state agencies. Considerable taxonomic data on this subspecies was presented in the theses of Wernsman (1973) and Stork (1975). CSU graduate student, David Propst, also made several collections in New Mexico to document the present existence of virginalis and prepared reports for the U.S. Forest Service and the New Mexico Department of Game and Fish.

\section{DISTRIBUTION}

There are two major unknowns concerning the native range of the Rio Grande cutthroat. The first concerns the limits of its southern distribution. Did it exist in Texas and Mexico? The second is whether or not virginalis exist naturally in the Canadian River drainage.

Cope (1886) reported on two specimens of cutthroat trout collected from an unknown drainage of southern Chilhuahua, Mexico, at an elevation of 7,000 to 8,000 feet near the boundaries of Sinaloa and Durango. The Pacific drainage streams of this area have the Mexican golden trout, Salmo chrysogaster, which lacks basibranchial teeth. Cope's specimens subsequently have been lost and no one has collected cutthroat trout in Mexico since Cope's publication. Jordan and Evermann (1896, and other publications) describes the range of the Rio Grande cutthroat trout as being "southward to Chihuahua, Mexico" (based on Cope's record). If a cutthroat trout, derived from the Rio Grande basin, is native to Mexico, the most likely area where it would be found if it is not extinct, would be the headwaters of the Rio Conchos. A discovery of native cutthroat trout in Mexico would be a most significant find.

A trout that is possibly native does exist in the head waters of the Rio Casas Grande, a disrupted tributary of the Rio Grande basin in Mexico (Needham and Gard, 1959). The Casas Grande trout, however, is similar to the trout of the Rio Yaqui, a Pacific drainage which, in turn, bears relationship to $S$. gilae of the Gila River basin. 
It is possible that Rio Grande cutthroat trout once existed in the Rio Grande and Pecos basin of Texas, although this was never verified by collections. J. W. Daniel wrote an article on Salmonidae in Texas in "Forest and Stream" magazine in 1878 [10 (48): 339]. Daniel, who served in Texas during the Civil War, had a "distinct recollection" of catching "speckled trout" from the Devils River, a Rio Grand tributary in Val Verde County, and from the Limpia River, which is tributary to the Pecos in Jeff Davis County. Daniel also mentioned he caught trout in the Rio Bonito, Lincoln County, New Mexico. The Rio Bonito did contain S.c. virginalis during Civil War times. It is a tributary to the Pecos drainage and its native trout was transplanted into Indian Creek, draining the western slopes of Sierra Blanca Peak in southcentral New Mexico, north of Almagordo. This trout still is present in the headwaters of Indian Creek and is typical of the Pecos form of virginalis, with large spots and about 175 lateral series scales.

Indian Creek is the southernmost known distribution of virginalis. The assumption that the Indian Creek trout is not native but introduced from the Rio Bonito is based on testimony of local people gathered by USFWS biologists Robert Azevedo and Terry Merkel, and on the fact that the creek drains to the White Sands desert, long isolated form any contact with the Rio Grande. Indian Creek also has several barrier falls which would have made it impossible for trout to reach the present headwater area even if they once occurred in the present White Sands desert area (Tularosa Desert).

Another article in "Forest and Stream" in 1878 by N. A. Taylor [10 (13):236] that "brook trout" occurred in the Limmpia River, Texas. The Limpia River was described as a "clear, cool, sparkling stream flowing through a region about 5,000 feet elevation" (Davis Mountains).

The only stream containing a self-reproducing trout population in Texas today is McKittrick Creek on Guadalupe Mountain. They are rainbow trout.

The occurrence of native trout in the Canadian River basin was never verified by early explorers. The headwaters of the Canadian River system draining the east slopes of the Sangre de Cristo Mountains in northern New Mexico contain much excellent trout habitat. Cutthroat trout introductions into the Canadian drainage were made as early as 1907, according to New Mexico Department of Fish and Game records.

The thesis by Stork (1975) pointed out that the cutthroat trout native to the Pecos drainage bears a resemblance to the greenback cutthroat trout, stomias, native to the Arkansas River drainage of Colorado. Stork suggested that greenback trout may have been native to the Canadian River system from a head water transfer from the Arkansas basin, and a later transfer between the Canadian and Pecos drainages establishing the present form of the Pecos cutthroat trout. There are many fish species in common between the upper Canadian and upper Pecos.

In 1975, lexamined a sample of specimens from the Canadian River drainage in Colorado (Ricardo Creek, tirbutary of the Vermajo River|. I found them to be typical of Rio Grande S.c. virginalis, with relatively small spots, not the Pecos form of virginalis, or the Arkansas River drainage greenback trout. In 1977, David Propst made collections in the Canadian drainage of New Mexico and in all populations not thoroughly hybridized beyond recognition, the Canadian drainage specimens are typical of the Rio Grande form of virginalis.

Probably the most convincing evidence that Rio Grande cutthroat trout is native to the Canadian River system is an anonymous article in an 1877 issue of "Forest and Stream" [9 (4):67] on "Rio Grande trout". The author claimed that the finest fishing was found in the headwaters of the Vermejo River. The author was describing his fishing experiences in Colorado, and the only Vermejo River in Colorado is tribuary to the Canadian River.

Although the southern limits of S.c. virginalis is not known, the known limits, to Sierra Blanca Peak in New: Mexico, are far to the south of any other subspecies of cutthroat trout. The rext most southerly natural distribution is that of S. c. pleuriticus in the San Juan River drainage of northwest New Mexico.

The distribution of S. c. virginalis pure populations in New Mexico was presented in the May/June 1977 issue of "New Mexico Wildlife" magazine. A map in this article, showing Little Blue Creek as tributary to the Pecos drainage is in error. Little Blue Creek is in the Canadian River drainage.

\section{TAXONOMIC NOTES}

As with distribution, there is also some confusion surrounding the nomenclature of this subspecies.

In 1853, a Pacific Railroad Survey preserved specimens of cutthroat trout from what is now called Ute Creek at Fort Massachusetts in the San Luis Valley of Colorado. Girard (1856) described "Salar virignalis" on 
the basis of these specimens. Girard gave the locality as "Utah Creek". A few years later more specimens were taken and preserved at Fort Garland, near Sangre de Cristo Creek. Cope (1872) examined these specimens and named a new speices, "Salmo spilurus", from "Sangre de Cristo Pass". Both Ute Creek and Sangre de Cristo Creek are tributaries to Trinchera Creek, and it can be assumed that Griard's virginalis and Cope's spilurus were the same form of cutthroat trout. Although Cope knew of Girard's description of virginalis, he believed spilurus was a valid species because it was "not so slender". Cope believed "S. plueriticus" (Colorado River cutthroat) also inhabited the Rio Grande drainage around Fort Garland.

Jordan (1891) mistakenly assumed that the type locality of virginalis ("Utah Creek") was in the Bonneville basin of Utah and used the name virginalis for the Bonne ville cutthroat trout and spilurus for the Rio Grande cutthroat trout. This usage continued in the literature until J. O. Snyder recognized the error in 1919. Jordan (1920) further elaborated on this correction in nomenclature.

Most of the early literature on Rio Grande cutthroat trout mentions two forms, a small-spotted and a large-spotted variety. As discussed, there are two forms of Rio Grande trout, but the large-spotted form is isolated in the Pecos basin, and the two forms do not occur together. I can find no basis from examination of hundreds of specimens that two distinct forms of cuthroat trout, comparable to the situation of the fine-spotted and Yellowstone cutthroat trouts in the upper Snake River of Wyoming, ever occurred in the Rio Grande. Although there may be some factual basis for these early observations,. I believe they were because of size, age, and environment, and did not represent two distinct genotypes occurring together.

The early descriptions of Rio Grande cutthroat trout by Girard and Cope are worthless for identification purposes. Jordan (1891) provided some taxonomic data and illustrations of specimens, but concluded that the Rio Grande cutthroat trout is "wholly identical" to the Colorado River cutthroat trout except for having fewer scales.

Jordan beleived the Rio Grande cutthroat was derived from the greenback cutthroat via a transfer from the Arkansas drainage into the Rio Grande, and subsequently gave rise to the Colorado River cutthroat trout from a transfer from the Rio Grande into the upper Colorado River basin. The cutthroat trout native to the Colorado River, the Rio Grande, and the South Platte and Arkansas drainages form a close-knit genetic group. I believe that the Rio Grande cutthroat was derived from the Colorado River basin/Gunnnison or San Juan drainages) via a headwater transfer, rather than from the greenback trout of the Arkansas River drainage. The Sangre de Cristo Mountains form a formidable barrier between the Arkansas-Rio Grande exchanges.

\section{LIFE HISTORY AND ECOLOGY}

No detailed studies have been published, but it can be assumed from the present distribution of Rio Grande cutthroat in small headwater tributaries that they are highly vulnerable to replacement by nonnative trouts, and this is characteristic of interior cutthroat trout in general. As with other cut throat trout, the Rio Grande cutthroat is vulne rable to angling and may suffer differential mortality where they coexist with another trout in waters receiving any significant fishing pressure. It was mentioned in Behnke and Zarn (1976) that the native cutthroat trout was dominant over the brown trout (S. trutta) in the Rio Chiquitto, near Taos, New Mexico, before the Rio Chiquito became a public fishing stream. Soon after this stream received significant angling pressure, the brown trout became the dominant species.

\section{STATUS}

The Rio Grande cutthroat trout or a trout that typifies this subspecies is rare throughout its original range in Colorado and New Mexico. This conclusion has been reached by all who have studied this fish in recent years (Wernsman, 1973; Stork, 1975). Propst (1977, unpublished report, "Taxonomic analysis of cutthroat trout collected in northernmost New Mexico, 1976", submitted to New Mexico Department of Game and Fish|, summarized previous findings and discussed his own collections to conclude that $S$. c. virginalis is in a precarious state. Most streams containing Rio Grande cutthroat populations suffer from habitat problems because of livestock grazing. Some streams have no physical barriers separating the headwater cutthroat populations from rainbow trout and hybrids occurring lower in the watersheds. In contrast to most Rocky Mountain waters where the eastern brook trout is the most serious threat to native cutthroat trout in small streams, the brown trout seems to be the greatest threat in New Mexico. 
The New Mexico Department of Game and Fish is aware of the survival problems faced by the native cutthroat trout and has initiated some projects such as barrier construction to protect headwater populations. Angling is prohibited above the protective barrier in the Rio Chiquito watershed in Rio de la Olla and in Rio Frijoles. The first attempt to propagate pure Rio Grande cutthroat trout failed when all the fish brought to the state's Seven Springs Hatchery died. The brood stock of "native" trout of unknown origin at the Seven Springs Hatchery appears to be a "Duke's Mixture" based on Propst's analysis of 10 specimens. The low scale counts, [130-160 (139)], and highly variable pyloric caeca counts up to 60, suggest a rainbow trout influence. The development of basibranchial teeth [7-35 $(20)]$, indicates Yellowstone Lake cutthroat trout. Phenotypic selection by hatchery personnel over the years, selecting those fish most resembling "native" trout for egg taking, evidently has not been successful in eliminating the nonnative heredity from this brood stock.

The Colorado Division of Wildlife has also been active in restoration projects for the Rio Grande cutthroat trout. The first attempt to establish a brood stock with trout from Trinchera Creek stocked into Lower Dome Lake failed when brook trout became reestablished in tributary streams, and the lake was drained for repairs on the dam. In 1977, after brook and rainbow trout and hybrid specimens appeared to be increasing in Trinchera Creek, the entire stream was treated with rotenone and restocked with Rio Grande cutthroat from Indian Creek, an isolated tributary to Trinchera Creek.

The Bureau of Land Management cooperated with the Colorado Division of Wildlife to treat Tuttle Creek in the San Luis Valley, put in a barrier dam and stream improvement devices, and introduced Rio Grande cutthroat from Indian Creek. Mr. Lloyd Hazzard, a Division of Wildlife biologist, also rotenoned Jim Creek, Torsido Creek, Jarosa Creek and the Lake Fork of the Conejos River in 1976 and 1977 and reintroduced the native cuthroat trout. Rio Grande cutthroat have also been stocked into La Jara Reservoir in an attempt to establish a brook stock for propagation to serve an expanding program of restoration. 


\section{YELLOWFIN CUTTHROAT TROUT, Salmo clarki macdonaldi}

\section{TYPICAL CHARACTERS}

Not known. The original description of silvery coloration with yellowish tints and yellow fins was likely due, in large measure, to a direct environmental influence from living in Twin Lakes.

\section{DESCRIPTION}

The original description of the yellowfin trout by Jordan and Evermann (1890), essentially repeated by Jordan (1891), does not give any hard evidence that two distinct groups of cutthroat trout existed in Twin Lakes. If only the original description and literature accounts of the yellowfin trout were consulted, the reality of macdonaldi could be questioned. That is, the yellowfin trout was nothing more than larger, older greenback trout (S. C. stomias) with a modified appearance.

Fortunately, when Jordan visited Twin Lakes in July, 1889, he preserved seven specimens of yellowfin trout and eight specimens of greenback trout for museum collections. Juday's collections at Twin Lakes in 1902 and 1903 also deposited 13 specimens of greenback trout in the U.S. National Museum Collection (Juday, 1906). The seven specimens of yellowfin trout collected by Jordan in 1889 are believed to be the only specimens (living or dead) of this trout in existence (five specimens are in the National Museum and two specimens formerly in the Stanford University collection, are now at the California Academy of Sciences).

When I examined the seven specimens of yellowfin trout and the 21 specimens of greenback trout from Twin Lakes and critically compared the data, I had no doubt that Jordan was correct; the yellowfin trout and the greenback trout from Twin Lakes were two distinct groups of cutthroat trout - at least in 1889.

Although long preserved, the specimens are in good condition and the small, "star" shaped spots and silvery coloration of the yellowfin trout specimens are clearly recognizable and readily differentiated from the dark coloration and pronounced, large, rounded spots of the greenback trout specimens, as illustrated and described by Jordan (1891). All of the specimens are between six and 12 inches in length so the difference in appearance between the yellowfin trout and the greenback trout specimens is not due to size differences. In the meristic characters, I noted more gillrakers in the yellowfin trout than in the greenback specimens from Twin Lakes (20-22 [21] vs. 18-21 [19]). The yellowfin specimens have 159-185 (175) scales in the lateral series and average 42 scales above the lateral line. The greenback specimens have 170-202 (186) scales in the lateral series and average 48 scales above the lateral line.

\section{DISTRIBUTION}

Known only from Twin Lakes, Colorado (Arkansas River drainage). propagation of yellowfin trout was carried out at the Leadville National Fish Hatchery from 1892 to 1905 . Introduced into many lakes in Colorado by Federal and state agencies, but because of continued introductions into the same lakes of rainbow trout and other cutthroat trout, no introduced yellowfin trout population is known to exist. Last reports (unauthenticated) of yellowfin trout persisting in a lake in Colorado date to 1930's.

\section{TAXONOMIC NOTES}

Although I have no doubt that there were two distinct groups of cutthroat trout living in Twin Lakes in 1889, I do have doubts that the yellowfin trout was native there. It may have been introduced by early anglers from the Eagle River of the Colorado River basin (S. c. pleuriticus). It is possible that an ancient headwater stream transfer could have brought $S$. c. pleuriticusfrom the headwaters of the Colorado River into the headwaters of the Arkansas River drainage above Twin Lakes and, under strong selections to maintain two ecologically distinct groups of cutthroat trout in Twin Lakes, the ancestral yellowfin trout and the greenback trout evolved reproductive isolation and a voided hybridization. Speculation is all that can be contributed on this matter, however, for there is no clear-cut evidence, concerning whether the yellowfin trout was native to Twin Lakes or introduced by man. 
Twin Lakes is near Leadville, Colorado, which was the second largest city in the state in the 1870's. Twin Lakes was a popular resort area; but the earliest reports on the trout fishing only mention the small, greenback trout. Charles Hallock's "Sportsman's Gazetteer and General Guide", published in 1877, discussed Twin Lakes fishing, mentioning that the trout were small in size (greenback trout), but anglers interested in larger trout could hike over Tennessee Pass to the Eagle River drainage. It would seem likely that some anglers, desiring larger trout in Twin Lakes, would have ca rried some of the Eagle River cutthroat back over the pass to stock into Twin Lakes. Differences in spawning time could have allowed reproductive isolation between the introduced cutthroat and the native greenback trout, at least for a few generations, until Jordan visited the lake in 1889.

Jordan also collected some trout from the Eagle River at Gypsum, Colorado, in 1889 and mentioned that they appeared to be almost identical to the yellowfin trout in appearance (Jordan, 1891). I have examined many cutthroat trout specimens from the Eagle River drainage and although they have been exposed to hybridization, enough of the original genotypes are still present to note that they have the typical $S$. $c$. pleuriticus coloration and spotting pattern (pronounced rounded spots). I believe the silvery specimens with small, irregular spots Jordan found in the Eagle River in 1889 was a direct environmental effect of turbidity and mine pollution in a large river environment. A point that should be noted, however, is that the two genotypes (yellowfin and greenback) did respond differently to the environmental conditions of Twin Lakes in regard to the phenotypic expression of coloration and spotting.

The first record that I am aware of mentioning a large, silvery trout in Twin Lakes is found in the 1885-1886 Report of the Colorado Fish Commissioner, John Pierce. Pierce claimed that a trout of yellow colors and with yellowish flesh reaching a weight of $10 \mathrm{lbs}$. was found in Twin Lakes. It was believed this trout spawned before the ice was off the lake. An attempt was made to transplant this trout into Island Lake on Grand Mesa.

\section{LIFE HISTORY AND ECOLOGY}

The large size of the yellowfin trout attracted the attention of anglers. The yellowfin reputedly attained weights of 10-12 lbs. and was piscivorous. Jordan (1891) mentioned its flesh was light colored from its diet, whereas the greenback cutthroat in Twin Lakes fed mainly on crustaceans and had red flesh. Jordan also recounted observations of fish culturists to the effect that when fed sucker meat, the captive yellowfin trout would eagerly devour it, but the greenback trout did not take to it naturally. There was a general belief that hybridization between the yellowfin and greenback trouts was avoided because the yellowfin spawned earlier, in the lake, and the greenback spawned later, in tributary streams.

\section{STATUS}

The yellowfin cutthroat trout has probably been extinct in Twin Lakes since about the turn of the century. Nonnative trouts were introduced in large numbers in the 1890's. Juday's collections of 1902-03 failed to find any yellowfin trout. Rainbow trout were dominant in the 1902-03 collections and greenback $x$ rainbow hybrids appeared. The greenback soon followed the yellowfin in extinction in Twin Lakes.

The U.S. Fish Commission Report for 1905 is the last record of yellowfin trout propagation at the Leadville hatchery. Due to past introductions and hybridizations, it is doubtful that "true" yellowfin trout were propagated in 1905. As mentioned, it was a common belief that introduced yellowfin trout persisted until the 1930's, particularly in Island Lake on Grand Mesa. The US. Fish Commission report for 1931 mentioned that the U.S. Forest Service was propagating yellowfin trout (probably from eggs taken from a silvery trout from Island Lake). I do not put much credence in such reports because so many nonnative trouts were stocked into Island Lake over the years that any of several subspecies of cutthroat trout or rainbow $x$ cutthroat hybrids with a typical lacustrine influenced silvery coloration could be called "yellowfin" trout.

In Jordan's autobiography, "Days of a Man", published in 1922, he recounted his discovery of the yellowfin trout in Twin Lakes in 1889. Jordan stated without verification that the yellowfin trout was "successfully introduced into France from eggs shipped from the Mount Massive, Leadville, hatchery." 
There is a remote possiblity that the yellowfin trout was once stocked into a barren lake where it was able to reproduce, and no other trout was later stocked into that lake. Even if such a situation existed, there is no way a trout could be verified as the original yellowfin trout of Twin Lakes.

It is not likely that any more will ever be known concerning the yellowfin trout. The mystery of its origin and validity of the name macdonaldi, whether native or introduced, will never be solved. 


\section{RAINBOW AND REDBAND TROUTS}

The phylogentic relationships of western trouts dipicted in Figure 1 is my interpretation of the evolutionary events resulting in the present groups of coastal rainbow trout and interior redband trout. Common patterns in taxonomic characters associated with distribution patterns (zoogeography) suggest to me that at least two major evolutionary groups are involved in the present diversity found in the trout commonly called "rainbow" trout. A common ancestor branched from the primitive cutthroat-like trout evolutionary line, and this divergence produced all of the present forms of rainbow trout and redband trout after a subsequent separation subdivided the ancestral rainbow-redband line into a rainbow trout evolutionary cluster and a redband trout evolutionary cluster. This split is somewhat comparable to the separation of the coastal cutthroat and interior cutthroat trout groups in age and in the magnitude of morphological divergence expressed.

I have not studied the rainbow and redband trouts as intensively as I have the cutthroat trouts, and I admit much uncertainty regarding evolutionary relationships and correct classification of the rainbow and redband trouts. I would point out that there are some groups which cannot be assigned to either the redband or the rainbow trout group on the basis of present knowledge.

If this monograph were to be a formal publication, I would take a conservative approach and classify all rainbow and redband trouts into a single species divided into subspecies as I have done with the cutthroat trout. For the purpose of this monograph, however, I believe that the reader's understanding of the two groups will be facilitated by separating the rainbow trout and redband trout groups into two species so that all forms discussed can be provisionally classified as either rainbow trout or redband trout. Setting up a hypothesis of evolutionary relationships delineated into two species groups will also facilitate the acceptance, rejection, or modification of my classification by future investigations when new information is developed.

\section{REALITY OF TWO MAIOR GROUPS OF “RAINBOW" TROUT}

As was reviewed, opinions on classification of trout, commonly called rainbow trout, has wavered from recognition of many species to considering all as a single species. David Starr Jordan first considered all rainbow trout as a single species in the 1880 's, but was mainly concerned with the classification of resident (nonmigratory) rainbow trout and anadromous steelhead trout-were they all one species or were they separate species? When Jordan discovered that some of the steelhead trout ascending the Columbia River had more scales (140-180) in the lateral series than he found on coastal rainbow trout (120-140), he recognized two species - S. gairdneri, for the fine-scaled steelhead of the Columbia River, and $S$. irideus, for the coarse-scaled rainbow trout occurring along the Pacific Coast.

In the 1890's when Jordan studied and described the California golden trout (S. aguabonita) and the fine-scaled resident trout of the McCloud River, California (S. stonei and S. shasta), he became uncertain and confused in regards to the relationship and classification of western trouts in general and "rainbow" trout in particular. This confusion was heightened by the trout collections of Jordan's associates, Evermann, Gilbert, and Rutter in the Columbia River basin in the 1890's. From Shoshone Falls of the Snake River, westward to the Cascade Range, they encountered resident populations of trout which seemed to bridge the gap between interior cutthroat trout and coastal rainbow trout. These trout had scale counts more similar to cutthroat trout (140-170) and often had traces of a cutthroat mark, but they lacked basibranchial teeth. This form of trout associated with the Columbia River basin east of the Cascades Range was recognized as the "silver"trout, S. gibbsi, by Jordan. Jordan (1892) described "Onocorhynchus kamloops" for the "Kamloops" trout native to lakes in the upper Columbia River and Fraser River basins of British Columbia. Later in his life, Jordan (in Jordan, Evermann, and Clark, 1930) recognized many (16) separate species in his classification of rainbow and golden trouts, although he then believed the Kamloops trout of British Columbia was the same (a synonym) of $S$. gairdneri (the fine-scaled rainbow trout of the Columbia River). Dymond (1932) continued to recognize $S$. kamloops as a distinct species separate from $S$. gairdneri.

The trout native to the upper Kalmath Lake drainage and to several desiccating basins of southern Oregon was long a mystery. E. D. Cope, the famous paleontologist-ichthyologist first called them rainbow trout, but later considered them to be cutthroat trout. Snyder (1908) classified these Oregon desert basin trout as cutthroat trout.

In the 1930's and 40's, much experimental data demonstrated that taxonomic characters such as the numbers of scales and vertebrae could be modified by incubating eggs at different temperatures. Most 
fishery workers followed the lead of Mottley (1934a, 1934b, 1936a, 1936b, 1937) in considering all forms of "rainbow" trout (except $S$. aguabonita) as a single species, S. gairdneri, assuming that characters were mainly environmentally induced and not a reflection of evolutionary divergence. Needham and Gard (1959) and MacCrimmon (1971) essentially lumped all non-cutthroat trouts of western North America as a single species, $S$. gairdneri.

In the early years of my graduate research, I recognized that there were consistent differences in scale numbers between the "rainbow" trout native to the upper Sacramento River basin of California, to the Oregon desert basins, and to the upper Columbia River basin on one hand, and those native to other coastal drainages on the other. These differences were too great, too consistent, and too widespread to be attributable to a direct environmental influence. Although I recognized long ago the reality of two major groups of "rainbow" trout, I first believed the "interior rainbow" trout resulted from hybridzation between interior forms of cut throat trout and coastal rainbow trout when the two species came into contact after the last glacial period. This opinion was expressed in a paper on the origin of hatchery rainbow trout from the McCloud River (Needham and Behnke, 1962).

Collections of trout specimens in northern California and southern Oregon in 1968, combined with studies on the California golden trout, led me to believe that the interior "non-cutthroat" trout, from the California golden trout of the Kern River drainage in southern California, to the "mountain Kamloops" trout in the headwaters of the Columbia River basin in British Columbia, represented variability within a single evolutionary line which branched off from the coastal rainbow trout in Pleistocene times. I noted a general trend in these interior "rainbow" trout (which I now call redband trout) for yellow and orange coloration, a trace of a "cutthroat" mark, vestigal basibranchial teeth, pronounced white or yellow tips on the dorsal, anal and pelvic fins, higher scale counts and lower pyloric caecal counts compared to coastal rainbow trout.

The geographical distribution of other fishes, animals, and plants reveal that in the Pleistocene, a "track" or pathway of distribution provided aquatic connections and favorable climatic conditions for trout to move from the Columbia River basin through the present desert basins of southern Oregon land to the upper Klamath Lake basin) to the Sacramento River basin of California. Glacial refuge areas existed in the Mt. Shasta region (McCloud River) and in the upper Kern River drainage of the Sacramento basin, allowing the preservation of relict populations in areas of glaciation.

I have expressed my opinion on the reality of the redband trout evolutionary line in several publications (Behnke, 1970; 1972; Schreck and Behnke, 1971), but have not heretofore discussed the taxonomy or distribution of redband trout in detail. Gold (1977) gave a description of the redband trout native to Sheepheaven Creek, an isolated tributary to the headwaters of the McCloud River in northern California. I would point out that the taxonomic characters presented by Gold for the redband trout of Sheepheaven Creek cannot be used to characterize all redband trout from diverse geographical areas. The Sheepheaven Creek trout is unique. Great variability is expressed in such characters as number of vertebrae, gillrakers, and scales in redband trout of different regions. For example, Gold found a mean value of 15.6 gillrakers in his sample of 25 specimens trout of the genus Salmo known from western North America.

In museum specimens of redband trout collected from Oregon desert basins in 1898 and 1904, I counted 20-25 gillrakers in specimens from some areas. Evidently the increased numbers of gillrakers in the desert basin redband trout is a "holdover" lacustrine adaptation acquired during the last glacial epoch when large lakes filled the present desert basins. The specimens I collected from the Oregon desert basins in 1968 and 1972 still exhibit higher than average gillraker counts (in comparison with coastal rainbow trout) and retain the basic coloration of redband trout, but they have been influenced by hybridization to varying degrees with hatchery rainbow trout.

In trout which I consider to be associated with the redband evloutionary line, mean values of vertebral numbers range from lows of 59-60 in California golden trout to highs of 64-66 in the redband trout native to the upper Columbia River basin (particularly the Snake Riverdrainage). Thus, if the data I have gathered on redband trout from throughout their range were to be quantitatively treated in the computer program used by Gold (1977, Fig. 4) the lines depicting redband trout would disperse to largely encompass coastal rainbow trout on one side and cutthroat trout on the other.

At present, it is not possible to quantitatively diagnose and separate all redband trout from all coastal rainbow trout or from all cutthroat trout on the bases of standard taxonomic characters or from unique gene loci. Utter and Allendorf $\mid 1977)$ demonstrated that the steelhead redband trout of the Columbia River basin east of the Cascade Range and from the upper Fraser River have consistently different frequencies of certain genes compared with coastal steelhead rainbow trout, but no complete distinction could be found at any 
gene locus. That is, a gene may have two or more distinct forms (alleles) and when this occurs, geographically remote populations a re likely to have significant differences in the relative proportion of the different alleles at a gene locus.

Different allelic frequencies associated with one taxonomic group or another can be used as supplemental evidence associated with other taxonomic characters for speculation on evolutionary relationships, but mere allelic frequency differences are not as powerful a taxonomic tool as complete ("species specific") differentiation at a gene locus between two groups. With complete differentiation, all of the alleles at a given gene locus in group $\mathrm{A}$ (for example, redband trout) are different from all of the alleles at this same locus in group B (for example, coastal rainbow trout). If such a gene locus could be found to distinguish all redband trout from all coastal rainbow trout, a powerful tool would be available to compare the relationships of the more dubious groups (such as Eagle Lake, California, "rainbow" trout, and Mexican "rainbow" trout).

Virtually all redband trout examined to date have 58 chromosomes, but coastal rainbow trout may have 58 to 64 chromosomes, with various combinations sometimes occurring in the same population (Thorgaard, 1977 and personal communication). Thus, at present, redband trout identification is most effectively assessed by means of standard taxonomic procedures in regard to geographical distribution, coloration, counts of scales, pyloric caeca, vertebrae, etc., much as is the case with the various subspecies of cutthroat trout.

It is likely that the interior redband trout came in to contact with coastal rainbow trout after the last glacial epoch, and hybridization occurred so that some of the forms that I consider to be rainbow trout or redband trout are actually the result of an ancient mixing of the two evolutionary lines. Only in areas isolated by barriers can we assume that the ancestral redband trout persisted without genetic mixing with coastal rainbow trout (until hatchery rainbows were stocked by man). These areas include the South Fork of the Kern River (California golden trout), the headwaters of the McCloud River (Sheepheaven Creek), and certain isolated headwaters in the Columbia River basin in British Columbia /the "mountain Kamloops" trout of Dymorid, 1932). From these areas, the native trout are conspicuoulsy differentiated from coastal rainbow trout. Simply by visual analysis, one would have no difficulty separating California golden trout from coastal rainbow trout. They also differ by a bout 40-50 lateral series scales, $20-25$ pyloric caeca, and 2-4 vertebrae, but no one has yet been able to find complete or even consistent differentiation at any gene loci between golden trout and coastal rainbow trout.

The major significance for fisheries management of the evolutionary separation of an ancestral line into a coastal rainbow trout group and an interior redband trout group does not concern the most correct taxonomic arrangement of relationships. Rather, it involves the adaptive specialization the different forms acquired under different selective pressures in different environments during the past several thousands years of evolution. There is an enormous wealth of genetic diversity yet to be tapped for fisheries management in rainbow and redband trout.

Anadromous steelhead populations are found in both coastal rainbow and redband trout groups. The only steelhead trout I presently classify with the redband group are those ascending the Columbia River east of the Cascade Range, and those in the Fraser River above Hell's Gate. It is possible that the steelhead trout that once ran up the Sacramento River to the McCloud River and to upper Klamath Lake were redband steelhead.

Some nonmigratory redband populations native to the Columbia River basin and the Oregon desert basins appear to have the genetic basis to be effective predators and to attain a large size. The large race of "Kamloops" rainbow trout native to Kootenay Lake evolved with kokanee salmon, Oncorhynchus nerka. After kokanee were introduced and flourished in Pend Oreille Lake, Idaho, the Kootenay "Kamloops" trout was stocked into Pend Oreille and attained weights to 37 pounds in five years (Scott and Crossman, 1973). This same race of "Kamloops" trout stocked into Je well Lake fish of 52.5 pounds is not considered the world record rainbow trout because it was trapped during spawn-taking operations and not caught by angling.

The "world record" angler-caught rainbow or redband trout is a 42 pound steelhead trout caught off of Bell Island, Alaska (Hart, 1973). I would assume that this record Alaskan steelhead trout belongs to the coastal rainbow trout group but would suggest the possibility that the "trophy" steelhead trout of southern Alaska and northern British Columbia are actually redband steelhead, or at least influenced from historical hybridization between rainbow and redband trouts. The Babine River, a major tributary of the Skeena River, which enters the Pacific Ocean just south of the Alaska-British Columbia border, is noted for the large size of its summer-run steelhead. Hart (1973) mentioned a 43 pound steelhead netted off Port Simpson, just north of the mouth of the Skeena River. 
The significance of the large "Kamloops" trout of Kootenay Lake is that there are relatively few lakes where rainbow trout or redband trout evolved together with kokanee salmon for several thousand years to acquire the adaptations necessary to become an effective predator on kokanee. Virtually all of these lakes with native populations of kokanee salmon occur in the upper Fraser and upper Columbia River basin with "Kamloops" trout. Kokanee salmon are widely propagated througout the West for introductions into large lakes and impoundments. Typically, where introuduced kokanee have flourished, the rainbow trout fishery has almost invariably declined. With the objective of establishing a trophy fishery in "kokanee" lakes, it is only common sense to consider the introduction of a "pre-adapted" kokanee predator such as the Kootenay "Kamloops" trout.

In the Oregon desert basins and in the arid regions of the Owyhee drainage (Columbia River basin) of southern Oregon, western Idaho, and northern Nevada, the redband trout has evolved adaptations to live in extremely harsh environments characterized by great temperature and flow extremes. I have mentioned the redband trout I caught in Chino Creek, Nevada, in water of 83 degrees F. I also mentioned that the redband trout of the Oregon desert basins evidently have retained an adaptation to be an effective predator on chubs of the genus Gila, apparently acquired when the trout and chubs inhabited the ancient lakes of these basins.

In most situations, hatchery strains of rainbow trout are not effective predators or competitors. The management of many lakes, characterized by warm summer water temperatures and abundant "rough" fish populations, consists of periodic eradication of all fish and restocking with hatchery rainbow trout. Would it not be worth while to consider a more innovative management approach by using the genetic diversity found in some redband trout populations and attempt to convert a forage fish liability into an asset?

\section{ORIGINS AND DISTRIBUTION}

The general time and geographic area involved in the separation of the ancient rainbow-redband evolutionary line from a primitive cutthroat trout-like ancestor and subsequent separation of this line into rainbow trout and redband trout lines is largely a matter of speculation. As was discussed, the retention of basibranchial teeth in the cutthroat species and their higher number of chromosomes indicate that the cutthroat trout is phylogenetically more primitive than the rainbow-redband group. The original distribution of cutthroat trout above the major barrier falls in the Columbia River basin and in the Great Basin indicates that they were in North America prior to the appearance of any member of the rainbow or redband group.

An Asiatic origin of the rainbow-redband group could by hypothesized, following the assumptions put forth by Neave (1958) who proposed that the genus Oncorhynchus was derived from the genus Salmo in isolated basins of the Pacific Ocean in the Far East during the Pleistocene. The fossil record now reveals the Oncorhynchus appeared before the Pleistocene, but Neave's speciation model might be applied to the original separation of the rainbow-redband group from a cutthroat-like ancestor and the subsequent separation of the rainbow trout from the redband trout.

If the center of origin were the Far East, the rainbow-redband line left little, if any, evidence of such an origin. Salmo mykiss of Kamchatka, appears to be a recent derivative of the coastal rainbow trout crossing over from North America during the late Pleistocene when the Bering Land Bridge existed. Ifind no evidence in taxonomic characters to suggest that $S$. mykiss is a primitive relic representing an early stage of evolution in the rainbow-redband line. The Formosan trout, known only from a few specimens from a single locality, Salmo formosanus, may represent the primitive transition from a cutthroat trout-like ancestor to the rainbow-redband line, or it may be a link between Salmo and Oncorhynchus.

In general, the most primitive living representative of the rainbow-redband group is the trout native to the head waters of the McCloud River above a series of barrier falls (Sheepheaven Creek trout). Certainly, the rainbow-redband group did not originate in the headwaters of the McCloud River, but rather represents a primitive interior dispersal pattern with the earliest invaders becoming isolated and protected from contact with the later invading coastal rainbow trout.

The characters useful for distinguishing redband trout from coastal rainbow trout-yellow and orange coloration, eliptical parr marks (vs. rounded) with supplemental dorsal and ventral rows of parr marks, a cheek "blotch" marking, higher scale counts, lower pyloric caecal counts, a faint cutthroat mark, and vistigial basibranchial teeth-are characters associated with cutthroat trout and with S. gilae, S. apache, and S. chrysogaster to some extent. The latter three species also share the pronounced white or yellowish tip 
mark on the dorsal, anal and pelvic fins with the redband trout. All of these shared characters can be considered primitive traits. The distribution patterns of redband trout in interior waters also indicates that they invaded North America before the coastal rainbow trout, but after the cutthroat trout.

As the ice sheets receded at the end of the last glacial epoch, redband trout spread throughout the interior reaches of the Columbia River basin until they were blocked by major falls. In this region the redband essentially replaced the cutthroat trout. Redband trout inhabited the lakes existing in the present Oregon desert basins (except Alvord Lake) during the late Pleistocene. The redband trout gained access to upper Klamath Lake and entered the Pit River via a connection from Goose Lake. Redband trout also became established in the upper Fraser River drainage of British Columbia. This distribution pattern suggest that redband trout were already differentiated from coastal rainbow trout prior to the beginning of the last period of glaciation. However, the possiblity that the coastal rainbow trout was derived from one of the existing branches of the redband line land not from a common ancestor giving rise to both rainbow and redband trouts|, such as the ancestral redband trout invading the Sacramento River basin, must be considered to fairly assess new information regarding relationships.

A precise distribution of redband trout cannot be given on the basis of present knowledge. "Rainbow" trout are native to the headwaters of the Athabasca and Peace River drainages of the Mackenzie River basin of Canada. The most probable origin of these Mackenzie basin "rainbow" trout is from headwater transfers from the upper Fraser River basin. Thus, I assume that the trout native to the Athabasca and Peace River drainages are derived from a redband ancestor.

Nothing is known of the characters of the trout native to the "transition" areas of the Columbia River (Cascade Range) and the Fraser River (Hell's Gate area) regarding their classification as redband trout, coastal rainbow trout, or intermediates between the two. Did the redband trout extend along the Pacific Coast to establish populations beyond the confines of the Columbia, Fraser, and Sacramento River basins? If so, are they still present today, sympatric with coastal rainbow trout in any area? Did they hybridize to produce a mosaic of forms? Utter and Allendorf (1977) found similar gene frequencies in Skeena River steelhead trout, redband trout (locality not given) and California golden trout. Undoubtedly, much new data will be developed in the next several years which may shed some light on the evolutionary history, distribution patterns, and the extent of hybridization of rainbow and redband trouts.

In the Columbia River basin, both anadromous steelhead and nonmigratory redband populations extended up the Snake River and its tributaries to Shoshone Falls. The redband trout extended its range to the very headwaters of the Columbia River proper in British Columbia, but were blocked by falls on the lower Pend Orielle River (Clark Fork-Flathead drainage) and lower Spokane River (St. Joe drainage) near the Washington-Idaho border. The upstream limits of redband trout distribution in the Kootenay River has never been adequately determined. Dymond (1932) noted that the "Kamloops" trout is native to Kootenay Lake, but not to the headwaters of the Kootenay drainage in British Columbia. The Kootenay River drains south from its origin in British Columbia into Montana. Its course through Montana and Idaho swings west and then north to enter Kootenay Lake. MacCrimmon (1971) drew the line at the British Columbia-Idaho border for the upstream limit of the natural distribution of "rainbow" trout in the Kootenay River. The actual native distribution extended upstream to some barrier on the Kootenay in Idaho or Montana.

Mr. Steve McMullin, a graduate student at the University of Idaho, recently sent me a copy of a paper written by two students, Darryl Esperland and Dean Scow, of Carroll College, Helena, Montana, titled "Native rainbow trout in Montana". In this paper, the major barrier falls on the Kootenay River to upstream movement is identified to exist between Troy and Libby, Montana. The natural distribution of redband trout in the Kootenay River probably extended to this falls. Heretofore, the rainbow (redband) trout has not been considered native to Montana.

The trout I call the coastal rainbow trout is distributed along the North American coast from the Kuskokwim River of Alaska to the Rio del Presidio, Durango, Mexico. I lack detailed data on the taxonomic characters of the trout native throughout most of this range and can only speculate on the rela tive influence of redband trout hybridization in the evolutionary history of the coastal rainbow trout. The characteristics of Mexican "rainbow" trout are particularly suggestive of a redband trout influence.

There is cause for concern regarding the future of the redband trout. The great majority of steelhead trout originally ascending the Columbia River must have been redband steelhead lonly a relatively small part of the basin lies west of the Cascades|. These runs have greatly declined and many local races are extinct due to dams, water development and land use practices in the Columbia basin. A historical summary of this decline and a discussion of present and future problems is discussed in a 1978 report: "A question of Balance: Water/Engergy-Salmon and Steelhead Production in the Upper Columbia River Basin," published 
by the Northwest Information Center, Eagle, Idaho. Although some runs are being maintained by hatchery propagation, there is no way a hatchery can maintain all the genetic diversity that was originally present in several discrete stocks homing to specific tributaries in a major river drainage after that drainage is blocked by a dam.

The introduction of hatchery rainbow trout and subsequent hybridization has largely elminated pure populations of resident redband trout in the upper Sacramento River basin, the Oregon desert basins and much of the Columbia River basin. As will be discussed, the common hatchery rainbow trout is overwhelmingly derived from coastal rainbow (steelhead) trout.

Undoubtedly, a considerable part of the original genetic diversity making up the redband trout evolutionary line has been lost during the past 100 years. Every effort should be made to save what remains.

\section{TAXONOMIC HISTORY}

Some background should be provided concerning the names I have chosen to designate the coastal rainbow trout, Salmo gairdneri, and the redband trout, S. newberryi. I will again point out that according to the international rules of zoological nomenclature, if all rainbow and redband trouts are treated as a single species, then $S$. mykiss is the name that should be used becauseS. mykiss is a member of the rainbowredband group and is the oldest name applied to any species in the group.

I have retained Richardson's name Salmo gairdneri for the coarse-scaled coastal rainbow trout because by general usage, $S$. gairdneri is associated with the common name of rainbow trout (American Fisheries Society's checklist of common and scientific names). Also the hatchery rainbow trout, introduced all over the world, is mainly derived from the coarse-scaled coastal rainbow trout. I have previously discussed that Richardson's S. gairdneri is based on a steelhead trout taken from Fort Vancouver, Washington, near the mouth of the Columbia River, and, most likely, was a redband steelhead because most of the Columbia caecal counts were given by Richardson, the identification of $S$. gairdneri as a coastal rainbow trout or an interior redband trout will never be known. With this degree of uncertainty, it is permissible to arbitrarily assign the name $S$. gairdneri to the coarse-scaled coastal rainbow trout.

For the selection of a scientific name for the redband trout species, two names, S. newberryi and S. gibbsi, must be considered. Girard described "Fario or Salmo newberryi" for a specimen from the upper Klamath Lake drainage in the Proceedings of the Academy of Natural Science of Philadelphia, Volume 10 for 1858. Suckley described Salmo gibbsi for the trout of the middle Columbia River basin in the Annals of the Lyceum of Natural History, New York, Volume 7 for 1858. The type specimen of gibbsi came from the Dalles area of the Columbia River, the previously mentioned "transition" zone immediately west of the Cascades. The type of newberryi (\#578) is in alcohol at the National Museum where three additional specimens (33959-33961) collected in 1883 from the Williamson River (tributary to upper Klamath Lake) exist. Examination of the type of newberryi and the three 1883 specimens from the Williamson River leaves no doubt in my mind that a trout derived from the redband evolutionary line was native to upper Klamath Lake. Although the dates for the names newberryi and gibbsi are both given as 1858 in Jordan, Evermann, and Clark (1930), according to Dean's Bibliography of Fishes, the actual publication date is 1859 for newberryi and 1862 for gibbsi. Thus, according to the rule of priority, newberryi takes precedence over gibbsi if both names are considered as the species name for redband trout. However, for subspecies recognition, gibbsi can still be used for Columbia River basin redband trout if it is assumed that the type specimen of gibbsi does represent a redband trout.

The next names applied to trout of the redband evolutionary line were given by Jordan. In 1892 Jordan described "Oncorhynchus kamloops" in Forest and Stream magazine for the trout of Kamloops Lake (Fraser River basin), British Columbia. Jordan also described "Salmo mykiss agua-bonita" for the golden trout native to the South Fork of the Kern River, California, in the 1892 biennial report of the State Board of Fish Commissioners of California. In the 1894 report, 1894, Jordan named "Salmo gairdneri gilberti" for the trout of the main Kern River, and "Salmo irideus stonei" and "Salmo gairdneri shasta" from specimens sent by Livingston Stone from the McCloud River, California. Needham and Behnke (1962) pointed out that there are no differences between the type specimens of "shasta" and "stonei" and they should be specimens represented a nonmigratory, fine-scaled trout (a redband trout) which differs from the coarse-scaled steelhead of the Sacramento River.

Thus, some names are available to use for subspecies designation of redband trout. S. newberryi kamloops 
for the trout native to the upper Fraser and upper and middle Columbia River basins unless all Columbia basin and Fraser basin redband trout a re classified under the older name gibbsi, S. newberryi aguabonita for the South Fork Kern golden trout, $S$. newberryi gilberti for the Kern River and Little Kern trout, and $S$. newberryi stonei following Snyder (1933) and Wales' (1939) selection of stonei over shasta for the redband trout of the McCloud River below the falls.

The redband trout native to the McCloud River above the series of impassible falls, presently known from Sheepheaven Creek, is considerably different (a distinct subspecies) from the trout named stonei and shasta from the lower McCloud. I attribute this difference to hybridization /more correctly, introgression or the infiltration of genes from one species into another along a contact zone resulting from limited hybridization) between the resident redband trout and coastal rainbow trout in the lower McCloud River. Evidently, the later invading coastal rainbow trout was not able to get above the falls into the headwaters of the McCloud.

The significance of the probable original coexistence of both redband trout and coastal rainbow steelhead trout in upper Klamath Lake and in the McCloud River is that sufficient divergence existed to maintain ecological segregation and reproductive isloation preserving the integrity of both groups.

\section{PROPAGATION HISTORY}

It has been commonly believed that the hatchery rainbow trout was derived from a nonmigratory trout ("Shasta" rainbow) of the McCloud River. Needham and Behnke (1962) reviewed the U.S. Fish Commission's fish cultural operations on the McCloud river from 1879 to 1888 based on the notes of Livingston Stone, director of the station on the McCloud. Needham and I pointed out that during the years of egg taking, the McCloud River drainage had a steelhead run (probably a coastal rainbow trout) and resident populations of fine-scaled trout (redband trout). Livingston Stone stated that he obtained small trout in tributary streams late in the year (November-December). Trout up to 10 pounds would appear in the McCloud River. Both the small (redband) tributary trout and the large (coastal steelhead) were caught, kept in holding ponds, and indiscriminantly spawned together. Because of the size differential, it can be assumed that the bulk of the genetic background of the rainbow trout first propagated in Federal hatcheries came from the coastal rainbow steelhead. This assumption is further borne out by the taxonomic characters I find in present stocks of domesticated hatchery rainbow trout-about 125-135 lateral series scales, 62-64 vertebrae, and 50-60 pyloric caeca.

Dollar and Katz (1964) further considered the origins of hatchery stocks of rainbow trout and concluded that they are all derived from the McCloud River, and no substantial mixing with other sources occurred until 25,000 eggs of Skagit River, Washington, steelhead were brought into the Manchester, Iowa, Federal hatchery in 1925. This, however, is far from the complete story.

It has been generally overlooked that a private hatchery operated on the McCloud River prior to the Federal operation and shipped many "rainbow" trout to other states (New York and Michigan in 1874-76 and to Japan in 1877) before the Federal station was in operation. Some of the history of the private hatchery operation of J. B. Campbell is given in Wales (1939) and MacCrimmon and Gots (1972). Mr. Campbell constructed his hatchery on Campbell Creek near its junction with the McCloud River. It is not known if the eggs shipped by Campbell were mainly redband trout, mainly coastal steelhead, or a hybrid mixture of the two. It is known that the first rainbow trout brood stocks established in New York by Seth Green at his Caledonia hatchery in 1874, in the Northville Michigan hatchery (private at that time) in 1876, and in Japan in 1877, came from J. B. Campbell's hatchery and not the Federal hatchery on the McCloud.

In 1879, Livingston Stone took over Campbell's operation for the U.S. Fish Commission and moved the hatchery to Crooks Creek (now Greens Creek), a tributary to the McCloud, 2.5 miles below Campbell Creek. From 1880 to 1888 , about 2.5 million "rainbow" trout eggs were shipped out by Livingston Stone, and brood stocks were established in Federal hatcheries in Wytheville, Virginia, and Northville, Michigan.

From 1895 to 1900, great numbers of steelhead (coastal rainbow) trout from Redwood Creek, California, the Williamette, Klamath, and Rouge Rivers of Oregon were propagated in the Federal hatcheries.

Probably the first propagation of rainbow trout was by the California Acclimatization Society. In the first report of the U.S. Commissioner of Fisheries for 1872-73, Livingston Stone wrote that he visited the trout ponds of the Society at San Pedro Point, about 20 miles south of San Francisco, where "California brook 
trout" were being raised. Stone mentioned that the Society had received many requests for eggs. The origin of the rainbow trout propagated by the California Acclimatization Society and the answer to the question regarding shipments to other states or countries is unknown to me.

Scott et al. (1978) discovered that the first rainbow trout established in New Zealand (1883) came from a private hatchery derived from eggs of steelhead trout from Sonoma Creek, a tributary to San Francisco Bay. Kiunen and Moring (1978) discussed the origins of six strains of rainbow trout propaged in Oregon hatcheries. Only one of these strains can be considered native to Oregon. Busack et al.(1979) examined the origins and genetic diversity of four hatchery strains of rainbow trout in California.

Thus, the overwhelming majority of hatchery brood stocks of rainbow trout maintained around the world originated mainly from various mixtures of anadromous coastal rainbow trout, with the redband trout of the McCloud River playing a minor role during the first years of hatchery operations on the McCloud River.

Exchanges of fish and eggs occurring between state, Federal, and private hatcheries, mixed rainbow trout stocks of diverse ancestry. Shebly (1922) and Leitritz (1970) reviewed the history of fish culture in California. From 1870 to 1960, 169 hatcheries and egg-taking stations wre operated in California. Even if hatchery records were to be examined in an attempt to document the origin of hatchery stocks, many unrecorded events occurred, such as crossing rainbow trout with cutthroat trout, which would not be discovered.

It may be that the genetic diversity of the various stocks that formed the present strains of hatchery rainbow trout provided the basis allowing rapid selection for domestication. Hatchery propagation of rainbow trout is more recent than that of brook trout, Salvalinus fontinalis, and much more recent than that of brown trout Salmo trutta, yet the rainbow trout is more highly domesticated (more efficiently reared in hatcheries).

Some of the original genetic diversity randomly used over the years in hatchery propagation is manifested in rainbow trout stocks established outside their native range. I (Behnke, 1972) once mentioned that two discrete runs of rainbow trout spawning in a tributary to Lake Huron may be derived from chance introductions of summer and winter run strains of steelhead that have maintained their genetic identity. Lake McConaughy, Nebraska, has a steelhead-like rainbow trout, developed from introductions in the North Platte River drainage many years ago, probably prior to the "complete domestication" of hatchery strains (Van Velson, 1974; 1978).

A discussion of the origins of domesticated strains of hatchery rainbow trout is largely of academic concern or perhaps useful for genetic considerations of hatchery characteristics such as disease resistance. Once a race of trout has been thoroughly domesticated by rigorous selection to perform well under hatchery conditions, the conclusion is that the genetic changes that have taken place favoring growth and survival under artificial conditions are negative changes in regard to survival under harsh natural conditions, particularly in competition with other fish species.

When considering the genetic resources available in a species in an attempt to solve fishery management problems, such as "rough" fish or kokanee salmon competition, extremes in water temperatures and lake level fluctuations, time and money should not be wasted experimenting with various strains of domesticated trout. The solution to these "problem" waters will be found in wild genotypes under natural selection. Although there has been a gradual awareness of the potential of wild genotypes in fisheries management programs, large-scale implementation of stocking offspring derived from wild populations is far from being achieved at the state or Federal level because wild trout propagation is difficult and does not readily conform to the efficiency standards of a typical hatchery operation.

In the proceedings of the "Wild Trout Management Symposium," held at Yellowstone Park, September, 1974, published in "Trout Unlimited", Nathaniel Reed, then Assistant Secretary of the Interior for Fish and Wildlife and Parks, said:

"The quality of stocked trout, their genetics, their stamina, the waters they will be stocked, their ability to grow, their wildness, will be key factors in fish production in the future. Hatchery programs, and this includes the Fish and Wildlife Service hatcheries, have been preoccupied in raising rapidly growing, oddly shaped, genetically tame candida tes more suitable for canning than for fishing. By hook or by order I hope I will see the Fish and Wildlife Service take a leadership role in developing strains of fish which will survive.

The qualities desired by Mr. Reed are only available for wild, not hatchery, sources of genetic diversity. The leadership role hoped for by Mr. Reed is yet to be manifested by any agency. 
Millions of surface acres of lakes and impoundments are stocked with rainbow trout each year. In those waters where the survival of fry or fingerling plants of rainbow trout is so low that a fishery can be maintained only at great expense by periodic poisoning, use of catchable size fish, etc., the genetics of the stocked trout is the primary factor governing survival and growth. Most instances of poor survival of rainbow trout fingerlings can be attributed to competition with "rough" fish or kokanee salmon with synergistic effects of warm summer temperatures and fluctuating water levels. A great wealth of genetic diversity is available in wild populations of rainbow and redband trouts "pre-adapted" to conditions found in some of these problem waters. Learning more about the role that wild genotypes can play in fisheries management will be well worth the time and effort of any fishery agency.

The Eagle Lake "rainbow" trout is propagated to a limited extent in California and Oregon. Oregon has established a brood stock of the Catlow Valley redband trout in a private ranch pond, and Wyoming has established a small stock of Chino Creek, Nevada, redband trout. Wyoming also propagates the wild rainbow trout of Lake DeSmet, particularly for introductions into reservoirs on the North Platte River, characterized by an abundance of "rough" fish.

For an agency considering the propagation of "wild" trout, it would be advisable to maintain brood stocks in natural waters to avoid genetic changes from domestication of hatchery brood stocks. Several stocks should be experimented with to learn the performance characteristics of each in different environments and to provide a source for hybridization and the creation of new genetic combinations. 

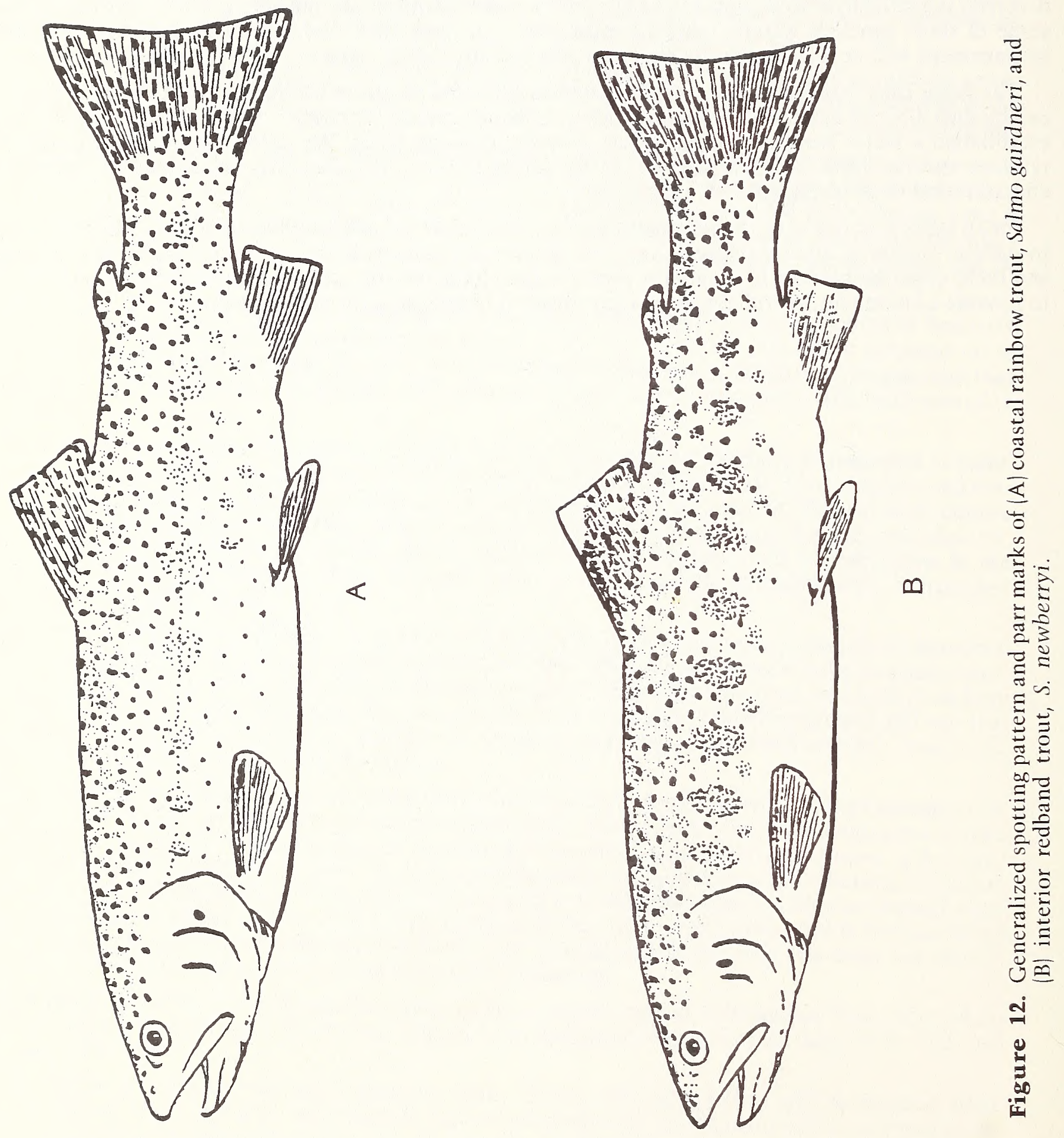


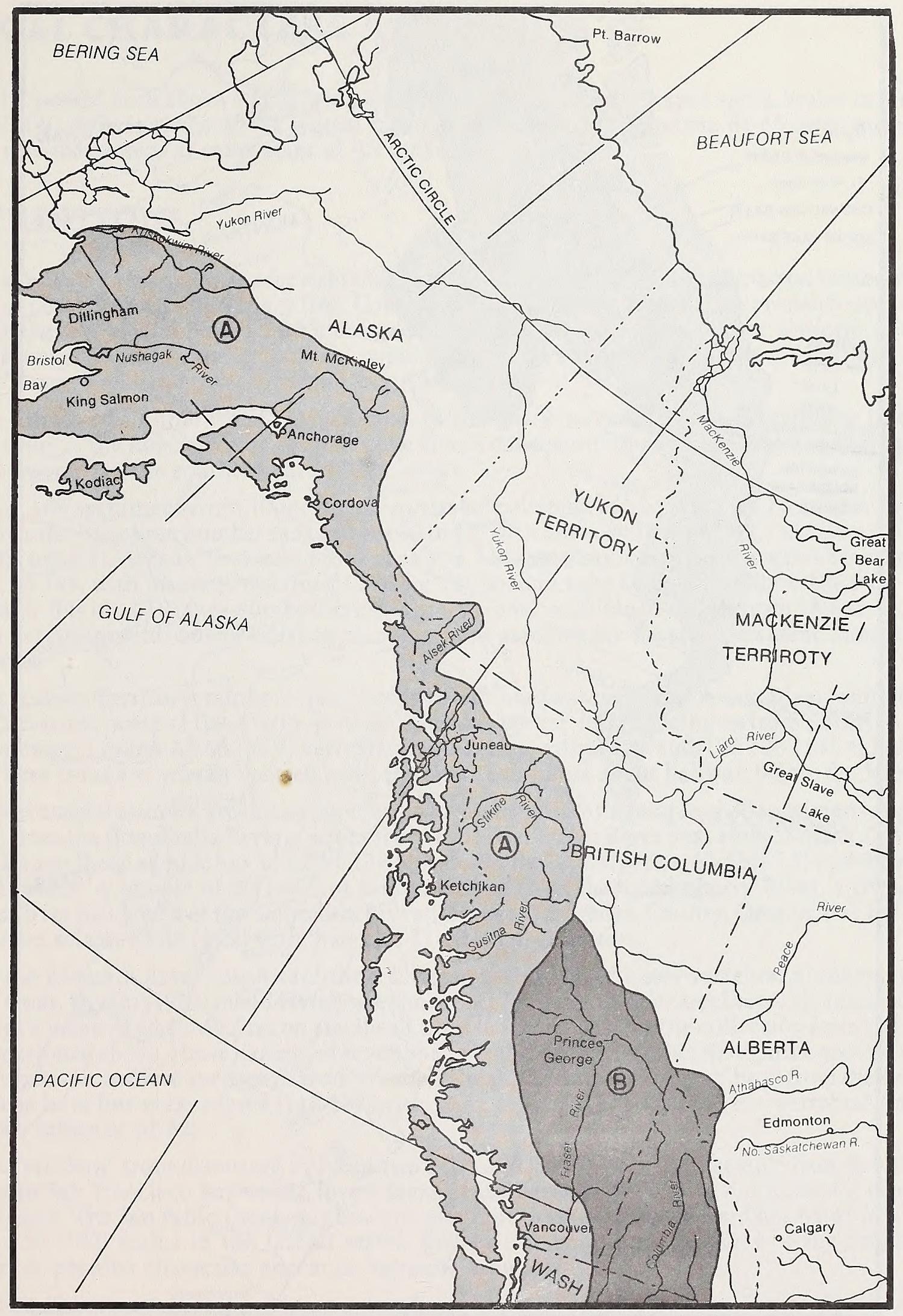

Figure 13A. Distribution of $[\mathrm{A}]$ coastal rainbow trout and $[\mathrm{B}]$ redband trout. 


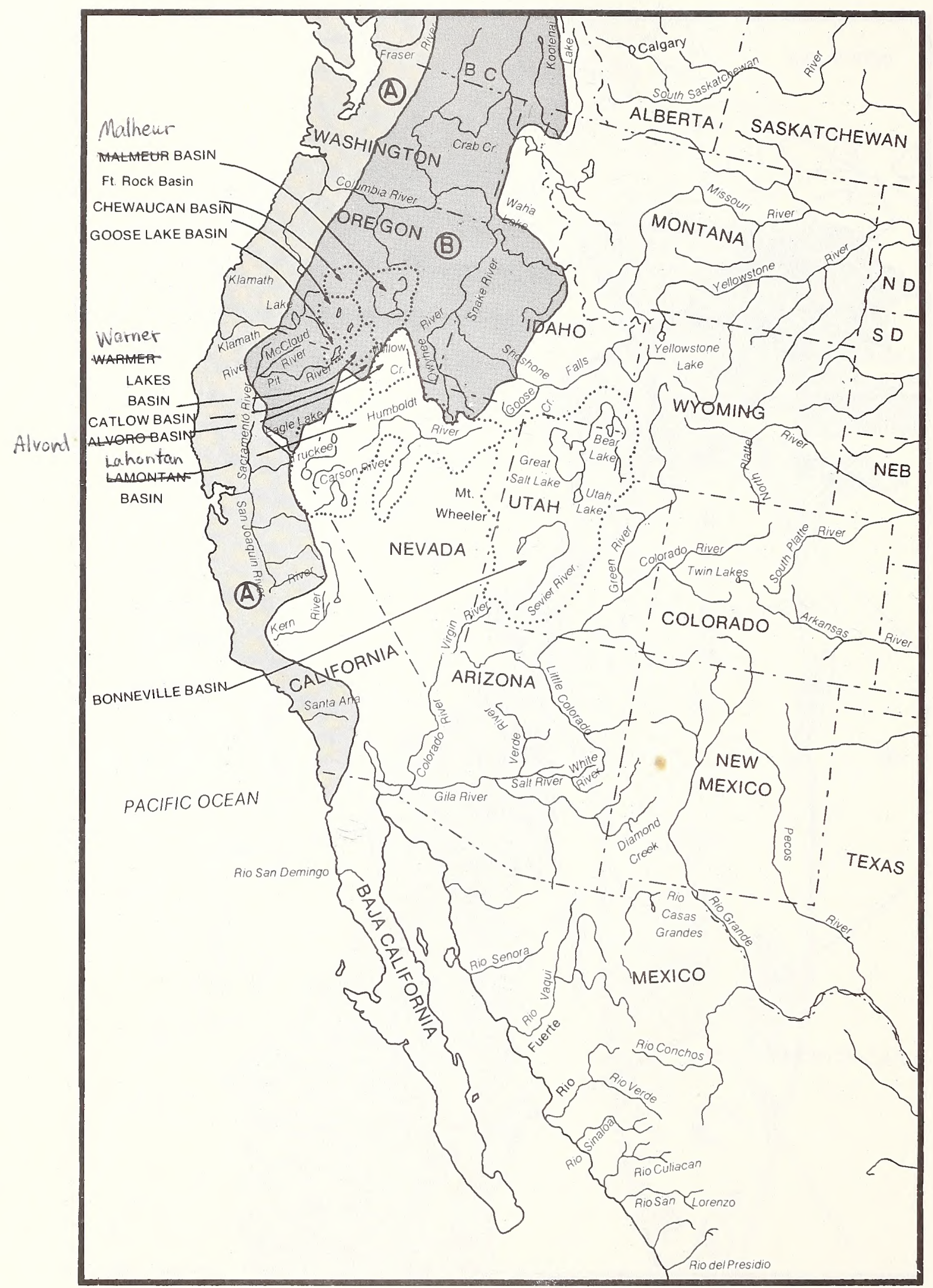

Figure 13B. Distribution of $[A]$ coastal rainbow trout and $[B]$ redband trout. 


\section{RAINBOW TROUT, Salmo gairdneri}

\section{TYPICAL CHARACTERS}

Heavily spotted both above and below lateral line with irregularly shaped spots. Scales in lateral series about 120-140. Pyloric caeca 40-70, typical mean values about 55. Vertebrae 61-65, with mean values of 62-64. A rose-red present at some stage of life cycle.

\section{DESCRIPTION}

At present, it is not possible to give a set of character values distinguishing all coastal rainbow trout from all trout of the redband evolutionary line. Considerable genetic interchange has probably occurred during and since the last glacial period, and many populations of rainbow trout do not conform to the typical diagnosis stated above. In these "variant" populations, such as Mexican "rainbow" trout and Eagle Lake "rainbow" trout, a redband trout influence is suspected.

There are no real clinal trends in variation in the characteristics of coastal rainbow trout. That is, rainbow trout in the northern part of their range do not consistently have more scales or vertebrae than do the rainbow trout in the southern part of their range.

Data on 166 specimens from 10 localities in Alaska, collected by the late P. R. Needham and myself in 1957 shows the vertebrae number ranges from 60 to 65, with mean values from 61.7 (Bedlam Lake on Kenai Peninsula) to 63.3 (Alagnak Tiver and Brooks Lake on Alaskan Peninsula). Lateral series scale counts range from 111 to 146, with mean values from 121.6 for the Bedlam Lake sample $(\mathrm{N}=20)$ to 136.9 for the Brooks Lake sample ( $\mathrm{N}=16$ ). Gill raker numbers range from 17 to 24 , with mean values from 18.6 to 20.2. As far as could be determined, all of the Alaskan rainbow trout samples are based on resident (non-anadromous) populations.

In the Yukon Territory, rainbow trout occur in the headwaters of the Alsek River, which enters the Pacific Ocean just north of the Alaska-British Columbia border. In 17 specimens from Kathleen Lake of the Alsek drainage, I found 63-66 (63.9) vertebrae, 15-20 (18.1) gillrakers, and 126-138 (131.4) lateral sereies scales. These trout are heavily spotted, with the spots extending about halfway below the lateral line.

A typical coastal rainbow steelhead population is represented by a sample of 30 specimens of pre-seaward migrants from the Coquihalla River, a tributary to the lower Fraser River near Hope, British Columbia. The Coquihalla steelhead sample has $111-138$ (124.5) scales in the lateral series, $62-65(63.5)$ vertebrae, and $18-22$ (19.2) gillrakers. A sample of 30 resident rainbow trout from the Salmonberry River, a tributary to the Nehalem River just south of the Columbia River drainage, Tillamook County, Oregon, has 117-143 (126.6) lateral series sclaes, 62-64 (63.2) vertebrae, and 17-20 (18.4) gillrakers.

From the Klamath River southward there is some indication of lower vertebral numbers in steelhead rainbow trout. Snyder (1931) made vertebral counts on $175 \mathrm{Klamath}$ river steelhead. He found a range from 60-65 with a mean of 62.2. My data on steelhead trout is sparse. Besides the collection from the Coquihalla River, mentioned above, I have examined seven specimens from the Russian River, nine specimens from the Sanlorenzo River, and five specimens from Waddell Creek, California, The steelhead from the southern part of the range have low scale counts (117-132, with mean values of $121-124)$ and low vertebral counts $(60-63$, with mean values of 61-62).

Of the "rainbow" trout discussed by Needham and Gard (1959), only their sample from San Pablo Creek, tributary to San Francisco Bay of the lower Sacramento River basin, can be considered a typical coastal rainbow trout. The San Pablo Creek rainbow trout sample of Needham and Gard has 61-65 (63.2) vertebrae and 121-153 (133) scales in the lateral series. Toward the southern extremity of the range of natural distribution, peculiar characters appear in "rainbow" trout populations.

Mr. John Hewitson, an ardent angler-naturalist, caught a peculiar trout in Pauma Creek, a headwater tributary to the San Luis Rey River on Mt. Palomar in southern California. The San Luis Rey River is about the southernmost limit of anadromous steelhead trout distribution. The trout of Pauma Creek exhibit yellowish colors on the sides of the body with occasional orange tints on the ventral surface and pronounced light-colored tips on the dorsal, anal, and pelvic fins. The parr marks are eliptical with supplementary small, round or oval markings ventral to the main row of parr marks. These traits are characteristic of redband trout, but in nine specimens of Pauma Creek trout sent to me by Mr. Hewitson, Ifound 62-63 (62.3) vertebrae, 122-140 (130.8) lateral series scales, and 17-19(18.3) gill rakers-typical of coastal rainbow trout. The pyloric caeca counts of 34-54 (42), however, are more typical of redband trout. 
A pond at the headwaters of Pauma Creek has a long history of stocking with hatchery rainbow trout, and a hatchery influence on the Pauma Creek population must be suspected. The unique appearance of the Pauma Creek trout and their low pyloric caecal nunmbers indicates that, predominantly, they represent the native trout of this region, and that this trout is differentiated from the typical coastal rainbow trout. Pauma Creek is isolated from the San Luis Rey River by a series of falls. The native trout isolated in headwater ares may represent the earliest invaders, perhaps the result of an early mixing of coastal rainbow and redband trouts when they first came into contact, or an early stage of the coastal rainbow trout divergence from the redband line.

A trout native to Baja, California, occurs in the Rio Santo Domingo drainage. This trout was described as a new species, Salmo nelsoni, by Evermann (1908). More complete descriptions of the Santo Domingo trout were given by Snyder (1926) and Needham and Gard (1959). More ichthyologists consider the Santo Domingo trout a disjunct population of coastal rainbow trout, S. gairdneri. The native trout of the Rio Santo Domingo typically have 61-62 vertebrae (low for coastal rainbow) and about 125-140 scales in the lateral series. Needham and Gard (1959) mentioned that one of their 25 specimens possessed three basibranchial teeth, a character not found in any other specimen of coastal rainbow trout. I counted the pyloric caeca in three specimens of Santa Domingo trout and found 46, 47, and 53 caeca.

The southernmost distribution of "rainbow" trout occurs in streams tributary to the Gulf of California in Durango and Sinaloa provinces of Mexico. Needham and Gard (1959) presented data from collections made in tributaries of the Rio del Presidio and the Rio San Lorenzo. The Rio del Presidio collections were made at about 24 degrees north latitude, just north of the Tropic of Cancer. With the native occurrence of Salmo formosanus and Oncorhynchus masou in Formosa at about the same latitude, these distributions are the southernmost natural occurrence of the family Salmonidae.

Since there has been considerable stocking of hatchery rainbow trout in Mexico, beginning with a shipment of 33,000 eggs from the McCloud River in 1888, the possible influence of introduction must be taken into account. The characters of the Mexican "rainbow" trout discussed by Needham and Gard (1959) are distinctive, and I do not believe they are derived from hatchery introductions. The trout of the Rio del Presidio and Rio San Lorenzo drainages are distinct from each other, and both are distinct from the Rio Santo Domingo trout of Baja California. The mainland Mexican trout appear to be more divergent from coastal rainbow trout than is the Baja California trout.

Needham and Gard (1959) presented data on 23 specimens from the Rio Tabacatiado and 27 specimens from the Rio Hondo, headwater tributaries to the Rio del Presidio. These trout are characterized by high vertebral counts, 63-66 (64.3 and 64.4) and relatively high lateral series scale counts, 125-150 (137 and 138). I counted $33-43$ (37.4) pyloric caeca in 10 specimens of Rio Tabacatiado trout, and 34 and 37 caeca in two specimens of Rio Hondo trout. These characteristics are somewhat typical of Columbia River basin redband trout.

Needham and Gard (1959) described trout from the Rio Truchas, a headwater tributary to the Rio San Lorenzo just to the north of the Rio del Presidio drainage. The Rio Truchas trout are characterized by low vertebrae counts, 58-63/61) in 17 specimens and high lateral series scale counts, 133-161 (149). I counted 31-39 (33.4) pyloric caeca in five Rio Truchas specimens. The Rio Truchas trout also have pronounced white tips on the dorsal, anal and pelvic fins.

The three drainages immediately to the north of the Rio San Lorenzo-the Rio Culiacan, Rio Sinaloa, and Rio Fuerte-have the Mexican golden trout, S. chrysogaster. The trout native to the Rio Mayo and Rio Yaqui, north of the range of the Mexican golden trout, are somewhat similar to the Gila trout, S. gilae, but differ considerably in chromosome numbers. The unusual characters of the Rio Truchas trout may be the result of hybridization between a Gila-like trout and/or Mexican golden trout and the "rainbow"-like trout of the Rio del Presidio.

Dr. Gary Thorgaard has done the most extensive work on rainbow trout chromosomes. He has found the predonminant diploid number to be 58 (as in redband trout), although populations characterized by 60 chromosomes are common, and 62 and 64 chromosomes were found in some California steelhead trout populations. It now appears that the coastal rainbow trout has evolved higher chromosome numbers by splitting a two-arm metacentric chromosome into two one-arm (acrocentic) chromosomes. That is, the chromosome complement of 58 is most primitive in the rainbow trout, and the higher numbers are more advanced conditions. Many populations are variable (polymorphic) for chromosome numbers, indicating mixing between local chromosomal races has occurred. 
Obviously, it is difficult to characterize "rainbow trout". It must be realized that when taxonomic papers depict "rainbow" trout with a line or a box in a phylogenetic diagram, the data on which it is based represents only a minute part of the whole of $S$. gairdneri. The problem of defining the redband trout is even more complex.

\section{DISTRIBUTION}

The northernmost boundary of rainbow trout is the Kuskokwim River, just south of the mouth of the Yukon River in Alaska. Little is known about the rainbow trout of the Kuskokwim drainage, since no published data exists on their taxonomic characters, and I have not seen a specimen from this area. Distribution is continuous along the Pacific Coast to southern California, where it then occurs as three disjunct groups, in the Rio Santo Domingo, Rio del Presidio, and Rio San Lorenzo of Mexico. The Mexican distribution can be accounted for during glacial periods when the ocean was colder, but the distinctions found in the Mexican "rainbow" trout indicate that more than one ancestral form was involved. To my knowledge, the mountain headwaters of the Rio Baluarte and Rio Acaponeta, south of the Rio del Presidio basin, have never been specifically collected to determine if trout are native to these drainages.

Coastal rainbow trout extend farther north, farther south, and farther inland than do the coastal cutthroat trout. Anadromous steelhead populations occur throughout the range of the coastal rainbow trout except in the northern and southern extremities of the range.

The coastal rainbow trout has been successfully established in suitable waters all over the world. MacCrimmon (1971) detailed the world-wide distribution of rainbow trout, but lacked details of rainbow trout occurrence in lran. I have observed that rainbow trout are now established in streams of the Zagros Mountains (Tigres River basin) and in the Zayanderud River (internal basin) in Iran. In streams of the Caspian Sea basin where brown trout, $S$. trutta, are native, introductions of rainbow trout have not established populations. This "competitive exclusion" of introduced rainbow trout by native brown trout is also generally true of European waters.

\section{TAXONOMIC NOTES}

I have considered all "rainbow" trout to be $S$. gairdneri without recognizing subspecies because of the paucity of sound systematic information concerning character variability and degrees of relationships. I consider the Eagle Lake, California, "rainbow" as most probably derived from, or at least influenced by, a redband trout ancestor, but the taxonomic evidence is not clear, and I will not dispute the current classification of the Eagle Lake trout as S. gairdneri aquilarum. Eagle Lake is an isolated part of the Lahontan basin. Its fish fauna is made up of typical Lahontan species with the exception of the native trout. The original trout of Eagle Lake, when it was directly connected to Lake Lahontan, should have been the Lahontan cutthroat trout. After the final desiccation of Lake Lahontan, a period of warmer, drier climate probably occurred, and the Lahontan cutthroat trout was eliminated from Eagle Lake. A subsequent cooler, wetter period provided a head water connection from the Pit River (upper Sacramento River basin)drainage into the Eagle Lake basin, and a rainbow or redband trout or a hybrid between the two gained access to Eagle Lake.

Snyder (1917) described the Eagle Lake rainbow trout as Salmo aquilarum. The origin, relationships, and correct classification of the Eagle Lake trout remains unclear. There is nothing in Snyder's original description to clearly differentiate the Eagle Lake trout from other rainbow trout. 1 counted 136-140 scales in the four specimens collected by Snyder from Eagle Lake. Needham and Gard (1959) based their description of the Eagle Lake trout on eight large specimens taken in 1951. The reported 19-21 (20.1) gillrakers 'I found 16-19 (17.8) in the four original specimens collected by Snyder], 61-65 (63.9) vertebrae, and 133-155 (143.4) lateral series scales in the eight specimens.

I examined 20 small specimens of Eagle Lake trout raised at the Crystal Lake, California, hatchery in 1957. These hatchery-reared specimens (eggs taken from the spawning rung of Eagle Lake trout in Pine Creek) have 16-21 (18.0) gillrakers, 61-64 (62.3) vertebrae, and 122-142 (130.5) lateral series scales.

Recently, I received some data on Eagle Lake trout from Mr. Craig Busack, University of California, Davis, based on examination of 25 specimens of hatchery origin. ln this most recent study, Eagle Lake trout were 
found to have 126-153 (138.3) lateral series scales, 58-63 (62.0) vertebrae, 17-21 (19.2) gillrakers, and 33-74 $(55.0)$ pyloric caeca. The chromosome number is 58 , and no gene loci differences from rainbow trout could be found from electrophoretic analysis, but no gene loci differences were found between the distinctive redband trout of Sheepheaven Creek and rainbow trout. The correct classification of the Eagle Lake trout remains a mystery.

The name S. irideus, or $S$. gairdneri irideus, was once commonly used to designate resident (nonanadromous/ rainbow trout. It is now obvious that all anadromous steelhead trout and all resident rainbow trout did not arise from two distinct evolutionary lines, but rather the two ecological forms have given rise independently to each other in various forms of rainbow trout. The royal silver trout of Lake Tahoe, $S$. regalis, and the emerald trout of Pyramid Lake, both in the Lahontan basin, were, in my opinion, based on hatchery introductions (Behnke, 1972). The trout of Crescent Lake, Washington, named S. gairdneri beardslei by Jordan was discussed under the coastal cutthroat trout section. The "Beardsley" rainbow was a specialized lacustrine rainbow trout isolated in Crescent Lake. Undoubtedly, it had evolved subtle behavioral and physiological differences significant for fish management considerations, but did not differ taxonomically from typical coastal rainbow trout. Because of a long history of hatchery trout introductions, it is doubtful that the Crescent Lake rainbow survives as a pure population.

\section{LIFE HISTORY}

The most significant life history attribute of coastal rainbow trout is the widespread occurrence of anadromous steelhead populations. Great life history variability is found among steel head populations. In general, steelhead populations are broadly divided into summer-run and fall or winter-run fish, depending on when the spawning migration enters fresh water. This is an oversimplification, however. Steelhead probably enter fresh water somewhere in their range during every month of the year. Spring-summer runs enter fresh water typically from May-August and move upstream to hold over until the following spring to spawn. Fall runs typically enter from September-November and spawn in the spring. Some rivers have later winter runs (December-March), in which spawning occurs soon after entering fresh water. In different parts of the range, spawning may occur from January to June. Spring/summer-run steelhead enter fresh water with immature gonads. Late winter-run steelheads have gonads almost fully mature by the time they ascend rivers.

There is a genetic basis for the timing of the runs (Neave, 1944, 1949; Ricker, 1972; Smith, 1969), and reproductive isolation exists between the stocks. The origin of the genetic differentiation resulting in different races of steelhead trout and the mechanisms of reproductive isolation separating these races when they occur in the same river is not understood. In the Cowichan River, British Columbia, two distinct runs of steelhead trout and a resident rainbow trout exist with reproductive isolation, although there appears to be no clear-cut separation in the time and place of spawning based on the Neave's studies.

It is tempting to speculate that the reproductive isolation between races of steelhead where they occur together is due to one race being derived from a redband trout and the other from the coastal rainbow trout. I do not believe this to be the case, however (Behnke, 1972). All studies to date indicate the close relationships between races of the same river system.

Typically, spring and summer-run steelhead spawn in the upper or headwater parts of a river basin or in river sections that can only be reached during the high flows of spring and early summer. Thus, the evolutionary selection causing divergence of anadromous species into discrete races results in more effective use of the total environment and increases the productivity of a species. Besides being a widespread phenomenon in trout, salmon, and charr species, distinct seasonal races are also found in other anadromous species, such as lampreys and sturgeon.

In addition to the loss of valuable genetic diversity in the coastal rainbow trout, there has been a loss of many of the distinct local races, particularly summer-run stocks because of dams, pollution, irrigation practices, and environmental changes.

Steelhead trout typically spend one to three years in fresh water before smolting and migrating to the ocean. After one to three years of ocean life, steelhead return to spawn in their "home" waters, typically at age III to V. Each race is characterized by a different life history mode. Generally, the largest steelhead are those that spend the longest time in the ocean (two or three years). The Winter 1976 issue of "Washington Wildlife" magazine article, "Breeding in Super Steelhead," discusses the State of Washington's selective breeding program to produce more steelhead with the hereditary basis to extend the period of ocean life. 
There is now a general a wareness that hatchery propagation of steelhead, which historically mixed stocks indiscriminantly, could be a significant factor in breaking down the separation among races. A symposium on the genetic implications of steelhead management, held at Humboldt State University in May, 1977, was devoted to this problem. More effective steelhead propagation practices will evolve when the significance of intraspecific genetic diversity is understood and when agencies obtain the necessary data to analyze cost-benefit ratios of those stocking programs that yield low returns by using "nonnative" stocks.

Although steelhead trout may spawn more than once, survival to second spawning is low. Most steelhead runs are comprised of about 10 to 20 percent repeat spawners. Barnhart (1975) presented a general review of steelhead management.

Non-anadromous or resident rainbow trout populations occur throughout the range of the coastal rainbow trout, often inhabiting the same streams used by spawning steelhead populations.

Rainbow trout generally spawn in the spring, but spawning does occur from January to June in some parts of the range and even into July in high elevation waters. Hatchery selection has developed fall spawning strains, and spawning occur in almost any month of the year with the diverse hatchery strains now a vailable. In nature, however, when temperatures rise and days lengthen, it appears that "fall" spawning rainbow trout revert to spring spawning. There are some unusual conditions, such as the rainbow trout from Lake McConaughy, Nebraska, migrating up the North Platte River in the fall and spawning in warmer tributary streams in October and November (Van Velson, 1974; 1978), and fall-spawning rainbows in the Firehole River of Yellowstone National Park where hot springs provide normal spawning temperatures in the fall and winter months (Kaya, 1977).

In inland fisheries, as is the case with steelhead trout, the largest rainbow trout are generally those that sexually mature at an older age. This is an important consideration for producing "trophy" rainbow trout from stocking programs. The age at sexual maturation is under both genetic and environmental control (Ricker, 1972). Hatcheries have selected for rapid growth and early maturation. A long evolutionary history in a large lake environment with selection favoring large, predatory trout should result in the hereditary basis for an older age of sexual maturity as is the case with the large "Kamloops" trout of Kootenay Lake. The "Beardsley" rainbow trout of Crescent Lake, Washington, may have incorporated this type of lacustrine programming into its life cycle, but it is doubtful that the original genotype remains intact.

Reports from personnel of the Alaska Department of Fish and Game indicate that the rainbow trout native to Lake Iliamna (tributary to Bristol Bay), attained a large size (10-15 pounds) had a long maximum life span (8-10 years), and did not spawn until it was 5 to 6 years old. The Lake Iliamna, or "Talarik", rainbow was obtained by the U.S. Fish and Wildlife Service in 1974, and a brood stock is maintained at the Fish Genetics Laboratory in Buelah, Wyoming. At the Genetics Lab, domestic strains of rainbow trout ma ture at two years of age, but under identical conditions, the Lake lliamna rainbow does not mature until it is four or five years old. I hope that the Iliamna rainbow can be established in the wild before hatchery selection inalterably changes its genetics. This trout may possess a genetic resource for longevity of great potential value for innovative fishery management and propagation programs.

\section{STATUS}

The coastal rainbow trout as a whole is doing well. With its establishment all over the world and tremendous hatchery production, it is likely more abundant now than it ever was. The area of concern involves the maintenance of gentic diversity manifested in the multitude of steelhead races and in unique forms such as the Lake Iliamna and Crescent Lake rainbow trout. Hopefully, we are now in a more enlightened period of fisheries management where recommendations, such as the one to stock Crescent Lake with massive numbers of a "good hatchery strain" of rainbow trout (discussed in the coastal cutthroat trout section/ because the native "Beardsley" rainbow was too difficult to propagate, will no longer be tolerated. 


\section{REDBAND TROUT, Salmo newberryi}

The validity of recognizing the redband trout as a species as distinct from coastal rainbow trout rests on the fact that the great diversity expressed in the trout I have assigned to the rainbow-redband evolutionary group is the result of a major phylogenetic divergence that separated a common ancestor into two groupsthe coastal rainbow trout and the redband trout. I reject the notion that only a single, essentially homogeneous, but plastic ancestral form is involved, and that all the diversity in life history, coloration, numbers of scales, vertebrae, pyloric caeca, gillrakers, etc., is merely a manifestation of direct evnrionmental influence on populations living under different conditions.

I have no doubt that there is a real phylogenetic divergence between redband trout and coastal rainbow trout, but the obscure area is the evolutionary branching sequences within the phylogeny that have produced the coastal rainhow trout on one hand and the redband trout on the other.

We might define the "type locality" associated with the common name "redband trout" as the upper McCloud River (Sheepheaven Creek) following the precedents of Schreck and Behnke (1971) and Gold (1977). The question then becomes: Is the trout native to Upper Klamath Lake, S. newberryi phylogentically more closely related to the Sheepheaven Creek trout than either of them are to the typical coastal rainbow trout? If so, then the name $S$. newberryi can be used for the redband trout if species separation is eventually deemed justified. The relationship between the Sheepheaven trout and the Kern River basin golden trout (aguabonita and gilberti) and among Sheepheaven trout, Oregon desert basin trout, the "Kamloops" trout, and the anadromous steelhead east of the Cascade Mountains in the Columbia and Fraser river basin must be tested and evaluated to support or reject my assumptions about relationships.

Data on more than 1,000 specimens from more than 100 localities to form the taxonomic basis for my interpretation. Most of the specimens were personally examined, but some data was taken from the literature or personal communication. Dr. Richard Wallace, University of Idaho, has provided considerable data on the characters of the steelhead trout of the Snake river drainage of Idaho. Considering the enormous geographical area and the number of geographically distinct groups involved, my da ta merely penetrates the surface of this complex situation. Environmental changes and a long history of introductions of hatchery rainbow trout have eliminated or altered most of the redband trout populations from most areas of their range, and this imposes additional difficulties for taxonomic studies.

My conclusions on evloutionary history and relationships are not dogmatic assertions, but rather provisional assumptions to be tested, modified, or rejected by future research. Unfortunately, new information based on chromosome study and gene loci data has not shed much light on the matter to date. The papers of Utter and Allendorf (1977) and Gold (1977) mention that about 20 gene loci in western trouts have been well studied. No unique or "species specific" gene locus has been found to support my separation of rainbow trout and redband trout into two species, or to verify my proposed relationships within the redband trout group. There are some consistent differences in some gene frequencies (alleles) at certain gene loci between the steelhead trout of the upper Columbia and upper Fraser river basins on one hand and the coastal steelhead on the other, but these differences do not persist in the Sheepheaven Creek trout or the California golden trout. There is certainly a genetic basis determining the trenchant morphological differences between Sheepheaven Creek trout and golden trout on one hand and coastal rainbow trout on the other. The problem appears to be that the genes governing morphology (regulatory genes) have evolved at a much more rapid rate than have the genes whose products can be studied by electrophoresis (structural genes).

\section{TYPICAL CHARA CTERS}

Because of the variability found in redband trout from different regions, I cannot list the characters that will allow identification and separation of all redband trout from all rainbow trout. Diagnosis must be based on geographic locality. There are some common trends of primitive characters that are shared by most redband trout which are useful for distinguishing them from coastal and hatchery rainbow trout. The parr marks characteristic of redband trout are typically more eliptical in shape (more rounded in rainbow trout) and typically, small, rounded, supplementary rows of markings are interspersed among the main row of parr marks both dorsally and ventrally. The parr marks of redband trout are typically more pronounced and persist in to the adult stage (at least in non-anadromous and non-lacustrine populations) in comparison with rainbow trout.

There is variability, however, within a single population in shape, number, and presence of supplementary rows of parr marks. A check blotch, or opercle marking, comparable to that found on cutthroat trout is often found on redband trout specimens. Light golden-yellow colors may cover the lateral sides of the fish with 
orange tints on the ventral surface and with a yellow or orange "cutthroat" mark present. Milky white loften orange or yellow on the dorsal fin) tips appear on the dorsal, anal, and pelvic fins and persist throughout the life of redband trout from most regions. This coloration is most intensely expressed in the golden trout of the South Fork of the Kern River. The intensity of coloration is less in specimens from the northern parts of the Sacramento River system and further fades in the Oregon desert basins and the Columbia River basin, but with certain isolated relict populations, such as the "mountain Kamloops" trout of British Columbia, again expressing yellow and orange coloration.

The typical spotting pattern of redband trout is mainly restricted to an area above the lateral line and on the caudal peduncle, somewhat similar to the pattern of most interior cutthroat trout. Coastal rainbow trout are typically more coarsely and profusely spotted all over the body down to the ventral surface. Except for the California golden trout, the spots on redband trout are relatively small and not rounded in outline, yet they are larger than the spots on typical coastal rainbow trout. The "redband" of the redband trout is typically a darker color (brick red, brownish or purplish red) than is the "rainbow" band of rainbow trout.

Scale counts in the lateral series are almost always higher in redband trout than in coastal rainbow trout. Coastal rainbow trout typically have $120-140$ scales in the lateral series. The highest scale counts in redband trout are found in the South Fork Kern golden trout, aguabonita, typically with mean values of about 170-180 or more. The lowest scale counts in redband trout are found in some populations in the Oregon desert basins and some resident populations in the Columbia River basin (typically 130-140).

There is considerable overlap in the number of pyloric caeca, but it appears that with a few notable exceptions, the mean value of pyloric caeca number is almost always lower in redband trout than in rainbow trout. Rainbow trout typically have $40-75$ pyloric caeca and mean values of about 55-60. The lowest mean values in redband trout caeca number are found in golden trout, aguabonita, with about 30. Most of the other populations of redband trout I have data from have mean values between 35-45. Higher means (48-50) are encountered in some samples of Snake River drainage steelhead trout, and the redband trout with the highest caeca counts (60-65) are found in some tributaries to the lower Pit River (upper Sacramento River basin).

Mean values for vertebral numbers range from less than 60 in golden trout to more than 65 in some samples from the Snake River drainage. There is also considerable variation in gillraker number. The lowest mean value of less than 16 is found in Sheepheaven Creek redband trout, and the highest mean values $|22-23|$ were characteristic of the trout originally found in the Goose Lake and Warner Lake basins (Oregon desert basins|.

Apparently, there is great variability in the wide-ranging group of trouts I collectively call the redband trout. Is this variability the result of a single ancestral form invading North American waters with subsequent dispersal, isolation, and divergence, or is it more than one ancestral form involved in the present diversity-such as an ancestor with low vertbral numbers becoming established in the Acaramento River basin, and an ancestor characterized by high vertebral numbers invading the Columbia River basin?

\section{DESCRIPTION AND DISTRIBUTION}

Except for the California golden trout and the trout of Sheepheaven Creek, there is little taxonomic data on redband trout, and no attempt has previously been made to characterize the redband trout as a whole. I will break down the redband group into geographical units and give my taxonomic data and interpretation of relationships for each unit. A logical starting point is the Upper Klamath Lake basin and the trout name Salmo newberryi.

\section{Upper Klamath Lake}

Upper Klamath Lake was once a larger body of water with connections to other internal drainages as can be perceived from its fish fauna (Hubbs and Miller, 1948; Smith, 1977). Upper Klamath Lake cut an outlet to the Pacific Ocean (Klamath River) and became reduced in size as the outlet trenched down. A redband trout probably entered the upper Klamath watershed from interior connections contemporary with the establishment of the bull trout, Salvelinus confluentis, and the tui chub, Gila bicolor. 
A trout collected in the Klamath River by Dr. Newberry in 1855 as part of the Pacific Railroad Surveys, was illustrated and briefly described as "Fario gairdneri" by Girard in the survey report. Shortly thereafter, in 1858, Girard changed his mind and wrote that the Klamath River specimen is not gairdneri, but a new species, "Fario or Salmo newberryi." Girard gave no real de tails on how newberryi differs from S. gairdneri,except to mention that it had yellowish-white coloration on the ventral surface. Girard's ichthyological work was poor even by 19 th century standards and still causes problems. For example, he named the tui chub, now considered a single species, Gila bicolor, at least six different species in three different genera.

Fortunately, the type specimen (\#578) is still in good condition in the collection of the U.S. National Museum. I counted 65 vertebrae, 20 gillrakers, about 45 pyloric caeca, 32 scales above the lateral line, and 142 scales in the lateral series on the type of newberryi. Three specimens collected from the Williamson River in 1883 in the National Museum collection are of the same form of trout. These specimens have $63(2)$ and 65 (1) vertebrae; 21,22, and 23 gill rakers; about 50, 56, and 58 pyloric caeca; $33-35$ scales above the lateral line; and 146-148 scales in the lateral series. Another character differentiating the upper Klama th Lake trout from other western trouts is their high number of branchiostegal rays. The four specimens from the Upper Klamath watershed have 12-14 branchiostegal rays; two specimens have 12 rays (both left and right sides) and two have $13-14$ rays.

Anadromous steelhead runs are native to the Klamath River, and it is pssible that, as in the Columbia River basin, the steelhead runs in the Klamath were originally composed of both coastal rainbow steelhead and redband steelhead (until the upper Klamath River was blocked by Copco Dam). The data I have on Klamath River steelhead trout indicate that they are coastal rainbow trout and quite distinct from the native lacustrine trout of upper Klamath Lake. Snyder (1931) found an average of 62.2 vertebrae in 175 specimens of Klamath River steelhead. In three specimens of steelhead from Spencer Creek, triburary to the Klamath, I found 62 vertebrae, $11-12$ branchiostegal rays, $17-20$ gillrackers, 28 scales above the lateral line, and 133-137 scales in the lateral series. The closest affinities of newberryi appear to lie with the redband trout native to the Oregon desert basins. It is not known how much of the original genotype of $S$. newberryi remains. I have not examined any specimens of trout caught in recent years from Upper Klamath Lake (they are quite rare).

In 1968 and 1970, I collected 25 trout specimens in the upper Klamath basin from Whitworth and Trout creeks (Sprague river tributaries), and Dr. Donald Seegrist, U.S. Forest Service, collected eight specimens from Butte Creek, a disrupted part for the upper Klamath basin in Siskiyou County, California. These recent collections represent resident stream populations and differ from the 19th century specimens discussed above, suggesting that two distincy groups of redband trout are native to the upper Klamath basin-a lacustrine specialized adfluvial trout and a resident tributary stream trout. Some of these differences are likely due to a hybrid influence from hatchery rainbow trout, but the differences are great enough to lead me to believe that two distinct groups of redband trout are native to the upper Klamath basin.

The recent collections from small streams have low gillraker counts, 17-21, with mean values from 18.8 to 19.4; low scale counts, means of 30-31 above lateral line and 133-139 in lateral series; branchiostegal ray counts of 9-13, mainly 11; and an indication of slightly lower vertebral counts, 62-65 (62.3 to 63.4); and pyloric caecal counts 36-56 (46 to 48); than possessed by the original lacustrine population of upper Klamath Lake. The specimens in the recent collections have the typical redband trout type of coloration with yellow and orange tints, eliptical parr marks with supplementary rows, and a trace of a cutthroat mark.

Of a total of 37 specimens examined from the upper Klamath basin, only one specimen, from Whitworth Creek, has a basibranchial tooth.

\section{The Oregon Desert Basins}

Between the Columbia River basin to the north and east, the Klamath basin to the west, and the Sacramento River basin and Lahontan basin to the south, a series of separate desert basins occur. As previously discussed, the easternmost of these basins, the Alvord basin, has a cutthroat trout as the native trout; the other six basins with native trout have the redband trout. I use the names given by Hubbs and Miller (1948) for these basins. During the Pleistocene, these basins contained large lakes (portrayed in USGS Map I-416, Pleistocene Lakes in the Great Basin/ where the redband trout occurred with an array of cyprinid fishes and suckers. The basins with native redband trout are: Malheur basin, Catlow Valley basin, Fort Rock basin, Chewaucan basin, Warner Lakes basin, and Goose Lake basin.

Some taxonomic data on these trout was given by Snyder (1908). I find that the lateral series scale counts 
given by Snyder for various samples are about 15 to 20 scales higher than I counted on some of Snyder's specimens now in museum collections. This is probably due to Snyder's belief that the desert basin trout were cutthroat trout and his scale counts were biased accordingly. Following Snyder, Hubbs and Miller (1948) assumed that the trout native to these basins were derived from a cutthroat trout, but they believed that the native trout had become thoroughly hybridized with hatchery rainbow trout.

The museum specimens I have been able to find of the desert basin redband trout are rather sparse (2-3 specimens per sample). A few specimen were collected by Evermann in 1897, the rest by Snyder in 1904. The specimens are in the U.S. National Museum collection and in the Stanford University collection, now part of the California Academy of Sciences' Fish collection. In 1968, 1970, and 1972, with the assistance of Dr. Donald Seegrist of the U.S. Forest Service; Dr. Ray Simon of the U.S. Fish and Wildlife Service; Richard Wilmot and Peter Bisson, then graduate students at Oregon State University; and William Hosford of the Oregon Dept. of Fish and Wildlife, I made collections from all of the six desert basins, from the upper Klamath basin, upper Sacramento basin and from the Columbia River basin (tributaries to the Malheur and Owyhee rivers of Snake River drainagel. I attempted to closely duplicate the collection sites visited by Snyder in 1904 to assess the relative hybrid influence occurring since the original collections.

I was surprised to find that a predominantly native redband trout still occurs in many streams of the Oregon desert basins, but a hybrid influence is indicated by the lesser number of gillrakers found in recent collections.

\section{Malheur Basin.}

When the large Pleistocene Lake in the Malheur basin desiccated about 8,000 years ago, it left two shallow, alkaline remnant bodies of water-Harney Lake and Malheur Lake on the valley floor. The Malheur basin is the largest of the Oregon desert basins and contains the greatest amount of trout habitat. Silver Creek drains from the north into Harney Lake, Silvies River drains from the north into Malheur Lake, and the Blitzen River drains into Malheur Lake from the south. The fish fauna of the Malheur basin is little differentiated from the Columbia River fauna, suggesting a rather broad and geologically recent connection of ancient Malheur Lake to the Malheur River (Columbia basin). Bisson and Bond (1971) also discussed probable transfers of fish from the upper John Day River (Columbia basin) into the Malheur basin. The redband trout of the Malheur basin was probably originally differentiated from the redband trout of contiguous Columbia River basin waters by higher numbers of gillrakers. However, I found little difference bet ween Malheur basin and Columbia basin redband trout collected in 1968-1972. These recent collections have probably been influenced by hybridization with hatchery rainbow trout.

In 1904, J. O. Snyder collected trout from Silver Creek and from the Silvies River. I examined six of Snyder's specimens from each of these sites and found 64-66 vertebrae 165 from Silvies River and 64.8 from Silver Creek specimens), 20-24 gillrakers (21 from Silvies River and 22.3 from Silver Creek). I counted 37-40 pyloric caeca in three specimens from Silver Creek and obtained mean values of 32 scales above the lateral line and 150-152 scales in the lateral series in Snyder's collections.

Recent collections examined include 25 specimens from Smyth Creek (Blitzen drainage), 34 specimens from Dairy and Sa wmill creeks (Silver Creek drainage), 13 specimens from Crooked and Camp Creeks, and 14 specimens from Myrtle Creek (Silvies drainage). The recent collection most closely approximating the specimens collected by Snyder in 1904 is from Smyth Creek. They have 18-22 (20.0) gill rakers, 63-66 (64.6) vertebrae, $33-45$ (37.5) pyloric caeca, and a verage 32 scales above the lateral line, and 148 in the lateral series. The mean values in the other recent samples are: gillrakers 19.5-19.8, vertebrae 63.7-64.8, pyloric caeca 39-42, scales $29-30$ above lateral line, and 136-144 in lateral series. The samples from Dairy Creek and Sawmill Creek (adjoining tributaries along roadsides in a popular recreation area) appear to be the most heavily hybridized samples, but even with these specimens, they still retain the predominant redband trout appearance with tints of yellow and orange and distinctive parr marks.

Although the conclusions are tenuous, I believe the original redband trout of the Malheur basin, before stocking of hatchery rainbow trout, were characterized by averages of $21-22$ gillrakers, about 65 vertebtae, 37-40 pyloric caeca, 32 scales above the lateral line, and about 150 scales in the lateral series. None of the 92 specimens examined from the Malheur basin have basibranchial teeth.

It is not known if pure populations of native trout persist in the Malheur basin. The "purest" of recent collections from Smyth Creek was made at the downstream limits of trout distribution in July, 1968, when 25 dead and dying specimens were taken from a pool in the largely intermittant stream, obviously suffering 
from high temperatures and oxygen depletion-hazards constantly faced by desert basin trout. These conditions, however, also select for survival characteristics and probably explain why arid region redband trout have so successfully resisted hybridization leading to "genetic swamping" - their genotypes are highly adapted to these unstable environments.

\section{Catlow Valley.}

The Catlow Valley basin lies immediately west of the southwestern part of the Malheur basin and is separated from the Alvord basin to the east by the Steens Mountains. There is little trout habitat left in Catlow Valley, and native trout inhabit only a few small streams.

I know of no ancient museum specimens of the native trout of Catlow Valley. My analysis of the Catlow Valley trout is based on 10 specimens collected from Three Mile Creek in 1968. These specimens have 62-65 (63.6) vertebrae, 20-22 (21.2) gillrakers, 30-46 (37) pyloric caeca, 28-33 (30) scales above the lateral line, and 129-146 (139) scales $n$ the lateral series. None of the specimens has basibranchial teeth.

The native trout and the few other native fish species in Catlow Valley are most likely derived from the Malheur basin, perhaps from a direct connection during the maximum lake level stage when the lake in Catlow Valley was tributary to the Malheur basin. The Catlow Valley (Three Mile Creek) redband trout appear similar to the original Malheur basin trout, but with slightly fewer scales and vertebrae. Because there are no museum specimens with which to compare the present Catlow valley trout, no estimation of hybrid influence, if any, can be made.

Trout also occur in Home Creek and Roaring Springs (north of Three Mile Creek). The only other trout stream in Catlow valley that I am awa re of is Rock Creek, the major tributary draining the western side of the basin. Several years ago, Rock Creek was treated with rotenone to make it safe for hatchery rainbow trout. The trout native to Three Mile Creek are now being propagated by the Oregon Fish and Game Department. A brood stock is maintained in a private ranch pond (Kunkle and Hosford, 1978).

\section{Fort Rock Basin.}

At maximum lake levels, the Fort Rock basin once drained in to the Deshutes River. An impressive outlet channel is still visible. The Fort Rock basin is contiguous with the upper Klamath basin to the southwest and the Chewaucan basin to the south. Silver Lake, an alkaline body of water barren of fish life, is the remnant of the large Pleistocene lake in the basin. All the present trout habitat in the basin that I am aware of is found in headwater areas of Buck, Bridge, and Silver creeks, tributary to Paulina Marsh. In 1968, native redband trout were found in the headwaters of Buck and Bridge Creeks, but only eastern brook trout, Salvelinus fontinalis, were found in tributaries to Silver Creek.

I examined six museum specimens collected by J. O. Snyder in 1904 from Buck Creek. The outstanding feature noted in this collection is the presence of basibranchial teeth in four of the six specimens. Of all redband trout samples I have examined, basibranchial teeth were commonly found only in the Sheepheaven Creek trout (in about half of the specimens). I found no basibranchial teeth in three specimens collected by B. W. Evermann in 1897 from Silver Creek. The other taxonomic characters of the six Buck Creek specimens collected in 1904 are: vertebrae 63-65 (63.7), gillrakers 19-22 (20.2), scales above the lateral line 28-33 (30), and scales in the lateral series 138-147(142). The three specimens from Silver Creek collected in 1897 have 63 (2) and 64 (1) vertebrae; 20, 21, 22 gillrakers; 31-35 scales above the lateral line; and 145-148 scales in the lateral series. The trout populations native to the Buck, Bridge, and Silver Creek drainages have probably been isolated from each other for several thousand years and have undergone slight differentiation from each other.

In 1968, 10 specimens from Buck Creek and 24 specimens from Bridge Creek were collected. Comparing the data from the 1968 sample from Buck Creek with the Buck Creek specimens taken in 1904 shows almost no difference in vertebrae $(63-65,64.0)$, gill rakers $(17-21,19.8)$, or scales laverage 31 above lateral line and 142 in lateral series). Only three of the 10 recent specimens possess basibranchial teeth. Pyloric caeca counts are $38-62|47|$. There appears to be a slight hatchery rainbow trout hybrid influence in the present Buck Creek trout as indicated in the apparent reduction in basibranchial teeth and the extreme range of caecal counts.

The trout in the headwaters of Bridge Creek appear to be less influenced by hyridization. This sample of 24 
specimens has 62-66 (64) vertebrae; $19-23$ (20.6) gillrakers; 29-34 (32) scales above the lateral line; 137-158 (145) scales in the lateral series; and 36-53 (43) pyloric caeca. Four of the 24 specimens have basibranchial teeth.

The original native trout of the Fort Rock basin are assumed to be characterized by an average of 64 vertebrae, 20-21 gillrakers, 30-32 scales above the lateral line, 140-145 scales in the lateral series, and 40-45 pyloric caeca. Basibranchial teeth probably occurred in half or more of the original Buck Creek trout, but occurred in lesser frequencies in the trout of Bridge and Silver Creek drainages. The closest relationship of the Fort Rock basin redband trout may lie with the redband trout of the Deshutes River where both resident and steelhead stocks occur.

\section{Chewaucan Basin.}

The Chewaucan basin is situated between the Warner Lakes basin to the east, the upper Klamath basin to the west, the Fort Rock basin to the north, and the Goose Lake basin to the south. There are two remnants of the Pleistocene lake-Summer Lake and Lake Abert-both highly alkaline and barren of fish life. The Chewaucan River drainage, tributary to Lake Abert, contains several good trout streams.

I examined two specimens collected by Evermann in 1897 and six specimens collected by Snyder in 1904 from the Chewaucan River. These specimens have 20-23 (22.4) gillrakers, 63-64 (63.5) vertebrae, 133-148 (142) scales in the lateral series, and $28-33(30)$ scales above the lateral line. One of the eight specimens has basibranchial teeth.

In 1968, 28 specimens were collected from Elder Creek, and in 1970, 10 specimens were collected from Dairy Creek in the Chewaucan drainage. Both these sites have easy access and receive relatively high recreation use. Undoubtedly much stocking of hatchery trout has occurred over the years. I was surprised to find that the trout in Elder and Dairy creeks did not resemble hatchery rainbow trout, but were quite typical of native redband trout in coloration, spotting, and parr markings. The meristic characters of the Elder Creek sample are: vertebrae 61-65 (63.2), gillrakerrs 19-24 (21.1), scales in lateral series 136-154 (143), above lateral lines 27-33 (30), pyloric caeca 33-46 (40), and two of 20 specimens (more than $100 \mathrm{~mm}$ ) have basibranchial teeth. The Dairy Creek sample has 61-64 (63) vertebrae, 19-22/21/gillrakers, 40-58 (46) caeca, an average of 30 scales above the lateral line, and 135 in the lateral series. Two of 10 Dairy Creek specimens have basibranchial teeth.

A slight hybrid influence is indicated by the lower gillraker counts of the recent specimens compared with the museum specimens and perhaps the lower scale counts and higher caecal counts in the Dairy Creek trout. These populations, however, predominantly retain the native genotype and should be considered and classified as the native trout of the Chewaucan basin.

The closest relationships of the Chewaucan basin redband trout probably are with the redband trout native to the Goose Lake and Warner Lakes basins.

\section{Warner Lakes Basin.}

The Warner Lakes basin is east of the Chewaucan basin and west of the Catlow Valley basin. The southwestern side of the basin is contiguous with the Goose Lake basin. An elongated Pleistocene lake extending about 60 miles on its north-south axis once filled the valley floor. The Warner Lakes are the remnants of the ancient lake.

I examined eight specimens collected by Snyder in 1904 from Honey Creek. These specimens have 61-63 (62.3) vertebrae; seven specimens have 23 gillrakers and one has 24 (23.1). Scales average about 31 above the lateral line and about 147 in the lateral series. This is the highest gillraker count obtained for any sample of desert basin redband trout, but the original trout of the Goose Lake basin probably were similar in gillraker number.

A sample of 19 specimens from Honey Creek made in 1968 reveals a hybrid influence. Their gillraker count is reduced to 20-24 (21.6), and scale counts reduced to an average of 29 above the lateral line and 133 in the lateral series. They have 62-64 (62.9) vertebrae and 35-54 (45) pyloric caeca. Other recent collections in the Oregon State University collection from the Warner basin Deep Creek and Willow Creek are more hybridized than is the Honey Creek collection. Eight Willow Creek specimens have 17-22 (19.5) gillrakers, 
and six Deep Creek specimens have 20-21 (20.3) gillrakers. A tentative diagnosis of the original Warner Lake trout is as follows: vertebrae typically 62-63, gillrakers about 23 , scales above lateral line $30-32$, in lateral series about 140-150, and pyloric caeca about 40 . No basibranchial teeth were found in any specimen from the Warner Lakes basin. The native trout of the Warner basin may have been virtually identical to the Goose Lake basin trout.

\section{Goose Lake Basin.}

The Goose Lake basin is continguous with the upper Klamath basin on the west, the Chewaucan basin on the north and the Warner Lakes basin o the east. Goose Lake at higher levels connects to the headwaters of the Pit river /upper Sacramento River basin/, and such direct connections to the Pit have occasionally taken place in historical times (Hubbs and Miller, 1948). The Goose Lake basin can be considered a semi-disrupted part of the upper Sacramento basin.

I found six specimens collected by Snyder in 1904 from Cottonwood Creek to be very similar to the specimens from Honey Creek of the Warner Lakes basin. The Cottonwood Creek specimens have 21-24 (22.8) gillrakers, 61-64 (62.8) vertebrae, and average 30 scales above the lateral line and 139 scales in the lateral series. From recent collections, I examined 38 specimens from Lassen Creek, 15 specimens from Thomas Creek, and 12 specimens from Davis Creek. These three samples have been influenced by hybridization with hatchery rainbow trout as is indicated by the gillraker counts of 18-24, with means of 20.1 (Lassen Creek), 20.5 (Thomas Creek), and 20.8 (Davis Creek). Caecal counts range from 35 to 54, with mean values of 42-43. Davis Creek specimens have higher than expected scale counts, averaging 33 above the lateral line and 147 in the lateral series (the other means are 30-132 and 30-136). Of the 71 specimens of trout examined from the Goose Lake basin, two (one from Thomas Creek and one from Davis Creek) have basibranchial teeth.

\section{Summary of Desert Basin Trout.}

The original invasion of a redband trout ancestor into the Oregon desert basins could have come from the Columbia River basin via the Deshutes River into the Fort Rock basin and via the Malheur River into the Malheur basin. Another possible route of entry would have been the Pit River connection to Goose Lake. If more than one distinct ancestral form were involved, transferrals of fish faunas among basins mixed the stocks and masked any clear-cut indications of diverse ancestry. The higher gillraker numbers (about 23) in Goose Lake basin and Warner Lakes basin trout suggest a longer existence under lacustrine evolution than in the other basins. The high vertebrae counts (64-65) in the native trout of the Fort Rock basin and the Malheur basin are similar to the Columbia River basin redband. The slightely lower vertebral counts $(62-63)$ in Goose Lake basin and Warner Lake basin trout, along with the differences in gillrakers, indicate a trend for divergence among the native trout of the different basins, but there is no evidence to argue the cause of this divergence-being derived from diverse ancestors, or local divergence in each basin by isolation from a common ancestor.

If the ancestor of the redband trout presently in Sheepheaven Creek gained entry into the Sacramento River basin through interior waters (the present Oregon desert basins), then the original redband trout of the desert basin region was very different from the trout that has been present since the late Pleistocene lakes occurred in these basins.

\section{Redband Trout of the Columbia and Fraser River Basins}

With limited data (and "noise" superimposed by hatchery introductions) for such a vast area, I will only attempt to outline some generalizations on the taxonomic characters I have gathered on the trout of these regions. Anadromous steelhead trout, lacustrine populations, and resident stream fish make up the native trout of the upper Fraser and upper Columbia River basin.

Dymond (1932) arbitrarily drew the line between coastal rainbow trout and interior "Kamloops" trout in the Fraser basin at Hell's Gate. I have arbitrarily drawn this same demarcation at the Cascade Mountains for the Columbia basin. I believe that the trout native to the upper Fraser and upper Columbia basins are closely 
related to each other, both being derived from a redband trout ancestor. There is probably a trend for slightly fewer vertebrae and scales in the Fraser redband (or "Kamloops") trout than in the upper Columbia basin redband trout. There are diverse stocks of steelhead redband trout and diverse stocks of resident redband trout.

P. R. Needham and I collected 107 trout specimens from four Fraser River basin localities in 1957 (Fish Lake, Trout Lake, Upper Fraser basin, Loon Lake and Riske Creek, and Middle Fraser basin).

These samples may have hatchery rainbow trout influence; they have 61-65 (average about 63) vertebrae, an average of about 30 scales above the lateral line and about 140 in the lateral series. Ido not recall yellow or orange coloration on Fraser basin trout, which is generally true of Columbia basin redband trout also, except for the more isolated "relict" populations like the "mountain Kamloops" trout, which do exhibit the yellow and orange tints characteristic of the Sacramento basin redband trout and, to a lesser extent, the desert basin redband trout.

Mottley (1937) presented data on vertebral counts from several trout populations in the upper Columbia basin of British Columbia. His counts range from 62-66, with means from 63.5 to 64.4. Lateral series scale counts generally average about 145 for upper Columbia basin resident trout in British Columbia except for at least some populations of isolated stocks of the "mountain Kamloops" trout which average about 160. I noted in seven specimens of "mountain Kamloops" from Bear Lake, British Columbia, that they all have nine pelvic rays. As discussed, almost all cutthroat trout have 9 pelvic rays, and almost all coastal rainbow trout have 10 . In redband trout, some populations predominantly have 9 pelvic rays, and some predominantly 10 . I noted in five specimens from Okanagen Lake, British Columbia, that the specimens exhibit a typical redband trout spotting pattern (restricted to above lateral line), and have 19-21 (20) gillrakers, 136-160 (147) scales in the lateral series, and 28-36 (32) scales above the lateral line.

"Rainbow" trout are native to the Peace and Athabasca river drainages of the Mackenzie River basin, but because these trout are most probably derived from head water transfers from the upper Fraser River basin, they should represent redband trout. I examined 32 specimens collected from Moberly Creek, Alberta, a tributary of the Wild Hay River of the Athabasca drainage. These specimens have a relatively high number of scales above the lateral line 29-36 (32.6), but a relatively low number in the lateral series 119-149 (133); they have 63-66 (64) vertebrae and 17-21 (19.4) gillrakers.

Anadromous steelhead redband trout probably have great variability in life histories and taxonomic characters among the many diverse stocks. Dr. Richard Wallace, University of Idaho, kindly provided me with much taxonomic data he has gathered on several samples of Snake River drainage steelhead trout. Dr. Wallace has found several age classes (to adult) of native redband trout in the North Fork of the Clearwater Riverdrainage in recent years (1974 to present) after Dworshak Dam blocked all anadromous migration into the North Fork of the Clearwater River in 1967. It was a common belief that all native "rainbow" trout in the Clearwater drainage were steelhead, and that they would disappear after the runs were blocked. The native trout can be readily distinguished from in troduced hatchery rainbow trout by comparing characters. It is not known if these present stocks of native redband trout in the North Fork of the Clearwater drainage were derived from steelheat trout "landlocked" by the completion of Dworshak Dam or if there were always non-anadromous stocks present.

The Clearwater drainage native redband trout are characterized by the highest vertebral counts known in the genus Salmo, 63-67, and averaging about 65. The highest mean value (65.6) was found in a sample of 12 specimens from Crooked Creek, tributary of the Lochsa River. Scale counts are relatively high, averaging about 145-155. Pyloric caeca counts average about 40-48 in Clearwater River drainage redbant trout. Eleven specimens from Orofino creek and its tributary, Rhodes Creek, are readily recognized as hatchery rainbow trout on the bases of their vertebrae counts of $61-64(62.6)$, caecal counts of $52-73(61)$, and scale counts averaging 133 in the lateral series.

The steelhead trout specimens from Marsh Creek, tributary to the Middle Fork of the Salmon River, Idaho, average 64.8 vertebrae, 43 pyloric caeca, and 145 scales $n$ the lateral series. The Marsh Creek specimens have 19-23 (21) gillrakers. Typically, Columbia River basin steelhead trout average about 19-20gillrakers. Basibranchial teeth were found in two of 153 specimens of Snake River drainage steelhead trout.

Two major groups of steelhead trout, called the A and B groups, pass up the Columbia River east of the Cascade Mountains. This differentiation is based on the timing of the runs and on the average size of the fish composing the runs, with B group the largest. Both the A and B groups of steelhead enter the Snake River. Part of the B group spawns in the Clearwater River drainage, and the above characterization of Idaho steelhead trout is assumed to be based on the B group. 
Non-anadromous stocks of redband trout are widely distributed in the Columbia basin (besides the "Kamloops" and "mountain Kamloops" of the headwater areas in British Columbia). These resident redband trout greatly confused ich thyologists in the 1890's when they were encountered between Shoshone Falls on the Snake River and the Cascade Range (Gilbert and Evermann, 1894; Evermann and Meek, 1898). Jordan and Evermann (1896) called this fish the silver trout, S. mykiss gibbsi. I examined a few museum specimens of "gibbsi"collected by Evermann's expeditions in the 1890's. Three specimens from the Umatilla River near Pendleton, Oregon, have 142,153, and 154 scales in the lateral series. A specimen from the Natches River near Yakima, Washington, is sparsely spotted, with spots only above the lateral line, and has 146 lateral series scales.

In 1972, I made three collections from the Malheur River drainage of eastern Oregon, consisting of 10 specimens from Swamp Creek and a collection of 15 specimens from Chino Creek, Elko County, Nevada, an isolated tributary to the south fork of the Owyhee River. These are the "arid lands" redband trout, often existing and seemingly flourishing under what would be considered intolerable conditions for trout. As mentioned, I collected the Chino Creek trout by angling with artificial flies in water of $83 \mathrm{~F}$. The conditions in Swamp Creek were similar to those of Chino Creek. The stream was intermittant, consisting of warm, stagnant, green water, yet the trout could be readily caught on flies, were in fine condition, and put up an excellent fight when hooked. To a trout biologist, these arid lands redband trout are amazing fish.

The vertebral numbers of the four samples range from 62-66, with means from 64 (Crane Creek) to 64.8 (Chino Creek). Gillrakers range from 17-22 with means from 18.3 (Chino Creek) to 19.6 (Swamp Creek). Lateral series scale counts range from 131.136 with means from 141 in Calamity Creek to 147 in Crane Creek to 41 in Swamp Creek. None of the specimens have basibranchial teeth.

Dr. Carl Schreck, Oregon Cooperative Fishery Unit, sent me data from trout collections made in Cook Creek and Cherry Creek, two small streams isolated from the Snake River by barrier falls in Eastern Oregon. These samples have low average lateral series scale counts (134 and 136), but have similar values for vertebrae (64.1 and 64.3) and for pyloric caeca (36 and 39) as do other arid lands redband trout.

I also examined a series of 32 specimens from 12 localities on BLM lands of the Snake river drainage of western Idaho, near the Oregon border. These specimens average 135 lateral series scales and about. 40 pyloric caeca. They have the typical redband trout parr marks and spotting pattern. Despite a long history of stocking hatchery rainbow trout in these streams, there is little or no detectible influence of nonnative trout.

Before leaving the Columbia basin, I will mention a few unusual specimens indicating the need for further sutdies. During Evermann's surveys of the Columbia basin in the 1890's, unusual trout were mentioned from the Wood River drainage of Idaho (Little Wood and Big Wood rivers). Hubbs and Miller (1948) discussed the Wood River fish fauna, pointing out that although the Wood River enters the Snake River below Shoshone Falls, it contains some elements of the upper Snake River and Bonneville basin fauna. Hubbs and Miller believed the native trout of the Wood River drainage is the cutthroat trout. In a specimen collected by Evermann's survey from the Little Wood River, near Shoshone, Idaho (Stanford Univ. 2023, now in Calif. Acad. Sci. collection), I counted 169 scales in the lateral series and 37 scales above the lateral line. This specimen has 64 vertebrae, 19 gillrakers and 9 pelvic rays. These characteristics are similar to the "mountain Kamloops" trout, suggesting that the trout native to the Wood River represents an older, relict form of the redband trout. Two specimens collected from the main Wood River near Shoshone, Idaho (S.U. 2040) are malformed, with deep, highly truncated bodies resulting from fusion of vertebrae. These specimens have 130-135 lateral series scales, but the low scale counts are likely influenced by their developmental abnormality.

The headwaters of the Wood River drainage from near Sun Valley, Idaho, and contain some excellent trout streams, such as Silver Creek. Excellent trout waters, historically stimulate heavy stocking with hatchery trout. I have not examined any recent collections from the Wood River drainage and have no information concerning the persistence of native trout. I also lack data on the "S. gibbsi" trout reported from the Payette and Boise river drainages of the Snake River system of Idaho and from most of the vast part of the Columbia River basin east of the Cascades Range.

A specimen in the Oregon State University collection (852) collected in 1961 from the Deshutes river near Fish Creek, has a basibranchial tooth, 36 scales above the lateral line, 147 scales in the lateral series, 9 pelvic rays, 41 pyloric caeca, spots above the lateral line, but only 61 vertebrae. Cutthroat trout are not known to be native to the Deshutes river. Until the native trout of the Deshutes River, both steelhead and resident stocks and particularly isolated populations little influenced by introductions, a re better studied, nothing can be said about their taxonomic characters. 


\section{Sacramento River Basin}

The coloration and other taxonomic characters of the redband trout of the Sacramento River bsin are the most variable of all geographical groups of redband trout, indicating that more than one ancestral form is involved to produce such diversity. In the northernmost section of the basin, in the headwaters of the Pit River drainage, the native trout is similar to the Goose Lake basin redband trout, which is expected because of the recent connections between Goose Lake and the Pit River. At the southern extreme of the basin, the South Fork Kern River golden trout, aguabonita, is one of the most strikingly colored trout in the world. The trout native to the main Kern and Little Kern, gilberti, is only slightly less colorful.

The relationship of the California golden trout to the redband trout, particularly the links between the trouts native to the main Kern and to Sheepheaven Creek in the northern Sacramento basin, were discussed by Schreck and Behnke (1971). Additional taxonomic data on golden trout were given by Gold and Gall (1975a, 1975b) and Gold (1977). Extremes in coloration and character values are found in aguabonita, which is characterized by the lowest numbers of vertebrae, 58-61 (59-60), the highest scale counts (35-45 above lateral line and 150-210 in lateral series), and lowest pyloric caecal counts [20-40 (31)] known among any trout of the redband evolutionary line. The Little Kern golden trout, whitei, and the main Kern trout, gilberti, were revised into one subspecies, gilberti, by Schreck and Behnke (1971). They differ from aguabonita in less intensity of coloration, more vertebrae [59-63 |60-61)], fewer scales (average 155-160 in lateral series and about 35 above lateral line), and more pyloric caeca (typically 35-40). I have never found basibranchial teeth in aguabonita, but they do occur occasionally in gilberti specimens. Three of 10 specimens of gilberticollected from the Kern River in 1893 and 1904 have basibranchial teeth. Some specimens from the Kern and Little Kern drainages have an unusual pattern of dentition on the tongue, with inner rows of teeth besides the normal row along the edge of the tongue. This tooth pattern on the tongue is also found in some Sheepheaven Creek trout.

The occurrence of two subspecies of golden trout in the Kern River drainage is likely the result of an early invasion of a primitive redband trout which also gave rise to the trout in the headwaters of the McCloud River prior to or during the last glacial epoch. The golden trout isolated in the headwaters of the South Fork of the Kern was more isolated from later invasions of other redband trout and/or coastal rainbow trout into the Kern River than was the Kern-Little Kern golden trout.

Evidently, except for the semi-isolated Kern Riverdrainage, coastal rainbow trout replaced redband trout in the southern Sacramento River basin (San Joaquin drainage). The redband trout, or at least a strong redband influence persisted in the northern part of the basin as far south as the Feather River, according to the descriptions and scale counts given by Rutter (1908).

The primitive redband trout that first invaded the Sacramento basin is probably best represented today by the population isolated in tiny Sheepheaven Creek of the upper McCloud River drainage. Gold (1977) gave a comprehensive description of the Sheepheaven trout based on 25 specimens. I have examined 21 specimens from Sheepheaven Creek, and my data essentially agrees with Gold's, except that I found basibranchial teeth present in 11 of 21 specimens, whereas Gold found these teeth in 9 of 25 specimens. The Sheephea ven Creek trout are not highly colored. They typically exhibit light or dull yellow tints on the sides and have a faint yellow "cutthroat" mark. In the numbers of vertebrae, 60-63 (61.4), scales in lateral series 153-174 (162), and pyloric aceca, 29-42 (36), they are similar to the Kern-Little Kern golden trout.

The Sheepheaven Creek trout have the lowest number of gillrakers of any western trout, 14-18 (15.6). Sheepheaven Creek is an isolated segment of the upper McCloud drainage, and it is possible that after the original ancestral radband trout gained access to the headwaters of the McCloud, differentiated forms substantially invaded before the series of barrierfalls were formed on the McCloud, but after the isolation of Sheepheaven Creek. I have examined specimens from other tributaries to the Upper McCloud above the falls (Tate, Edson, Trout, Raccoon, and Moosehead Creeks) and, although these specimens from other waters in the upper McCloud drainage share one or more characters with Sheepheaven Creek trout, they differ in others. There is no way to estimate how much of this variability found in other tributaries to the upper Mccloud is natural and how much is due to introductions and hybridization. Basibranchial teeth were found in one of three Trout Creek specimens, three of 15 Moosehead Creek specimens, and one of 16 specimens from Edson Creek.

In the McCloud River below the series of falls, there is also great variability in characters between trout of different tributaries. In the 12 specimens used by Jordan in his description of $S$. stonei and $S$. shasta, I found 
$61-64(62.6)$ vertebrae, $17-22$ (20) gillrakers, 28-35/32) scales above the lateral line, 139-160(146) scales in the lateral series, and 10-13 (11.5 right, 11.8 left) branchiostegal rays. The branchiostegal ray count in Sheepheaven Creek trout is $8-11$ (9.5 right and 9.8 left). The characteristics of the specimens used by Jordan to name stonei and shasta might serve to diagnose the subspecies stonei and are generally characteristic of the redband trout of the $\mathrm{McCloud}$ and Pit river drainages. However, there is such variability in numbers of vertebrae, scales, and pyloric caeca in the populations in various tributaries of the McCloud and Pit rivers that the name stonei would be useful only as a name for the trout of a particular geographical region (upper Sacramento basin), but not as a natural evolutionary unit. I believe the great variability I found is the result of mixing of more than one ancestral form of redband trout, and with a coastal rainbow trout influence in some populations.

Snyder collected six specimens from the head waters of the Pit River at the mouth of Joseph Creek in 1904. These specimens have 62-63 (62.5) vertebrae, 19-23 (21.3) gillrakers, and 138-155 (148) scales in lateral series-similar to the "type" specimens of stonei and sha stafrom the McCloud River, and also similar to the redband trout of the Goose Lake basin. In intervening areas, however, patterns of variability randomly occur without a smooth transition. For example, in tributaries to the McCloud River, mean vertebral counts range from 60.8 for 20 specimens from Hawkins Creek to 63.6 for 23 specimens from Clairborne Creek. Most pyloric caeca counts of $\mathrm{McCloud}$ and Pit river drainage redband trout average about 40-45, as is common in most redband trout, but in the lower Pit River drainage, collections from a series of tributaries (Kosk, Snowslide, Nelson, Burney, and Hat creeks and the Lost River) have caeca counts higher than found in typical coastal rainbow trout (53-79). In coloration and other characters, these trout are redband trout, except for the occurrence of large, roundish spots on the body, similar to cutthroat trout.

A collection of 10 specimens from the South Fork of Parker Creek in the northern headwaters of the Pit River have 62-65 (63.6) vertebrae, 19-23 (20.7) gillrakers, 37-49 (43) pyloric caeca, and average 33 scales above the lateral line and 149 in the lateral series. Despite a long history of continued stocking of hatchery rainbow trout, the South Fork Parker Creek trout closely resemble the museum specimens collected by Snyder from the headwaters of the Pit River. Basibranchial teeth occur in about 5 percent of the specimens from the Pit River drainage.

\section{TAXONOMIC NOTES}

It is difficult to adequately explain the variability in the trout discussed above in terms of a classification reflecting evolutionary reality. If all of the trout I have considered to be redband trout do indeed represent a phylogenetic separation from the coastal rainbow trout, and they are recognized as a separate species, Salmo newberryi, how can a logical breakdown into subspecies be made?

It appears that at least two major ancestral groups are involved in the present diversity-one characterized by low numbers of vertebrae and bright coloration centered in the Sacramento River basin, and one with high numbers of vertebrae and less coloration in the Columbia River basin. The ancestral forms probably mixed in the region of the Oregon desert basins, with a northern influence penetrating into the upper Sacramento basin. Superimposed on this mixing between diverse groups of redband trout, further hybridization probably occurred with coastal rainbow trout. I believe that the original situation, before introductions of hatchery trout and modification of environments, was highly complex and would have been very difficult to interpret, but under the present circumstances, an evolutionary interpretation, classifying the diversity of redband trout into subspecies reflecting evolutionary reality is impossible.

The name newberryi is associated with the native lacustrine trout of upper Klamath Lake; but, the tributaries of the upper Klamath basin appear to have a trout differentiated from the lacustrine form. The name kamloops has been used as a species or subspecies to characterize the trout native to the upper Fraser and upper Columbia basins in British Columbia. As demonstrated, in an evolutionary context, the "Kamloops" trout is not restriced by the U.S.-Canadian border, but occurs throughout the Columbia River basin east of the Cascade Range in a diversity of forms.

In the Oregon desert basins, the influence of a past large lake existence can be noted in the slightly higher number of gillrakers. The trout native to each basin, however, are not sharply differentiated from the trout of contiguous basins. The Malheur basin native trout are similar to the Columbia basin trout, and the Goose Lake basin trout to the trout native to the upper Pit River. Thus, the patterns of variability found in the redband trout of the Oregon desert basins are not readily delineated into subspecies, either as one inclusive subspecies covering all the basins or by recognizing separate subspecies for each basin. 
Despite the range in variability in numbers of vertebrae, scales, and pyloric caeca, populations from diverse geographical areas exhibit a complete transition between extreme forms. The only groups with some clear-cut distinctions are those long isloated from contact with other redband trout and from contact with coastal rainbow trout, such as the South Fork Kern golden trout, aguabonita, the Kern-Little Kern golden trout, gilberti, and the unnamed Sheepheaven Creek trout.

I will briefly mention the taxonomy of golden trout. As discussed by Schreck and Behnke (1971), five species were named for these trout. We revised the former classification into two subspecies, aguabonita and gilberti. We combined the trout native to the Little Kern, whitei, and the trout native to the main Kern, gilberti, into the same subspecies. Because gilbertiis the older name, whitei became a synonym of gilberti in our revised classification. We did this because we could find no differences between the specimens collected in 1893 from the Kern River upon which Jordan based the name gilberti, and the specimens collected by Evermann in 1904 from the Little Kern, on which he named whitei.

The current classification of Little Kern trout as S. aguabonita whitei, and the Kern River trout as $S$. gairdneri gilberti, is inconsistent with evolutionary relationships. Although there were likely some minor differences between the native trout of the Kern River and the trout native to the Little Kern, they were certainly more closely related to each other than were the Kern trout and the coastal rainbow trout, gairdneri. The classification proposed by Carl Schreck and I places the Kern and Little Kern trouts in the same species and subspecies and is based on the fact that we could detect no real differences between the original specimens of gilberti and the original specimens of whitei. From our study, we concluded that the original, pure form of trout native to the main Kern River no longer exists. Thus, new information supporting or modifying our conclusions is not likely to be forthcoming. Unless someone discovers a pure population of the of the original Kern River trout, gilberti, and can demonstrate subspecific differences between it and the Little Kern trout, or unless someone reexamines the original (type specimens) material on which the names gilberti and whitei are based and finds subspecific differences overlooked by Schreck and I, the Little Kern golden trout is most correctly classified as the subspecies gilberti.

For published literature, I would continue to use the name aguabonita as a species name and S. aguabonita gilberti for the Kern- Little Kern trout. This is a conservative approach until more is known about the evolutionary relationships of the trouts discussed as redband trout. I have little doubt, however, that both subspecies of the golden trout share closer evolutionary relationship to the redband trout than they do to the coastal rainbow trout, with the closest links being between the Kern-Little Kern trout, gilberti, and the trout of Sheepheaven Creek.

\section{LIFE HISTORY AND ECOLOGY}

It is apparent that the redband trout cannot be simply diagnosed in regard to life history traits-there are too many diverse forms of them. I will emphasize certain life history and ecological attributes associated with redband trout of different areas to point out the genetic resources available to fisheries management, particularly in relation to the genetic bases governing an advanced age at sexual maturity, long maximum life span, proclivity for predation, and adaptations to exist and flourish in harsh, unstable environments.

I will begin with the original trout of Upper Klamath Lake, S. newberryi. Upper Klamath Lake is an eutrophic body of water with an abundance of cyprinids and suckers, although the introduced black bullhead is now one of the more common fish. It has a long geologic history of existence. Under these circumstances it could be assumed that the native trout was under selection pressure to evolve to be a large and effective predator. Evermann and Meek (1898) visited upper Klamath Lake in 1896 and found the trout to be aboundant and large, with 8 to 10 pound fish common. They wrote: "The trout of upper Klamath Lake are probably not surpassed by any lake-dwelling trout in America in beauty, size, gameness, or sweetness and delicacy of flavor." They recommended that this excellent trout be widely propagated and distributed.

Concerning the present use of the native Klamath Lake trout in fisheries programs, the most important question is: Does this trout still exist? There has been a long history of massive stocking of hatchery rainbow trout into the upper Klamath watershed. The harsh environmental conditions for salmonid fish in Upper Klamath Lake would exert strong selective pressures to maintain the original genotype. But after almost 100 years of constant exposure to genetic dilution from hybridization with introduced rainbow trout, how much of the original genotype remains? Large trout are still occasionally taken by anglers. The March 1967 issue of the Izaak Walton League publication, Outdoor America, has an article titled "Conservation on the Klamath River in Oregon," with a photograph of a 20 pound trout caught in 1966 from the Wood River, 
tributary to Klamath Lake. Is this large trout S. newberryi, an introduced rainbow trout, or a hybrid mixture?

The taxonomic characters of newberryi are sufficiently distinct from coastal and hatchery rainbow trout so that a detailed examination of a few specimens of the present trout of Upper Klamath Lake should allow for an evaluation of the situation.

In British Columbia, the geologic history of the area created numerous large, typically highly elongated lakes clustered in the upper Fraser and upper Columbia river basins. Kokanee salmon are also native to many of these lakes. This area is the most likely site to find a trout pre-adaped to coexist with, and be an effective predator on, kokanee salmon. The trout native to these lakes, commonly called "Kamloops" trout, has long been noted for its large size.

Perhaps the largest of the "Kamloops" trout is the one native to Kootenay Lake. The native trout of Kootenay Lake are unusual in that they comprise two distinct, reproductively isolated forms: a "normal" trout, and one that spawns only in the Lardeau River and is characterized by an older age at maturity, a longer maximum life span, and a much greater maximum size (Behnke, 1972). The growth potential is best expressed in new environments where the first generation of introduced fish have virtually unlimited food resources to exploit without intensive competition. The Kootenay "Kamloops" trout stocked into Lake Pend Oreille, Idaho reached 37 pounds, and those stocked into Jewel Lake, British Columbia, attained weights up to 52.5 pounds. The large trout of Kootenay Lake were widely propagated in British Columbia, but it is doubtful that pure stocks have been maintained in the waters where they were introduced.

The native trout of the Oregon desert basins likely evolved adaptations for coexisting with and preying of cyprinid fishes, particularly the tui chub, Gila bicolor, in the Pleistocene lakes of these basins. It is significant to note that the trout in Three Mile Creek of Catlow Valley, after gaining access to a reservoir constructed by diverting the creek, became an effective predator of the tui chub in the reservoir and express a rapid growth, averaging 3-3/4 pounds at age III+ (Kunkel, 1976).

I have previously mentioned that a brood stock of the redband trout of Three Mile Creek is now established in a private ranch pond by the Oregon Department of Fish and Wildlife. Such propagation practices are to be recommended over attempts to create a hatchery brood stock, in which the negative effects of domestication are unavoidable. The desert basin redband trout probably also possess a genetic basis for high temperature tolerance and tolerance for high alkalinity and high $\mathrm{pH}$. Fortunately, the Three Mile Creek population appears to be among the purest stocks of redband trout that I have examined.

Wilmot (1974) studied the chromosomes and gene loci on specimensfrom Three Mile Creek and found no variability (heterozygosity) in about 20 gene loci. He was concerned that the apparent lack of heterozygosity could be detrimental to their survival. The Three Mile Creek trout appear well adapted and flourishing. I have no concern for its continued existence as long as the environment is not drastically altered and no introductions of nonnative trout are made into the drainage. It is generally true that small, isolated populations of organisms exhibit low levels of heterozygosity. This is not "bad" for the particular population, but it is bad for propagation purposes. Increasing the amount of heterozygosity by hybridizing two or more isolated stocks would likely increase the success when the offspring are introduced into new waters la broader base of heterozygosity should create broader adaptability|. For example, the Three Mile Creek brood stock could be crossed with the redband trout of Home Creek or Roaring Springs, just to the north of Three Mile Creek in Catlow Valley. If such an ambitious propagation progaram were to be attempted, the parental brood stocks should be maintained separately and not mixed together.

For "warm-adapted" trout, the genetic resources available in the "arid lands" redband trout appear promising. I have mentioned the trout of Chino Creek, Nevada, and Swamp Creek, Oregon, that flourish and feed in stagnant, intermittent pools where maximum summer water temperatures exceed $80 \mathrm{~F}$. I have also mentioned that the Wyoming Game and Fish Department has established a small brood stock of the Chino Creek trout in a private ranch pond. Chino Creek and Swamp Creek are small habitats and the native trout probably have low heterozygosity. Interracial crosses would likely yield better results in new environments than would a "pure" strain.

The steelhead of the Columbia River are summer-run fish, and two major groups, A and B, are recognized. The A group enters the Columbia River earlier (before mid-August) than the B group. Both groups cross Ice Harbor Dam on the Snake River about the same time, but maintain reproductive isolation by homing to specific tributary streams. The B group, characteristic of the Clearwater River drainage of Idaho, averages a larger size (10-15 lbs.) because they typically spend a longer period in the ocean. Actually, both the A and B groups consist of numerous subgroups, associated with particular "home" streams. The coastal rainbow steelhead of the Columbia River are winter-run fish (entering the river in November-December) and spawn 
in tributaries west of the Cascade Range. Before dams in the basin blocked the migrations of many of the stocks, steelhead were known to spawn in the Columbia River above the Arrow Lakes in British Columbia and in Snake River tributaries up to Shoshone Falls-a migration of almost 1,000 miles from the ocean (Fulton, 1970).

The coastal rainbow trout and the coastal cutthroat trout coexist over a broad range. From the present distribution of cutthroat in interior waters, it appears that when the redband trout came into contact with the interior cutthroat trout, the cutthroat was eliminated in most areas. Coexistence has been historically maintained between interior cutthroat trout, S. clarkilewisi, and redband steelhead trout in the Salmon and Clearwater drainages of Idaho, but the life history differences and habitat preferences of the two species are such that there is almost no interaction between them.

\section{STATUS}

A changing environment and introduction of hatchery rainbow have depleted the genetic divesity once possessed by the redband trout. Most obvisous here are the dams, pollution, and irrigation diversions in the Columbia River basin that have greatly reduced the historical abundance of the steelhead trout and have exterminated many local races. The maintenance of the remaining diversity is one of the great challenges of fisheries research and management. Many other unique forms, such as the upper Kla math Lake trout and the trout of the Oregon desert basis, may be largely extinct as pure populations.

The California Department of Fish and Game's "Threatened Trout Committee" has been active in protecting and enhancing the survival of various forms of native trout. The redband trout of Sheepheaven Creek has been transplanted into barren streams, and the Sheepheaven watershed was acquired by the U.S. Forest Service.

The South Fork Kern golden trout, S. aguabonita, has been widely stocked in western states and is more abundant now than it was historically. It will only maintain pure populations, however, if no rainbow trout or cutthroat trout are stocked with it. Many, if not most, "golden" trout populations in the Rocky Mountain region are actually hybrids. In the South Fork of the Kern River, the abundance and distribution of golden trout has been drastically reduced because of the invasion of brown trout, $S$. trutta. Attempts have been made, with limited success to date, to eliminate the brown trout by poison and barrier construction from the headwaters of the South Fork. In view of the vulnerability of the golden trout to angling, restrictive regulations have been instituted on golden trout waters.

In the Little Kern drainage, pure populations of the Little Kern golden trout, gilberti or "whitei", persist in only a few head water tributaries (Upper Soda Springs Creek, Deadman Creek, and Wet Meadows Creek). The Little Kern golden trout has been proposed for "threatened" status under the Endangered Species Act. This proposal was made because of proposed logging of the Little Kern watershed, but the problem has been elminated by creating the Golden Trout Wilderness Area.

The status of the Little Kern golden trout and plans for its rehabilitation are discussed in California Fish and Game Inland Fisheries Endangered Species Program Special Report 78-1 (Jan. 1978), written by D. P. Christenson. A Little Kern golden trout management plan has recently (July, 1979) been finalized by the Sequoia National Forest. 


\section{KAMCHATKAN TROUT, Salmo mykiss}

It was known to naturalists by the middle of the 18 th century that besides Pacific salmon and charr, a trout inhabited the waters of the Kamchatkan Peninsula. Three names were formally proposed for the Kamchatkan trout: Salmo mykiss, given in 1792, and S. purpuratus and S. penshinensis given in 1814. Until recent years, however, it was not known if there is more than one species of trout native to Kamchatka and what the relationships are to other species in the genus.

Although no taxonomic evidence concerning relationships was available at the time, David Starr Jordan first believed the Kamchatkan trout was a cutthroat and used the name S. purpuratus (later S. mykiss) as the name for North American cutthroat trout. About 1896, Jordan recieved a head and skin of a large specimen (about 3 feet long) of a Kamchatkan "steelhead" trout. From this specimen, he concluded that S. mykiss was not a cutthroat trout, but was closely related to the Atlantic salmon, $S$. salar. In the addenda to the third volume of Jordan and Evermann's work on the fishes of North America (1898), a change was made in the species name for cutthroat trout, from S. mykiss to S. clarki.

Several years ago, I examined the specimen of Kamchatkan trout at Stanford University (S.U. 12011) which Jordan had examined many years before. This specimen appeared to be typical of a steelhead rainbow trout, and I could not understand the basis for Jordan's opinion that it is closely related to the Atlantic salmon, particularly in light of the zoogeographical evidence on the origin and affinities of Kamchatkan fishes.

In 1960, I examined seven specimens of Kamchatkan trout in museums in Moscow and Leningrad. I published my conclusions that there is one species of trout native to Kamchatka represented by both resident and anadromous forms, and that it is very closely related to the rainbow trout, S. gairdneri (Behnke, 1966). The only difference I could detect between S. mykiss and S. gairdneri was the low number of vertebrae (57-59) in the specimens of S. mykiss. I later learned that a mixup occurred in the x-ray films I examined, and the counts I reported for S. mykiss were based on a nother species (probably the Siberian "lenok", Brachymystax lenok). S. mykiss actually has 61-65, typically $62-63$ vertebrae.

Until my paper on S. mykiss was published in 1966, this trout had received almost no attention from Russian researchers. Since then, several Russians have published numerous papers. Thanks to Dr. K. A. Savvaitova of the University of Moscow, I believe I have reprints of most of the work published on S. mykiss. Most of these studies have been published in the Soviet journal, Voprosy Iktiologii, or the "Journal of Ichthyology". Articles on S. mykiss available in English in the Journal of Ich thyology include: Kokhmenko (1972) on food habits; Maksimov (1971, 1972, 1976) on reproductive biology, ecology, and life history; Mina (1973) on techniques of aging; Savvaitova (1975) on chromosomes. I have a copy of a 118-page work, coauthored by the above listed persons, published in limited quantities by Vorontzh University in 1973, titled, "Kamchatskiye blagorodnye lososi" or the nobel salmon of Kamchatka, which is a compendium of taxononmic and biological information on S. mykiss.

Mednikov and Akhundov (1975) published their study on DNA hybridization among resident and anadromous forms of S. mykiss and steelhead and hatchery rainbnow trout in the journal, Doklady Nauk, which is also available in English.

Prior to this spate of research interest in S. mykiss, little was known, and this trout was generally considered to have a negative value as a potential predator on young slamon. S. mykiss is now being touted as an excellent fish with a bright future for propagation and introduction into other waters of the Soviet Union. The biology of $S$. mykiss appears identical to that of $S$. gairdneri. Hatchery rainbow trout have long been propagated in the Soviet Union, and in recent years, steelhead rainbow trout from Oregon have been imported into the USSR, mainly to establish runs in the Caspian and Black seas.

Undoubtedly, there are Kamchatkan "steelhead" populations with life histories similar to the imported stocks, and such introductions of foreign fish can likely be attributed to the "grass is greener" human syndrome. With a view to future exchanges of fish with the USSR, I would point out that the anadromous brown trout native to the Caspian Sea basin, S. trutta caspius, is the largest of all the many forms of brown trout in the world. Berg (1948) gave an unverified maximum weight of 112 pounds for the Caspian trout. There are, or were, many different stocks of trout native to the Caspian basin. Evidently the race attaining the largest size was the winter race ascending the Kura River. In 1916 and 1935, the average weight of trout in this run was 33 pounds. In connection with the Great Lakes of the U.S., I would point out that the major forage fish in the Caspian Sea historically has been species of herring, including the genus Alosa (alewife). 


\section{TYPICAL CHARACTERS}

Vertebrae, 61-65 (62-63); scales in lateral series, 125-135; scales above lateral line, 24-29; pyloric caeca, 25-60 (35-50); gillrakers, 16-22, typically 19 . Coloration and general appearance similar to coastal rainbow trout.

\section{DESCRIPTION}

Since my publication of 1966 , much additional taxonomic data have become available. As mentioned, the major correction to my original diagnosis of $S$. mykiss is in the number of vertebrae (61-65 instead of 57-59). Most of the anadromous steelhead stocks a verage 40-45 pyloric caeca, but resident stocks average from 34 to 51 caeca. Considerable geographical variability occurs in the number of pyloric caeca in Kamchatkan trout. Their lower number of pyloric caeca appears to be the major difference between them and the typical coastal rainbow trout of North America. However, I have no data on the characters of Alaskan steelhead trout.

DNA hybridization and protein comparisons (electrophoresis) agree on the close relationship between mykiss and gairdneri, but these techniques have so far generally failed to correctly assess genetic differences between closely related species or subspecies of salmonid fishes.

The chromosomes of $S$. mykiss were studied by Vasilyev (1975). From 17 specimens of trout from the Kamchatka River (resident populations), 57-63 chromosomes were counted in various cells with modal values of 58 and 60 and a total number of $104 \mathrm{arms}$ associated with the chromosomes. This karyotype is also most frequently found in $S$. gairdneri. In steelhead $S$. mykiss from three Kamchatkan rivers, Vasilyev reported modal counts of 60-62 chromosomes with 108 arms. In $S$. gairdneri (origin not stated), Vasilyev counted 62 chromosomes and 104 arms. Some of these seemingly aberrant counts are likely due to techniques, and I will reserve judgement on the karyotypes of $S$. mykiss until additional studies are made.

\section{DISTRIBUTION}

In addition to the Kamchatkan Peninsula, S. mykiss occurs in the Commander Islands, off the east coast of Kamchatka. In the Okhotsk Sea basin, it occurs, at least sporadically, as far south as the mouth of the Amur River along the mainland. The distribution of a "rainbow" trout in the Far East is most likely explained by events during the last glacial period when so much of the earth's waters were tied up in ice, ocean levels were lowered, and a land bridge connected the Chukotsk Peninsula of the USSR to the Seward Peninsula of Alaska. The present distribution of different forms of Arctic charr and Dolly Varden charr indicates that the closest genetic similarities of $S$. mykiss are with the rainbow trout from the Alaskan Peninsula to the Kuskok wim River. That is, if future studies definitely indicate that $S$. mykiss differs from typical North American coastal rainbow trout in some character, such as its chromosomes, then the "S. mykiss character" will also be found in the rainbow trout in the northernmost part of its range in Alaska.

It is possible that the present diversity found in Kamchatkan trout is the result of more than one form of rainbow trout or a trout with a redband influence invading Far Eastern waters during the last glacial period.

\section{TAXONOMIC NOTES}

Previous to my publication in 1966, the Russian literature treated the Kamchatkan trout as two species-S. mykiss for the resident form and S. penshinensis for the anadromous steelhead form. All the recent Russian authors agree with me that only one species, $S$. mykiss, should be recognized, and the resident and anadromous forms are expressions of life history and ecological differentiation within a single species.

As discussed, $S$. mykiss is definitely part of the rainbow-redband trout group, with closest relationships apparently to the coastal rainbow trout. If all of this group is classified as one species, $S$. mykiss is the valid name because it is the oldest name for any member of the group. I would hesitate to formally propose a name change from $S$. gairdneri to $S$. mykiss because, unlike most scientific names of fish mainly of concern to ichthyologists and taxonomic work, the name $S$. gairdneri for rainbow trout is firmly entrenched in 
nontaxonomic literature. An obvious tactic to indefinitely delay a decision on making $S$. gairdneri a synonym of $S$. mykiss is to use the cliche, "further research is necessary." It is assumed, of course, that further research will always be necessary and will go on without end.

\section{LIFE HISTORY AND ECOLOGY}

The steelhead form of $S$. mykiss exists mainly in rivers on the west coast of the peninsula, and resident forms occur mainly in rivers on the east coast. The maximum age is reported to be eight for steelhead and nine for resident fish. Steelhead young spend one to four years (generally $2-3$ ) in freshwater and one to four years in the ocean (generally 2-3), which is comparable to steelhead populations in the northern part of their range in North America. A length of about 39 inches and a mazimum weight of about 23 pounds may be attained by the largest Kamchatkan steelhead.

To date, Russian researchers have not identified two separate runs of steelhead comparable to the summer and fall or winter runs in North America. Steelhead begin the spawning migration about mid-August in the southern rivers of Kamchatka, and these runs last until November in the northern rivers. In the Bolshaya River there is some indication that in addition to the late summer, early fall run, another run occurs in the spring just prior to spawning. Spawning occurs from April through June. There is also an indication that $S$. mykiss steelhead have distinct runs comparable to North American steelhead by the identification of two forms of steelhead-an "ocean" form and a "coastal" form-in the Russian literature. The ocean form spends more time in the ocean (2-3 years) and attains a larger size.

In resident freshwater forms of $S$. mykiss, two forms have been described: a strictly freshwaterform and an estuarine form that feeds in bays and estuaries. It is likely that in the absence of coastal cutthroat trout in Kamchatka, S. mykiss has evolved ecological forms that fill the niche used by the cutthroat trout along the Pacific Coast of North America.

Lake Azabachye (Kamchatka River basin) has a lacustrine form of S. mykiss. With increasing size, the $L$. Azabachye trout becomes highly predaceous. The bulk of its diet consists of smelt, stickleback, sockeye salmon, and charr.

\section{STATUS}

S. mykiss is more common and widespread than formerly believed. I find nothing in the Soviet literature regarding threats to its environment or overexploitation problems. It is mentioned that bears may take considerable numbers in small, shallow streams. S. mykiss has been proposed for propagation and introduction into new waters in the USSR, but I am not aware of any large-scale propagation and introduction program at present. 


\section{TROUTS NATIVE TO GULF OF CALIFORNIA DRAINA GES}

In addition to the trout native to the Rio del Presidio and Rio San Lorenzo of Mexico, discussed under rainbow trout, a highly divergent trout, the Mexican golden trout, is native to three drainages to the north of the Rio San Lorenzo. Those include the Rio Culiacan, Rio Sinaloa, and Rio Fuerte.

In the Gila River system of the lower Colorado River basin, two additional species of trout have been named, S. gilae and S. apache. Trout are also native to the Rio Yaqui, tributary to the Gulf of California north of the Rio Fuerte, and to the Rio Casas Grandes, a disrupted part of the Rio Grande basin of Mexico. Trout are also native to the Rio Mayo between the Rio Fuerte and Rio Yaqui drainages, but no published information exists on Rio Mayo trout.

The trouts native to Gulf of California drainages are the most recently named of the western North American trouts and are the least studied. They include: S. gilae in 1950, S. chrysogaster in 1964, S. apache in 1972. There are many unknowns concerning their correct position in the phylogeny of western trouts.

My present interpretation of relationships of these trouts places them closer to each other than any of them to rainbow-redband trout or to cutthroat trout. I previously suggested (Behnke, 1970; Schreck and Behnke, 1971), that Gila and Apache trouts may be closely related to golden and redband trout because of the yellow coloration, pronounced light colored tips on the dorsal, anal, and pelvic fins, and low numbers of vertebrae and pyloric caeca, as well as the evidence of past faunal connections between the lower Colorado basin and California coastal drainages. I do not believe this relationship is as close as I once assumed it to be. The similarity in characters between the golden and redband trout on one hand and the Gila and Apache trout on the other, is more likely due to a sharing of primitive characters that have been retained in diverse evolutionary lines. That is, a common ancestor with these characters is placed in a more distant position in the phylogeny of western trouts and is not an immediate common ancestor to an evolutionary line giving rise to redband, Gila, and Apache trouts, as I once believed.

The relationships indicated in Figure 1, depicting my assumed phylogeny of western trouts, show an early branching from the main line leading to cutthroat and rainbow-redband trouts, which gave rise to the Mexican golden, Gila, and Apache trouts. The relationship between Gila and Apache trouts appears to be close (mainly a difference in spotting pattern), but the Mexican golden trout is the most sharply differentiated species of western trout, and its actual relationship to any other species is largely a matter of speculation at present.

Some of the divergence and speciation giving rise to the living species may be attributable to geological events in upper Pliocene times in the northern part of the Gulf of California as discussed by Minckley (1973). During colder periods of the Pleistocene, forms of the rainbow-redband evolutionary line extended into Mexico with probable opportunities for hybridization with the trout established from earlier times. During historical times, destruction and modification of trout habitat and introductions of hatchery rainbow trout have added to the difficulty of unraveling the mysteries of the taxonomy of trouts native to the Gulf of California drainages. 

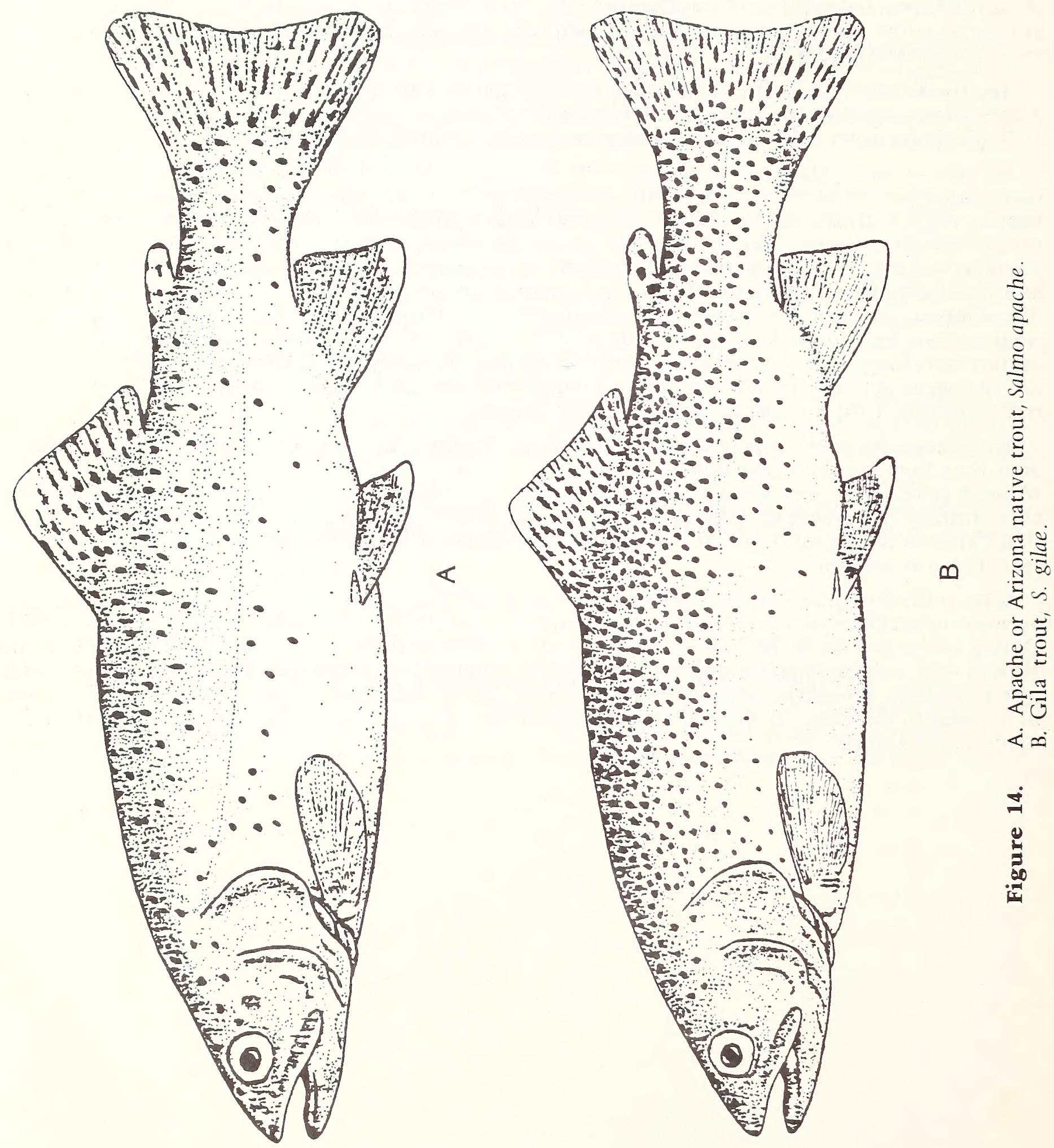


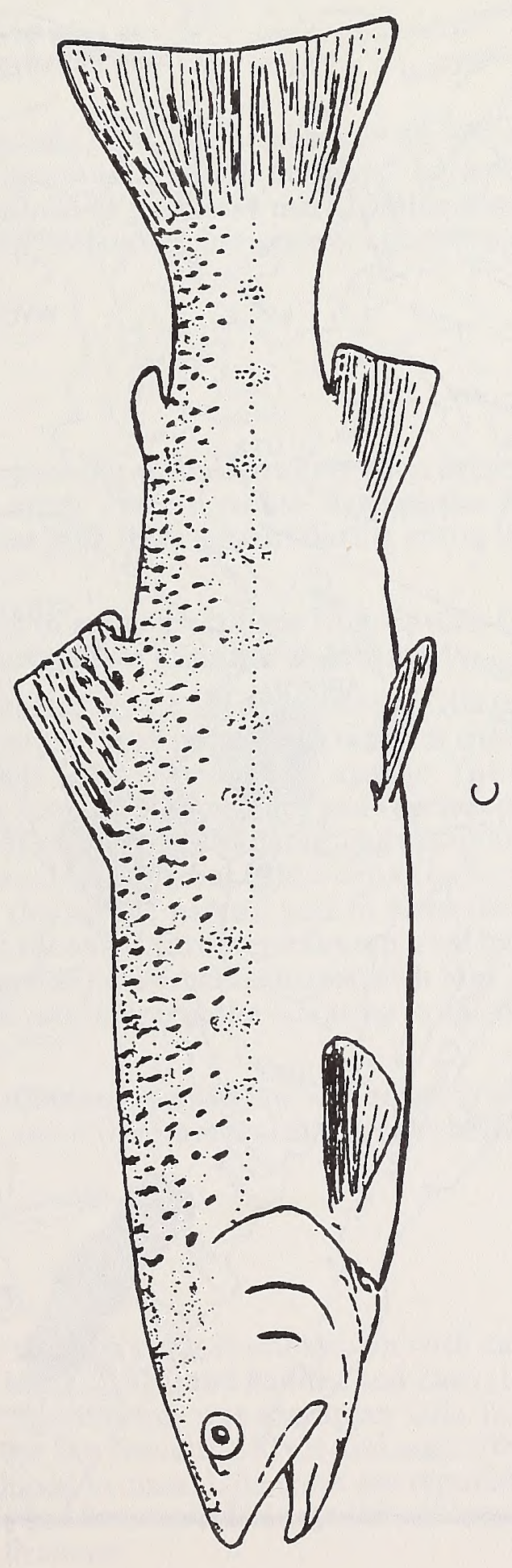

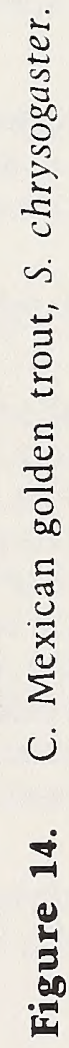




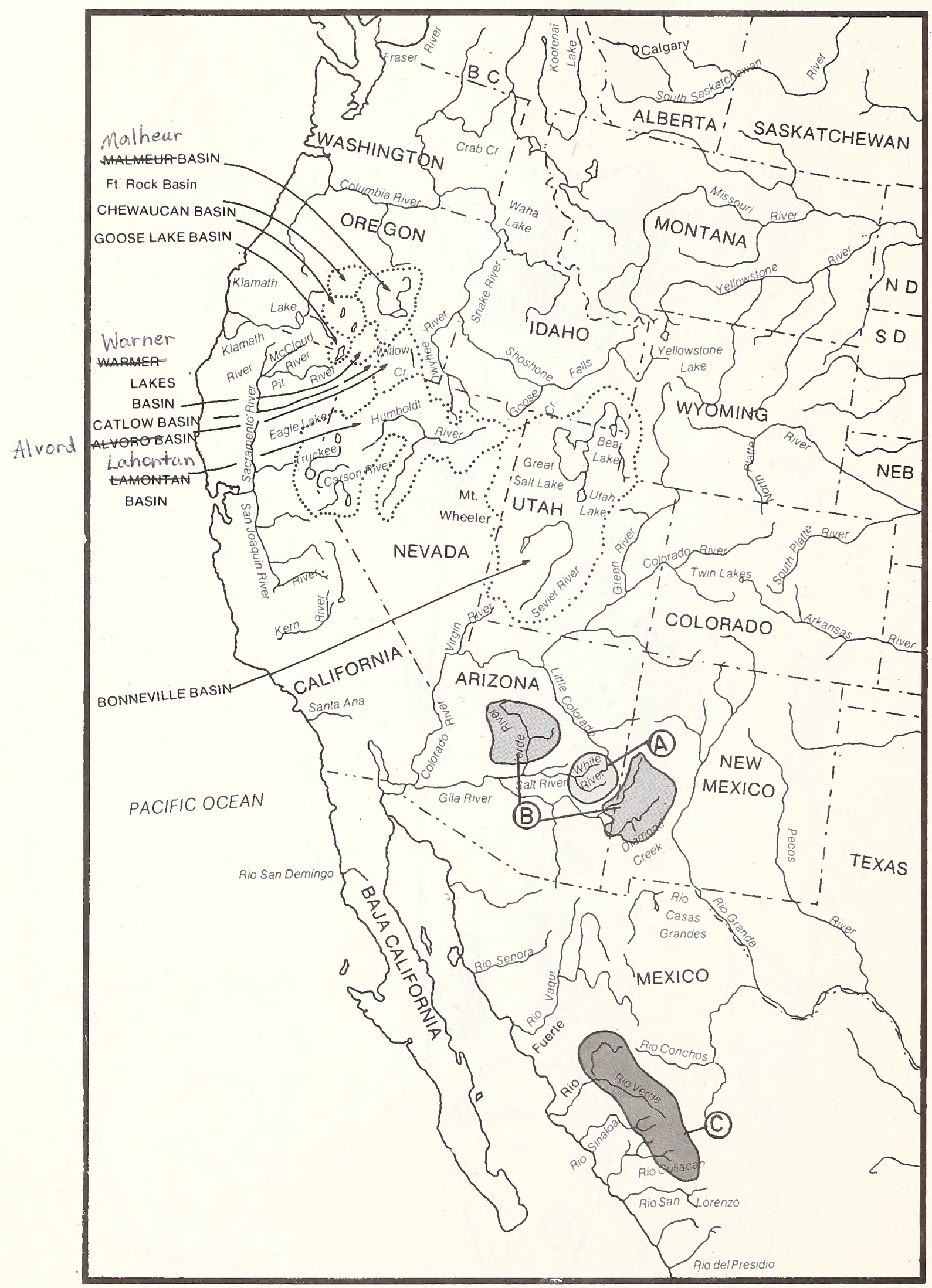

Figure 15. Distribution of $[\mathrm{A}] \quad$ S. apache, $[\mathrm{B}]$ [C] S. chrysogaster. 


\section{GILA TROUT, Salmo gilae}

Since I wrote about Gila trout in Behnke and Zarn (1976), new information became available on chromosomes (Beamish and Miller, 1977), and a general update of Gila trout is found in a draft recovery plan (1977) and in a manuscript written by Kim Mello and Paul Turner of New Mexico State University for the U.S. Fish and Wildlife Service, titled: "Population Status and Distribution of Gila Trout in New Mexico" (1978). Also, Rinne (1978) published a paper on habitat evaluation and population estimates. However, the taxonomic status of $S$. gilae and its survival status have not changed since I wrote on this fish in 1976.

\section{TYPICAL CHARACTERS}

Lateral series scale counts $135-165$ (150-155), vertebrae 59-63 (60-61), pyloric caeca 25-45 (32-35), except in Spruce Creek population, with mean value of 48 . Yellowish coloration, with diffuse pink-red tints along lateral line in mature males. Yellowish cutthroat mark, profusion of small spots on body, mainly above lateral line. The most consistent difference between S. apache and S. gilae is in the smaller and more numerous spots on S. gilae.

\section{DESCRIPTION}

S. gilae and S. apache have morphological similarities in their deeper, more tuncated bodies and longer fins which differentiate them from other western trouts. Besides the difference in spotting patterns, $S$. gilae differs from $S$. apache in the red or pink hues (absent during entire life of $S$. apache) and by the retention of parr marks in older age classes.

Basibranchial teeth are found in some specimens from Spruce Creek, New Mexico, and are present in museum specimens from the Verde River drainage of Arizona.

Beamish and Miller (1977) reported on the chromosomes of Gila trout based on examination of cells from four specimens of the Main Diamond Creek population raised at the Sterling Springs Hatchery, Arizona. The most frequent count obtained was 56 , the same as in $S$. apache. The total number of chromosome arms was 105, with 49 metacentric or two-armed chromosomes and seven acrocentric or one-armed chromosomes. If this count is correct, then S. gilae must be variable (polymorphic) in the number of metacentric and acrocentric chromosomes and total arm number. In the cells, the haploid sets of chromosomes lone set from the male parent and one from the female parent) pair to form the diploid set of chromosomes. Matings between a male and female with the set of chromosomes reported by Beamish and Miller would yield sperm and eggs with haploid combinations of 24 metacentrics with four acrocentrics and 25 metacentrics with three acrocentrics. These would recombine in the offspring as 48,49 , or 50 metacentric chromosomes with six, seven, or eight acrocentrics.

Additional studies on the chromosomes of $S$. gilae will be necessary to determine if this polymorphism is real or due to small sample size, and if there are real differences between the chromosome sets of $S$. gilae and S. apache.

\section{DISTRIBUTION}

The original distribution of the Gila trout is not known with certainty. Some of the unusual aspects of distribution were discussed by Miller (1972) and Behnke and Zarn (1976). When Miller (1950) named S. gilae, he believed that its historical distribution was the upper Gila River basin of New Mexico and that the population in Spruce Creek of the San Francisco River drainage, tributary to the Gila River joining the Gila in western Arizona, was introduced by man. Gila trout are reputed to be native to Eagle Creek, Arizona, a tributary to the Gila west of the San Francisco drainage (Minckley, 1973), and should have been native to at least part of the San Francisco drainage.

Gila trout were also native to the Verde and probably to the Agua Fria drainages tributary to the Salt River segment of the Gila River basin in central Arizona (Behnke and Zarn, 1976). Minckley (1973) pointed out that the unusual distribution of Gila trout has much in common with a subspecies of chub, Gila robusta grahami.Rinne (1976) presented an excellent discussion of geological and climatic changes in the present Gila River basin in relation to the distribution of chubs of the genus Gila. It is likely that these events were 
also responsible for the distribution of Gila trout and for any divergence that may have occurred between groups of Gila trout in different geographical areas.

\section{TAXONOMIC NOTES}

The differences between $S$. gilae and S. apache are comparable to the differences between subspecies of cutthroat trout. Future investigations, obtaining better da ta on degrees of genetic relatedness, may indicate that Gila and Apache trout should be more correctly considered as subspecies of a single species.

There is an indication in the specimens from Spruce Creek (basibranchial teeth and high numbers of pyloric caeca) and in the specimens from the Gila trout originally native to the Verde drainage (Miller, 1972) that considerable differentiation occurred among populations of $S$. gilae.

The spotting pattern in S. gilae is always more profuse than in S. apache, but I have noted variability in the size and shape of the spots. The typical, or "idealized" spotting pattern of very small, uniform sized spots is found consistently only in the South Diamond Creek population. These fish have a spotting pattern similar to the fine-spotted Snake river cutthroat trout. In other populations of $S$. gilae, relatively large, rounded or oval spots can be observed along the dorsal surface. It is not known whether this variability in spotting is entirely natural or if it is due to a hybrid influence from introduced trout.

\section{LIFE HISTORY AND ECOLOGY}

The life history and ecological information on Gila trout is of limited value for diagnosing anything unique about Gila trout. That is, any trout species living in the small, largely intermittent streams presently inhabited by $S$. gilae would yield similar results in regard to age, growth, fecundity, feeding habits, etc. The largest Gila trout collected in the wild in recent years was a specimen from South Diamond Creek, measuring about 13 inches. Individuals in the abundant population in Main Diamond Creek almost never exceed 9 inches. The small size of Gila trout is due to the tiny, harsh environments in which they are presently restricted, and is not the result of genetic dwarfism. Given ideal conditions and an abundant food supply, I am confident that $S$. gilae can exhibit growth comparable to other trout species.

\section{STATUS}

The present distribution of Gila trout includes Main Diamond, South Diamond, McKenna and Iron Creeks (upper Gila River tributaries in New Mexico), and Spruce Creek (San Francisco River Drainage, New Mexico. Introduced populations, derived from Main Diamond Creek, occur in McKnight Creek (Mimbres River drainage, a disrupted part of the Rio Grande basin, New Mexico), sheep Corral Creek (Gila drainage, New Mexicol, and Gap Creek, a tributary of the Verde River, Arizona. This distribution is identical to that given by Behnke and Zarn (1976), but reproduction has since been verified in the introduced populations in Sheep Corral and Gap creeks, and the McKnight Creek population has increased in abundance. All of these habitats, however, are small watersheds in arid regions. The streams are largely intermittant during the summer and fall and are highly susceptible to nega tive impacts from domestic livestock grazing. A forest fire or severe flash flood could eliminate any of the populations.

The Gila trout is the only trout currently listed as endangered under the Endangered Species Act. Other trout, formerly listed as endangered (Lahontan, Paiute, and greenback cutthroat trouts and Apache trout), have been downgraded to a threatened status. 


\section{APACHE OR ARIZONA NATIVE TROUT, Salmo apache}

\section{TYPICAL CHARACTERS}

Deep, compressed body; golden-yellow or olive-yellow body coloration; pronounced, moderate size rounded or oval spots, more or less evenly distributed over sides of body and onto top of head. Dorsal fin typically largest of any western trout. Vertebrae 58-61 (59-60), lateral series scales 135-170(150-155), pyloric caeca $21-44$ (27-33). About 5 percent of some populations possess basibranchial teeth.

\section{DESCRIPTION}

I prefer the common name Apache trout for this fish, instead of the "official" name of Arizona native trout, because three species of trout, S. gilae, S. apache, and S. clarki pleuriticus, are native to Arizona. Thus, there are three species of "Arizona native trout."

The spotting differences between Apache and Gila trout can be compared to the differences between subspecies of cutthroat trout. The Apache trout has a spotting pattern similar to most interior subspecies of cutthroat except that the spots tend to be slightly smaller, occur anteriorly below the lateral line more-orless evenly over the sides of the body, and occur on top of the head in specimens of Apache trout. The Gila trout resembles the fine-spotted Snake River cutthroat trout in its spotting pattern.

The Apache trout typically has brighter golden-yellow colors than does the Gila trout, but has no red or pink colors on the body. A relatively constant and distinctive mark in Apache trout is a horizontal band of dark pigment on the iris of the eye, producing a mask-like effect.

There is considerable environmental influence (non-genetic) determining trout morphology, but Apache and Gila trout typically are differentiated from other western trouts by deeper, "chunkier", more compressed body forms, longer fins, and by the dorsal fin originating more posteriorly on the body. The dorsal fin of Apache trout is on the average longer (depressed length) than in any other trout, and the Gila trout typically has the longest adipose fin.

A complete taxonomic description of S. apache was given by Miller (1972).

\section{DISTRIBUTION}

The original distribution, based on Miller's (1972) examination of museum specimens, includes the White and Black river drainages (headwaters of the Salt River division of Gila River basin), the headwaters of the Little Colorado drainage, and the Blue River (specimen from KP Creek), a tributary to the San Francisco River drainage. These are located in the White Mountains of Arizona.

Apache trout first became established in the headwaters of the Salt river drainage and made headwater stream transfers to invade headwater sections of the Little Colorado and San Francisco drainages. The original distribution of Apache trout is estimated to include about 600 miles of stream habitat (Recovery plan draft, 1977), but this has been reduced to about 30 miles of small, headwater tributaries.

\section{TAXONOMIC NOTES}

The correct classification of Apache trout has long been a mystery. Early ichthyologists, E. D. Cope and D. S. Jordan, considered it a representative of the Colorado River cutthroat trout, S. c. pleuriticus. This was before it was realized that the range of the Colorado River cutthroat trout did not extend to the Grand Canyon. When Miller (1950) described S. gilae, he knew that trout were native to the White river, Arizona, and at that time, provisionally classified Apache trout with $S$. gilae. After examining more specimens, Miller (1972) separated the Apache trout as a distinct species, S. apache. He believed the most likely origin of apache trout was from a cutthroat trout ancestor isolated in the head waters of the Little Colorado drainage.

The closest relationships of $S$. apache are almost certainly to $S$. gilae, and future studies will likely indicate that they are more correctly classified as two subspecies of a single species. Miller's contention of a cutthroat trout ancestor could be correct with the sequence being: cutthroat trout-Apache trout-Gila trout. I believe, however, that the common ancestor to the Gila and a pache trouts had its evolutionary connections 
associated more closely with the Mexican golden trout, rather than with the cutthroat trout. There is no hard evidence on phylogenetic relationships, however, and speculation can be made only on the basis of general similarities in the yellow coloration and zoogeographical implications.

Needham and Gard (1964) suggested Gila and Apache trout and Mexican golden trout may have had a hybrid origin from rainbow and cutthroat trout coming into contact in the lower Colorado River basin. The chromosome data (karyotypes of S. apache and S. gilae) negate the hybrid origin theory.

The distribution patterns of S. gilae and S. apacheare unusual in relation to each other. If the Apache trout were established in the headwaters of the Salt River, why was it not the native trout in the Verde and Agua Fria drainages, which are tributaries to the Salt River, instead of the Gila trout? Did a single common ancestor invade the Gila River basin and give rise to both Gila and Apache trouts, or were their ancestors already distinct when they gained access to the Gila basin?

\section{LIFE HISTORY AND ECOLOGY}

As with the Gila trout, nothing is known about the life history and ecology of Apache trout that indicates differences from other trout species living under similar circumstances. Harper (1978) and Rinne (1978) presented the most comprehensive information on the biology and habitat of Apache trout.

Apache trout are presently restricted to small headwater streams at high elevations $(7,000-9,000$ feet $)$ in the White Mountains. In such waters, they seldom attain a size of more than 10 inches. Introductions have been made into three lakes: Christmas Tree, Lee Valley, and Bear Canyon. The angler-caught record Apache trout was caught in Bear Canyon Lake in 1973. It weighed 3.6 pounds and measured 22 inches.

The draft recovery plan for $S$. apache contains a summary of biological information.

\section{STATUS}

In 1975 , the status of S. apache was changed from endangered to threatened under the Endangered Species Act.

It is estimated that Apache trout now inhabit only about 30 miles of the original 600 stream miles. Because the streams presently inhabited are typically small headwater streams, the present distribution and abundance on comparative surface area basis is probably no more than one percent of the original distribution and abundance. The Apache trout, however, is more abundant and has a better survival status than the Gila trout. The White Mountain watersheds receive good snow packs, and the steams are perennial with more stable flows than those where Gila trout are found. Introductions into 13 new streams and into 3 lakes have been carried out. Of the lake populations, natural reproduction has been verified only in a tributary to Christmas Tree Lake.

Most of the introductions were made from Ord Creek stock raised at the Sterling springs Hatchery. The hatchery stock of Apache trout was lost in 1974, and a new stock was obtained from Soldier Creek, a very small tributary of the Black River. I examined only four small specimens from Soldier Creek, but found them to be typical Apache trout.

The main cause of the decline of Apache trout has been the introduction of nonnative trouts. Brown trout and brook trout often replace apache trout, and hybridization occurs with rainbow trout. In Behnke and Zarn (1976), I mentioned that when I sampled upper Ord Creek in 1967, the Apache trout was dominant over the brown trout and brook trout, but by 1975, the situation was reversed. In 1977, Ord Creek was treated to eliminate all nonnative trouts and was restocked with Apache trout.

The upper Bonito Creek watershed, the major stronghold of pure populations of Apache trout, was logged in 1975-76. The full impact of this logging on the Apache trout is not yet known. The greatest danger may be a long-term effect of altered habitat and warming temperatures favoring invasion of rainbow trout from downstream areas and the stimulation of hybridization. 


\section{MEXICAN GOLDEN TROUT, Salmo chrysogaster}

\section{TYPICAL CHARACTERS}

Sides of body with light golden yellow coloration. Orange on ventral surface. Spots sparse and diffuse, mainly restricted to area above lateral line Vertebrae counts, 56-59, and pyloric caeca counts $10-30$ (21-23), are lowest found in any western North American trout. Branchiostegal rays 8-10; pelvic rays, 9.

\section{DESCRIPTION}

The Mexican golden trout was described and illustrated by Needham and Gard (1959), but was not given the name S. chrysogaster until 1964 (Needham and Gard, 1964).

The low numbers of vertebrae and pyloric caeca and the distinctive coloration make the Mexican golden trout the most sharply differentiated of all western trouts. The basic characters of the Mexican golden trout are probably generalized primitive characters retained from an ancestor common to all western North American trouts. Miller (1972) believed the Mexican golden trout represents the most primitive living species of western trout. Needham and Gard, however, did not find basibranchial teeth in any of the 100 specimens examined. Since basibranchial teeth must have been a trait of an ancient common ancestor to all western trouts, the evolutionary branch leading to the Mexican golden trout must have lost these teeth. Robert R. Miller and Ted Uyeno, University of Michigan, told me that their recent (June, 1979) karyotyping of $S$. chrysogaster revealed a diploid number of 60 chromosomes and a total arm munber of 104. This karyotype does not appear to be primitive in relation to other living species of western trouts.

Lateral series scale counts reported by Needham and Gard (1959) are variable. They range from 115 to 158 , with mean values from about 126 to 142 in different samples.

\section{DISTRIBUTION}

The Mexican golden trout is known only from headwater tributaries to the Rio Culiacan, Rio Saloa, and Rio Fuerte, and tributaries to the Gulf of California in Durango and Sinaloa, Mexico.

\section{TAXONOMIC NOTES}

In Needham and Gard's original publication (1959), they considered the Mexican golden trout to be a form of rainbow trout, S. gairdneri. They attributed the highly divergent characters of these trout to environmental influences. By 1963, I had accumulated five years of data on thousands of specimens of all forms of western trouts, and it became obvious that the unique characters of the Mexican golden trout compared to other trouts could not be explained by environmental influences. They are a distinct and highly divergent evolutionary line from other western trouts. Needham and Gard (1964) then proceeded to describe the Mexican golden trout as a new species, $S$. chrysogaster. They proposed a hybrid origin between cutthroat trout and rainbow trout in the lower Colorado River basin, which gave rise to the Mexican golden, Gila, and Apache trouts.

A hybrid origin for Gila and Apache trouts can be dismissed on the basis of their chromosomes. The chromosome number of 60 for Mexican golden trout also argues against a hybrid origin, unless the hybridization occurred between an ancestor to the Gila and Apache trouts (with 56 chromosomes), but numbers of vertebrae and pyloric caeca are evidence against such a hybrid origin.

\section{LIFE HISTORY AND ECOLOGY} known.

Needham and Gard (1959) presented some descriptions of habitat, but no other biological information is 


\section{STATUS}

Needham and Gard (1959) and Needham's field notes reveal that much environmental deterioration and loss of habitat has occurred, which has greatly reduced the distribution and abundance of this trout. The potential threat from hybridization with introduced rainbow trout is now known, but $R$. R. Miller related to me that a reservoir at the headwaters of the Rio Fuerte is stocked with rainbow trout which might escape in to the Rio Fuerte during high water periods.

It would be highly desirable to obtain current data on the status of Mexican golden trout and to have the Mexican government formulate plans to preserve this species. 


\section{OTHER MEXICAN TROUT}

Trout that have not been formally assigned to any species occur in the drainages of the Rio Yaqui, Rio Casas Grandes, Rio Mayo, and perhaps other Mexican river systems. Needham and Gard (1959) presented data on collections from the Rio Yaqui and Rio Casas Grandes drainages. Although the Rio Casas Grandes is an isolated segment of the Rio Grande basin, its headwaters are in close proximity to the headwaters of the Rio Yaqui, and the Casas Grandes trout are probably derived from the Rio Yaqui by headwater transfer.

Needham and Gard discussed a collection of specimens from Black Canyon, a headwater tributary to the Rio Casas Grandes, Chihuahua, Mexico. They found them to be similar in appearance. Light yellowish coloration with a yellow cutthroat mark, a strong red band on the side, bright red-orange lower fins with white tips of the pelvic and anal fins, and an orange tip on the dorsal fin. The parr marks are eliptical with supplementary rows. Vertebrae counts ranged from 58 to 61 (60), and lateral series scale counts averaged 138 in the Black Canyon sample and 146 in the sample from the Rio Seco.

R. R. Miller, University of Michigan, presented a paper at the Desert Fishes Council meeting (Novermber, 1978) on trout of the Rio Yaqui and Rio Mayo. Miller believes (as I do) that the closest relationships of the trout native to the Rio Yaqui land also the Casas Grande and Rio Mayo trout) are to the Gila trout. However, the chromosomes of the Rio Yaqui and Rio Mayo native trout, with a diploid number of 64 and 104 arms, is distinct from the karyotype of Gila trout. The karyotype of Rio Yaqui and Rio Mayo trout probably gave rise to the Gila and Apache trouts' karyotype by a fusion of 16 one-arm chromosomes into 8 two-arm chromosomes.

I have seen color slides of Rio Yaqui and Rio Mayo trout. The major superficial difference I noted between these trouts and Gila trout is that Rio Yaqui and Rio Mayo trouts have fewer and larger spots than is typically found on Gila trout and exhibit more red coloration.

There is no published account to date on trout in the Rio Mayo. They were first discovered by University of Arizona students on a field trip in 1975. Trout were observed both above and below Basasechic Falls in the Rio Caudamena, tributary to the Rio Mayo, Chihuahua. The Rio Mayo drainage is between the Rio Yaqui drainage to the north and the Rio Fuerte to the south.

Much is yet to be learned on the distribution and classification of Mexican trout. The report of Cope (1886) describing a trout with basihyal (basibranchial) teeth collected near the junction of Durango, Sinaloa, and Chihuahua, is still a mystery, but it does indicate that a trout very different from any collected from Mexico in recent years exists or existed in the 19th century, waiting to be rediscovered.

It is not surprising that our understanding of Mexican trout is inadequate in view of how little is really known concerning evolutionary relationships and classification of the native trouts in such well studied areas as the Columbia and Sacramento river basins.

The native trouts of western North Amerrica of the subgenus Parasalmo can never be reduced to a system of classification into species and subspecies that accurately reflects all of the degrees and nuances of evolutionary relationships. The most realistic goal is to attempt to approximate the major and minor branching sequences of the actual but unknown phylogeny based on critical evaluation of all evidence of relationships and to create a classification best reflecting evolutionary history.

It can be assumed that no system of classification of western trouts will ever be agreed upon by all ichthyologists. My advice then, to fishery biologists, managers, and administrators, is to avoid fretting over taxonomic problems and the "most" correct scientific name for any particular trout, but to recognize that particular forms of trout are native to particular areas and that these forms are differentiated from each other. The sum total of this differentiation comprises the diversity or genetic resources of western trouts. Among this diversity are trout adapted to meet specific needs of fisheries management programs.

The genetic diversity of the trouts native to western North America can be considered a natural resource, but a resource that has been historically neglected and has suffered great depletion. 


\section{REFERENCES}

Andrusak, H., and T. G. Northcote. 1970. Management implications of spatial distribution and feeding ecology of cutthroat trout and Dolly Varden in coastal Bristish Columbia lakes. B.C. Fish Wildlife Branch, Fish. Mgt. Publ. 13: 14p.

Armstrong, R. H. 1971. Age, food, and migration of sea-run cutthroat trout, Salmo clarki, at Eva Lake, southeastern Alaska. Trans. Am. Fish. Soc., 100 (2): 302-306.

Averett, R. C. and F. A. Espinosa. 1968. Site selection and time of spawning by two groups of kokanee in Odell Lake, Oregon. Jour. Wildlife Mgt., 32: 76-81.

Bailey, R. 1978. Restoration of a wild Lahontan cutthroat trout fishery in the Truckee River, CaliforniaNevada.p. 53-55, in J. R. Moring (Ed.), Proc. Wild Trout-Catchable Trout Symposium. Ore. Dept. Fish and Wildlife.

Barnhart, R. 1975. Steelhead trout, p. 7-11, in W. King (Ed.), Wild Trout Management Symposium. Trout Unlimited, Denver, Colo.

Baxter, G. T., and J. R. Simon. 1970. Wyoming fishes. Wyoming Games and Fish Dept. Bull. 4: 168 p.

Beamish, R. J., and R. R. Miller. 1977. Cytotaxonomic study of Gila trout, Salmo gilae. Jour. Fish. Res. Bd. Canada, 34 (7): 1041-1045.

Behnke, R. J. 1959. A note on Oncorhynchus formosanum and Orcorhynchus masou. Jap. Jour. Ichthyol., 7/5, 6): $151-152$.

Behnke, R. J. 1960. Taxonomy of the cutthroat trout of the Great Basin with notes on the rainbow series. M.A. Thesis, Univ. Calif., Berkeley: 98 p.

Behnke, R. J. 1966. Relationships of the Far Eastern trout, Salmo mykiss Walbaum. Copeia (2): 346-348.

Behnke, R. J. 1968. A new subgenus and species of trout, Salmo (Platysalmo) platycephalus, from southcentral Turkey, with comments on the classification of the subfamily Salmoninae. Mitt. Hamburg. Zool. Mus. Inst., 66: 1-15.

Behnke, R. J. 1970. The application of cytogenetic and biochemical systematics to phylogenetic problems in the family Salmonidae. Trans. Am. Fish. Soc., 99 (1): 237-248.

Behnke, R. J. 1972a. The salmonid fishes of recently glaciated lakes. Jour. Fish. Res. Bd. Can., 29 (6): 639-671.

Behnke, R. J. 1972b. The rationale of preserving genetic diversity. Proc. West. Assoc. State Game, Fish Comm. 52: $559-561$.

Behnke, R. J. 1978. Use of native trout in special regulations fisheries. p. 45-47, in K. Hashagen (Ed.), Wild trout management symposium proceedings. Published by Calif. Trout, Inc.

Behnke, R. J., P. R. Needham, and T.P. Koh. 1962. Status of the landlocked salmonid fishes of Fromosa with a review of Oncorhynchus masou (Brevoort). Copeia (2): 400-407.

Behnke, R. J., and M. Zarn. 1976. Biology and management of threatened and endangered western trout. USDA Forest Service, Gen. Tech. Rep. RM-28: 45 p.

Bendire, C. E. 1882. Notes on Salmonidae of the upper Columbia. Proc. U.S. Nat. Mus., 4: 81-87.

Benson, S. B., and R. J. Behnke. 1961. Salmo evermanni a synonym of Salmo clarki henshawi. Calif. Fish and Game, 47 (3): 257-259.

Berg, L. S. 1948. Freshwater fishes of the USSR and adjacent countries. Acad. Sci. USSR, Fauna USSR, 27 (1): 466 p. (English translation 1962, OTS 61-31218).

Binns, N. A. 1977a. Present status of indigenous populations of cutthroat trout, Salmo clarki, in southwest Wyoming. Wyoming Game and Fish Dept. Fish. Tech. Bull. 5: 58 p.

Binns, N. A. 1977b. Evaluation of trout habitat that would be impacted by Cheyenne's proposed Phase II water development in the North Fork Little Snake River drainage. Wyoming Game and Fish Dept. Adm. Rep., Proj. No. 5076-09-6602: 22 p.

Binns, N. A. 1978. Quantification of fluvial trout habitat in Wyoming. Trans. Bonneville Chapt. Am. Fish. Soc. 1978 meeting: 32-45.

Binns, N. A., and F. M. Eiserman. 1979. Quantification of fluvial trout habitat in Wyoming. Trans. Am. Fish Soc. 108 (3): 215-228. 
Bisson, P. A., and C. E. Bond. 1971. Origin and distribution of fishes of Harney basin, Oregon. Copeia (2): $268-281$.

Bjornn, T. C. 1971. Trout and salmon movements in two Idaho streams as related to temperature, food, stream flow, cover, and population density. Trans. Am. Fish. Soc., 100 (3): 423-438.

Bjornn, T. C. 1975. The St. Joe River cutthroat fishery-a case history of angler preference. Proc. West. Assoc. State Game, Fish Comm., 55: 187-194.

Bjornn, T. C., and T. H. Johnson. 1978. Wild trout management, an Idaho experience.p. 31-39, in K. Hashagen (Ed.), Wild trout management symposium proceedings. Published by Calif. Trout, Inc.

Bjornn, T. C., and J. Mallet. 1964. Movements of planted and wild trout in an Idaho river system. Trans. Am. Fish. Soc. 93 (1): 70-76.

Bond, C. E. 1961. Keys to Oregon fishes. Agr. Exp. Sta., Ore. State Univ., Tech. Bull. 58: 42 p.

Bond, C. E. Endangered plants and animals of Oregon, Vol. 1, Fishes. Agr. Exp. Sta., Ore. State Univ., Spec. Rep. 205: $8 \mathrm{p}$.

Broecker, W. S., and A. Kaufman. 1965. Radiocarbon chronology of Lake Lahontan and Lake Bonneville II, Great Basin. Bull. Geol. Soc. Am., 76: 537-566.

Brown, C. J. D. 1971. Fishes of Montana. Big Sky Books, Bozeman, Mont.: 207 p.

Bulkley, R. V. 1961. Fluctuations in age composition and growth rate of cutthroat trout in Yellowstone Lake. U.S. Fish and Wildlife Service, Bur. Sport Fish and Wildlife Res. Rep. 54: 31 p.

Bulkley, R. V. 1963. Natural variation in spotting, hyoid teeth counts, and coloration of Yellowstone cutthroat trout, Salmo clarki lewisi. U.S. Fish and Wildlife Service, Spec. Sci. Rep.-Fish. 460: 11 p.

Busack, C. A. 1978. Genetic vartiation among population of Pauite trout (Salmo clarki seleniris). M.S. Thesis, Univ. Calif., Davis: 155 p.

Busack, C. A., R. Halliburton, and B. A. E. Gall. 1979. Electrophoretic variation and differentiation in four strains of domesticated rainbow trout (Salmo gairdneri). Can. J. Genet. Cytol., 21: 81-94.

Bustard, D. R., and D. W. Narver. 1975. Preferences of juvenile coho salmon (Oncorhynchus kisutch) and cutthroat trout (Salmo clarki) relative to simulated alteration of winter habitat. Jour. Fish. Res. Bd. Can., 32 (5): 681-687.

Butler, R. L., and D. P. Borgeson. 1965. California "catchable" trout fisheries. Calif. Dept. Fish and Game Fish Bull. 127: 47 p.

Campbell, V. R. 1971. The westslope cutthroat. Montana Outdoors, 2 (3): 7-9.

Carl, G. C., W. A. Clemens, and C. C. Lindsey. 1967. The freshwater fishes of British Columbia. B. C. Prov. Mus., Handbook 5: $192 \mathrm{p}$.

Cartwright, J. W. 1961. Investigations of the rainbow trout of Kootenay Lake British Columbia with special reference to the Lardeau River. B. C. Fish and Game Branch, Mgt. Publ. 7: 46 p.

Cavender, T. M. 1978. Taxonomy and distribution of bull trout, Salvelinus confluentis (Suckley), from the American Northwest, Calif. Fish and Game, 64 (3): 139-174.

Cavender, T. M., and R. R. Miller. 1972. Smilodonichthys rostrosus, a new Pliocene salmonid fish. Mus. Nat. Hist., Univ. Oregon Bull., 18: 45 p.

Cope, E. D. 1872. Report on the reptiles and fishes obtained by the naturalists of the expedition, p. 432-442, in U.S. Geol. Surv. Wyoming (Hayden's Survey).

Cope, E. D. 1886. The most southern salmon. Amer. Nat., 20 (8): 735.

Cope, O. B. 1955. The future of the cutthroat in Utah. Proc. Utah Acad. Sci., Arts, Letters, 32: 89-93.

Cope, O. B. 1956. Some migration patterns in cutthroat trout. Proc. Utah Acad. Sci., Arts, Letters, 33: 113-118.

Cope, O. B. 1957a. Six years of catch statistics on Yellowstone Lake. Trans. Am. Fish. Soc., 85: 106-179.

Cope, O. B. 1957b. Races of cutthroat trout in Yellowstone Lake. U.S. Fish and Wildlife Service, Spec. Sci. Rep.-Fish. 208: 74-84. 
Cope, O. B. 1964. Revised bibliography on the cutthroat trout. U.S. Fish and Wildlife Service, Bur. Sport Fish. and Wildlife, Res. Rep., 65: 43 p.

Cordone, A. J., and S. J. Nicola. 1970. Harvest of four strains of rainbow trout, Salmo gairdneri, from Beardsley Reservoir, California. Calif. Fish and Game, 56 (4): 271-287.

Dahlem, E. A. 1979. The Mahongany Creek watershed-with and without grazing. p. 31-34, in: O. B. Cope (Ed.), Proc. Forum-Grazing and riparian/stream ecosystems. Trout Unlimited, Denver, CO.

De Witt, J. W. 1954. A survey of the coast cutthroat trout, Salmo clarki clarki in California. Calif. Fish and Game, 40 (3): 329-335.

Diana, J. S., and E. D. Lane. 1978. The movement and distribution of Paiute cutthroat trout, Salmo clarki seleniris, in Cottonwood, Creek, California. Trans. Am. Fish. Soc. 107 (3): 444-448.

Dickson, I. W., and R. H. Kramer. 1971. Factors influencing scope for activity and active and standard metabolism of rainbow trout. Jour. Fish. Res. Bd. Can., 28 (4): 587-596.

Dollar, A. M., and M. Katz. 1964. Rainbow trout brood stocks and strains in American hatcheries as factors in the occurrence of hepatome. Prog. Fish Cult., 26 (4): 167-174.

Donaldson, L. R., D. D. Hansler, and T. N. Buckridge. 1957. Interracial hybridization of cutthroat trout, Salmo clarki,and its use in fisheries management. Trans. Am. Fish. Soc., 86: 350-360.

Dwyer, W. P., and R. H. Kramer. 1975. The influence of temperature on scope for activity in cutthroat trout, Salmo clarki. Trans. Am. Fish. Soc. 104 (3): 552-554.

Dymond, J. R. 1931. Description of two new forms of British Columbia trout. Contrib. Can. Biol., Fish., 6 (16): 391-395.

Dymond, J. R. 1932. The trout and other game fishes of British Columbia. Dept. Fish., Ottawa, Canada: 51 p.

Evermann, B. W. 1896. A report upon salmon investigations in the headwaters of the Columbia River, in the state of Idaho, in 1895, together with notes upon the fishes observed in that state in 1894 and 1895 . Bull. U.S. Fish. Comm., 16: 149-202.

Evermann, B. W. 1906. The golden trout of the southern High Sierras. Bull. U.S. Bur. Fish., 25: 1-51.

Evermann, B. W. 1908. Description of a new species of trout (Salmo nelsoni) and a new cyprinodont (Fundulus meeki) with notes on other fishes from Lower California. Proc. Biol. Soc. Wash., 21: 19-30.

Evermann, B. W., and S. E. Meek. 1898. A report upon salmon investigations in the Columbia River basin and elsewhere in the Pacific Coast in 1896. Bull. U.S. Fish Comm., 17: 15-84.

Evermann, B. W., and J. T. Nichols. 1909. Notes on the fishes of Crab Creek, Washington, with description of a new species of trout. Proc. Biol. Soc. Wash., 22: 91-94.

Flick, W. A. 1971 . New trout for old waters. N.Y. State Conservationist, June-July 1971: 18-21.

Flick, W. A., and D. A. Webster. 1964. Comparative first year survival and production in wild and domestic strains of brook trout, Salvelinus fontinalis. Trans. Am. Fish. Soc., 93 (1): 53-69.

Flick, W. A., and D. A. Webster. 1976. Production of wild, domestic and interstrain hybrids of brook trout (Salvelinus fontinalis) in natural ponds. Jour. Fish. Res. Bd. Can., 33 (7): 1525-1539.

Fremont, J. C. 1845. Report of the exploring expeditions to the Rocky Mountains in the year 1842, and to Oregon and northern California in the years 1843-1844. U.S. Senate, Gale and Seaton, printers: 583 p.

Fulton, L. A. 1970. Spawning areas and abundance of steelhead trout and coho, sockeye, and chum salmon in the Columbia River basin-past and present. Nat. Marine Fish. Ser., Spec. Sci. Rep.-Fish. 618: 37 p.

Gharrett, A. J., R. C. Simon, and J. D. McIntyre. 1977. Reassociation and hybridization properties of DNA's from several species of fish. Comp. Biochem. Physiol. B 56 (1): 81-85.

Giger, R. D. 1972. Ecology and management of coastal cutthroat trout in Oregon. Ore. Game Comm., Fish. Res. Rep. 6: 61 p.

Gilbert, C. H., and B. W. Evermann. 1894. A report on investigations in the Columbia River basin with descriptions of four new species of fishes. Bull. U.S. Fish Comm., 14: 169-207.

Girard, C. 1856. Notice upon the species of the genus Salmo of authors observed chiefly in Oregon and California. Proc. Acad. Nat. Sci. Phila., 8: 217-220. 
Girard, C. F. 1858. Ichthyological notices. Proc. Acad. Nat. Sci. Phila., 10: 223-225.

Gold, J. R. 1977. Systematics of western North American trout (Salmo) with notes on the redband trout of Sheepheaven Creek, California. Canad. Jour. Zool., 55 (11): 1858-1873.

Gold, J. R., J. C. Avise, and G. A. E. Gall. 1977. Chromosome cytology in the cutthroat trout series, Salmo clarki (Salmonidae). Cytologia, 42: 377-382.

Gold, J. R., and G. A. E. Gall. 1975a. The taxonomic structure of six golden trout (Salmo aguabonita) populations from the Sierra Nevada, California. Proc. Calif. Acad. Sci., 40 (10): 243-263.

Gold, J. R., and G. A. E. Gall. 1975b. Further record of Little Kern golden trout, Salmo aguabonita whitei, in the Little Kern River basin, California. Calif. Fish and Game, 61 (4): 248-250.

Gold, J. R., G. A. E. Gall, and S. J. Nicola. 1978. Taxonomy of the Colorado cutthroat trout (Salmo clarki pleuriticus) of the Williamson Lakes, California. Calif. Fish and Game, 64 (2): 98-103.

Goode, G. B. 1888. American fishes. Standard Book Co., W. A. Houghton, New York: 496 p.

Gordon, C. D., D. W. Chapman, and T. C. Bjornn. 1970. The preferences, opinions, and behavior of Idaho anglers as related to quality in salmonid fisheries. Proc. West. Assoc. State Game, Fish. Comm., 49: 98-114.

Hanzel, D. A. 1959. The distribution of the cutthroat trout (Salmo clarki) in Montana. Proc. Mont. Acad. Sci., 19: $32-71$.

Harper, K. C. 1978. Biology of a southwestern salmonid, Salmo apache. p. 99-111, in: J. R. Moring (Ed.), Proc. Wild Trout-Catchable Trout Symposium. Ore. Dept. Fish and Wildlife.

Hart, J. L. 1973. Pacific fishes of Canada. Fish, Res. Bd., Can. Bull. 180: 740 p.

Hartman, G. F. 1956. A taxonomic study of cutthroat trout, Salmo clarki clarki, rainbow trout, salmo gairdneri, and reciprocal hybrids. M.S. Thesis, Univ. British Columbia: $71 \mathrm{p}$.

Hartman, G. F. 1969. Reproductive biology of the Gerrard stock of rainbow trout, p. 53-67, in: P. A. Larkin (Ed.), Symposium on salmon and trout in streams. H. R. MacMillan Lectures in Fisheries. Univ. British Columbia, Vancouver, B.C.

Hasler, T. J., and R. R. Van Kirk (Eds.). 1977. Genetic implications of steelhead management symposium proceedings. Calif. Coop. Fish. Res. Unit, Spec. Rep. 77-1: 57 p.

Hayden, F. V. 1872. Report of F. V. Hayden, in: Preliminary report of the United States Geological Survey of Montana and adjacent territories. Fifth Ann. Rep. 1872: 11-165.

Heede, B. H. 1977. Case study of a watershed rehabilitation project: Alkali Creek, Colorado. USFS Rocky Mtn. For. Rng. Exp. Sta., Res. Pap. RM-189, 18 p.

Hickman, T. J. 1978. Systematic study of the native trout of the Bonneville basin. M.S. Thesis. Colo. State Univ., Fort Collins: $122 \mathrm{p}$.

Hickman, T. J., and R. J. Behnke. 1979. Probable discovery of the original Pyramid Lake cut throat trout. Prog. Fish Cult., 41 (3): 135-137.

Hochachka, P. W. 1961. Liver glycogen reserves of interacting resident and introduced trout populations. Jour. Fish. Res. Bd. Can., 18 (1): 125-135.

Holden, P. B., W. White, G. Sommerville, D. Duff., R. Gervais, and S. Gloss. 1974. Threatened fishes of Utah. Proc. Utah Acad. Sci. Arts, Letters, 51 (2): 46-55.

Horak, D. L., and W. D. Klein. 1967. Influence of capture method on fishing success, stamina, and mortality of rainbow trout (Salmo gairdneri) in Colorado. Trans. Am. Fish. Soc., 96 (2): 220-222.

Hubbs, C. L. and R. R. Miller. 1948. Correlation between fish distribution and hydrographic history in the desert basins of western United States. Bull. Univ. Utah, 38 (20). (Biol. Ser., 10 [7]): 17-166.

Hubbs, C. L., R. R. Miller, and L. C. Hubbs. 1974. Hydrographic history and relict fishes of the North-Central Great Basin, Mem. Calif. Acadm. Sci., 7: 254 p.

Hunsaker, D., L. F. Marnell, and F. P. Sharpe. 1970. Hooking mortality of Yellowstone cutthroat trout. Prog. Fish Cult., 32 (4): 231-235. 
Hunt, R. L. 1976. A long-term evaluation of trout habitat development and its relation to improving management-related research. Trans. Am. Fish. Soc., 105 (3): 361-364.

Idyll, C. 1942. Food of rainbow, cutthroat and brown trout in the Cowichan River system, B. C. Jour. Fish. Res. Bd. Can., 5 (5): 448-458.

Jenkins, T. M. 1971. The role of social behavior in dispersal of introduced rainbow trout. Jour. Fish. Res. Bd. Can., 28 |5|: 1019-1027.

Jessop, B. M. 1976. Distribution and timing of tag recoveries from native and nonnative Atlantic salmon (Salmo salar) released into Big Salmon River, New Brunswick, Jour. Fish. Res. Bd. Can., 33 (4): 829-833.

Johnson, J. M. 1976. Rebuilding our native cutthroat runs. Washington Wildlife 28 (4): 14-15.

Johnson, J. M. 1979. Sea-run cutthroat: Stillaguamish River creel census (1978) and harvest limit recommendations. Wash. State Game Dept., Fish. Mgt. Div.: 26 p.

Johnson, J. M., and S. P. Mercer. 1976. Searun cutthroat in saltwater pens: broodstock development and extended juvenile rearing (with life history compendium). Wash. State Game Dept., Fish. Res. Rep. Proj. AFS-57-1: $92 \mathrm{p}$.

Johnson, J. M., and S. P. Mercer. 1977. Searun cutthroat broodstock/developoment and evaluation of a new enhancement technique. Wash. State Game Dept., Fish. Res. Rep. Proj. F-68-S: 22 p.

Johnson, R. R., and D. A. Jones (Eds). 1977. Importance, preservation and management of riparian habitat: a symposium. USFS Rocky Mtn. For., Rng. Exp. Sta., Gen. Tech. Rep. RM-43: 217 p.

Jordan, D. S. 1891. Report of explorations in Colorado and Utah during the summer of 1889, with an account of the fishes found in each of the river basins examined. Bull. U.S. Fish. Comm., 9: 1-40.

Jordan, D. S. 1892. Description of a new species of salmon (Oncorhynchus kamloops) from the lakes of British Columbia. Forest and Stream, 39 (12): 405-406.

Jordan, D. S. 1894. Description of new varieties of trout. Thirteenth Bien. Rep. State Bd. Fish. Comm., California. 1893-1894: 142-143.

Jordan, D. S. 1896. Notes on fishes little known or new to science. Proc. Calif. Acad. Sci., 2nd ser., 6: 201-244. Jordan, D. S. 1920. Trout of the Rio Grande. Copeia, 85: 72-73.

Jordan, D. S., and B. W. Evermann. 1890. Description of the yellow-finned trout of Twin Lakes, Colorado (Salmo mykiss macdonaldi). Proc. U.S. Nat. Mus., 12: 453-454.

Jordan, D. S., and B. W. Evermann. 1896, 1898. The fishes of North and Middle America. Bull. U.S. Nat. Mus., 47, pt. 1 (1896): 1240 p.; pt. 2 (1898): 2183a-3136.

Jordan, D. S., and B. W. Evermann. 1902. American Food and Game Fishes. Doubleday, Page and Co., New York: $573 \mathrm{p}$.

Jordan, D. S., B. W. Evermann, and H. W. Clark. 1930. Checklist of fishes and fishlike vertebrates of North and Middle America north of the northern boundary of Venezuela and Columbia. Rep. U.S. Fish. Comm. for 1928, pt. 2: 670 p.

Jordan, D. S., and M. Oshima. 1919. Salmo formosanus, a new trout from the mountain streams of Formosa. Proc. Acad. Nat. Sci. Phila., 71: 122-124.

Juday, C. 1906. A study of Twin Lakes, Colorado, with especial consideration of the food of the trouts. Bull. U.S. Bur. Fish., 26: 147-178.

Kaya, C. M. 1977. Reproductive biology of rainbow and brown trout in a geothermally heated stream: the Firehole River of Yellowstone National Park. Trans. Amer. Fish. Soc., 106 (4): 354-361.

Kemmerer, G., J. F. Bovard, and W. R. Boorman. 1924. Northwestern lakes of the United States: biological and chemical studies with reference to possibilities in production of fish. Bull. U.S. Bur. Fish., 39: 51-140.

Kiefling, J. W. 1978. Studies on the ecology of the Snake River cutthroat trout. Wyo. Game and Fish Dept., Fish. Tech. Bull. 3: 198 p.

Kimmel, P. G. 1975. Fishes of the Miocene-Pliocene Deer Butte Formation, southest Oregon. Univ. Mich. Mus. Paleontology, Papers on Paleontology No. 14: 69-87. 
Kinunen, W., and J. R. Moring. 1978. Origin and use of Oregon rainbow trout brood stocks. Prog. Fish. Cult., 40 (3): $187-189$.

Klein, W. D. 1965. Mortality of rainbow trout caught on single and treble hooks and released. Prog. Fish. Cult. 27 (3): $171-172$.

Klein, W. D. 1966. Mortality of trout caught on artificial lures and released by fishermen. Trans. Am. Fish. Soc., 95 (3): 326-328.

Klein, W. D. 1974. Special regulations and elimination of stocking: influence on fishermen and the trout population at the Cache la Poudre River, Colorado. Colorado Div. Wildlife, Tech. Publ. 30: 57 p.

Kokhmenko, L. V. 1972. The food of the mykiss (Salmo mykiss) in Kamchatka. Jour. Ichthyol., 12 (2): 282 290.

Koops, $H_{\text {, }}$ and H. Mann. 1975. Morphometric measurements of rainbow trout reared under different conditions. Arch. Fisch. Wiss., 25 (3): 99-102. (In German.)

Kunkel, C. M. 1976. Biology and production of the redband trout (Salmo sp.) in four southeastern Oregon streams. M.S. Thesis, Ore. State Univ.: 64 p.

Kunkel, C., and W. Hosford. 1978. The native redband trout-one alternative to stocking hatchery rainbows in southeastern Oregon. p. 49-51, in J. R. Moring (Ed.), Proc. Wild Trout-Catchable Trout Symposium. Ore. Dept. Fish and Wildlife.

La Rivers, I. 1964. A new trout from the Barstovian (Miocene) of western Nevada. Biol. Soc. Nevada, Occ. Pap., 3: $1-4$.

La Rivers, I. 1966. Paleontological miscellanei. Ibid. 11: 1-8.

Leitritz, E. 1970. A history of California's fish hatcheries-1860-1970. Calif. Dept. Fish and Game Fish. Bull. 150: $92 \mathrm{p}$.

MacCrimmon, H. R. 1971. World distribution of rainbow trout (Salmo gairdneri). Jour. Fish. Res. Bd. Canada, 28 (5): 663-704.

MacCrimmon, H. R., and B. L. Gots. 1972. Rainbow Trout in the Great Lakes. Ontario Ministry of Nat. Res., Sport Fish. Branch: $66 \mathrm{p}$.

MacPhee, C. 1966. Influence of differential angling mortality and stream gradient on fish abundance in a trout-sculpin biotope. Trans. Am. Fish. Soc., 95 (4): 381-387.

Maksimov, V. A. 1971. Reproductive biology of the freshwater mykiss, Salmo mykiss, from the Kamchatka River basin. Jour. Ichthyol., 11 (1): 36-44.

Maksimov, V.A. 1972. Some data on the ecology of the Kamchatkan trout (Salmo mykiss) from the Utkholok River. Jour. Ichthyol., 12 (5): 759-766.

Maksimov, V. A. 1976. The ecology of the Kamchatkan trout, Salmo mykiss, population from the Bolshaya River (western Kamchatka). Jour. Ichthyol., 16 (1): 12-17.

Marnell, L. F., and D. Hunsaker. 1970. Hooking mortality of lure-caught cutthroat trout (Salmo clarki) in relation to water temperature, fatigue, and reproductive maturity of released fish. Trans. Am. Fish. Soc., 99 (4): 684-688.

Marshall, T. L. 1973. Trout populations, angler harvest and value of stocked and unstocked fisheries of the Cache La Poudre River, Colorado. Ph.D. Thesis, Colo. State Univ., Fort Collins: 91 p.

Mason, J. W., O. M. Brynildson, and P. E. Degurse. 1967. Comparative survival of wild and domestic strains of brook trout in streams. Trans. Am. Fish. Soc., 96 (3): 313-319.

Mason, J. W., and R. L. Hunt. 1967. Mortality rates of deeply hooked rainbow trout. Prog. Fish. Cult., 29 $(2): 87-91$.

McConnell, R. J., and G. R. Snyder. 1972. Key to field identification of anadromous ju venile salmonids in the Pacific Northwest. NOAA Tech. Rep. NMFS Circ. 366: 6 p.

Mednikov, B. M., and A. D. G. Akhundov. 1975. Taxonomy of Salmo based on molecular hybridization of DNA. Dokl. Akad. Nauk SSSR, 2222: $744-746$ (in Russian). 
Mednikov, B. M., Yu. S. Reshetnikov, and E. A. Shubina. 1977. The relationships of whitefishes (Coregonidae) based on molecular hybridiaztion of DNA. Zool. Zhur., 58: 333-341 (In Russian).

Meek, S. E. 1899. Notes on a collection of cold-blooded vertebrates from the Olympic Mountains. Publ. Field Columbian Mus. (Zool.), 1: 225-236.

Miller, R. B. 1954. Comparative survival of wild and hatchery-reared cutthroat trout in a stream. Trans. Am. Fish. Soc., 83: 120-130.

Miller, R. R. 1950. Notes on the cutthroat and rainbow trouts with a description of a new species from the Gila River, New Mexico. Occ. Pap. Mus. Zool. Univ. Mich., 529: 1-42.

Miller, R. R. 1961. Man and the changing fish fauna of the American Southwest. Pap. Mich. Acad. Sci., Arts, Letters, 46: 365-404.

Miller, R. R. $1972 \mathrm{a}$. Classification of the native trouts of Arizona with the description of a new species, Salmo apache. Copeia (3): 401-422.

Miller, R. R. 1972 b. Threatened freshwater fishes of the United States. Trans. Am. Fish. Soc., 101 (2): $239-252$.

Mina, M. V. 1973. A means of obtaining unbiased and accurate estimates of the age of fish with special reference to the "mikizha", Salmo mykiss from the Kamchatka River, Jour. Ichthyol., 13 (1): 96-104.

Minckley, W. L. 1973. Fishes of Arizona. Arizona Game and Fish Dept.: 293 p.

Moring, J. R., and R. L. Lantz. 1975. The Alsea watershed study: Effects of logging on the aquatic resources of three headwater streams of the Alsea River, Oregon. Ore. Dept. Fish and Wildlife, Fish. Res. Rep. 9, pt. 1: 66 p.; pt. 2: 39 p.; pt. 3: 24 p.

Mottley, C. McC. 1934a. The origin and relations of the rainbow trout. Trans. Amer. Fish. Soc., 64: 323-327.

Mottley, C. McC. 1934b. The effect of temperature during development on the number of scales in the Kamloop trout, Salmo kamloops Jordan. Contr. Canad. Biol. Fish., 8 (20): 253-263.

Mottley, C. McC. 1936a. A biometric study of the Kamloops trout of Kootenay Lake, Salmo kamloops Jordan. Jour. Biol. Bd. Canada. 2 (4): 359-377.

Mottley, C. McC. 1936b. The classification of rainbow trout of British Columbia, Biol, Bd. Canada, Pac. Biol. Sta., Prog. Rep., 27: 3-5.

Mottley, C. McC. 1937. The number of vertebrae in trout (Salmo). Jour. Biol. Bd. Canada, 3 (2): 169-176.

Mullan, J. W. 1975. Condition $(\mathrm{K})$ as indicative of non-suitability of Snake River cutthroat in the management of high gradient, low diversity streams. Proc. West. Asc. State Game and Fish Comm., 55: 267-274.

Murphy, T. C. 1974. A study of the Snake River cutthroat trout. M.S. Thesis, Colo. State Univ., Fort Collins: 73 p.

Neave, F. 1944. Racial characteristics and migratory habits in Salmo gairdneri. Jour. Fish. Res. Bd. Canada, 6 (3): $245-251$.

Neave, F. 1949. Game fish populations of the Cowichan River. Bull. Fish. Res. Bd. Canada, 85: 32 p.

Neave, F. 1958. The origin and speciation of Oncorhynchus. Trans. Roy. Soc. Canada, 52 ser. 3, Sect. 5: 25-39.

Needham, P. R., and R. J. Behnke. 1962. The origin of hatchery rainbow trout. Prog. Fish. Cult., 24 (4): 156-158.

Needham, P. R., and R. Gard. 1959. Rainbow trout in Mexico and California with notes on the cutthroat series. Univ. Calif. Publ. Zool., 67 (1): 1-124.

Needham, P. R., and R. Gard. 1964. A new trout from central Mexico: Salmo chrysogaster, the Mexican golden trout. Copeia (1): 169-173.

Nicholas, J. W. 1978a. A review of the literature and unpublished information on cutthroat trout (Salmo clarki clarki) of the Willamette watershed. Oregon Dept. Fish. Wildlife, Information Rep. Ser., Fish. 78-1: $22 \mathrm{p}$.

Nicholas, J. W. 1978b. Life history differences between sympatric populations of rainbow and cutthroat trouts in relation to fisheries management strategy. p. 181-188, in J. R. Moring (Ed.), Proc. Wild Trout-Catchable Trout Symposium. Ore. Dept. Fish and Wildlife. 
Nielson, B. R., and D. L. Archer. 1977. Bear Lake cutthroat fisheries enhancement program. Annual performance report 1975-1976. Utah Dept. Nat. Res., Publ. 77-14: 43 p.

Nilsson, N. A. 1971. The cutthroat trout. B. C. Fish. Wildlife Branch, Fish. Tech. Circ. 7: 9 p.

Platts, W. S. 1957. The cutthroat trout. Utah Fish and Game, 13 (10):4, 7.

Platts, W. S. 1974. Geomorphic and aquatic conditions influencing salmonids and stream classification. U.S. Forest Service, SEAM publication, Billings, Mont.: 199 p.

Qadri, S. U. 1959. Some morphological differences between the subspecies of cutthroat trout, Salmo clarki clarki and Salmo clarki lewisi, in British Columbia. Jour. Fish. Red. Bd. Can., 16 (6): 902-922.

Radford, D. S. 1977. An evaluation of Alberta's fishery management program for east slope streams. Alberta Dept. Recreation, Parks, Wildlife, Fish. Mgt. Rep. 23: 62 p.

Redding, J. M. 1977. The adaptive significance of certain enzyme polymorphisms in steelhead trout (Salmo gairdneri). M.S. Thesis, Ore. State Univ., Corvallis: 34 p.

Reisenbichler, R. R., and J. D. McIntyre. 1977. Genetic differentiation in growth and survival of juvenile hatchery and wild steelhead trout, Salmo gairdneri. Jour. Fish. Res. Bd. Can., 34 (1): 123-128.

Ricker, W. E. 1941. The consumption of young sockeye salmon by predaceous fish. Jour. Fish. Bd. Can., 5 (3): 293-313.

Ricker, W. E. 1972. Hereditary and environmental factors affecting certain salmonid populations. p. 19-160, in R. A. Simon and P. A. Larkin (Eds.), The stock concept of Pacific salmon. H. R. Mac Millan Lectures in Fisheries. Univ. B. C., Vancouver.

Ringler, N. H., and J. D. Hall. 1975. Effects of logging on water temperature and oxygen in spawning beds. Trans. Am. Fish. Soc., 104 (1): 117-121.

Rinne, J. N. 1976. Cyprinid fishes of the genus Gila from the lower Colorado River basin, Wasmann Jour. Biol., 34 (1): 65-107.

Rinne, J. N. 1978. Development of methods of population estimation and habitat evaluation for management of the Arizona and Gila trouts. p. 113-115, in J. R. Moring (Ed.), Proc. Wild Trout-Catchable Trout Symposium. Ore. Dept. Fish and Wildlife.

Roscoe, J. W. 1974. Systematics of the westslope cutthroat trout. M.S. Thesis, Colo. State Univ., Fort Collins: $74 \mathrm{p}$.

Rutter, C. 1908. The fishes of the Sacramento-San Joaquin basin, with a study of their distribution and variation, Bull. U.S. Bur. Fish., 27: 105-152.

Ryan, J. H., and S. J. Nicola. 1976. Status of the Paiute cutthroat trout, Salmo clarki seleniris Snyder, in California. Calif. Dept. Fish and Game Inland Fish. Admin. Rep. 76-3: 59 p.

Savvaitova, K. A. 1975. The population structure of Salmo mykiss in Kamchatka. Jour. Ichthyol., 15 (6): $876-888$.

Savvaitova, K. A., and V. A. Maksimov. 1969. Age and growth of the Kamchatkan anadromous trout (Salmo mykiss). Jour. Ichthyol., 9 (4): 536-546.

Savvaitova, K. A., M. V. Mina, and V. A. Maksimov. 1975. Evolutionary aspects of the reproductive ecology of trout of the genus Salmo in Kamchatka. Jour. Ichthyol., 15 (1): 18-27.

Schreck, C. B., and R. J. Behnke. 1971. Trouts of the upper Kern River basin, California, with reference to systematics and evolution of western North American Salmo. Jour. Fish. Res. Bd. Canada, 28 (7): $987-$ 998.

Schumm, S. A. 1969. A geomorphic approach to erosion control in semiarid regions. Trans. Am. Soc. Agr. Eng., 12: $60-68$.

Schultz, L. P. 1935. Species of salmon and trout in the northwestern United States. Proc. Fifth Pac. Sci. Cong.: $3777-3782$.

Schultz, L. P. 1936. Keys to the fishes of Washington and Oregon and closely adjoining regions. Univ. Wash. Publ. Biol., 2 (4): 105-228.

Schultz, L. P. 1941. Fishes of Glacier National Park, Montana. U.S. Fish. Wildlife Ser., Conserv. Bull. 22: 42 p. 
Schutz, D. C., and T. G. Northcote. 1972. An experimental study of feeding behavior and interaction of coastal cutthroat trout (Salmo clarki clarki) and Dolly Varden (Salvelinus malma). Jour. Fish. Res. Bd. Can., $29|5|:$ 555-556.

Scott, D., J. Hewiston, and J. C. Fraser. 1978. The origins of rainbow trout, Salmo gairdneri, in New Zealand. Calif. Fish and Game., $64(3):$ 210-218.

Scott, W. B., and E. J. Crossman. 1973. Freshwater fishes of Canada. Fish. Res. Bd. Can. Bull. 184: 966 p.

Sekulich, P. T. 1974. Role of the Snake River cutthroat trout (Salmo clarki subsp.) in fishery management. M.S. Thesis, Colo. State Univ., Fort Collins: 102 p.

Shebley, W. H. 1922. A history of fish cultural operations in California, Calif. Fish and Game, 8 (2): 61-99.

Shetter, D. S., and L. N. Allison. 1955. Comparison of mortality between fly-hooked and worm-hooked trout in Michigan streams. Mich. Dept. Conserv. Misc. Publ. 9: 44 p.

Siebenaller, J., and G. N. Somero. 1978. Pressure adaptive differences in lactate dehydrogenases of congeneric fishes living at different depths. Science, 201: 255-257.

Sigler, W. F., and R. R. Miller. 1963. Fishes of Utah. Utah Dept. Fish and Game: 203 p.

Smith, G. R. 1975. Fishes of the Pliocene Glenns Ferry Formation, southwest Idaho. Univ. Mich. Mus. Paleontology, Papers on Palentology No. 14: 1-68.

Smith, G. R. 1977. Biogeography of intermountain fishes. p. 17-42, in Great Basin Naturalist Memoirs, Intermountain Biogeography: a Symposium.

Smith, S. B. 1969. Reproductive isolation in summer and winter races of steelhead trout. p. 21-38, in T. G. Northcote (Ed.). Symposium on trout and salmon in streams. H. R. MacMillan Lectures in Fisheries. Univ. B. C., Vancouver.

Snyder, I. O. 1908. Relationships of the fish fauna of the lakes of southeastern Oregon. Bull. U.S. Bur. Fish., 27: $69-102$.

Snyder, I. O. 1914. A new species of trout from Lake Tahoe. Bull. U.S. Bur. Fish., 32: 23-28.

Snyder, J. O. 1917. Fishes of the Lahontan system of Nevada and northeastern California. Bull. U.S. Bur. Fish., 35: $33-86$.

Snyder, J. O. 1919. Three new whitefishes from Bear Lake, Idaho and Utah. Bull. U.S. Bur. Fish., 36: 3-9.

Snyder, J. O. 1926. The trout of the San Pedro Matir, Lower California. Univ. Calif. Publ. Zool., 21 (17): 419426.

Snyder, J. O. 1931. Salmon of the Klamath River, California. Calif. Dept. Fish and Game, Fish Bull. 34: 130 p.

Snyder, J. O. 1933a. California trout. Calif. Fish and Game, 19 (2): 81-112.

Snyder, I. O. 1933b. Description of Salmo seleniris, a new California trout. Proc. Calif. Acad. Sci., 20: $471-472$.

Snyder, J. O. 1940. The trouts of California. Calif. Fish and Game, 26 (2): 96-138.

Stork, E. F. 1975. Distribution of Rio Grande cutthroat trout in the Santa Fe National Forest. M.S. Thesis, Colo. State Univ., Fort Collins: 55 p.

Stringer, G. E. 1967. Comparative hooking mortality using three types of terminal gear on rainbow trout from Pennask Lake, British Columbia. Can. Fish. Cult., 39: 17-21.

Suckley, G. 1874. On the North American species of salmon and trout. Rep. U. S. Fish Comm. (1872-73): 91160.

Sumner, F. H. 1940. The decline of the Pyramid Lake fishery. Trans. Am. Fish. Soc., 69: 216-224.

Sumner, F. H. 1953. Migrations of salmonids in Sand Creek, Oregon. Trans. Am. Fish. Soc., 82: 139-150.

Sumner, F. H. 1962. Migration and growth of the coastal cutthroat trout in Tillamook County, Oregon. Trans. Am. Fish. Soc., 91 (1): 77-83.

Suzumoto, B. K., C. B. Schreck, and J. D. Mcintyre. 1977. Relative resistances of three transferrin genotypes to bacterial kidney disease. Jour. Fish. Res. Bd. Can., 34 (1): 1-8. 
Thorgaard, G. H. 1977. Chromosome studies of steelhead. p. 20-25, in T. J. Hasler and R. R. Van Kirk (Eds). Genetic implications of steelhead management symposium. Calif. Coop. Fish. Res. Unit, Spec. Rep. 77-1.

Trojnar, J. R., and R. J. Behnke. 1974. Management implications of ecological segregation between two introduced populations of cut throat trout in a small Colorado lake. Trans. Am. Fish. Soc., 103 (3): 423430.

Utter, F. M., and F. W. Allendorf. 1977. Determination of the breeding structure of steelhead populations through gene frequency analysis. p. 44-54, in T. J. Hasler and R. R. Van Kirk (Eds.). Genetic implications of steelhead management symposium. Calif. Coop. Fish. Res. Unit, Spec. Rep. 77-1.

Utter, F. M., F. W. Allendorf, and H. O. Hodgins. 1973. Genetic variability and relationships in Pacific salmon and related trout based in protein variation. Syst. Zool., 22: 257-270.

Van Velson, R. C. 1974. Self-sustaining rainbow trout (Salmo gairdneri) population in McConaughy Reservoir, Nebraska. Trans. Amer. Fish. Soc., 103 (1): 59-64.

Van Velson, R. C. 1977. Rainbow trout in the North Platte Valley, Nebraska Game and Parks Comm.: 14 p.

Van Velson, R. C. 1978. The McConaughy rainbow-life history and a management plan for the North Platte River Valley. Neb. Game and Parks Comm., Tech. Ser. 2: 83 p.

Vasilyev, V. P. 1975. Karyotypes of different forms of the Kamchatkan trout, Salmo mykiss, and the rainbow trout, Salmo gairdneri. Jour. Ich thyol., 15 (6): 889-900.

Vestal, E. H. 1947. A new transplant of the Paiute trout (Salmo clarki seleniris) from Silver King Creek, Alpine County, California. Calif. Fish. and Game, 33: 89-95.

Vincent, R. E. 1960. Some influences of domestication on three stocks of brook trout. Trans. Am. Fish. Soc., 89 (1): $35-50$.

Vladykov, V.D. 1963. A review of salmonid genera and their broad geographical distribution. Trans. Roy. Soc. Can. (Ser. 4), 1: 459-504.

Wales, J. H. 1939. General report on investigation on the McCloud River drainage in 1938. Calif. Fish and Game, 25 (4): 272-309.

Warner, K. 1976. Hooking mortality of landlocked Atlantic salmon, Salmo salar, in a hatchery environment. Trans. Am. Fish. Soc., 105 (3): 365-369.

Warner, K. 1978. Hooking mortality of lake-dwelling landlocked Atlantic salmon, Salmo salar. Trans. Am. Fish. Soc., 107 (4): 518-522.

Warner, K., and P. R. Johnson. 1978. Mortality of landlocked Atlantic salmon (Salmo salar) hooked on flies and worms in a river nursery area. Trans. Am. Fish. Soc., 107 (6): 772-775.

Washington, P. 1977. The sea-run cutthroat trout resource and sport fishery. Mar. Fish. Rve., 39 (12): 20-22.

Weisel, G. F. 1955. Fish guide for intermountain Montana. Mont. State Univ. Press, Missoula: 88 p.

Wernsman, G. 1973. The native trouts of Colorado. M.S. Thesis, Colo. State Univ., Fort Collins: 57 p.

Wheeler, S. S. 1969. The desert lake. Caxton Printers, Caldwell, Idaho: 133 p.

Wiley, R. W. 1969. An ecological evaluation of the Snake River cutthroat fishery with emphasis on harvest. M.S. Thesis, Univ. Wyoming, Laramie: $106 \mathrm{p}$.

Wilmot, R. L. 1974. A genetic study of the redband trout (Salmo sp). Ph.D. thesis, Ore. State Univ.: 60 p.

Wilson, M. 1977. Middle Eocene freshwater fishes from British Columbia. Roy. Ont. Mus., Life Sci. Contrib., 113: $61 \mathrm{p}$.

Withler, I. L. 1966. Variability in life history characteristics of steelhead trout (Salmo gairdneri) along the Pacific coast of North America. Jour. Fish. Res. Bd. Can., 23 (3): 365-393.

Womack, W. R. 1975. Erosional history of Douglas Creek, northwestern Colorado. M.S. Thesis, Colo. State Univ., Fort Collins: $76 \mathrm{p}$.

Wydoski, R. W., G. Klar, T. Farley, J. Braman, Y. Kao, and C. Stalnaker. 1976. Genetic biochemical and physiological studies of trout enzymes. NMFS final rep. 1-87R: $163 \mathrm{p}$. 
Wydoski, R. W., G. A. Wedemeyer, and N. C. Nelson. 1976. Physiological responses to hooking stress in hatchery and wild rainbow trout (Salmo gairdneri). Trans. Am. Fish. Soc., 105 (5): 601-606.

Yarrow, H. C. 1874. On the speckled trout of Utah Lake, Salmo virginalis Girard. Rep. U.S. Fish Comm. for 1872-73: $363-368$.

Zimmerman, G. D. 1965. Meristic characters of the cutthroat trout. Proc. Mont. Acad. Sci., 25: 41-50.

Bureau of Land Management

Library

Biog. 50, Denver Federal Center

Denver, c0 80225 


\section{ADDENDA}

The following references were received too late for inclusion in the text or were cited but not included in references:

Behnke, R. J. 1979a. (In Press). Livestock grazing impacts on stream fisheries: problems and suggested solutions. In J. Menke (Ed.), A symposium on livestock interactions with wildlife, fisheries and their environments. USDA For. Ser. Pac. SW For., Range Exp. Sta., Berkeley, CA.

Behnke, R. J. 1979b. (In Press). Values and protection of riparian ecosystems. In Proc. Mitigation Symposium, Fort Collins, CO, July, 1979.

Behnke, R. J. and R. F. Raleigh. 1979. Grazing and the riparian zone:impact and management perspectives. p. 263-267, in R. R. Johnson and J. F. McCormick (Tech. Coord.). Strategies for protection and management of floodplain wetlands and other riparian ecosystems. Proc. Symp., Dec. 1978. USDA For. Ser., GTRWO-12.

Hanson, D. L. 1977. Habitat selection and spatial interaction in allopatric and sympatric populations of cutthroat and steelhead trout. Ph.D. Thesis, Univ. Idaho, Moscow: 76 p.

Hartman, G. F. and C. A. Gill. 1968. Distribution of juvenile steelhead and cutthroat trout (Salmo gairdneri and S. clarki clarki) within streams in south western British Columbia. Jour. Fish. Res. Bd. Canada, 25 (1): 33-48.

Hickman, T. J. and D. A. Duff. 1978. Current status of cutthroat trout subspecies in the western Bonneville basin. Great Basin Nat., 38 (2): 193-202.

Kiefling, J. W. 1973, 1974. Habitat evaluation of the Snake river and tributary streams. Wyo. Game, Fish Comm., Proj. F-37-R-6: 109 p.; F-37-R-7: 84 p.

Rawstron, R. R. 1977. Harvest, survival, and weight returns of tagged Eagle Lake and Coleman rainbow trout stocked in Lake Berryessa in 1972. Calif. Fish and Game, 63|4|: 274-276. 
Bureau of Land Management Library

Bldg. 50, Denver Federal Center Denver, CO 80225 
Bureau of Land Management Library

Bldg. 50, Denver Federal Center Denver, CO 80225 
